\title{
ANÁLISE DAS RELAÇÕES INTER-REGIONAIS E INTERSETORIAIS NA ECONOMIA BRASILEIRA EM 1985 : UMA APLICAÇÃO DE INSUMO-PRODUTO
}

\author{
FRANCISCO CONSTANTINO CROCOMO \\ Economista
}

Orientador: Prof. Dr. JOAQUIM JOSÉ MARTINS GUILHOTO

Tese apresentada à Escola Superior de Agricultura

"Luiz de Queiroz", Universidade de São Paulo, para obtenção do título de Doutor em Ciências, Área de Concentração: Economia Aplicada.

PIRACICABA

Estado de São Paulo - Brasil

Julho - 1998 
Dados Internacionais de Catalogação na Publicação (CIP) DIVISÃo DE BIBLIOTECA E DOCUMENTAÇÃo - Campus "Luiz de Queiroz"/USP

Crocomo, Francisco Constantino

Análise das relaçōes inter-regionais e intersetoriais na economia brasileira em 1985 : uma aplicação de insumo-produto / Francisco Constantino Crocomo. - Piracicaba, 1998.

$179 \mathrm{p}$.

Tese (doutorado) - Escola Superior de Agricultura Luiz de Queiroz, 1998. Bibliografia.

1. Análise económica 2. Economia agricola 3. Economia regional 4. Planejamento econômico 5. Relaçăo insumo-produto 1. Título 


\section{ANÁLISE DAS RELAÇÕES INTER-REGIONAIS E INTERSETORIAIS NA ECONOMIA BRASILEIRA EM 1985 : UMA APLICAÇÃO DE INSUMO-PRODUTO}

FRANCISCO CONSTANTINO CROCOMO

Prof. Dr. JOAQUIM JOSÉ MARTINS GUILHOTO

Orientador 


\section{DEDICO ESTE TRABALHO}

Aos meus pais, Francisco e Immaculada e a meus nove irmãos, e especialmente para Faridi, Marcio e ao pequeno Lucas. 


\section{AGRADECIMENTOS}

É muito dificil lembrar de todos que, de forma direta ou indireta, contribuíram para com a realização deste trabalho. Porém algumas pessoas não podem deixar de ser esquecidas.

Primeiramente, não tenho como agradecer, aos meus maiores colaboradores, Faridi, Marcio e Lucas, os presentes que Deus me deu.. Faridi e Marcio: além de suportarem toda a sobrecarga de tarefas, provocadas pela minha "ausência", neste período, também contribuíram, em algumas atividades da tese. $O$ pequeno Lucas: meu grande estímulo, esperança e alento.

Quero deixar um agradecimento muito especial, ao prof. Joaquim Martins Guilhoto, pela sua grande capacidade, paciência e principalmente pelo estímulo na realização do trabalho.

Aos professores Joaquim Bento Souza F. Filho e João Martines, pelas valiosas observações no trabalho, que espero ter assimilado.

Quero deixar um grande agradecimento para a professora Angela Maria Cassavia Jorge Corrêa, que através de sua notória capacidade e extrema disposição, contribuiu também, com preciosas observações.

Ao colega e amigo, Warli Anjos dos Santos, pelas discussões, auxílio no uso do programa de matrizes e constante estímulo.

A Lu, pela extrema agilidade e boa vontade, na procura das bibliografias, em nossa biblioteca.

A Emeli Kassouf e Silvio Marcondes, pela ajuda na hora certa..

Deixo, também, um agradecimento ao professor Geraldo Santana, pelo estimulo que nos deu, no início desta empreitada.

A todos colegas de trabalho, professores e funcionários, da UNIMEP e ESALQ, pelo estímulo e compreensão no período da realização desta pesquisa. 


\section{SUMÁRIO}

Página

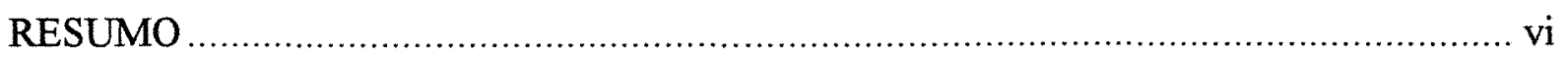

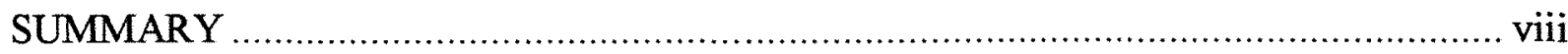

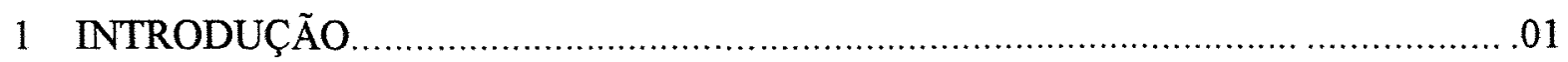

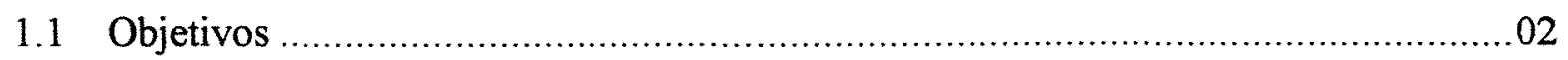

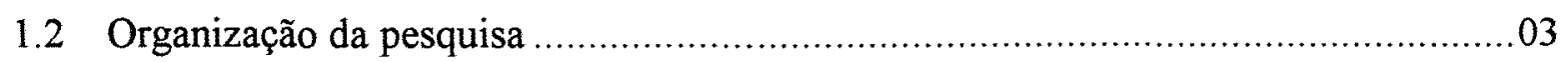

2 O DESEQUILIBRIO REGIONAL BRASILEIRO E O PLANEJAMENTO .............05

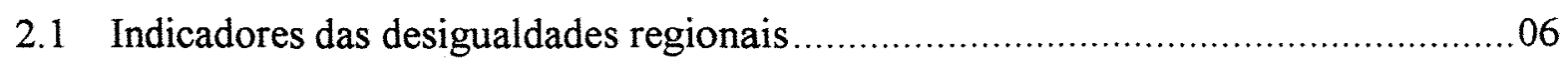

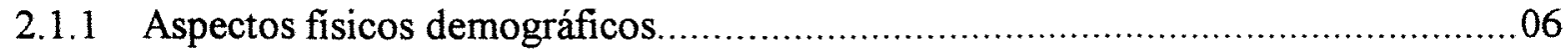

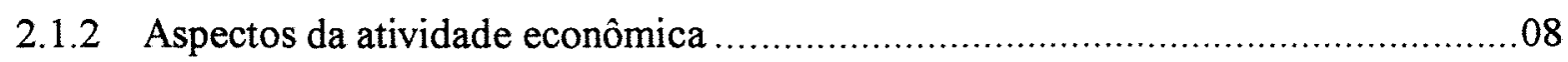

2.2 A prática do planejamento regional no Brasil .....................................................

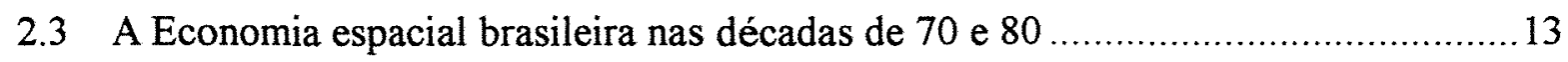

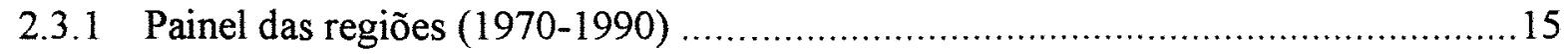

3 A MATRIZ INSUMO-PRODUTO DE LEONTIEF: CONCEITO E APLICAÇÕES . 18

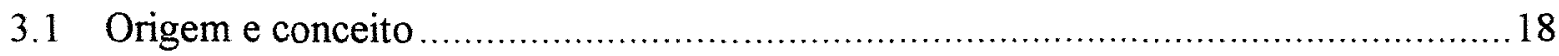

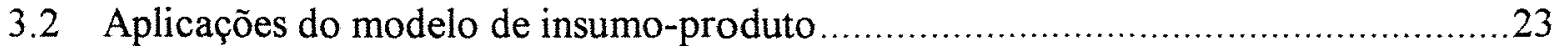

4 EXPERIÊNCIA BRASILEIRA COM MATRIZ DE INSUMO-PRODUTO ….........25

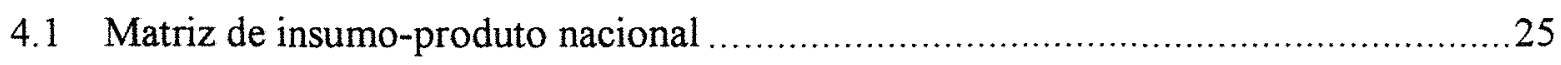

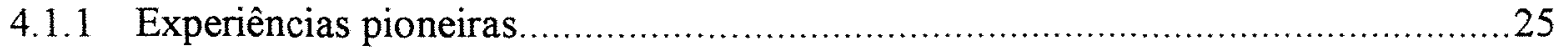

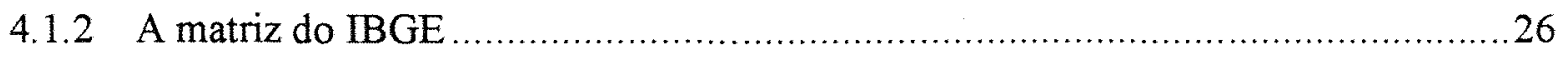

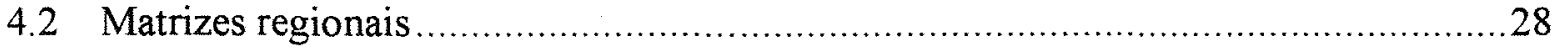

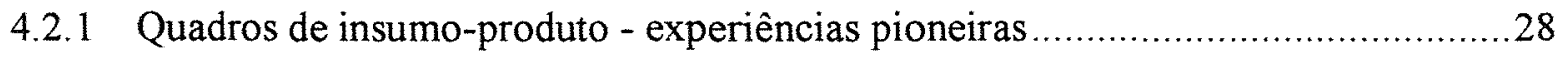

4.2.2 Matriz de insumo-produto para as regiões do Norte e Nordeste ...........................29 


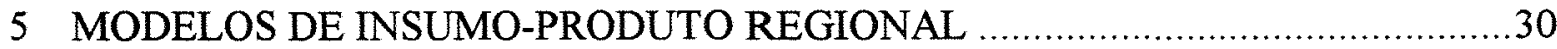

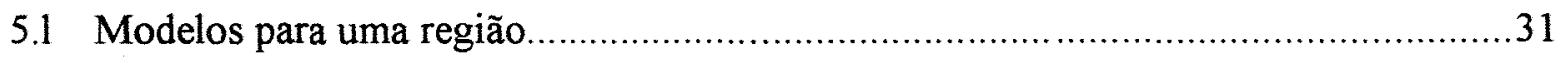

5.1.2 Derivação a partir da matriz nacional de coeficientes .........................................31

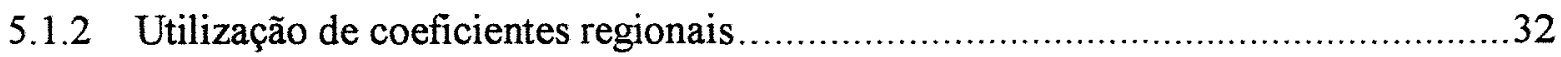

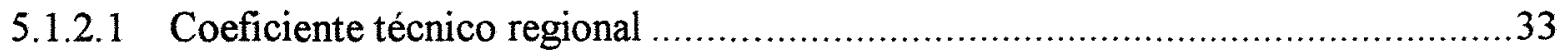

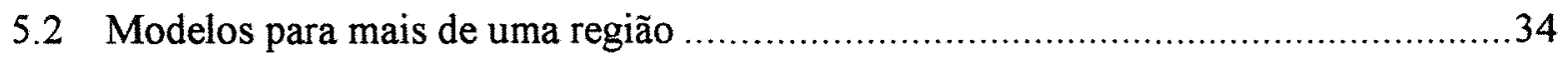

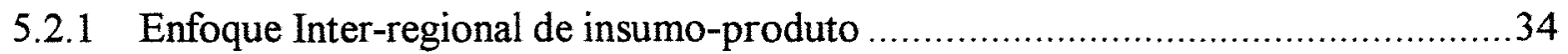

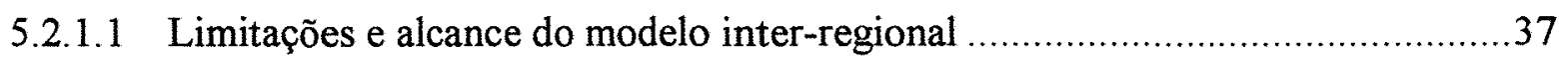

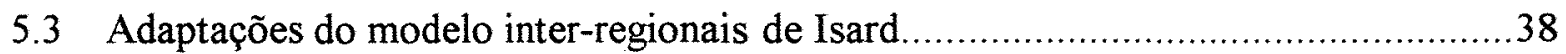

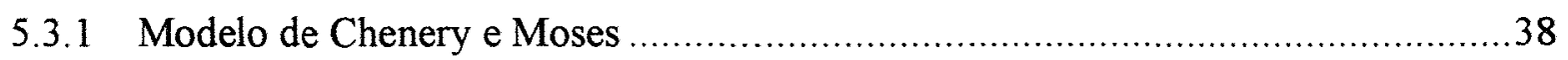

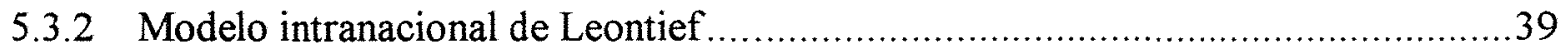

5.3.3 O modelo multirregional de Leontief e Strout (modelo gravitacional) ...................40

5.4 Técnicas para obtenção de coeficientes regionais.................................................. 41

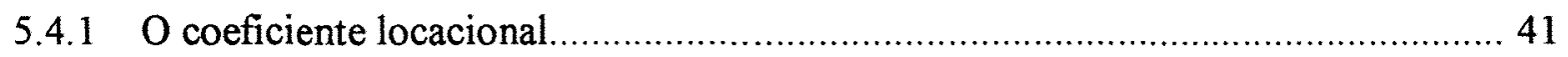

5.4.2 O método das matrizes biproporcionais (RAS) …........................................... 42

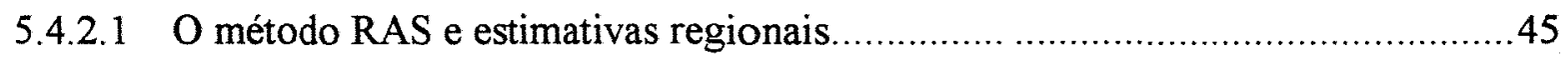

5.4.3 Aplicações de técnicas de estimativas regionais .................................................46

6 CONSTRUÇÃO DA MATRIZ INTER-REGIONAL DO BRASIL DE 1985 _............49

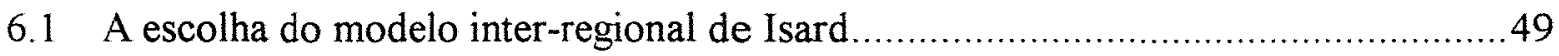

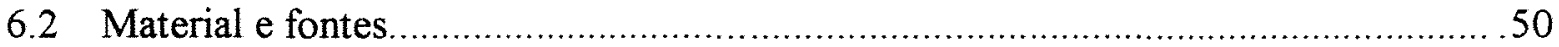

6.3 Construção da matriz inter-regional do Brasil 1985 ………….............................52

6.3.1 Variáveis e formulações utilizadas no processo ……......................................52

6.3.3.1 Formulações gerais para obtenção da matriz $Z$, inter-regional.............................52

6.3.2 Os estágios da construção da matriz inter-regional.............................................54

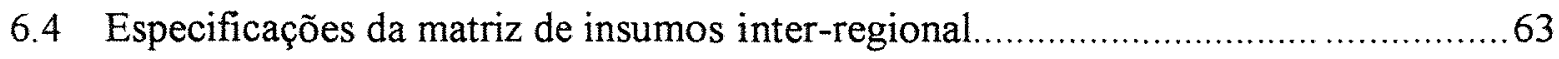

6.5 A matriz inter-regional do Brasil, 1985, especificações e apresentação sintética ......67

7 MÉTODOS DE ANÁLISE DA ESTRUTURA PRODUTIVA …..............................72

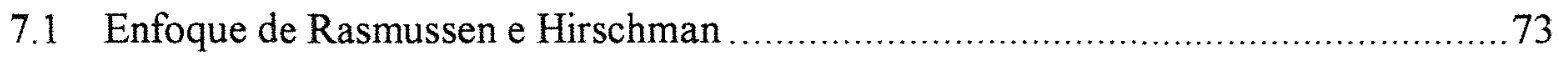


7.2 Enfoque de campos de influência .

7.3 Modelo GHS, ligações em uma estrutura multirregional: índices puros e integração de abordagens alternativas.

8 ANÁLISE DA ESTRUTURA PRODUTIVA REGIONAL DA ECONOMIA

BRASILEIRA EM 1985 81

8.1 Índices de ligações, Rasmussen e Hirschman e a matriz inter-regional de $1985 \ldots \ldots . . .81$

8.1.1 Ligações para a frente, Rasmussen e Hirschman, Brasil e regiões, 1985 ….............84

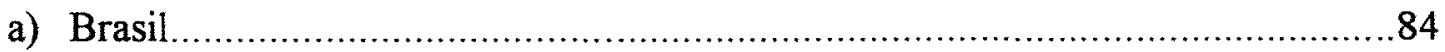

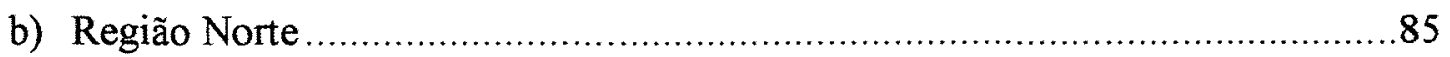

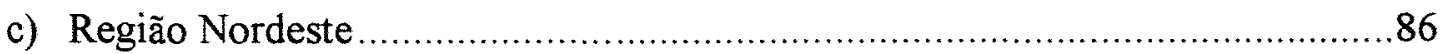

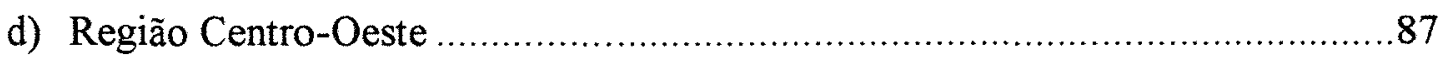

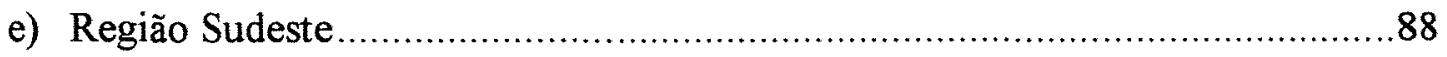

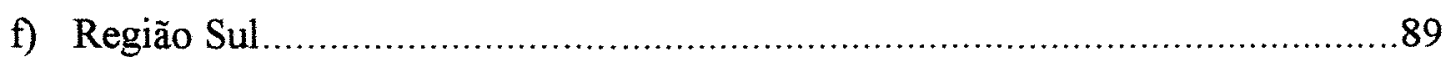

g) Consolidação dos índices de ligações para frente, Brasil e regiões ....................90

8.1.2 Ligações para trás, Rasmussen e Hirschman, Brasil e regiões, 1985 ....................92

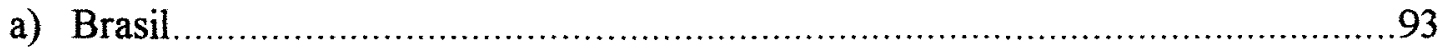

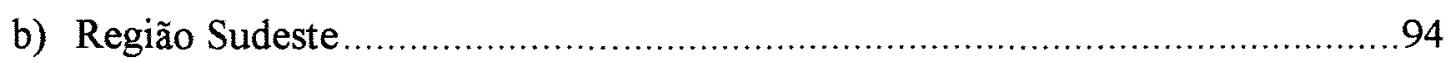

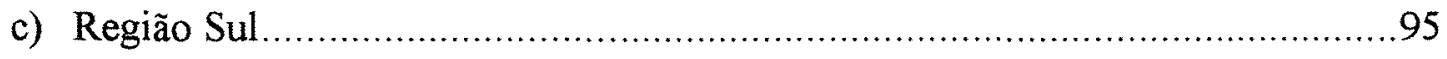

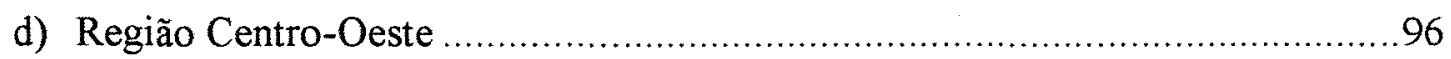

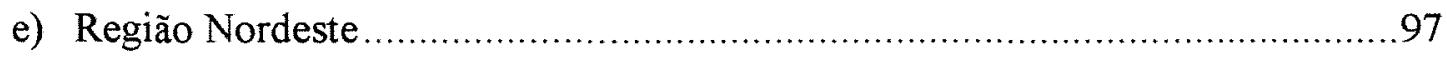

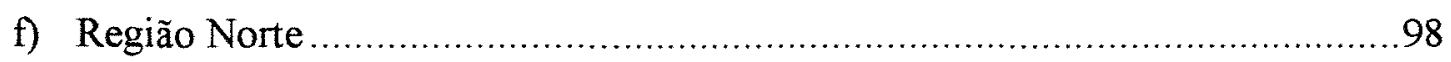

g) Consolidação dos índices das ligações para trás, Brasil e regiões ....................99

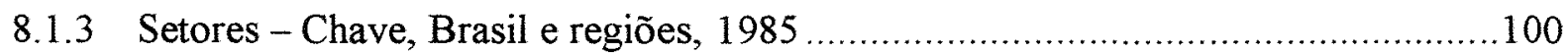

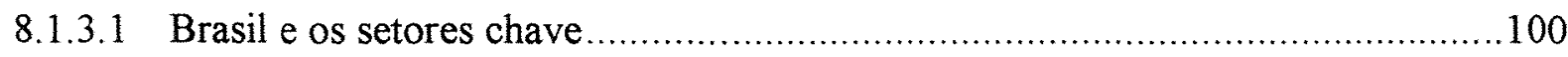

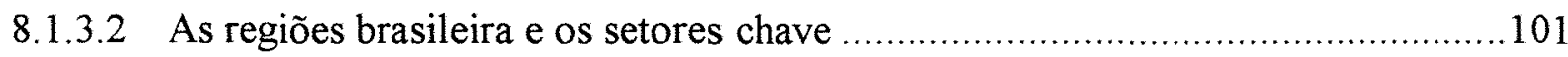

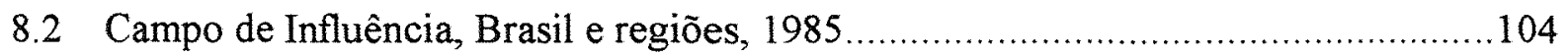

8.3 Índices puros de ligações e a matriz inter-regional brasileira, 1985 ........................107

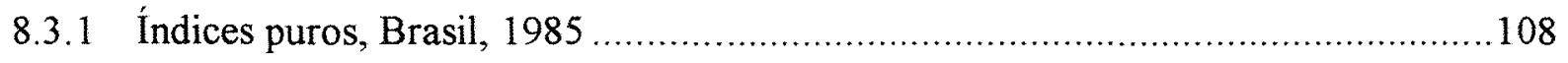

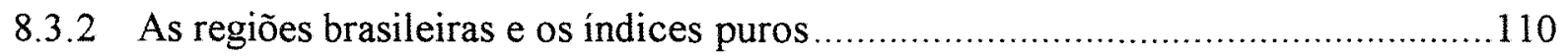

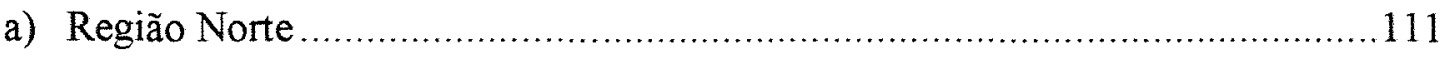




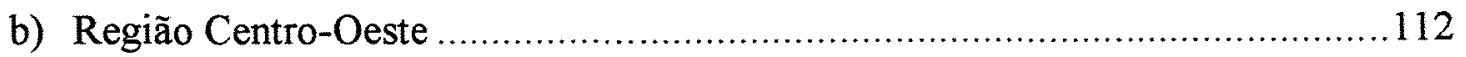

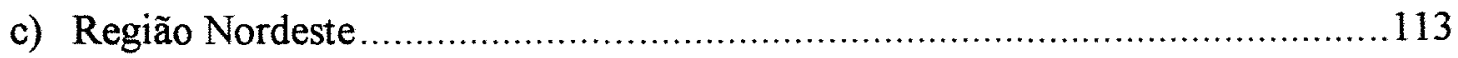

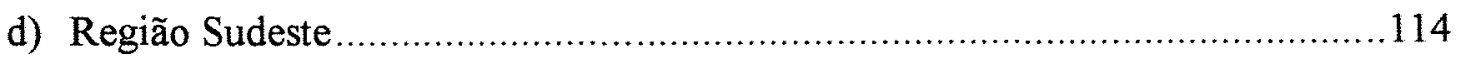

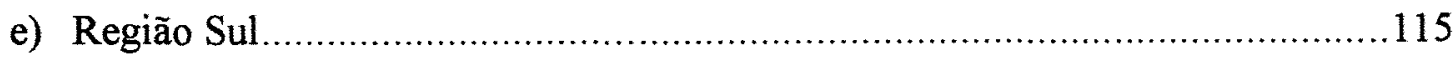

8.3.3 Consolidação dos índices puros para frente e para trás, regiões e Brasil, 1985 ......116

a) Ligações puras para a frente, consolidadas para as regiões ..............................116

b) Ligações puras para a trás, consolidadas para as regiões ................................116

8.3.4 Setores chave, comparação com a média de economia, Brasil e regiões, 1985 ......117

8.4 Comparação e consolidação dos índices de Rasmussen Hirschman e Puros ..............119

8.5 Interação entre as regiões brasileiras e impactos da demanda final sobre a

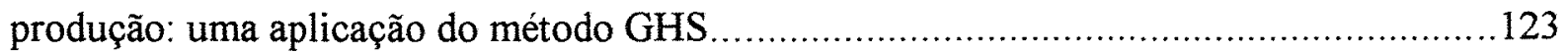

8.5.1 Interação entre as regiões brasileiras. Enfoque região $\mathrm{x}$ resto do Brasil ..................123

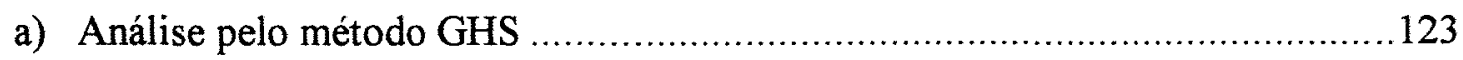

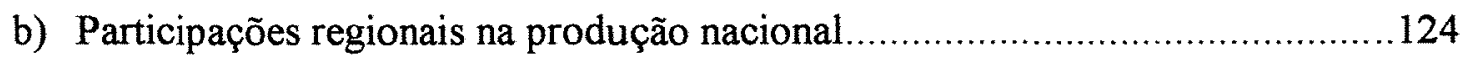

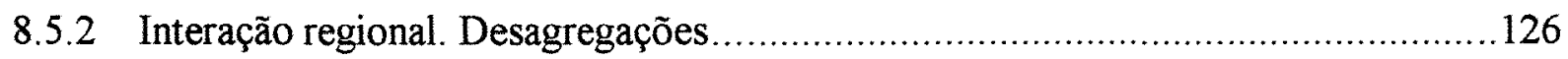

8.5.2.1 Desagregações regionais das produções induzidas pelas demandas finais ..........126

8.5.2.2 Desagregações setoriasi das produções induzidas pelas demandas finais............127

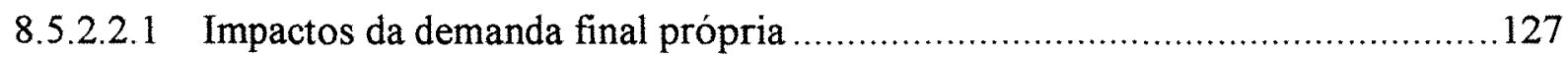

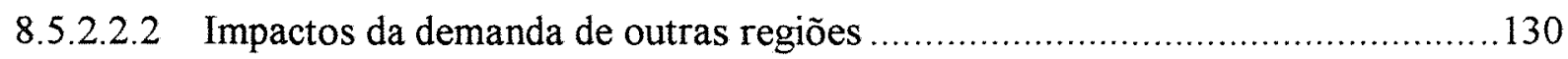

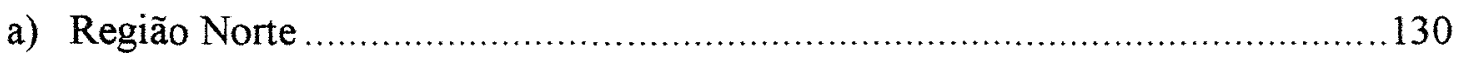

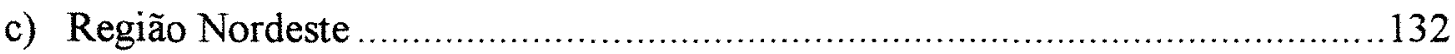

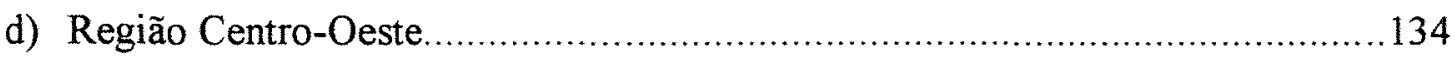

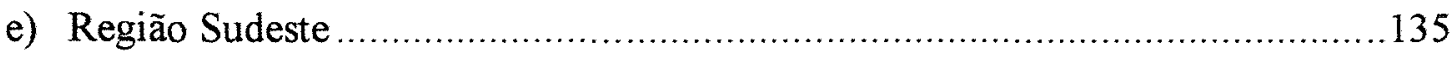

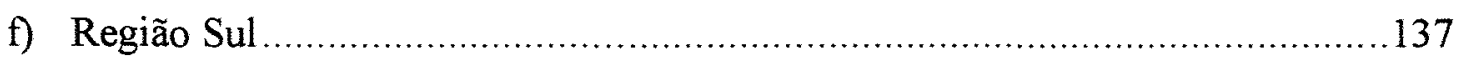

9 CONCLUSÕES

ANEXOS. 


\title{
ANÁLISE DAS RELAÇÕES INTER-REGIONAIS E INTERSETORIAIS NA ECONOMIA BRASILEIRA EM 1985 : UMA APLICAÇ̃̃O DE INSUMO- PRODUTO
}

\author{
Autor: FRANCISCO CONSTANTINO CROCOMO \\ Orientador: Prof. Dr. JOAQUIM JOSÉ MARTINS GUILHOTO
}

\section{RESUMO}

Neste trabalho, é construído um sistema de insumo-produto inter-regional para a economia do Brasil, que é usado para estudar as relações inter-regionais e intersetoriais para o ano de 1985.

A obtenção da matriz de insumo-produto, inter-regional brasileira dá-se via desagregação da matriz nacional de insumo-produto do IBGE para 1985, em 05 regiões, conforme critério do IBGE (Norte, Nordeste, Centro-Oeste, Sudeste e Sul). O procedimento de desagregação realiza-se através de: a) informações dos censos econômicos do IBGE, para 1985; e b) das matrizes do Norte, Silva et al. (1994) e do Nordeste, Silva et al. (1992), ambas para 1985. A base metodológica adotada segue o modelo inter-regional desenvolvido por Isard (1951), bem como as técnicas de obtenção de coeficientes inter-regionais, coeficiente locacional e das matrizes biproporcionais.

A análise tem o objetivo de identificar encadeamentos e elos de ligações interregionais e intersetoriais, setores-chave, pólos dinâmicos e alguns impactos de demanda final sobre setores e respectivas regiões. Para tal, faz-se uso dos resultados da aplicação dos métodos de índices de ligações de Rasmussen (1956) e Hirschman (1958), do enfoque de campo de influência de Sonis e Hewings (1989 e 1994), dos índices puros de 
ligações e integração de abordagens alternativas de Guilhoto, Hewings e Sonis (GHS) (1997).

Com base nestas teorias, a pesquisa apresenta, como principais conclusões, a identificação de setores chave para as cinco regiões estudadas, conforme se segue: Região Nordeste: Metalurgia, Refino de Petróleo, Químicos Diversos e Indústria Têxtil; Região Sudeste: Metalurgia, Mecânica, Refino de Petróleo e Material de Transporte; Região Sul: Agropecuária, Outros Produtos Alimentares, Refino de Petróleo e Vestuário e Calçados; Região Norte: Agropecuária, Mineração e de Material Elétrico; Região Centro-Oeste; Agropecuária, Mineral não Metálico e Outros Produtos Alimentares.

A região Sudeste revela-se quase que inteiramente independente do resto do Brasil. A sua dinâmica basta para o seu desenvolvimento; por outro lado, sua integração na economia é altamente desejável. As regiões Sul e Nordeste, alternam-se na segunda posição em termos de dinâmica de suas estruturas econômicas, seguidas das regiões Norte e Centro-Oeste. Um dos destaques dos resultados refere-se à existência de um forte intercâmbio entre a região Nordeste e a região Norte. 


\title{
THE INTERREGIONAL AND INTERSECTORAL RELATIONS IN THE BRAZILIAN ECONOMY IN 1985: AN INPUT-OUTPUT APROACH
}

\author{
Author: FRANCISCO CONSTANTINO CROCOMO \\ Adviser: Prof. Dr. JOAQUIM JOSÉ MARTINS GUILHOTO
}

\section{SUMMARY}

In this work it is built an input-output interregional system for the Brazilian economy which is used to study the interregional and intersectoral relations for the year of 1985.

The interregional input-output matrix for the Brazilian economy is obtained by breaking down national input-output table (IBGE, 1991) at the level of the five macro regions (North, Northeast, Middle-West, Southeast and South). In the process of disaggregation it is made use of: a) the information contained in the economic census for 1985; and b) the Northeast Silva et al. (1992) and the North Silva et.al (1994) inputoutput matrices built for 1985. The methodological source is based in the interregional model developed by Isard (1951), it is also made use of the tecniques of location quotients as well as biproportional matrices.

The main goal in the process of this analysis was to identify how the sectors and regions do interact among themselves, in such way that it would be possible to identify key sector, dynamic regions, and how the final demand do impact the different regions in the system. To do so it made use of the Rasmussen (1956) and Hirschman(1958) linkages, the field of influence approach developed by Sonis and Hewings (1989 and 1994), and the pure linkages and alternatives techniques of 
identifying integration among regions and sectors developed by Guilhoto, Hewings and Sonis (GHS)(1997).

Based on the above theories in this work it was possible to identify key sectors in each of the five regions, which are as follow:

Northeast; Refined Petroleum, Textile Products, Chemical Products and Metallurgy. Southeast; Metallurgy, Machinery, Refined Petroleum and Transport Equipment.. South; Agriculture, Food Products, Refined Petroleum and Clotting and Footwear. Middle-West; Agriculture, Non Mettalic Minerals and Food Products. North; Agriculture, Mining and Electrical Equipment.

As a general findings one gets that the Southeast region shows the greatest independence among the Brazilian regions whith it own dynamic being enough to sustain its growth, however it has an important role in the productive process of the other regions. The South and Northeast alternated themselves as the second most important region in the economy, followed by the Middle-West and the North region. There also seems to have na strong trade link among the Northeast and North regions. 


\section{INTRODUÇÃO}

O desenvolvimento desigual da economia, no espaço brasileiro, deve-se em parte, a fatores naturais como os de ordem geográfica, localização e extensão, bem como a aspectos históricos, políticos e culturais. Por outro lado, alguns analistas debruçam-se em investigações que envolvem diferentes abordagens, desde discussões sobre conceitos de região, enfoques de espaço e regionalismo, até escolha, criação e adaptação de metodologias adequadas ao caso brasileiro. Como exemplo de alguns destes estudos, destacam-se o trabalho de Ablas (1985), que trata do intercâmbio desigual da economia brasileira; Carleial (1992), que discute os conceitos de região e sua importância para investigações sobre os desequilíbrios regionais no Brasil, dentre outros.

O instrumental de insumo-produto de Leontief (1953) e seus desdobramentos na aplicação para análise regional incluem-se dentre estas metodologias e têm se revelado extremamente úteis para análises inter-regionais, tanto para as estruturas internas nacionais, como para conformações de blocos ou regiões internacionais. Estes tipos de modelos permitem incorporar valores, reais ou estimados, referentes aos fluxos setoriais e inter-regionais, informações estas fundamentais, já que a estrutura produtiva nacional representa um processo de integração e cada espaço participa de forma diferente desse processo. As diferenças inter-regionais, portanto, decorrem da integração do capital em cada espaço. Segundo Carleial (1992, p.7), uma análise regional deve ter claro “...que é exatamente no contexto da integração econômica nacional que faz sentido discutir região, suas próprias relações e sua relação com as demais regiões..." As análises sobre disparidades regionais e sua integração, baseadas nas técnicas de insumo-produto, são 
encontradas, mais freqüentemente, na literatura internacional para casos de paises estrangeiros. Estudos inter-regionais no Brasil com esta metodogia são raros. A maioria dos trabalhos, inclusive aqueles baseados em modernas teorias do desenvolvimento, restringe-se ao campo das comparações entre agregados regionais e agregado nacional, com base nos censos do IBGE, Contas Nacionais, Matriz de Insumo-Produto, nacionais ou construídos para uma determinada região em especial, ou seja, as inferências sobre desequilíbrios econômicos no espaço brasileiro ressentem-se de subsídios empíricos, ou de uma estrutura que identifique a integração econômica das regiões e seus respectivos setores produtivos com o agregado nacional, o que poderia ser viável com a produção de matrizes inter-regionais.

\subsection{Objetivos}

Com base nesta situação é que surge o propósito principal deste trabalho: analisar a estrutura inter-regional brasileira, que se viabiliza através de duas tarefas básicas. A primeira delas é a própria construção da matriz inter-regional para o Brasil, que se dá via desagregação da matriz nacional de insumo-produto do IBGE para 1985, em 05 regiões, conforme critério do IBGE (Norte, Nordeste, Centro-Oeste, Sudeste e Sul). O procedimento de desagregação faz uso das informações dos censos econômicos, também do IBGE, para o mesmo ano e das matrizes do Norte, elaborada por Silva et al. (1994) e do Nordeste, elaborada também por Silva et al. (1992). A base metodológica adotada segue o modelo inter-regional de Isard (1951), bem como as técnicas de obtenção de coeficientes inter-regionais, coeficiente locacional e das matrizes biproporcionais. A primeira tarefa, portanto, consiste na obtenção da estrutura econômica regional brasileira, com as informações das regiões integradas de forma consistente com os valores da matriz nacional.

A segunda tarefa trata da revisão e aplicação da metodologia ligada a índices de ligações para frente e para trás, campos de influência e outros métodos sobre a matriz 
inter-regional construída, com o propósito de identificar encadeamentos e elos de ligações dos setores inter-regionais, setores-chaves, pólos dinâmicos, alguns impactos da demanda final sobre setores e respectivas regiões dentre outros aspectos.

Cabe, aqui, explicitar que a opção pelo ano de 1985 deve-se ao fato de ser o período, disponível mais atual, em que coexistem as informações dos censos econômicos do IBGE, para todas as regiões e por setor com a matriz de insumo-produto nacional, também do IBGE e as matrizes de insumo-produto para as regiões Norte e Nordeste elaboradas com base na metodologia da matriz nacional.

\subsection{Organização da Pesquisa}

Esta pesquisa é organizada discutindo no capítulo 2, alguns indicadores do desequilíbrio regional e o planejamento no Brasil e breve comentário sobre o cenário econômico, no espaço brasileiro, nas décadas de 70 e 80 . No capítulo 3, apresenta o desenvolvimento do modelo de insumo-produto de Leontief, suas origens, características e aplicações. No capítulo 4, relata a experiência brasileira na construção de matriz insumo-produto nacional e por regiões.

Alguns dos principais modelos regionais de insumo-produto são descritos no capitulo 5, bem como os instrumentos para cálculos de coeficientes utilizados na construção de matrizes regionais, como coeficientes locacionais e método das matrizes biproporcionais. Este capitulo, portanto, fornece a base para a escolha do modelo e das técnicas mais apropriadas utilizadas neste trabalho.

A metodologia e o resultado de sua aplicação, na construção da matriz interregional brasileira de 1985 são apresentados no capítulo 6. As análises desta estrutura econômica aparecem no capítulo 8, com base na revisão sobre as principais técnicas, realizada no capitulo 7 , tais como indices de ligações, campo de influência, etc.. É importante salientar que a revisão elaborada no capítulo 7 tenta apresentar uma 
determinada evolução no instrumental de análise de estruturas regionais de insumoproduto, assim como demonstrar seu grau de complementaridade.

Mesmo considerando algumas limitações, quanto a seu aspecto estático, característico dos modelos de insumo-produto e a não viabilidade da comparação temporal, devido à inexistência de estatísticas econômicas regionais mais recentes até o momento de sua elaboração, espera-se que esta pesquisa demonstre algumas das potencialidades do modelo regional, por meio de algumas inferências regionais desagregadas e estimule seu aperfeiçoamento. 


\section{O DESEQUILÍBRIO REGIONAL BRASILEIRO E O PLANEJAMENTO}

Este capítulo apresenta alguns indicadores dos desequilibrios regionais do Brasil, uma breve discussão sobre os programas de desenvolvimento regional brasileiro e comentários sobre a economia espacial brasileira nas décadas de 70 e 80 .

Muitos especialistas ressaltam os movimentos de diferenciação econômica, como resultado da difusão desigual da dinâmica capitalista no espaço. Neste sentido, a compreensão do processo de acumulação desigual do capital, no espaço brasileiro, necessária ao planejamento econômico da nação, é indispensável via análise regionalizada.

O Brasil já foi dividido em várias regiões, segundo diversos critérios. No final da década de 60, o IBGE, através dos critérios de homogeneidade e funcionalidade (aspectos geo-econômicos), construiu uma base de regionalização, agregando estados, que permanece até os dias atuais, resultando em 05 grandes regiões que são discriminadas abaixo:

Região Norte: Amazonas, Pará e Acre, Amapá, Roraima e Rondônia; Região Nordeste: Maranhão, Piauí, Ceará, Rio Grande do Norte, Paraíba, Pernambuco, Alagoas, Sergipe e Bahia. Fernando de Noronha é considerado parte do estado de Pernambuco; Região Sudeste: São Paulo, Rio de Janeiro, Minas Gerais, Espírito Santo; Região Centro-Oeste: Mato Grosso, Mato Grosso do Sul, Goias, Tocantíns e Distrito Federal, e Região Sul: Paraná, Santa Catarina e Rio Grande do Sul. 
Considerando esta divisão regional discutem-se, a seguir, alguns indicadores das disparidades regionais no Brasil.

\subsection{Indicadores das Desigualdades Regionais}

\subsubsection{Aspectos físicos demográficos}

O Brasil ocupa um vasto território, ver Tabela 2.1 , cerca de oito milhões e meio de quilômetros quadrados, uma das maiores áreas do mundo. A região Norte, representa quase que a metade desta área, em sua maior parte ocupada pela floresta amazônica.

A grande concentração populacional no Brasil, conforme informações da Tabela 2.1, encontra-se na região Sudeste, com cerca de 72 habitantes por quilômetro quadrado no ano de 1996, bem acima das regiões Sul e Nordeste, seus seguidores mais próximos. O nivel da taxa de urbanização no Brasil, notadamente nas regiões Sudeste, seguida pelas regiões Centro Oeste e Sul, são explicadas, basicamente, por três fatores segundo IBGE (1996, p.22): o crescimento vegetativo nas áreas urbanas; a migração da zona rural para a urbana, principalmente dentro dos próprios estados, a incorporação de áreas urbanas, que nos Censos anteriores, eram tidas como rurais. Observa-se que. no período 80/96, a região Norte apresenta o maior incremento em sua densidade demográfica, 91,5\%. Entretanto, sua ocupação ainda é bem reduzida, cerca de 3 habitantes por quilômetro quadrado. Observa-se, ainda, que a região Nordeste, que possui a segunda menor taxa de urbanização, apresenta o maior aumento relativo de urbanização dentre as regiões, $29,20 \%$, para o mesmo período.

As estimativas da participação da população nas grandes regiões brasileiras, desde a época colonial até 1996 , registradas pela mais recente contagem da população brasileira pelo IBGE, evidenciam o grande fluxo migratório interno, fundamentalmente da região Nordeste para outras regiões. Ao examinar-se a Tabela 2.2 , nota-se que o Nordeste concentrava, até 1872 , a maior parcela da população brasileira, posição que passou a ser assumida pela Região Sudeste no final do século passado. 
Tabela 2.1. Área, Densidade-Demográfica e Urbanização - Brasil e Grandes Regiões 1980/1996

\begin{tabular}{l|ccc|c|c|c|c|c|c|c|c}
\hline \multirow{2}{*}{ Regiões } & \multicolumn{3}{|c|}{ Área } & \multicolumn{4}{c|}{ Habitante por $\mathbf{k m}^{2}$} & \multicolumn{4}{c}{ Urbanização (\%) } \\
\cline { 2 - 11 } & $\mathbf{( \mathbf { k m } ^ { 2 } )}$ & $\mathbf{( \% )}$ & $\mathbf{1 9 8 0}$ & $\mathbf{1 9 9 1}$ & $\mathbf{1 9 9 6}$ & $\begin{array}{c}\mathbf{9 6 / 9 1} \\
\mathbf{( \% )}\end{array}$ & $\mathbf{1 9 8 0}$ & $\mathbf{1 9 9 1}$ & $\mathbf{1 9 9 6}$ & $\begin{array}{c}\mathbf{9 6 / 9 1} \\
\mathbf{( \% )}\end{array}$ \\
\hline Norte & $3.851 .560,40$ & 45,25 & 1,53 & 2,60 & 2,93 & 91,50 & 51,65 & 59,05 & 62,35 & 20,70 \\
Nordeste & $1.556 .001,10$ & 18,28 & 22,37 & 27,31 & 28,77 & 28,61 & 50,46 & 60,65 & 65,21 & 29,20 \\
Sudeste & $924.266,30$ & 10,85 & 55,97 & 67,88 & 72,49 & 29,52 & 82,81 & 88,02 & 89,29 & 7,82 \\
Sul & $575.316,20$ & 6,76 & 33,08 & 38,46 & 40,88 & 23,58 & 62,41 & 74,12 & 77,21 & 23,71 \\
C-Oeste & $1.604 .852,30$ & 18,85 & 4,70 & 5,87 & 6,54 & 39,15 & 67,79 & 81,28 & 84,42 & 24,53 \\
\hline Brasil & $8.511 .996,30$ & 100,00 & 13,98 & 17,25 & 18,45 & 31,97 & 67,59 & 75,59 & 78,36 & 15,93 \\
\hline
\end{tabular}

Fonte: IBGE (1996)

Tabela 2. 2 Participação Relativa da População das Grandes Regiões no Total do Brasil: 1771/1996

\begin{tabular}{lrrrrrrrrrr}
\hline & $1772-82$ & 1872 & 1900 & 1940 & 1950 & 1960 & 1970 & 1980 & 1991 & 1996 \\
\hline Norte & 4.1 & 3.4 & 4.0 & 3.6 & 3.5 & 3.7 & 3.9 & 4.9 & 7.0 & 7.2 \\
Nordeste & 47.4 & 46.7 & 38.7 & 35.0 & 34.6 & 31.7 & 30.3 & 29.3 & 28.9 & 28.5 \\
Sudeste & 41.8 & 40.5 & 44.9 & 44.5 & 43.4 & 43.7 & 42.7 & 43.4 & 42.6 & 42.6 \\
Sul & 1.9 & 7.3 & $10 . .3$ & 13.9 & 15.1 & 16.8 & 17.7 & 16.0 & 15.1 & 15.0 \\
C.-Oeste & 4.8 & 2.1 & 2.1 & 3.0 & 3.3 & 4.2 & 5.4 & 6.4 & 6.4 & 6.7 \\
\hline Total & 100.0 & 100.0 & 100.0 & 100.0 & 100.0 & 100.0 & 100.0 & 100.0 & 100.0 & 100.0 \\
\hline
\end{tabular}

Fontes: Baer (1996,p.285) e IBGE (1996).

O Sudeste e Nordeste sempre registraram as maiores proporções de população. Porém, conforme IBGE (1996, p.20), os percentuais respectivos a estas regiões, em 1996 estão nos seus patamares históricos mais baixos. O Nordeste registra sua menor participação dentro do periodo e revela uma série declinante.

As regiões Norte e Centro-Oeste aumentaram sua participação populacional no país com ênfase nas décadas de 60 e 70, atingindo seus maiores patamares em 1996, situação explicada, em grande parte, por outra conformação de migração, particularmente 
do Sul para Norte e Centro-Oeste. O que justifica a maior estabilidade das porcentagens da região Sul e quedas relativas do Sudeste e Nordeste.

\subsubsection{Aspectos da atividade econômica}

Ao comparar-se a distribuição da população nas principais regiões do Brasil, com a participação no PIB real brasileiro em 1995, conforme Figura 2.1, nota-se um alto grau de desigualdade entre essas variáveis. A maior discrepância refere-se ao Nordeste, que, com cerca de $30 \%$ da população brasileira, participa com apenas cerca de $13 \%$, enquanto que o Sul com apenas $15 \%$ da população, contribui com cerca de $15 \%$ do PIB real nacional.

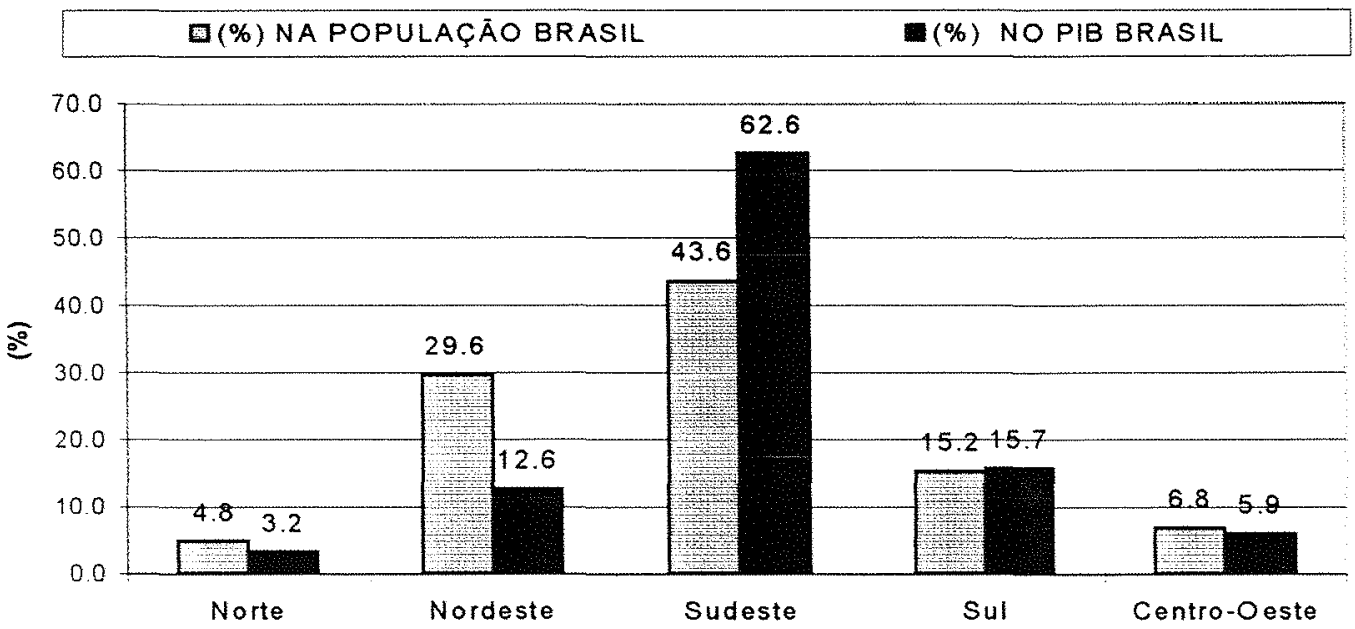

Figura 2.1 Participação da População e PIB Real nas Regiões - Brasil 1995 Fonte: INTITUTO DE PESQUISA APLICADA (IPEA) (1997)

Com relação a participação das regiões no PIB nacional, nos anos de 1970, 1985 e 1990, a região Sudeste é responsável por mais da metade deste agregado. Porém como pode ser observado pelos dados apresentados na Tabela 2.3 , nota-se que ocorre uma melhora, temporal, na participação de outras regiões, com exceção da região Sul, que, praticamente, se estabilizou em torno de 16 a $17 \%$ 
Tabela 2.3 - Participação do PIB regional no PIB nacional nacional (\%): Brasil 1970-85-90

\begin{tabular}{lrrrrr}
\hline \multicolumn{1}{c}{ Período } & \multicolumn{1}{c}{ Norte } & \multicolumn{1}{c}{ Nordeste } & Centro-Oeste & \multicolumn{1}{c}{ Sudeste } & \multicolumn{1}{l}{ Sul } \\
\hline $\mathbf{1 9 7 0}$ & 2,20 & 12,00 & 3,80 & 65,00 & 17,00 \\
$\mathbf{1 9 8 5}$ & 4,30 & 13,00 & 5,40 & 59,40 & 17,10 \\
$\mathbf{1 9 9 0}$ & 5,50 & 15,00 & 5,70 & 56,20 & 16,70 \\
\hline
\end{tabular}

Fonte : Baer $(1996$, p.285)

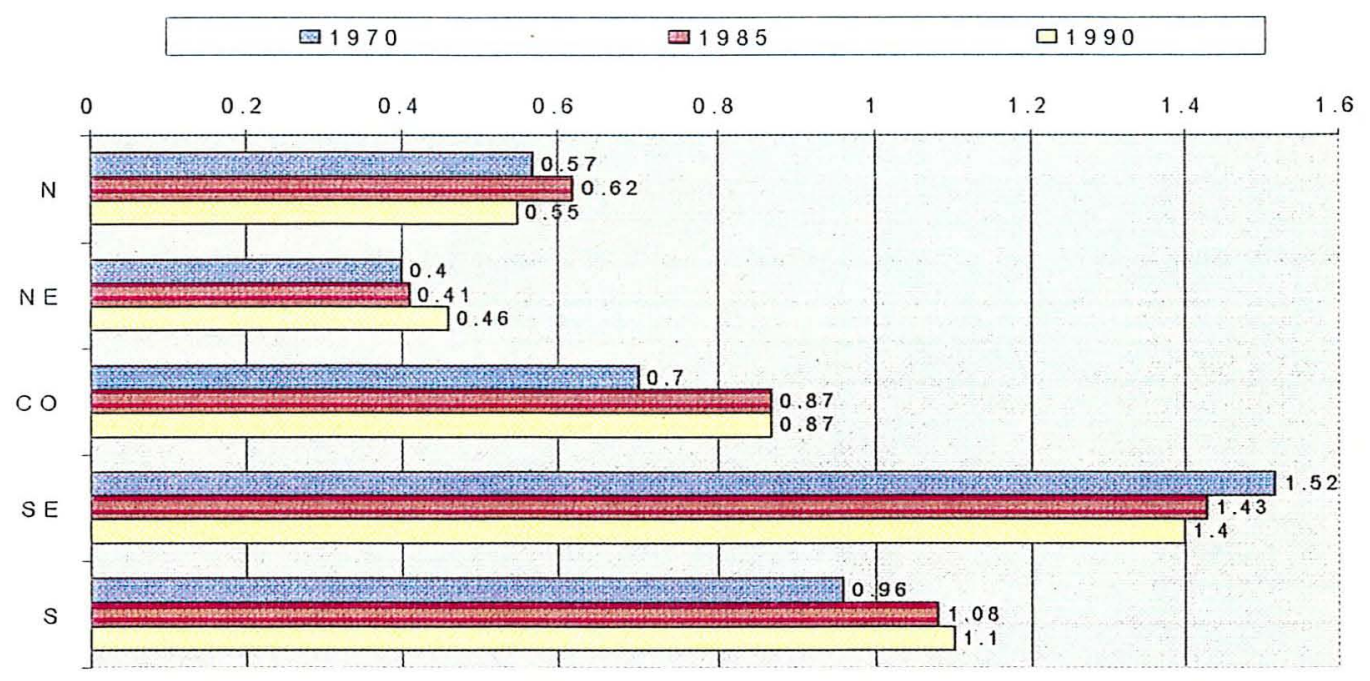

Figura 2.2 .Participação do PIB per capita regional no PIB per capita nacional. Brasil 1970, 1985 e 1990.

Fonte: Baer (1996, p.285)

Evidencia-se pela leitura das porcentagens da Tabela 2.3 e Figura 2.2, a grande disparidade da participação das regiões no PIB brasileiro e que somente as regiões Sudeste e Sul possuem um produto per capita maior que a média nacional. Nota-se uma sensível melhora nestes índices para Nordeste, devido ao aumento de participação no PIB nacional (de 12\% em 1970 para 19\% em 1990) e redução de população, por um lado, via migração interna e por outro, pela diminuição da taxa de crescimento populacional. A Figura 2.2 demonstra uma ligeira tendência de evolução do PIB per capita nas regiões brasileiras frente a um retrocesso da região Sudeste. 
Quanto à Produção industrial, nota-se, claramente, através dos dados apresentados na tabela 2.4 , a grande diferença na participação regional da produção industrial dentre as cinco regiões, no periodo considerado. A região Sudeste participa com cerca de $66 \%$ da produção industrial nacional, enquanto as quatro outras regiões, apesar de estarem aumentando sua porcentagem, permanecem em patamares muito inferiores a este.

Tabela 2.4 Distribuição (\%) Regional Produção Industrial Brasil, 1949, 1959, 1970 e 1985

\begin{tabular}{lcccc}
\hline Regiōes & $\mathbf{1 9 4 9}$ & $\mathbf{1 9 5 9}$ & $\mathbf{1 9 7 0}$ & $\mathbf{1 9 8 5}$ \\
\hline Norte & 1,0 & 1,7 & 1,1 & 4,0 \\
Nordeste & 9,4 & 8,3 & 7,0 & 12,1 \\
Sudeste & 75,4 & 76,9 & 79,1 & 65,7 \\
Sul & 13,5 & 12,3 & 12,0 & 15,7 \\
Centro-Oeste & 0,7 & 0,8 & 0,8 & 2,5 \\
\hline Brasil & 100,0 & 100,0 & 100,0 & 100,0
\end{tabular}

Fonte: Baer (1996, p.286)

A Tabela 2.5 reforça, através da renda familiar per capita, as grandes disparidades regionais no Brasil. Pode-se notar que os valores para o Nordeste representam, aproximadamente, a metade daqueles atribuídos a região Sudeste.

Tabela 2.5 - Evolução da Renda Familiar per capita urbana nas regiōes brasileiras (RS 95) no período de 1987 até 1995.

\begin{tabular}{lllllll}
\hline Período & Norte & Nordeste & Sudeste & C-Oeste & Sul & Brasil \\
\hline $\mathbf{1 9 8 7}$ & 232,94 & 169,51 & 342,04 & 301.69 & 296,66 & 293,07 \\
$\mathbf{1 9 8 8}$ & 204,27 & 155,51 & 325,03 & 291,17 & 271.57 & 275,78 \\
$\mathbf{1 9 8 9}$ & 274.87 & 177.67 & 395,70 & 338.08 & 330,39 & 332,60 \\
$\mathbf{1 9 9 0}$ & 263,90 & 168.59 & 336.61 & 335.10 & 302.72 & 293,67 \\
$\mathbf{1 9 9 2}$ & 164,59 & 145,93 & 285.49 & 241.96 & 273.45 & 244.31 \\
$\mathbf{1 9 9 3}$ & 177,79 & 153.61 & 286.87 & 255,41 & 274.67 & 248.23 \\
$\mathbf{1 9 9 5}$ & 206.23 & 173,05 & 347.40 & 278.93 & 319.67 & 292.48 \\
\hline
\end{tabular}

Fonte: IPEA (1997, p. 13) 
Vários outros indicadores, principalmente os de ordem sócio-econômica, atestam os desequilibrios regionais no Brasil, os estudiosos do assunto destacam a necessidade de implantação de programas específicos de enfrentamento das disparidades regionais no Brasil. Nesse sentido, apresenta-se a seguir, um breve relato sobre a prática de planejamento regional no Brasil e a opinião de alguns destes estudiosos.

\subsection{A prática do planejamento regional no Brasil}

A maioria dos especialistas em estudos de desenvolvimento regional apontam para a necessidade de elaboração e implementação de projeto nacional de longo prazo, que diminua as disparidades regionais no Brasil. Baer (1996), ao discutir as desigualdades regionais da economia brasileira, apresenta de forma sintética, mas completa, as políticas regionais adotadas pelos formuladores de politica econômica desde os anos 30 , chamando a atenção para a falta de prioridade, com as questões que tratam da eqüidade regional no processo de desenvolvimento econômico .

O citado autor afirma que, antes da II Guerra Mundial, não se dispunha, no Brasil, de políticas econômicas regionais. Existiam, apenas programas especificos e com efeitos nas áreas mais desenvolvidas, conforme suas próprias palavras:

"Na medida em que havia alguns programas econômicos nacionais, eles eram dirigidos à proteção de setores especificos - os programas de defesa do café, por exemplo, que datam do inicio do século e que foram assumidos pelo Governo Federal na década de 30 - e cujo efeito regional normalmente concentrava o crescimento econômico nas áreas mais desenvolvidas do pais especialmente no Centro-Sul"(Baer, 1996, p.301).

A partir do final da década de 50, ou, seja desde o final da II Guerra Mundial, surgem as primeiras políticas regionais "explicitas", segundo Baer, com metas direcionadas para rápido crescimento, em determinados setores industriais e controle de 
inflação, em detrimento dos objetivos de eqüidade regional, originando políticas contraditórias.

Baer, ainda faz menção ao Programa de Metas, segunda metade dos anos 50, que apresenta nítido favorecimento à Região Sudeste e a criação, em 1959, da Superintendência do Desenvolvimento do Nordeste (SUDENE), com objetivo de implementar um programa de desenvolvimento para o Nordeste, que fracassou devido a falta da consideração, em sua formulação e aplicação, dos problemas específicos da região.

Os planos Econômicos na década de 60 , eram elaborados tendo em vista a estabilização, sem atentar para projetos especificos que tratem das estratégias para solução de problemas regionais, mesmo com a criação do Ministério do Interior, que centralizou as decisões federais relativas à formulações de políticas regionais coerentes, não houve mudanças nessa linha de planejamento.

Nos anos 70, uma grande seca no Nordeste levou o Governo a implementar uma política regional específica, através de um Programa formado de 3 elementos: Programa de Integração Nacional (PIN), o Programa de Modernização para a Agricultura (PROTERRA) e o Programa Especial para o Desenvolvimento para a área do São Francisco (PROVALE), porém os objetivos destes programas não foram alcançados.

O Plano de Desenvolvimento Nacional, implementado no período de 1975 a 1979, que adota incentivos fiscais para a realização de programas de investimentos federais e privados, cria também, pólos de desenvolvimento para as regiões mais atrasadas, bem como incentiva a agricultura do Nordeste. Quanto à sua modernização e diversificação. Entretanto muito pouco foi sentido, conforme Baer (1996), em termos de desenvolvimento com a preocupação de integração regional.

A política governamental brasileira foi implementada prioritariamente, com maior enfase na década de 80 , no combate à inflação e demais problemas financeiros de ordem imediata. Com isso o planejamento estratégico de desenvolvimento da nação não existe, ou pelo menos, não se evidencia. A esse respeito podem ser destacadas as afirmações de Haddad (1989) ao discutir os condicionantes do planejamento regional 
brasileiro para a década de 90. "Ao longo da atual década de 80, o Brasil abandonou a pratica de planejamento de médio e longo prazos e jogou-se numa sequiência de politicas de curto prazo, cuja elaboração e execução se alternavam ao longo dos anos em termos de objetivos e estilos próprios, mas que resultaram muma dinâmica perversa para os objetivos gerais do nosso processo de desenvolvimento econômico e social." (Haddad, 1989, p. 70)

O citado autor esperava que, durante a década de 90 , fossem implementadas politicas públicas com atenção para, além das questões relacionadas à demanda agregada (política fiscal, salarial, etc.), também aquelas relativas às desigualdades sociais e espaciais importantes para o desenvolvimento do país.

Neste sentido, o Congresso Nacional instalou em 01.04 .92 uma comissão especial mista composta de 13 senadores e 13 deputados federais, que representavam várias regiões brasileiras, com o propósito de discutir o desequilibrio econômico interregional do país. Identificam-se, no relatório, Brasil, (1993, V3, p. 7).com parecer desta comissão, as mesmas preocupações quanto à falta de programas regionais específicos,

denominados "projetos de futuro", que cuidem do modelo de desenvolvimento e do tipo de organização social e espacial que se pretende construir para a nação, além de trabalhos que tratem do equacionamento da crise econômico -financeira e da reestruturação político-institucional, como base para um novo processo de crescimento econômico acelerado e sustentável, que são chamados neste relatório de "programas de curto prazo".

\section{3 A Economia espacial brasileira nas décadas de 70 e 80 .}

O periodo de 1967 a 1990 é considerado por Negri (1996), como segunda fase da industrialização pesada, quando a indústria sofreu modernização de sua estrutura, com ampliação de segmentos mais complexos, tais como aqueles relacionados a insumos básicos, mecânica, material de transporte, material elétrico e de comunicação. O grande destaque, no período entre 1970 até 1990, foi a acentuada desconcentração do Valor de 
Transformação Industrial do Estado de São Paulo, que passa de 58,2\% em 1970 para $49,2 \%$ com relação ao total do Brasil.

Alguns sinais de integração da economia brasileira podem ser notados a partir da década de 70, a despeito das críticas levantadas no ítem anterior deste trabalho. Estes sinais de integração, podem ser atribuídos a vários fatores combinados, tais como criação e atuação de órgãos voltados para a questão regional, incentivos fiscais e financeiros ao setor privado, bem como a implementação de empresas estatais em setores estratégicos da economia.

Neste período (década de 70), destacam-se a queda da participação do estado de São Paulo no PIB, os movimentos migratórios para o Norte, originários principalmente do estado do Paraná, devido ao seu progresso tecnológico na agricultura, bem como a decadência do estado do Rio de Janeiro, que contrasta com a maior participação no valor de transformação industrial da região Nordeste, através do estado da Bahia, seguida pela região Sul e Norte, conforme (Carleial,1992, p.3).

$\mathrm{Na}$ década de 80 , o esgotamento da entrada de capitais externos, a perda de capacidade de financiamento do setor público, combinados com outros fatores, como a não solução da divida externa, precipitam em uma grande crise, onde as questões inflacionárias e distributivas são agravadas. O crescimento do PIB na década foi de apenas $2,69 \%$, muito aquém dos $9 \%$ registrado na década anterior. Esta estagnação não significa que não ocorreram rearranjos na matriz produtiva nacional, ora por força de politicas estatais bem definidas, ora por vinculação a mercados externos, conforme afirma Smith, 1990.

Os destaques destes rearranjos, podem ser identificados no maior dinamismo da industria extrativa, no período de 1980-87, fundamentalmente na Bacia de Campos, estado do Rio de Janeiro, seguida pela região Nordeste. Os estados de Minas Gerais e Espirito Santo experimentam uma queda em sua participação neste setor.

A agropecuária, no período de 1980-87, tem um crescimento em média de $5 \%$, e apresenta forte sinais de desconcentração espacial, através do avanço da produção de cereais e grãos na região Centro-Oeste, e através da ampliação da fronteira em direção a 
esta região, com repercussões em alguns estados da região Nordeste; Bahia, Piaú e Maranhão, e de Minas Geral, da região Sudeste.

De forma geral na década de 80 a agropecuária apresentou um crescimento e participação significativa em todas as regiões, o que seu deu através de diversificação de culturas e formação de complexos agro-industriais, permitindo maior integração agricultura-industria, via mudanças tecnológicas.

No setor da indústria enquanto o estado de São Paulo mantém sua posição, o estado do Rio de Janeiro continua perdendo sua participação. A região Sul apresenta importante crescimento neste setor, apenas abaixo do estado da Bahia. A região CentroOeste pode ser destacada pelo seu crescimento industrial relativo, porém ainda não significante em termos de participação nacional.

Negri (1996), afirma que a estrutura industrial do Brasil quase não se modifica na crise da década de 80 , ocorre maior crescimento nos segmentos que ganham espaço no mercado internacional, como parte da agroindústria, papel e celulose, metalurgia, calçados, mecânica e material de transportes, a desconcentração do estado de São Paulo aumenta neste período, devido a maturação de investimentos em outras regiões.

De maneira geral, o quadro apresenta ainda grandes desigualdades regionais, com a grande supremacia da região Sudeste.

\subsubsection{Painel das regiões (1970-1990)}

A economia brasileira passa por varias fases no período de 1970 a 1990 . Até 1993, grande dinamismo o chamado "milagre econômico". No período de 1974 até 1980, o PIB apresenta um crescimento médio de 7,1\%. Já na década de 1980 , este processo de crescimento é estancado, chegando a um incremento médio do PIB, de apenas 2,6\%. Istvan Karoly, apresenta importante documento para a comissão especial de deputados e senadores, Brasil (1993, p. 180-190), no qual detalha aspectos fundamentais deste período nas regiões brasileiras, resumidos a seguir: 


\section{Região Sul}

Os estados de Santa Catarina e Paraná experimentam um crescimento econômico, neste periodo, compensando a queda destes indicadores no Rio Grande do Sul, o que explica a estagnação no crescimento agregado da região Sul. A região atingiu a segunda colocação em termos de produção, no pais, porém a região Sudeste é 3,64 vezes mais poderosa em valores absolutos.

Constatou-se que a produção estava mal distribuida, proporcionando diferenciais de renda, emprego e desenvolvimento. Karoly propõe adoção de politicas governamentais e estaduais integradas, de longo prazo, para minorar estes problemas.

\section{Região Sudeste}

A região Sudeste mantém sua posição dominante, como pólo econômico, tanto em números absolutos, como relativos, mesmo com sua queda na participação do PIB brasileiro, de 4,65\% no período. Esta queda foi resultado do ganho em produção de alguns estados do Norte, Nordeste e Centro-Oeste. O Estado de Minas Gerais apresentou um grande crescimento, sobretudo no período 1975/1985. São Paulo, o mais importante Estado da Federação, diminuiu levemente sua participação. A maior queda, no periodo deu-se no estado de Rio de Janeiro.

\section{Região Nordeste}

De 1970 para 1975, a participação desta região no PIB caiu, não se beneficiou significativamente da fase do "milagre". A partir de 1975, a região experimenta um crescimento, devido aos maciços investimentos que lá foram realizados, entretanto, o crescimento não se ocorre de forma uniforme. O Estado da Bahia teve a maior participação neste crescimento, o Maranhão também realizou incrementos de produção, especialmente na segunda metade da década de 80. Os demais Estados não apresentam crescimento, alguns como, Piauí, Paraiba, Pernambuco, Alagoas e Sergipe, 
experimentam taxa negativa, neste período, o que faz com que a região, continue sendo a mais pobre do pais.

\section{Região Norte}

Esta região apresentou, o maior crescimento nestes 20 anos. O seu PIB cresceu $62 \%$ contra $45 \%$ do Centro-Oeste, o segundo colocado. Mesmo assim a participação no PIB nacional continua baixa, passa de 2,15\% para 3,49\%, entre 1970 e 1990.

O Estado do Pará lidera a economia da região. Roraima, Rondônia e Amazonas, foram os estados que mais cresceram, enquanto os indicadores de maior estagnação ficaram com Acre e, principalmente, Amapá.

\section{Região Centro-Oeste}

Esta região obteve ótimo crescimento no período. O processo de interiorização do pais, devido à criação da capital Brasília, originou uma força polarizadora na região. Mato Grosso do Sul foi um dos estados que mais se destacaram em crescimento, enquanto o Distrito Federal permaneceu estável na década de 80.

Karoly conclui, que as regiões Sudeste e Sul, as mais industrializadas do país, foram as que mais sofreram os reflexos da crise doméstica, o que se deu pela incapacidade de crescimento auto-sustentado, via financiamento do setor privado pelo setor público, bem como pelo crescimento do estado-empresário. Soma-se a estes aspectos a falta de acesso a fontes alternativas de financiamento no periodo, principalmente na década de 80 .

$\mathrm{Na}$ sequência, capitulo 3 , a formulação do modelo de insumo-produto de Leontief é apresentada. 


\section{A MATRIZ INSUMO-PRODUTO DE LEONTIEF: CONCEITO E APLICAÇÕES}

\subsection{Origem e conceito}

A análise de insumo-produto é resultado dos estudos do professor Wassily Leontief, no final dos anos 30. Economista russo nascido em 1903, radicado nos Estados Unidos desde 1931, a aplicação de seus trabalhos como instrumental para o planejamento econômico, tanto no enfoque macro como microeconômico, lhe valeu o Prêmio Nobel de Economia em 1973.

O modelo de Leontief assenta-se na sistematização da inter-relação existente entre os insumos e os produtos no sistema econômico, consubstanciados em coeficientes técnicos que podem orientar o planejamento econômico. Alternativamente à posição da macroeconomia Keynesiana, que contribuiu para a elaboração das contas nacionais em uma visão agregada, Leontief visualiza a inter-relação dos agentes e operações no sistema econômico. Utilizando de sua próprias palavras, pode-se ratificar esta alternativa

"A análise de insumo-produto é uma extensão prática da teoria clássica de interdependência geral, que vê a economia inteira de uma região, de um pais ou inclusive do mundo como um só sistema e se propõe interpretar todas as suas funções em termos das propriedades especificas mensuráveis de sua estrutura". Leontief $(1986$, p. 5)

Em essência, a preocupação foi a de registrar como são gerados Produto, Renda, Poupança e demais agregados, em "...circunstâncias de interdependência entre ramos de atividade económica. Ou ainda, como o funcionamento de determinado ramo 
de atividade econômica está na dependência do funcionamento dos demais". Figueiredo $(1975$, p. 111)

A idéia original do desenvolvimento desta contabilidade detalhada deve ser creditada ao fisiocrata francês François Quesnay, 1758, quando da criação do "Tableau Economique". Deve-se, também, creditar a Walras, 1847, a utilização de coeficientes de produção, relativos à quantidades de fatores requeridas para produzir uma unidade de produto. O modelo de Leontief é, segundo Miller e Blair $(1985$, p. 2), uma aproximação do elaborado por Walras, com simplificações importantes, que levam à aplicação da Teoria do Equilibrio Geral.

O modelo de insumo-produto de Leontief é representado por um sistema de equações lineares, cada uma das quais representando a distribuição do produto e de sua indústria dentro da economia, segundo Miller e Blair (1985, p.2). A estrutura matemática do modelo de insumo-produto, conforme Dervis, et.al. (1982):

... "consiste em um conjunto de $n$ equações lineares com $n$ incógnitas, $e$ pode ser resolvido através de inversão de matrizes. A solução do sistema dá os requerimentos necessários de cada produto para satisfazer determinado setor de demanda final, o que consiste muma solução de equiliibrio geral na esfera produtiva da Economia ".

As informações do modelo de insumo-produto devem ser organizadas em um instrumento que facilita a visualização e a integração da estrutura de um sistema econômico, o quadro de insumo-produto, que descreve os insumos e as produções dos diferentes setores de um sistema econômico, para um dado período. Suas linhas representam a distribuição da produção e suas colunas os insumos absorvidos pelos setores na produção. A seguir, apresenta-se um modelo genérico da matriz insumoproduto, através do Quadro 3.1. 
Quadro 3.1 - Matriz de Insumo-Produto do Tipo Leontief para dois setores

\begin{tabular}{|c|c|c|c|c|c|c|c|c|c|c|}
\hline & \multicolumn{8}{|c|}{ Setores compradores $(j)$} & \multirow{3}{*}{$\begin{array}{l}\text { Valor } \\
\text { bruto } \\
\text { da } \\
\text { produção }\end{array}$} \\
\hline & & \multicolumn{3}{|c|}{ Demanda Intermediária } & \multicolumn{5}{|c|}{ Demanda final } & \\
\hline & & $\begin{array}{c}\text { Setor } \\
1\end{array}$ & $\begin{array}{c}\text { Setor } \\
2\end{array}$ & $\begin{array}{c}\text { Sub-total } \\
\text { (dem.inter- } \\
\text { mediária) }\end{array}$ & $\begin{array}{l}\text { Con- } \\
\text { sumo }\end{array}$ & $\begin{array}{c}\text { Investi- } \\
\text { mento }\end{array}$ & $\begin{array}{l}\text { Gasto do } \\
\text { Governo }\end{array}$ & $\begin{array}{l}\text { Exporta- } \\
\text { ções }\end{array}$ & $\begin{array}{c}\text { Sub-total } \\
\text { (demanda } \\
\text { final) }\end{array}$ & \\
\hline \multirow{2}{*}{$\begin{array}{c}\text { Setores } \\
\text { vendedores } \\
\text { (i) }\end{array}$} & Setor 1 & $z_{11}$ & $z_{12}$ & $\sum_{j=1}^{n} z_{1 j}$ & $C_{1}$ & $I_{1}$ & $G_{\mathrm{t}}$ & $E_{1}$ & $Y_{1}$ & $X_{1}$ \\
\hline & Setor 2 & $z_{21}$ & $z_{22}$ & $\sum_{j=1}^{n} z_{2 j}$ & $C_{2}$ & $I_{2}$ & $G_{2}$ & $E_{2}$ & $Y_{2}$ & $X_{2}$ \\
\hline \multicolumn{2}{|c|}{ Sub-total } & $\sum_{i=1}^{n} z_{i 1}$ & $\sum_{i=1}^{n} z_{i 2}$ & $\sum_{i, j=1}^{n} z_{i j}$ & $\sum_{i=1}^{n} c_{i}$ & $\sum_{i=1}^{n} 1_{i}$ & $\sum_{i=1}^{n} G_{i}$ & $\sum_{i=1}^{n} E_{i}$ & $\sum_{i=1}^{n} y_{i}$ & $\sum_{i=1}^{n} x_{i}$ \\
\hline \multicolumn{2}{|l|}{ Importações } & $M_{1}$ & $M_{2}$ & $\sum_{j=1}^{n} I M_{j}^{D I}$ & $I M C$ & $I M I$ & $I M G$ & $I M E$ & $M M^{Y}$ & \\
\hline \multicolumn{2}{|c|}{ Tributos/depreciação } & $N_{\mathrm{l}}$ & $N_{2}$ & $\sum_{j=1}^{n} N_{j}$ & & & & & & \\
\hline \multicolumn{2}{|l|}{ Salários } & $L_{1}$ & $L_{2}$ & $\sum_{j=1}^{n} L_{j}$ & & & & & & \\
\hline \multicolumn{2}{|c|}{ Valor adicionado } & $V A_{\mathrm{I}}$ & $V A_{2}$ & $\sum_{j=1}^{n} w A_{j}$ & & & & & & \\
\hline \multicolumn{2}{|c|}{ V. bruto da produção } & $X_{1}$ & $X_{2}$ & $\sum_{j=1}^{n} x_{j}$ & & & & & & \\
\hline
\end{tabular}

Fonte: Adaptado conforme tabela apresentada em Haddad (1976, p. 103)

As variáveis componentes da matriz de insumo-produto, representam :

$z_{i l} \quad$ fornecimento de insumos do setor $i$ para o setor $j$;

$C_{i}$ fornecimento de insumos do setor $i$ destinado ao consumo final privado;

$I_{i} \quad$ fornecimento do setor $i$ destinado ao investimento privado;

$G_{i} \quad$ formecimento do setor $i$ destinado ao Governo (consumo mais investimento do governo);

$E_{\mathrm{i}} \quad$ fornecimento do setor $i$ destinado às exportações para o resto do mundo;

$Y_{\mathrm{i}} \quad$ total da demanda final atendida pelo setor $i,\left(C_{i}+I_{i}+G_{i}+E_{i}\right)$;

$X_{\mathrm{i}} \quad$ produção bruta do setor $i$ :

IMj. $\quad$ importação do setor $j$; 
$L_{j} \quad$ salários pagos pelo setor $j$ no processo de sua produção;

$N_{j} \quad$ aluguéis, juros, lucros, tributos indiretos líquidos e depreciações pagos pelo setor $j$;

$V A_{j} \quad$ valor adicionado $\left(L_{j}+N_{j}\right)$,

$\sum_{j=1}^{n} I M_{j}^{D I} \quad$ total das importações do setor $j$, para ademanda intermediária,

IMC importações destinadas à bens de consumo,

IMI importações destinadas a bens de investimento,

IMG importações destinas ao gastodo governo,

IME importações destinas à exportação.

$I M^{Y} \quad$ total das importações para demanda final.

A partir destas definições e da disposição do Quadro 3.1, pode-se estabelecer um conjunto de igualdades, dentre as quais:

Pelo vetor linha:

$$
\begin{aligned}
& \sum_{j=1}^{n} z_{i j}=z_{i 1}+z_{i 2} \text { e } Y_{i}=C_{i}+I_{i}+G_{i}+E_{i}, \\
& X i=\sum_{j=1}^{n} z_{i j}+Y_{i}
\end{aligned}
$$

Pelo vetor coluna, tem-se:

$$
\sum_{i=1}^{n} z_{i j}=z_{1 j}+z_{2 j} \text { e } V A_{j}=L_{j}+N_{j} \text { e } X j=\sum_{i=1}^{n} z_{i j}+V A_{j}+I M_{j}
$$

Estas equações representam duas óticas do valor bruto da produção. Ao considerar-se a igualdade obtida no vetor linha (3.1), pode-se definir um sistema de equações lineares simultâneas, cujos parâmetros são estimados empiricamente, e genericamente demonstrados como:

$$
X_{i}=z_{i 1}+z_{i 2}+\cdots+z_{i j}+Y_{i}
$$

E pode se construir uma equação para cada um dos $n$ setores $(i$ e $j=1,2, \ldots n)$. 
Admitindo-se que a quantidade de insumo no setor $i$ utilizado pelo setor $j$ é diretamente proporcional à produção do setor $j$, obtêm se os coeficientes técnicos de produção $a_{i j}$, como se segue:

$$
a_{i j}=\frac{z_{i j}}{X_{j}}
$$

Ou seja $a_{i j}$, representa quanto o setor $j$ compra do setor $i$, se o setor $j$ produzir um total $X_{j}$.

Os coeficientes técnicos de produção são medidas fixas das relações ocorridas entre um setor produtivo e seus insumos. A economia de escala não é considerada. O sistema de Leontief opera considerando retornos constantes à escala. A análise do insumo-produto requer que os setores usem insumos em proporções fixas.

Considerando que (3.4) pode ser descrita da seguinte forma:

$$
\begin{aligned}
& Z_{i j}=a_{i j} X_{j}, \text { pode-se, então, modificar (3.3), como se segue: } \\
& X i=a_{i 1} X_{1}+a_{i 2} X_{2}+\ldots+a_{i i} X_{i}+\ldots+a_{i n} X_{n}+Y_{i}
\end{aligned}
$$

que resulta em um sistema de equações lineares simultâneas que possuem, como parâmetros os coeficientes técnicos de produção.

Isolando-se $Y_{1}$ e colocando $X_{1}$ em evidência, em (3.5), tem-se:

$$
\left(1-a_{i 1}\right) X_{1}-a_{i 2} X_{2}-\ldots-a_{i i} X_{i}-\ldots a_{i 2} X_{n}=Y_{1}
$$

e dessa forma para todos os $n$ setores.

Assim definem-se, de forma genérica, as matrizes:

$$
A=\left[\begin{array}{cccccc}
a_{11} & a_{12} & \cdots & a_{1 i} & \cdots & a_{1 n} \\
a_{21} & a_{22} & \cdots & a_{2 i} & \cdots & a_{2 n} \\
\vdots & \vdots & \vdots & \vdots & \vdots & \vdots \\
a_{n 1} & a_{n 2} & \cdots & a_{n i} & \cdots & a_{n n}
\end{array}\right], \quad X=\left[\begin{array}{c}
X_{1} \\
X_{2} \\
\vdots \\
X_{n}
\end{array}\right], \quad Y=\left[\begin{array}{c}
Y_{1} \\
Y_{2} \\
\vdots \\
Y_{n}
\end{array}\right]
$$

A matriz de coeficientes técnicos, de ordem $(\mathrm{n} \times \mathrm{n})$; 
$X$ vetor do valor bruto da produção, de ordem $(\mathrm{n} \times 1)$;

$Y$ vetor da demanda final total, de ordem $(\mathrm{n} \times 1)$.

Que podem ser expressas em notação matricial:

$$
\mathrm{X}=\mathrm{AX}+\mathrm{Y}
$$

Esta equação explicita a dependência dos fluxos intersetoriais nos produtos totais de cada setor. Conforme:

"A aplicação mais usual do modelo de insumo-produto é a de se determinar o vetor dos niveis setoriais de produção bruta quando são conhecidos os valores dos elementos que compõem o vetor da demanda final. Portanto, se resolvermos o modelo, teremos Haddad (1976, p.109)

$$
\begin{aligned}
& \mathrm{X}-\mathrm{AX}=\mathrm{Y}, \text { ou } \\
& (I-A) X=Y
\end{aligned}
$$

onde a matriz $(I-A)$, é a chamada a matriz de Leontief, portanto:

$$
X=(I-A)^{-1} Y
$$

Que representa a matriz dos requisitos diretos e indiretos por unidade da demanda final, de acordo com a demanda final. Ou seja a matriz inversa de Leontief $(I-A)^{-1}$, capta os efeitos diretos e indiretos das modificações exógenas da demanda final sobre a produção dos n setores. Portanto, a partir da expressão (3.9), podem ser avaliados os impactos de políticas setoriais, sobre outros setores e no total nacional, assim como pode ser aplicada, com algumas adaptações, à análise regional.

\subsection{Aplicações do modelo de insumo-produto}

Estima-se que, no início da década de 60, 40 nações, no mundo, adotavam o modelo de Leontief, e que, após a II Guerra Mundial, esta técnica foi empregada para 
programas de reconstrução na Noruega, Holanda e Itália. Acrescenta-se, ainda, que as nações da África, Ásia e latino-americanas, também aplicaram os modelos de insumoproduto para seus programas de aceleração e desenvolvimento econômico.

Mais recentemente, Miller e Blair (1985), destacam a plena utilização do modelo nos Estados Unidos, tanto para a economia agregada, como também e, principalmente, para economias regionais. O modelo já é largamente aplicado em todo o mundo, inclusive é utilizado pelas Nações Unidas, como instrumento de planejamento para os paises menos desenvolvidos.

No próximo capitulo apresenta-se a experiència brasileira, na construção de modelos de insumo-produto. 


\section{EXPERIÊNCIA BRASILEIRA COM MATRIZ DE INSUMO-PRODUTO}

\subsection{Matriz de insumo-produto nacional}

\subsubsection{Experiências pioneiras}

A primeira experiência com construção de tabelas de insumo-produto, no Brasil, não se refere, propriamente, a modelos de insumo-produto, mas a um modelo de equilíbrio geral. Willy van Rijckeghem constrói um Modelo de Consistência Intersetorial para o planejamento no Brasil, elaborado para informações de 1959, editado na obra de Ellis (1969, p. 376-402)

O modelo de Rijckeghem foi elaborado com base nas informações dos censos econômicos de 1960, do IBGE e pesquisa de orçamentos familiares da Fundação Getúlio Vargas (1961-62 e 1962-63). As tabelas de Insumo-Produto foram construídas para 32 setores. O autor simulou, através deste modelo, um crescimento do PIB de $7 \%$ para o periodo de 1968-70.

Conforme Guilhoto (1986, p.46), trata-se do primeiro esforço na construção de um modelo multisetorial para a economia brasileira. " $E$ um modelo simples direcionado para problemas relativamente simples". O modelo não apresenta nenhuma referência quanto à distribuição de renda, índices de preços, etc..

Uma segunda experiência partiu da iniciativa conjunta do Banco Central do Brasil e do Conselho Interministerial de Preços, no esforço da elaboração da Matriz Insumo - Produto para o Brasil de 1967. O Objetivo desta construção esta ligado à programação econômica, conforme as considerações discriminadas a seguir.. 
"A construção da matriz Insumo Produto visou, principalmente, à criação de um instrumento de grande relevância para a programação econômica, inclusive através de modelos de programação global de curto-prazo. Além de significativo elemento para análise, tal instrumento permite uma visão imediata dos prováveis resultados da utilização de diversas alternativas de politica econômica que se pretende utilizar (Leão, 1973,p.10).

Por outro lado, o Conselho Interministerial de Preços, através de seus técnicos, esperava obter uma previsão de intervalo de variações de preços dos setores da economia, com possíveis efeitos no sistema geral de preços.

As informações para a construção desta matriz foram coletadas nas guias de recolhimento do IPI para 25 ramos de atividade. A vantagem deste modelo refere-se ao pouco tempo para elaboração, três anos. Porém, a sua maior inconsistência recai sobre a diferença de período dos dados primários, de 1971, e os dados para fechamento da matriz que faziam referência às Contas Nacionais de 1969, resultando em coeficientes técnicos não confiáveis.

\subsubsection{A matriz do IBGE}

O IBGE, publicou, em 1979, a Matriz de Relações Intersetoriais - Brasil 1970. O Projeto de construção de matrizes de Insumo-Produto, quinquenalmente, com a mesma periodicidade dos censos, objetiva-se propiciar suporte a estudos de interdependência industrial, permitindo o desenvolvimento de análises sobre a estrutura da economia brasileira, bem como subsidiar políticas macroeconômicas.

A matriz foi elaborada, em sua versão definitiva, para 87 setores de atividade econômica e 160 grupos de produtos, com informações do censo demográfico e dos censos econômicos de 1970. Trata-se da primeira experiência consistente e articulada em termos de estatísticas intersetoriais no Brasil, sobretudo pela sua relação com o novo 
Sistema de Contas Nacionais o SCN-69, o qual se constituiu em um avanço em relação ao anterior o SCN-52, pelo melhor aproveitamento das características da estrutura produtiva da economia com detalhes das relações interindustriais, porém estes trabalhos ainda não estavam totalmente integrados ao sistema recomendado pelo programa de System of National Accounts-SNA, 1968 da Organização das Nações Unidas (ONU).

O IBGE publicou, em 1987, a matriz de 1975 com a mesma concepção e estrutura de organização utilizada na construção da matriz de 1970, apenas incorporando alguns detalhes nos setores produtivos, demanda final, produtos e algumas categorias de valor adicionado (IBGE, 1987, p. 43).

Em 01/12/86, as tarefas de construção das contas nacionais do Brasil passaram para o IBGE, já que eram de responsabilidade da Fundação Getúlio Vargas, FGV até então. Com a fusão dos técnicos destas duas instituições, implantou-se, no IBGE, durante o período de 1987 até metade de 88, o Departamento de Contas Nacionais (DECNA), com atribuição precípua de calcular as contas nacionais do país e de elaborar as matrizes de Insumo-Produto para o Brasil.

A matriz de Insumo-Produto de 1980, divulgada em 1989, foi elaborada pelo DECNA, totalmente integrada ao novo sistema de contas nacionais. Esta matriz tem como base o, System of Nacional Accounts (SNA), proposto pela ONU, (IBGE, $1989 \mathrm{p}$. 2). A metodologia adotada no desenvolvimento do novo Sistema de Contas Nacionais, definição de instrumentos de trabalho e apresentação dos resultados, tomaram por base a experiência do sistema francês de contas nacionais, através de convênio de cooperação assinado pelo IBGE e o Instituto Nacional de Estatísticas e Estudos Econômicos da França.

"Dessa forma, a Matriz de Insumo-Produto passa a ser um trabalho derivado do Sistema de Contas Nacionais, mais especificamente das tabelas de Insumo-Produto, formadas pelas contas de oferta e demanda de bens e serviços, de produção e de distribuição operacional da renda, por setores de atividade. Assim sendo, passaremos a contar, 
doravante com a possibilidade de se construir matrizes de InsumoProduto anuais".(IBGE, 1989, p. 3)

O IBGE, a partir desta data já produziu as matrizes de 1990 até 1995, inclusive com acesso via disquetes e internet.

\section{2 Matrizes regionais}

\section{2.1 Quadros de insumo-produto - experiências pioneiras}

Poucas foram as experiências na construção de matrizes de Insumo-Produto regionais no Brasil. Todas as iniciativas limitam-se a determinada região em particular, ou seja, não se identifica-se sistema de matrizes que insira todas as regiões do Brasil, de forma consistente com o agregado nacional.

O Banco de Desenvolvimento de Minas Gerais (BDMG) e o Centro de Desenvolvimento e Planejamento Regional (CEDEPLAR), conduziram e publicaram os seguintes quadros de Insumo-Produto, conforme sumariza Haddad (1976):

\section{Quadro de insumo-produto de Minas Gerais - 1953}

Utilizaram-se, como fonte, os boletins de produção do registro industrial. O modelo apresentou-se incompleto pela dificuldade em estimar a demanda final;

Quadro de insumo-produto da cidade industrial de Contagem-MG - 1968

Quadro componente de um estudo de viabilidade de expansão do distrito industrial de Contagem, dentro da região metropolitana de Belo Horizonte, realizado pelo BDMG.

Quadro de insumo-produto de Minas Gerais - 1959

Quadro elaborado pelo CEDEPLAR. Os resultados apresentaram-se incompletos, pela falta dos vetores da demanda final e pela não discriminação dos valores dos insumos importados. 


\section{Quadro de insumo-produto do município de Itabirito-MG - 1970}

É considerado o mais completo destes quadros, constitue-se em importante modelo para análise da interdependência estrutural, específica ao estudo de economia urbana . Incorporou estatísticas de transações intermunicipais e externas, composição do valor agregado e estrutura da demanda final de consumo por grupo de renda.

\section{2. 2 Matriz de insumo-produto para as regióes do Norte e Nordeste}

Duas importantes experiências na construção de matriz para grandes regiões no Brasil, que apresentam consistência com a matriz de Insumo-Produto do Brasil, referemse aos trabalhos para a Região Norte ${ }^{1}$ (1980 e 1985) publicado em 12/92, e para Região Nordeste $^{2}$ (1980 e 1985) publicado em 1994. Estes dois trabalhos foram realizados, práticamente, pela mesma equipe e mesma metodologia, que consiste em manter a mesma estrutura da matriz nacional do IBGE, referente aos anos de 1980 e 1985. Foram tomadas como base e fontes: os censos demográfico e econômicos, bem como a utilização de inquéritos econômicos da região e, dados do comércio externo e inter-regional.

Existem ainda, conforme relatos verbais, experiências com matrizes para os estados, de São Paulo, Ceará, Bahia. Existe também uma matriz em construção para o Estado do Rio Grande do Sul, elaborada pela Universidade Federal do Rio Grande do Sul, através de seu Departamento de Economia.

Iniciativas estão aumentando neste sentido. Entende-se que existe uma necessidade dos órgãos oficiais instituírem a desagregação das informações da matriz nacional, que vêm sendo elaborada ano a ano, a partir de 1990 .

A seguir apresenta-se o capítulo dedicado aos modelos de insumo produto regionais.

\footnotetext{
${ }^{1}$ Matriz de Insumo-Produto do Norte - 1980 e 1985 , por Antônio Braz de Oliveira e Silva, Cláudio Monteiro Considera,Kleper Mauro de Mendonça Magalhães, Carlos César Bittencourt Sobral. Belém: SUDAM, 1994.

${ }^{2}$ Matriz de Insumo-Produto do Nordeste - 1980 e 1985, por Antônio Braz de Oliveira e Silva, Cláudio Monteiro Considera,

Kleper Mauro de Mendonça Magalhães e Roberto Luis Olinto Ramos. Fortaleza: BNB, 1992.
} 


\section{MODELOS DE INSUMO PRODUTO REGIONAL}

O modelo de Leontief, inicialmente elaborado para estudos das relações internas da economia de uma nação, vem sendo adaptado para investigações de determinada região e para estudos de sua relação com outras regiões. O próprio Leontief, fazendo referência à análise inter-regional de insumo-produto, encara o sistema econômico não somente em termos de indústrias interdependentes, mas também compondo várias regiões inter-relacionadas.

"A produção de cada região é definida como uma combinação da produção de atividades econômicas realizadas dentro de suas fronteiras geográficas; consequentemente, seus insumos compreendem os insumos diretos dessas indústrias e os bens e serviços absorvidos diretamente pelos setores de demanda final por região" (Leontief, 1986, p. 11).

Apresenta-se, neste capitulo, a formulação clássica do modelo inter-regional e algumas de suas adptações, passando pela descrição do modelo para uma região, de acordo com Miller e Blair (1985). Em seguida, descrevem-se as técnicas de coeficientes locacionais e o método de matrizes biproporcionais, que foram utilizados para estimar e ajustar as desagregações regionais necessárias à obtenção da matriz inter-regional brasileira, uma das tarefas da presente pesquisa. 


\section{I Modelos para uma região}

\subsubsection{Derivação a partir da matriz nacional de coeficientes}

Os primeiros estudos regionais que fizeram uso de modelos de insumo-produto referem-se aos trabalhos ${ }^{3}$ de Isard \& Kuenne (1953), e Miller (1957), os quais, através da matriz nacional de coeficientes técnicos, $\mathrm{A}$, em conjugação com um processo de ajustamento, estimaram características de algumas economias regionais, visto que não dispunham de coeficientes regionais específicos. Este processo de ajustamento consiste em estimar porcentagens de oferta para cada setor, em uma determinada região, da seguinte forma:

$$
p_{j}^{R}=\frac{\left(X_{j}^{R}-E_{j}^{R}\right)}{\left(X_{j}^{R}-E_{j}^{R}+M_{j}^{R}\right)}
$$

onde:

$X_{j}^{R}$, representa a produção total do setor $j$ da região $\mathrm{R}$;

$E_{j}^{R}$, a exportação da produção do setor $j$ da região $\mathrm{R}$, $\mathrm{e}$

$M_{j}^{R}$, representa a importação realizada pelo setor $j$ da região $\mathrm{R}$.

Portanto $p_{j}^{R}$, representa a participação da produção do setor $j$ da região $\mathrm{R}$ no total consumido do setor $j$ na região $\mathrm{R}$.

\footnotetext{
${ }^{3}$ Isard \& Kuenne (1953), aplicaram o modelo para a região urbana industrial da grande New York englobando dois centros em Connecticut, onze em New York, dezenove em New Jersey e cinco na Pensylvania. Por sua vez Miller estudou Washingtom, Oregon e Idaho. In: Miller \& Blair (1985, p.47).
} 
Aplicando estas proporções para cada setor da região $R$, sobre os coeficientes nacionais de produção, obtém-se o modelo de insumo-produto regional, conforme notação matricial a seguir:

$$
A^{R}=\hat{P} A
$$

$A^{R}$, matriz de coeficientes de insumos regionais;

$\hat{P}$, matriz diagonalizada das proporções calculadas para cada setor, e

A, matriz de coeficientes técnicos nacionais.

Considerando a equação básica de Leontief (3.9):

$$
X=(I-A)^{-1} Y
$$

pode-se obter a produção regional $\mathrm{X}^{\mathrm{R}}$, para uma demanda exógena na região $\mathrm{R}, \mathrm{Y}^{\mathrm{R}}$.

$$
X^{R}=(I-\hat{P} A)^{-1} Y^{R}
$$

O pressuposto forte deste processo é o de considerar a técnica de produção regional idêntica à da técnica nacional.

\subsubsection{Utilização de coeficientes regionais}

De posse das matrizes dos coeficientes intra e inter-regional, é possivel construir modelos de insumo-produto para uma região, como se segue:

Supondo que uma nação seja dividida em duas regiões: $L$ e $M$, sendo $M o$ resto da economia nacional, e :

$z_{i j}^{L L} \quad$ fluxo monetário do setor $i$ para o setor $j$ na região $\mathrm{L}, \mathrm{e}$ 
$z_{i j}^{M L}$ fluxo monetário do setor $i$ da região $M$ para o setor $j$ da região $L$.

Portanto, podem ser definidos os seguintes coeficientes:

$$
\begin{aligned}
& a_{i j}^{L L}=\frac{z_{i j}^{L L}}{X_{j}^{L}} \text { coeficiente de insumo regional (intraregional) } \\
& a_{i j}^{M L}=\frac{z_{i j}^{M L}}{X_{j}^{L}} \text { coeficiente de insumo inter-regional }
\end{aligned}
$$

Matricialmente, tem-se:

$$
\begin{aligned}
& A^{L L}=Z^{L L}\left(\hat{X}^{L}\right)^{-1} \\
& A^{M L}=Z^{M L}\left(\hat{X}^{L}\right)^{-1}
\end{aligned}
$$

Portanto:

$$
X^{L}=\left(I-A^{L L}\right)^{-1} Y^{L}
$$

Que representa o impacto na produção da região $\mathrm{L}$, quando existir alteração na demanda pelo produto do setor na região $L$. Notar que $A^{L L}$ é uma estimativa da matriz $A^{R}=\hat{P} A$, uma vez que os elementos de $A^{R}$ são uma estimativa de $A^{L L}$.

\subsubsection{Coeficiente técnico regional}

Pode-se também definir o coeficiente técnico regional, $a_{i j}^{L}$, que registra a proporção dos fluxos para a região $L$, quando não se identifica o valor e a respectiva região de origem dos fluxos inter-regionais, como se segue: 


$$
\begin{aligned}
& z^{. L}=z^{L L}+z^{M L} \\
& a_{i j}^{L}=\frac{z_{i j}^{L L}}{X_{j}^{L}}=\frac{z_{i j}^{L L}+z_{i j}^{M L}}{X_{j}^{L}} \\
& a_{i j}^{L L}=a_{i j}^{L L}+a_{i j}^{M L} \\
& A^{L}=Z^{L}(\hat{X})^{-1} \\
& X^{L}=\left(I-A^{L}\right)^{-1} Y^{L}
\end{aligned}
$$

\subsection{Modelos para mais de uma região}

\subsubsection{Enfoque inter-regional de insumo-produto}

O modelo inter-regional de insumo-produto, também chamado de "modelo Isard", devido à aplicação de Isard (1951), requer uma grande e diversificada massa de dados, fundamentalmente quanto às informações sobre fluxos inter-setoriais e interregionais. Como exemplo de utilização por completo deste modelo, Miller e Blair (1985), citam as matrizes inter-regionais construídas para o Japão e Holanda.

Normalmente, pode-se lançar mão de estimativas dos fluxos intersetoriais e inter-regionais, através de aproximações matemáticas, e utilizá-las no modelo interregional de insumo-produto. Algumas desta técnicas de estimação matemática são utilizadas na presente pesquisa, no sentido de estimar e ajustar informações necessárias à construção do modelo inter-regional brasileiro.

Para melhor entendimento da formulação do modelo, apresenta-se no Quadro 5.1, um esquema hipotético do fluxo intersetorial e inter-regional de bens para as regiões $\mathrm{L}$, com 3 setores e para a região $\mathrm{M}$, com 2 setores: 
Quadro 5.1 - Fluxo intersetorial e inter-regional de bens para duas regiões

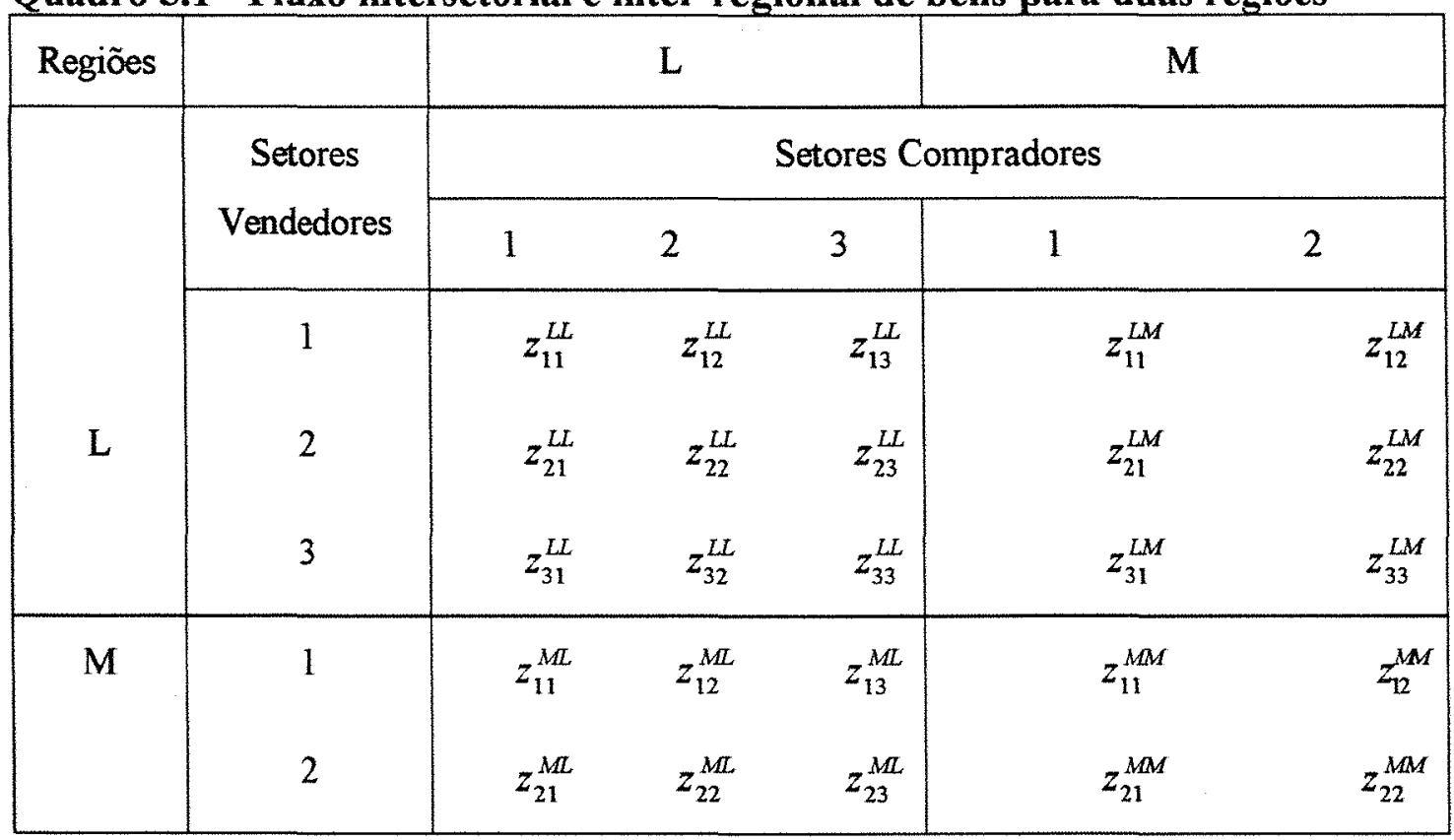

Fonte: Miller e Blair (1985, p. 55)

A partir de:

$Z_{i j}^{L L}$ - fluxo monetário do setor $i$ para o setor $j$ na região $\mathrm{L}$,

$Z_{i j}^{M L} \quad$ - fluxo monetário do setor $i$ para a região $\mathrm{M}$, para o setor $j$ na região $\mathrm{L}$

pode-se montar a matriz: $Z=\left[\begin{array}{cc}Z^{L L} & Z^{L M} \\ Z^{M L} & Z^{M M}\end{array}\right]$

E considerando a equação básica:

$$
X_{i}=z_{i 1}+z_{i 2}+\ldots+z_{i i}+\ldots+z_{i n}+Y_{i}
$$

é possivel aplicá-la conforme:

$$
X_{1}^{L}=z_{11}^{L L}+z_{12}^{L L}+z_{13}^{L L}+z_{11}^{L M}+z_{12}^{L M}+Y_{1}^{L}
$$

E construir equações similares para $X_{2}^{L}, X_{3}^{L}, X_{1}^{M}, X_{2}^{M}$. 
Considerando os coeficientes de insumo regional para $\mathrm{L}$ e $\mathrm{M}$, ou coeficientes intraregionais:

$$
\begin{array}{ll}
a_{i j}^{L L}=\frac{z_{i j}^{L L}}{X_{j}^{L}} & \Rightarrow z_{i j}^{L L}=a_{i j}^{L L} \cdot X_{j}^{L} \\
a_{i j}^{M M}=\frac{z_{i j}^{M M}}{X_{j}^{M}} & \Rightarrow z_{i j}^{M M}=a_{i j}^{M M} \cdot X_{j}^{M}
\end{array}
$$

E coeficientes inter-regionais:

$$
\begin{array}{ll}
a_{i j}^{L M}=\frac{z_{i j}^{L M}}{X_{j}^{M L}} & \Rightarrow z_{i j}^{L M}=a_{i j}^{L M} \cdot X_{j}^{M} \\
a_{i j}^{M L}=\frac{z_{i j}^{M L}}{X_{j}^{L}} & \Rightarrow z_{i j}^{M L}=a_{i j}^{M L} \cdot X_{j}^{L}
\end{array}
$$

Pode-se substituí-los em (5.11), obtendo:

$X_{1}^{L}=a_{11}^{L L} X_{1}^{L}+a_{12}^{L L} X_{2}^{L}+a_{13}^{L L} \cdot X_{3}^{L}+a_{11}^{L M} X_{1}^{M}+a_{12}^{L M} X_{2}^{M}+Y_{1}^{L}$

As produções para os demais setores são obtidas de forma similar.

Isolando a demanda final, $Y_{1}^{L}$, e colocando em evidência a produção do setor 1 , da região $\mathrm{L}, X_{1}^{L}$, tem-se:

$\left(1-a_{11}^{L L}\right) X_{1}^{L}-a_{12}^{L L} X_{2}^{L}-a_{13}^{L L} X_{3}^{L}-a_{11}^{L M} X_{1}^{M}-a_{12}^{L M} X_{2}^{M}=Y_{1}^{L}$

As demais demandas finais podem ser obtidas similarmente.

Portanto, de acordo com $A^{L L}=Z^{L L}\left(\hat{X}^{L}\right)^{-1}$, constrói-se a matriz $A^{L L}$, para os 3 setores: 


$$
A^{L L}=\left[\begin{array}{lll}
a_{11}^{L L} & a_{12}^{L L} & a_{13}^{L L} \\
a_{21}^{L L} & a_{22}^{L L} & a_{23}^{L L} \\
a_{31}^{L L} & a_{32}^{L L} & a_{33}^{L L}
\end{array}\right]
$$

Da mesma forma para : $A^{L M}, A^{M M}, A^{M L}$

Definem-se agora as seguintes matrizes:

$$
A=\left[\begin{array}{ccc}
A^{L L} & \vdots & A^{L M} \\
\cdots & \cdots & \cdots \\
A^{M L} & \vdots & A^{M M}
\end{array}\right] \quad X=\left[\begin{array}{c}
X^{L} \\
\cdots \\
X^{M}
\end{array}\right] \quad Y=\left[\begin{array}{c}
Y^{L} \\
\cdots \\
Y^{M}
\end{array}\right]
$$

O sistema inter-regional completo de insumo produto é representado por:

$$
(I-A) X=Y
$$

e as matrizes podem ser dispostas da seguinte forma:

$$
\left\{\left[\begin{array}{ccc}
I & \vdots & 0 \\
\cdots & \because & \cdots \\
0 & \vdots & I
\end{array}\right]-\left[\begin{array}{ccc}
A^{L L} & \vdots & A^{L M} \\
\dddot{M} & \because & \dddot{M} \\
A^{M M} & \vdots & A^{M M}
\end{array}\right]\right\}\left[\begin{array}{c}
X^{L} \\
\cdots \\
X^{M}
\end{array}\right]=\left[\begin{array}{c}
Y^{L} \\
\cdots \\
Y^{M}
\end{array}\right]
$$

Efetuando estas operações, obtém-se:

$$
\begin{aligned}
& \left(I-A^{L L}\right) X^{L}-A^{L M} X^{M}=Y^{L} \\
& -A^{M L} X^{M}+\left(I-A^{M M}\right) X^{M}=Y^{M}
\end{aligned}
$$

Estes são modelos básicos, necessários à análise inter-regional proposta por Isard.

\subsubsection{Limitações e alcance do modelo inter-regional}

A restrições que se impõe ao modelo inter-regional, básicamente referem-se ao próprio modelo de insumo-produto de Leontief, dentre as quais destacam-se, segundo Cavalcanti (1993), ... "é que o valor monetário dos bens e serviços fornecidos por uma indústria é função linear e homogênea do nivel de produção dos setores compradores". 
As suposições especificas, segundo Cavalcanti, são: inexistência de produtos conjuntos, retornos constantes à escala e não substituição entre insumos, aditividade. $O$ efeito total da produção é a soma dos efeitos separados, o que elimina a possibilidade de economias e deseconomias externas. O sistema está em equilibrio, não há limites para o fornecimento de insumos e produtos, ou seja, a oferta de cada bem ou serviço é perfeitamente elástica nas versões estáticas do modelo.

Quanto ao alcance do modelo inter-regional de Isard, ele revela magnitudes de efeitos do comércio setor/região e entre eles. O modelo viabiliza, através da demanda final para cada região, a determinação de efeitos de encadeamentos entre setores e regiões, incrementos na exportação, no consumo e demais agregados.

\subsection{Adptações do modelo inter-regional de Isard}

\subsubsection{Modelo de Chenery e Moses}

Esse modelo contém partes das matrizes de coeficientes de insumos regionais, $\mathrm{A}^{\mathrm{LL}}$, e de matrizes de coeficientes de comércio entre regiões, como $\mathrm{A}^{\mathrm{LM}}$. Os esforços neste enfoque, fazem se no sentido de especificar um modelo no qual as informações requeridas sejam em menor número, sua estrutura foi sugerida por Chenery (1953) e Moses (1955), independentemente.

O modelo utiliza a matriz de coeficientes técnicos $A^{L}$, no lugar de coeficientes de insumos $A^{L L}$, ou seja:

ao invés de

$$
a_{i j}^{L}=\frac{z_{i j}^{L}}{X_{j}^{L}},
$$

$$
a_{i j}^{L L}=\frac{z_{i j}^{L L}}{X_{j}^{L}}
$$


As interconexões entre regiões, ou seja as relações inter-regionais, são captadas nas tabelas de coeficientes de comércio, $\left(C_{i}^{L M}\right)$. Os fluxos de comércio são tomados por setor.

Neste modelo, tem-se que:

$$
c_{i}^{L M}=\frac{z_{i}^{L M}}{T_{i}^{M}}
$$

onde $z_{i}^{L M}$, é o valor do fluxo do bem i da região $L$, para a região $M$. inclui o fluxo para produção e para a demanda final, e

$T_{i}^{M}$, representa os totais de exportação dos bens i da região $M$ para todas as regiões do modelo:

\subsubsection{Modelo intranacional de Leontief}

Segundo Haddad (1976, p.213), o modelo intranacional leva em consideração a estrutura conceitual de insumo-produto com o tamanho dos mercados das mercadorias, ou seja, os mercados regionais e mercados nacionais. O objetivo do modelo é o de determinar a quantidade produzida de cada mercadoria, em cada região ou sub-região, através da estrutura tecnológica regional, da estrutura da demanda final, e estrutura de distribuição regional da produção nacional.

"Uma vez determinados os niveis de produção das diferentes mercadorias em cada região ou sub-região, podemos compará-los com os valores correspondentes de demanda total e derivar a estrutura de exportação e importação de cada região. É óbvio que no caso das mercadorias sub-regionais e regionais não haverá comércio externo ao nivel de cada sub-região e região, respectivamente"(Haddad, 1976, p.225). 
O modelo denomina-se intranacional por demonstrar os vetores de exportação e de importação de mercadorias de cada região ou sub-região, sem identificar a origem das importações ou o destino das exportações.

"O modelo intranacional de Leontief aplica-se, em estudos que têm por objetivo examinar os efeitos regionais de politicas nacionais alternativas de comércio internacional ou de investimentos, particularmente, quando não se sabe de antemão o padrão de localização da nova capacidade produtiva a ser instalada" (Haddad 1976,p. 226).

\subsubsection{O modelo de Leontief-Strout (modelo gravitacional)}

O modelo gravitacional, conforme Haddad (1976,pag. 227): considera que as exportações de uma mercadoria $i$, da região $\mathrm{r}$ para a região $\mathrm{j}$, por exemplo, $\left(X_{i}^{r}\right)$, são diretamente proporcionais à produção total na região de origem $\left(X_{i}^{r}\right)$ e ao seu consumo na região de destino $\left(X_{i}^{j}\right)$, e inversamente proporcionais à distância entre as duas regiões $\left(d^{r}\right)$

Este modelo, segundo Cavalcanti (1994), é adequado a situações de alterações nos padrões de comércio inter-regional, ocorridas devido a alterações na produção, consumo e custo de transferência entre as regiões de origem e destino.

"O modelo pressupõe que o fluxo de determinado pool produto, de uma região para outra, pode ser vizualizado como o intercâmbio entre um pool de oferta regional e um pool de demanda regional do produto, sem especificar os diversos setores exportadores $e$ importadores daquele produto"(Cavalcanti (1994, p.110).

$\mathrm{O}$ modelo não faz referência à origem dos insumos, bem como o modelo não discrimina o destino dos produtos. O problema mais critico deste modelo, conforme 
observa, ainda Cavalcanti (1994), refere-se à dificuldade de se estimar o coeficiente de comércio, que refere-se aos custos de transferência de um produto de uma região para outra.

\subsection{Técnicas para obtenção de coeficientes regionais}

Apresentam-se a seguir as formulações do coeficiente locacional, o método biproporcional de matrizes e uma breve descrição da experiência da aplicação destas técnicas para a Indonésia.

\subsubsection{O Coeficiente locacional}

Miller e Blair (1985), dedicam um capitulo completo para apresentar alguns dos principais métodos para estimar dados, seja pela falta total (não censitários), ou pela disponibilidade parcial (censo parcial). Dentre eles, os autores explicitam o coeficiente locacional, ou o chamado coeficiente locacional simples para uma determinada região R:

$$
L Q_{i}^{R}=\left[\frac{X_{i}^{R} / X^{R}}{X_{i}^{N} / X^{N}}\right],
$$

$X_{i}^{R}$ e $X_{i}^{N}$, representam os totais de produção do setor $i$, regional e nacional respectivamente, e $X^{R}$ e $X^{N}$, o total da produçao regional e nacional repectivamente, portanto $L Q_{i}^{R}$ coeficiente de locação simples do setor $i$ na região $\mathrm{R}$. O numerador demonstra a contribuição do setor $i$ da região, na produção total da região $\mathrm{R}, \mathrm{e} o$ denominador, a participação da produção do setor $i$ nacionalmente na produção total nacional.

Sempre que $L Q_{i}^{R} \geq 1$ a produção do setor $i$ é mais "localizada" na região $\mathrm{R}$ do que nacionalmente, ou seja a produção do setor $i$ é mais concentrada na região $\mathrm{R}$ do que na nação como um todo, portanto este setor pode estar orientado para exportação. Logicamente se $L Q_{i}^{R}<1$, o setor $i$ da região $\mathrm{R}$, é um setor importador em potencial. 
Quando o setor mostra-se com orientação para exportação, o coeficiente $r_{i j}$, pode ser representado pelo coeficiente nacional $a_{i j}$, e quando ocorrer o inverso, o coeficiente $r_{i j}$, será obtido por $L Q_{i}^{R} * a_{i j}$.

Haddad (1989), ao fazer uma avaliação dos limites e pontenciliades das medidas de localização, chama a atenção para a utilidade do coeficiente locacional, em uma fase exploratória dos estudos regionais, e devem ser utilizados em conjunto com outras informações sobre as regiões estudadas.

\subsubsection{O Método das matrizes biproporcionais (RAS)}

O método RAS, que tem tal sigla em decorrência de sua formulação, conforme explícitado a seguir, estima matrizes tanto em sua dimensão temporal como na espacial. Este método vem sendo muito utilizado, especialmente para estimar e ajustar matrizes regionais a partir de informações agregadas.. Bacharach (1970) e Miller e Blair (1985), apresentam com detalhes, a formulação e aplicação do RAS, a partir de sua proposta de estimativa temporal, o que se sumariza a seguir:

A estimativa de uma matriz de coeficientes de insumo-produto para um determinado ano $1, \tilde{A}(1)$, pode ser realizada a partir de uma matriz conhecida, $\mathrm{A}(0)$, de ano anterior. Para tal descrevem-se os passos dos método RAS.

Preliminarmente lembra-se que:

$$
\begin{array}{ll}
a_{i j}=\frac{Z_{i j}}{X_{j}}, & \text { representam os elementos da matriz } A_{i j}, \\
Z_{i j}, & \text { vendas do setor } i \text { para o setor } j \mathrm{e} \\
X_{j} & , \text { o total de produtos do setor } j .
\end{array}
$$


Admitindo-se que são conhecidos além de $A(0)$,

$X_{j} \quad$ já definido,

$U_{\mathrm{i}} \quad$ vendas interindustriais totais realizadas pelo setor $i$, que representa

$\sum_{j=1}^{n} Z_{i j} \mathrm{e}$

$V_{j}$ compras de insumos interindustriais totais realizados pelo setor $j$, que representa $\sum_{i=1}^{n} Z_{i j}$

Com o propósito de obter-se $\widetilde{A}(1)$, definem-se os vetores:

$$
X(1)=\left[\begin{array}{c}
X_{1} \\
\vdots \\
X_{n}
\end{array}\right] ; \quad U(1)=\left[\begin{array}{c}
U_{1} \\
\vdots \\
U_{n}
\end{array}\right] \quad \text { e } \quad V(1)=\left[V_{1}, \ldots, V_{n}\right]
$$

Os vetores $\mathrm{U}(1)$ e $\mathrm{V}(1)$ representam respectivamente a soma das linhas e colunas da matriz Z.

Partindo-se da hipótese de que $\mathrm{A}(0)=\tilde{\mathrm{A}}(1)$, ou seja os coeficientes técnicos permanecem estáveis no tempo e ainda lembrando que:

$$
Z_{i j}=a_{i j} X_{i j}, \mathrm{e}
$$

representado matricialmente por:

$$
\begin{aligned}
& A=Z(\hat{X})^{-1}, \text { temos que: } \\
& Z=A(\hat{X}), \text { como a hipótese é } A(0)=\tilde{A}(1), \text { é possível escrever que: } \\
& Z=A(0) \hat{X}(1)
\end{aligned}
$$


A tarefa a seguir consiste em verificar se a somatória de linhas e colunas de $Z$, correspondem a $\mathrm{U}(1)$ e $\mathrm{V}(1)$ respectivamente.

Pós multiplicando $Z$ pelo vetor $i$, definido como vetor de valores unitários (1), obtem-se o total estimado das linhas de $Z$, denominado de $U^{1}$, ou seja:

$$
[A(0) \hat{X}(1)] \cdot i=U^{1}
$$

Pré multiplicando $\mathrm{Z}$ pelo vetor $\mathrm{i}$, obtém-se o total estimado das colunas de $\mathrm{Z}$, denominado de $\mathrm{V}^{1}$, ou seja:

$$
i^{\prime}[A(0) \hat{X}(1)]=V^{1}
$$

Se $U^{1}=U(1) \quad$ e $\quad V^{1}=V(1)$

As estimativas para os elementos de $\tilde{A}(1)$ estão de acordo com a hipótese inicial e o trabalho finaliza-se após o cálculo:

$$
\widetilde{A}(1)=Z(1)[\hat{X}(1)]^{-1}
$$

Porém o que normalmente ocorre é que:

$$
U^{1} \neq U(1) \quad \text { e } \quad V^{1} \neq V(1)
$$

Então os elementos de Z, poderão ser corrigidos pelas seguintes proporções:

$$
r_{i}^{1}=\frac{U_{i}(1)}{U_{i}^{1}} \quad \text { e/ou } \quad s_{i}^{1}=\frac{V_{i}(1)}{V_{i}^{1}}
$$

Considerando as notações matriciais

$$
R(1)=\left[\begin{array}{ccc}
r_{1}^{\prime} & 0 & 0 \\
0 & r_{2}^{\prime} & 0 \\
\vdots & \vdots & \vdots \\
0 & 0 & r_{n}^{\prime}
\end{array}\right] \quad, \quad S(1)=\left[\begin{array}{ccc}
s_{1}^{\prime} & 0 & 0 \\
0 & s_{2}^{\prime} & 0 \\
\vdots & \vdots & \vdots \\
0 & 0 & s_{n}
\end{array}\right]
$$

A correção poderá então ser realizada simultaneamente, conforme: 
$\tilde{\mathrm{A}}(1)=\mathrm{R}(1) \cdot \mathrm{A}(0) \cdot \mathrm{S}(1)$

O que explica as siglas RAS, observando-se as letras do lado direito da equação.

Este processo deve ser repetido quantas vezes for necessário, ou seja até convergir para a melhor estimativa possível.

\subsubsection{O método RAS e as estimativas regionais}

A aplicação dos mesmos príncipios do RAS, utilizados para projeções, podem ser úteis para estimar matrizes regionais, ou seja ajustar coeficientes no espaço, a partir de informações agregadas Pode-se estimar $A(R)$, matriz de coeficientes de insumo produto para uma região $R$, a partir de $A(N)$, e outras informações sobre a região $R$, como $X(R)$ produção total e $U(R)$ e $V(R)$ vendas e compras iteríndustriais, respectivamente.

Uma tabela regional $A(N)$, segundo Miller e Blair (1985), reflete uma média de relações de insumo-produto, em vária regiões da nação, a minimização da chamada "distância das informações", inerentes a técnica RAS, pode ser apropriada para a questão regional.

O uso do procedimento RAS tem sido intensivo devido a escassez de dados regionais. Existem experiências de seu uso em conjugação com a técnica de coeficiente locacional, a exemplo do trabalho para a Indonésia, que é apresentado a seguir. 


\subsubsection{Aplicação de técnicas de estimativas regionais. $O$ caso da Indonésia}

Diversos modelos para obtenção de matrizes regionais vêm sendo elaborados e aplicados. Destaca-se o trabalho de Hewings e Hulu (1993), em que se desenvolvem modelos inter-regionais de insumo-produto para as 5 principais regiões da Indonésia, sob condições de informações limitadas, para 1980 e 1985. Procedimento este que possibilitou a identificação e respectiva exploração da estrutura produtiva da economia da Indonésia, através do exame dos campos de influência, permitindo, também, algumas inferências sobre condicionantes de desenvolvimento e crescimento, quando da aplicação de politicas regionais.

Os procedimentos resultaram de uma combinação de diversos modelos de insumo produto regional e, principalmente, dos trabalhos de Round (1978), (1979) e (1983), que tratam de técnicas para construção de matrizes de insumo-produto, em situações de falta completa e parcial das informações, e de técnica de ajustamento biproporcional através do método RAS. Hewings e Hulu (1993), creditam a maior criatividade deste trabalho, ao processo desenvolvido em 02 estágios, como se segue:

\section{Primeiro Estágio}

Construção de modelos de 02 regiões, considerando cada região $(\mathrm{R})$, relacionando-se com o resto da Indonésia (ROI), ou seja a soma de todas outras regiões, este sistema pode ser visualizado de forma genérica no quadro a seguir:

Quadro 5.2 Esquema do modelo insumo-produto para duas regiões, Indonésia, 1980 e 1985

\begin{tabular}{|l|l|l|}
\hline R,R & R,ROI & SOMA DA LINHA \\
\hline ROI, R & ROI, ROI & SOMA DA LINHA \\
\hline SOMA DA COLUNA & SOMA DA COLUNA & \\
\hline
\end{tabular}

Fonte: Hewings e Hulu (1993, p. 141) 
São construídas matrizes, conforme esquema apresentado acima, para as cinco regiões da Indonésia, sendo que a maior complexidade foi estimar os fluxos interregionais de cada conjunto destas quatro matrizes. O pressuposto inicial foi $\mathrm{o}$ de considerar que a tecnologia regional era identica a nacional, com base nisto a caracterização dos coeficientes regionais é considerada através da compras realizadas na região e em outras regiões da Indonésia, ou seja:

$$
a_{i j}=a_{i j}(r)=r_{i j}+m_{i j},
$$

onde: $a_{i j}$ e $a_{i j}(r)$ representam respectivamente o total de requerimentos técnicos de insumo $i$, nacional e regional, usados pelo setor $j$. Por sua vez, $r_{i j}$ e $m_{i j}$, representam respectivamente, a separação de insumos vindos de $i$ da região e de outras regiões da Indonésia, usados pelo setor $j$.

Em razão disto, pode-se afirmar que:

$$
r_{i j} \in(R, R), \mathrm{e}(R O I, R O I), \text { enquanto } m_{i j} \in(R, R O I) \text {, e }(R O I, R)
$$

A maior questão é a da escolha do chamado estimador $r_{i j}$. Segundo Hewings e Hulu (1993, p.142) apesar da literatura apresentar varias contribuições para este problema, as evidências empíricas parecem não corrobora as estimativas, portanto muitos ajustes e combinações são realizados.

O coeficiente de locacional (LQ), proposto por Round (1979), foi usado para ajustar os $a_{i j}$, no sentido de derivar os $r_{i j}$.

Se $L Q_{i} \geq 1 \Rightarrow r_{i j}=a_{i j} \Rightarrow m_{i j}=0$

Se $L Q_{i}<1 \Rightarrow r_{i j}=L Q_{i}^{*} a_{i j} \Rightarrow m_{i j}=a_{i j}-r_{i j}$ 


\section{Segundo Estágio}

No segundo estágio, estimou-se, de forma completa, o modelo inter-regional de insumo-produto para as cinco regiões da Indonésia, através da adptação da proposta de Round (1979), adotando-se a aproximação biproporcional, ou seja uma aplicação do método RAS.

O capítulo seguinte descreve a metodologia e sua aplicação, na obtenção da matriz inter-regional brasileira de 1985. 


\section{CONSTRUÇÃO DA MATRIZ INTER-REGIONAL DO BRASIL DE 1985}

O detalhamento do processo de construção da matriz inter-regional do Brasil de 1985 e seus principais resultados, constituem-se no propósito deste capítulo. Inicialmente realiza a explicitação dos motivos da escolha do modelo inter-regional, em seguida descrimina o material e fontes utilizados. Através de um esquema da construção da matriz, na seqüência os procedimentos metodológicos são delineados e finalmente procede-se a apresentação sintética da matriz inter-regional obtida neste processo.

\subsection{A escolha do modelo inter-regional de Isard}

A matriz inter-regional brasileira para 1985 foi construída através da formulação do modelo inter-regional (setor x setor), detalhado no capitulo 5 , item 5.2.1 deste trabalho. Este modelo proposto por Isard em 1951, requer grande número de informações, dentre elas os fluxos inter-regionais, intercâmbio entre produtos e setores que se realizam entre as regiões. O modelo é considerado completo e ideal pela literatura especializada em estudos de insumo-produto regional.

As adptações do modelo inter-regional distinguem-se basicamente pelo tipo e volume das informações disponíveis. Optou-se pelo modelo inter-regional pela disponibilidade de um grande número de informações por região e mesmo período, ou seja a matriz nacional, do Norte e a do Nordeste e Censos Econômicos (o mais recente até o momento da elaboração da pesquisa), com informações das produções setoriais desagregadas por estados. Estas informações e as estimativas dos fluxos inter-regionais 
por setor, obtidos via aplicação dos métodos de coeficientes locionais e calibrados pela técnica RAS, possibilitaram a utilização do modelo proposto por Isard.

Em suma, a massa de informações obtidas, ora diretamente ou por estimativas confiáveis e consistentes permitiram esta escolha

\subsection{Material e fontes}

\subsubsection{Conformação das regiōes estudadas}

Preliminarmente, apresentamos os estados componentes das regiões, consideradas na pesquisa:

Região Norte: Amazonas, Pará e Acre, Amapá, Roraima e Rondônia., Mato Grosso, Região Nordeste: Maranhão, Piauí, Ceará, Rio Grande do Norte, Paraiba, Pernambuco, Região Centro-Oeste: Mato Grosso do Sul, Goias, Tocantíns e Distríto Federal, Região Sudeste: São Paulo, Rio de Janeiro, Minas Gerais, Espírito Santo e Região Sul: Paraná, Santa Catarina e Rio Grande do Sul.

Esta classificação difere da base de regionalização do IBGE, apresentada no capítulo 2 desta tese, apenas pela inclusão do estado de Mato Grosso na região Norte, ao invés da região Centro-Oeste. Este procedimento se justifica, pela necessidade de conciliação de procedimentos, com as matrizes das regiões Norte e Nordeste, já construídas.

\subsubsection{Discriminação dos valores e fontes básicas}

Os valores básicos para a construção da matriz inter-regional - Brasil 1985, foram coletadas das matrizes de insumo e de produção do Brasil, Norte e Nordeste, conforme dimensões, tipo de documento e fontes discriminados no Quadro 6.1. O Quadro 6.2 , discrimina os tipo de documentos e respectivas fontes que contribuíram para a construção das matrizes do Centro-Oeste, Sudeste e Sul. 
Quadro 6.1 - Informações básicas para construção da matriz inter-regional - Brasil 1985

\begin{tabular}{|c|c|c|c|c|c|}
\hline \multirow{3}{*}{ REGIÃO } & \multicolumn{4}{|c|}{ MATRIZ (bilhōes em cruzeiros - 1985) } & \multirow{3}{*}{ DOCUMENTO E FONTE } \\
\hline & \multicolumn{2}{|c|}{ PRODUCĀO } & \multicolumn{2}{|c|}{ INSUMO } & \\
\hline & IDENTIF. & DIMENSÃO & IDENTIF. & DIMENSÃO & \\
\hline BRASIL & $\mathbf{V}$ & $42 \times 80$ & $\mathbf{U}$ & $80 \times 42$ & $\begin{array}{l}\text { Matriz nacional de insumo-produto, } 1985- \\
\text { Brasil } \\
\text { Fonte- IBGE } \\
\end{array}$ \\
\hline NORTE & $\mathbf{V}^{\mathrm{N}}$ & $71 \times 129$ & $\mathbf{U}^{N}$ & $129 \times 71$ & $\begin{array}{l}\text { Matriz de insumo-produto do Norte 1980-85 } \\
\text { Fonte - Silva, Considera, Magalhães e Ramos, } \\
\text { SUDAM, } 1994\end{array}$ \\
\hline NORDESTE & $\mathbf{V}^{\mathrm{NE}}$ & $80 \times 128$ & $\mathbf{U}^{\mathrm{NE}}$ & $128 \times 80$ & $\begin{array}{c}\text { Matriz de insumo-produto do Nordeste 1980-85 } \\
\text { Fonte - Silva, Considera, Magalhães e } \\
\text { Bittencourt,BMB ,1992 } \\
\end{array}$ \\
\hline
\end{tabular}

Quadro 6.2 - Fontes para construção das matrizes - Centro-Oeste, Sudeste e Sul - 1985

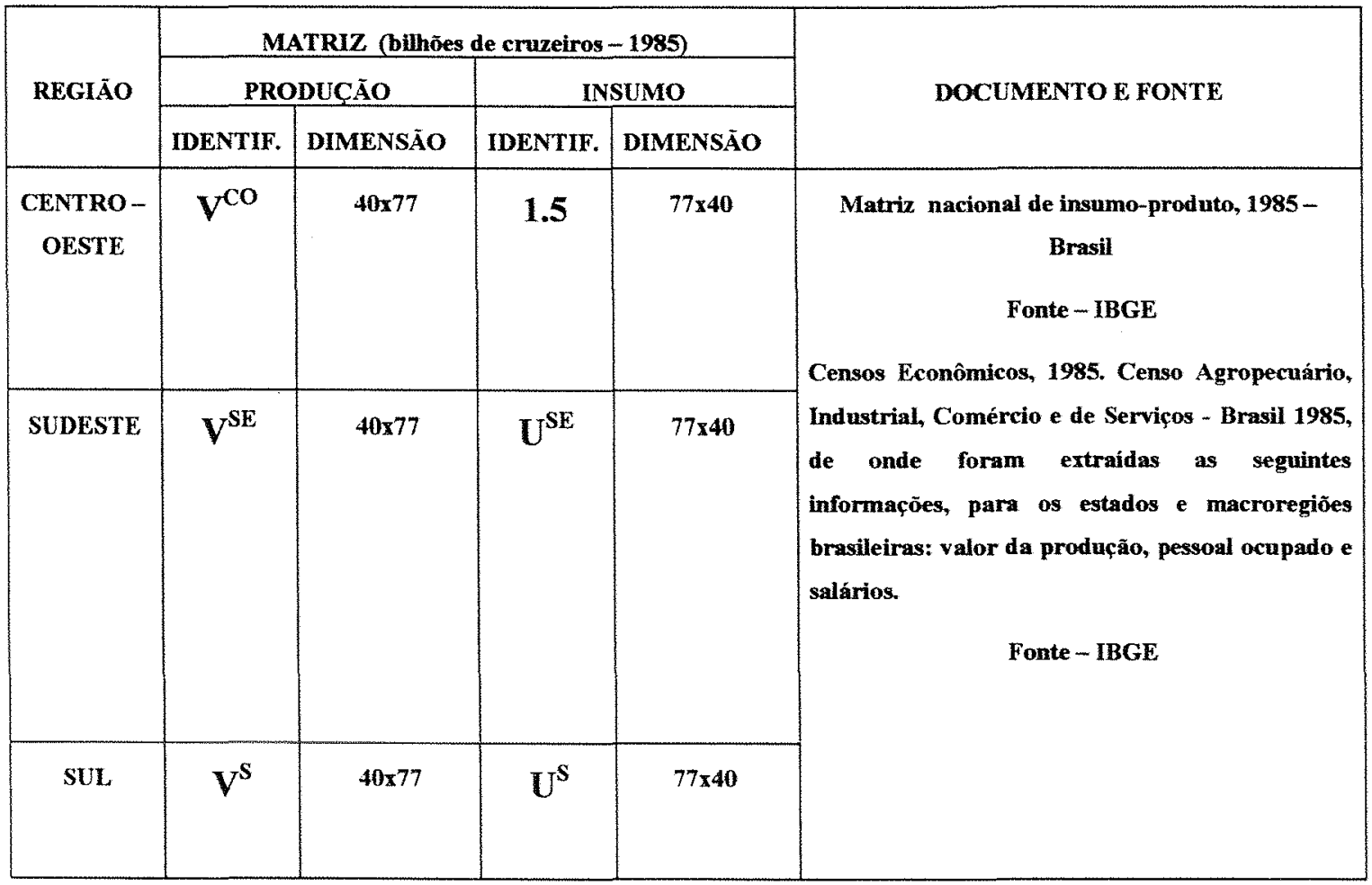




\subsection{Construção da matriz inter-regional do Brasil, 1985.}

O processo de construção da matriz inter-regional para o Brasil, 1985, tomou por base a matriz $Z$ (setor $x$ setor), de fluxos inter-setoriais e inter-regionais, conforme modelo apresentado no capítulo 5 desta pesquisa, especificamente no quadro 5.1.

Com objetivo de apresentar os passos deste processo, apresentam-se, preliminarmente, as variáveis e os esquemas da construção da matriz $Z$, estes representados nas Figuras 6.1 e 6.2 .

\subsubsection{Variáveis (matrizes) e formulações utilizadas no processo}

a) produção: $V^{\mathrm{N}}, \mathrm{V}^{\mathrm{NE}}, \mathrm{V}^{\mathrm{CO}}, \mathrm{V}^{\mathrm{SE}} \mathrm{e} \mathrm{V}^{\mathrm{S}}$ (o sobrescrito identifica cada região)

b) vetores coluna, do total de produção por produto, $Q^{N}, Q^{N E}, Q^{C O}, Q^{S E}$ e $Q^{S}$

c) coeficientes de produção: $D^{N}, D^{N E}, D^{C O}, D^{S E}$ e $D^{S}$, obtidos através da formulação genérica, onde o sobrescrito $\mathrm{R}$, indica região. $D^{R}=V^{R}\left(\hat{Q}^{R}\right)^{-1}$.

d) insumos, $U^{\mathrm{N}}, \mathrm{U}^{\mathrm{NE}}, \mathrm{U}^{\mathrm{CO}}, \mathrm{U}^{\mathrm{SE}}$ e $\mathrm{U}^{\mathrm{S}}$, tanto para demanda intermediária como para a final e total.

e) importações, impostos, remunerações, salário, contribuições, excedente bruto, valor adicionado a custo de fatores, e a preços básicos, impostos e subsídios sobre atividades, $\mathrm{C}^{\mathrm{N}}, \mathrm{C}^{\mathrm{NE}}, \mathrm{C}^{\mathrm{CO}}, \mathrm{C}^{\mathrm{SE}}$ e $\mathrm{C}^{\mathrm{S}}$, tanto para a demanda intermediária como para a final e total.

f) Vetores linha, do total de produção, $X^{N}, X^{N E}, X^{C O}, X^{S E} e X^{S}$.

\subsubsection{Formulações gerais para obtenção da matriz $Z$, inter-regional}

Obtém-se $\mathbf{Z}$, através da composição em blocos, de acordo com os três passos indicados abaixo, e ilustrados através do esquema, detalhado na Figura 6.1.

a) $Z^{R}=D^{R} * U^{R}$, prémultiplicação das matrizes de insumo de cada região $\mathrm{U}^{\mathrm{R}}$, pelas respectivas matrizes de coeficientes de produção das regiões, $\mathrm{D}^{\mathrm{R}}$ bloco a bloco, em linha, obtendo-se 130 linhas e 168 colunas de sua primeira parte (demanda intermediária, final mais o total), 
b) $Z^{C}=C^{R}$, transferência dos blocos de matrizes $C^{R}$, bloco a bloco, em linha, abaixo da matriz formada em a), totalizando 141 linhas e 168 colunas e

c) $Z^{X}=X^{R}$, transferência dos blocos de matrizes $X^{R}$, bloco a bloco, em linha, abaixo da matriz formada em b), totalizando 142 linhas e 168 colunas.

\begin{tabular}{|c|c|c|c|c|c|c|c|c|c|c|c|c|c|}
\hline \multirow[t]{3}{*}{$Z$} & \multirow[t]{3}{*}{$D^{R}$} & & \multicolumn{11}{|c|}{$U^{\mathrm{R}}$} \\
\hline & & & \multicolumn{5}{|c|}{ DEMANDA,INTERMEDIARLA } & \multicolumn{5}{|c|}{ DEMANDA FINAL } & \multirow{2}{*}{$\begin{array}{c}\text { TOTAL } \\
0\end{array}$} \\
\hline & & & $\mathrm{N}$ & NE & $\mathrm{CO}$ & SE & $s$ & $\mathbf{N}$ & $\mathrm{NE}$ & $\mathrm{CO}$ & SE & $s$ & \\
\hline$z^{N}$ & $n^{N}$ & $N$ & 1 & 2 & 5 & 6 & 7 & 36 & 37 & 40 & 41 & 42 & 71 \\
\hline$Z^{\mathrm{NE}}$ & $=D^{\mathrm{NE}}$ & 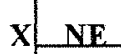 & 3 & 4 & 8 & 9 & 10 & 38 & 39 & 43 & 44 & 45 & 72 \\
\hline$z^{\text {co }}$ & $=D^{\mathrm{Co}}$ & 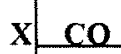 & 11 & 14 & 17 & 18 & 19 & 46 & 49 & 52 & 53 & 54 & 73 \\
\hline$Z^{\mathrm{SE}}$ & $=D^{\mathrm{SE}}$ & \begin{tabular}{l|l}
$X$ & $S E$
\end{tabular} & 12 & 15 & 20 & 21 & 22 & +7 & 50 & 55 & 56 & 57 & 74 \\
\hline$z^{s}$ & $=D^{S}$ & $x \leq s$ & 13 & 16 & 23 & 24 & 25 & 48 & 51 & 58 & 59 & 60 & 75 \\
\hline$z^{c}$ & $=$ & $c$ & 26 & 27 & 28 & 29 & 30 & 61 & 62 & 63 & 64 & 65 & 76 \\
\hline$z^{x}$ & $=$ & $\mathbf{x}$ & 31 & 32. & 33 & 34 & 35 & 66 & 67 & 68 & 69 & 70 & 77 \\
\hline
\end{tabular}

Figura 6.1 -Esquema para construção - matriz $Z$ - insumo - produto inter-regional, Brasil 1985

\begin{tabular}{|c|c|c|c|c|c|c|c|c|c|c|c|}
\hline & \multicolumn{5}{|c|}{ DEMANDA INTERMEDIARIA } & \multicolumn{5}{|c|}{ DEMANDA FINAL } & \multirow{2}{*}{$\begin{array}{c}\text { TOTAL } \\
\mathrm{X}^{\prime}\end{array}$} \\
\hline & $N$ & $\mathrm{NE}$ & $\mathrm{CO}$ & SE & $S$ & $\mathbf{N}$ & NE & $\mathrm{CO}$ & SE & $S$ & \\
\hline $\mathrm{N}$ & $\mathbf{z}^{\mathrm{NN}}$ & $\mathrm{z}^{\mathrm{NNE}}$ & $\mathrm{z}^{\mathrm{NCO}}$ & $\mathbf{z}^{\mathrm{NSE}}$ & $\mathrm{Z}^{\mathrm{NS}}$ & $\mathbf{Y}^{\mathrm{YN}}$ & $\mathbf{Y}^{\mathrm{NNE}}$ & $\underline{z}^{\mathrm{NCO}}$ & $\mathbf{Z}^{\mathrm{NSE}}$ & $\mathrm{z}^{\mathrm{NS}}$ & $\mathbf{X}^{\mathrm{N}}$ \\
\hline $\mathrm{NE}$ & $\mathbf{Z}^{\mathrm{NEN}}$ & $z^{\text {VENE }}$ & $\mathbf{z}^{\mathrm{NECO}}$ & $Z^{\text {NESE }}$ & $z^{\mathrm{NES}}$ & $\mathbf{Y}^{\mathrm{NEN}}$ & $\mathbf{Y}^{\mathrm{NENE}}$ & $\mathbf{z}^{\mathrm{Neco}}$ & $\mathrm{Z}^{\text {NESSE }}$ & $\mathrm{Z}^{\mathrm{NES}}$ & $\mathrm{X}^{\mathrm{NE}}$ \\
\hline $\mathrm{CO}$ & $\mathbf{Z}^{\mathrm{COM}}$ & $\mathbf{Z}^{\mathrm{CONE}}$ & $\mathbf{Z}^{\text {coco }}$ & $\mathrm{Z}^{\text {COSE }}$ & $\mathbf{z}^{\mathrm{cos}}$ & $Y^{\text {CON }}$ & $\mathrm{Y}^{\mathrm{CONE}}$ & $\mathrm{z}^{\mathrm{coco}}$ & $\mathbf{Z}^{\mathrm{COSE}}$ & $\mathbf{Z}^{\cos }$ & $x^{\text {co }}$ \\
\hline $\mathrm{SE}$ & $\mathbf{z}^{\text {sEM }}$ & $\mathrm{z}^{\mathrm{SENE}}$ & $\mathrm{z}^{\text {sEco }}$ & $z^{\text {SESE }}$ & $z^{\text {sES }}$ & $y^{\mathrm{SEN}}$ & $\mathrm{Y}^{\sin E}$ & $\mathbf{z}^{\mathrm{seco}}$ & $z^{\text {SESE }}$ & $z^{\mathrm{SES}}$ & $\mathbf{x}^{\mathrm{SE}}$ \\
\hline $\mathbf{S}$ & $z^{5 N}$ & $\mathbf{z}^{\mathrm{SNE}}$ & $z^{\mathrm{sco}}$ & $\mathbf{Z}^{\text {SSE }}$ & $z^{s s}$ & $Y^{S N}$ & $\mathbf{Y}^{\mathrm{SNE}}$ & $z^{\mathrm{sCO}}$ & $\mathbf{Z}^{\mathrm{SSE}}$ & $\mathrm{z}^{\mathrm{ss}}$ & $x^{s}$ \\
\hline C & $\mathrm{c}^{\mathrm{N}}$ & $\mathrm{C}^{\mathrm{vE}}$ & $\mathrm{C}^{\mathrm{co}}$ & $\mathrm{C}^{\mathrm{SE}}$ & $c^{s}$ & $\mathrm{CX}^{\mathrm{N}}$ & $\mathrm{CY}^{\mathrm{NE}}$ & $\mathrm{CY}^{\mathrm{CO}}$ & $\mathrm{CY}^{\mathrm{SE}}$ & $\mathrm{CY}^{\mathrm{s}}$ & \\
\hline $\mathrm{X}$ & $\left(\mathrm{X}^{\mathrm{N}}\right)^{\prime}$ & $\left(\mathrm{X}^{\mathrm{NE}}\right)$ & $\left(x^{\mathrm{cg}}\right)$ & $\left(X^{\mathrm{SE}}\right)^{\prime}$ & $\left(\mathbf{X}^{s}\right)$ & & & & & & \\
\hline
\end{tabular}

Figura 6.2- Esquema da matriz $Z$, insumo produto inter-egional (setor $x$ setor)

\section{Brasil 1985}

As numerações constantes nas matrizes dos esquemas das Figuras 6.1 e 6.2, bem como nas demais que serão apresentadas nesta seção, prestam-se a identificação das matrizes ou blocos de matrizes e principalmente para facilitar a visualizações das desagregações efetuadas ao longo do processo de construção da matriz inter-regional. Por sua vez a coloração em cinza de algumas matrizes, a seguir, identifica aquelas que já são 
conhecidas, conforme informações básicas do Quadro 6.1, ou seus valores são conhecidos de forma agregada. Na seqüência apresentam-se os estágios do processo.

Observa-se, também, que nos estágios apresentados a seguir, serão demonstradas operações de adição e subtração de matrizes, o que está representado pelos sinais convencionais de $(+)$ e $(-)$.

\subsubsection{Os estágios da construção da matriz inter-regional}

$1^{0}$ - estágio. Consolidação dos produtos e setores das matrizes originais de produção e de insumo para o Brasil, Norte e Nordeste. Este procedimento resultou em 40 setores (linhas), e 77 produtos (colunas), indicados no Quadro abaixo.

Quadro 6.3 - Consolidação das matrizes de produção e de insumos, Brasil, Norte e Nordeste,

\begin{tabular}{|c|c|c|c|c|c|c|c|c|}
\hline \multirow{3}{*}{ REGIÃO } & \multicolumn{4}{|c|}{ MATRIZ PRODUÇÃO } & \multicolumn{4}{|c|}{ MATRIZ INSUMOS } \\
\hline & \multicolumn{2}{|c|}{ ORIGINAL } & \multicolumn{2}{|c|}{ CONSOLIDADA } & \multicolumn{2}{|c|}{ ORIGINAL } & \multicolumn{2}{|c|}{ CONSOLIDADA } \\
\hline & IDENTIF. & DIMENSĀO & IDENTIF. & DIMENSÃO & IDENTIF. & DIMENSÃO & IDENTIF. & DIMENSÃO \\
\hline BRASIL & $\mathbf{V}$ & $42 \times 80$ & $\mathbf{V}$ & $40 \times 77$ & $\mathbf{U}$ & $80 \times 42$ & $\mathbf{U}$ & $77 \times 40$ \\
\hline NORTE & $\mathbf{V}^{N}$ & $71 \times 129$ & $\mathbf{V}^{N}$ & $40 \times 77$ & $\mathbf{U}^{\mathrm{N}}$ & $129 \times 71$ & $\mathbf{U}^{N}$ & $77 \times 40$ \\
\hline NORDESTE & $\mathbf{V}^{\mathrm{NE}}$ & $80 \times 128$ & $\mathbf{V}^{\mathrm{NE}}$ & $40 \times 77$ & $\mathbf{U}^{\mathrm{NE}}$ & $128 \times 80$ & $\mathbf{U}^{\mathrm{NE}}$ & $77 \times 40$ \\
\hline
\end{tabular}

Observação: a discriminação dos setores e produtos consolidados por matriz de produção e de insumos, para o Brasil, região Norte e Nordeste, encontra-se no Anexo B desta pesquisa . 
$2^{0}$ - estágio - Após consolidação (estágio 1), obtém-se as matrizes de insumos, $\mathrm{U}^{\mathrm{RB}}$ (produto, setor), para o resto do Brasil, ou seja, as regiões Centro-Oeste, Sudeste e Sul agregadas. Através da dedução da matrizes de insumos do Norte e Nordeste, $\left(\mathrm{U}^{\mathrm{N}}\right.$ e $\mathrm{U}^{\mathrm{NE}}$ ) da matriz de insumos do Brasil $\left(\mathrm{U}^{\mathrm{BR}}\right)$, conforme Figuras 6.3 e 6.4 .

Matriz de Insumos Brasil $\left(\mathrm{U}^{\mathrm{BR}}\right)$

$(-)$

\begin{tabular}{|c|c|c|c|}
\cline { 2 - 4 } \multicolumn{1}{c|}{} & \multicolumn{3}{|c|}{ Setor } \\
\cline { 2 - 5 } \multicolumn{1}{c|}{ Dem. Int. } & Dem. Fin. & Total $(Q)$ \\
\hline Produto & 1 a 25 & 36 a 60 & 71 a 75 \\
\hline C & 26 a 30 & 61 a 65 & 76 \\
\hline Total $(X)$ & 31 a 35 & 66 a 70 & 77 \\
\hline
\end{tabular}

Matriz de Insumos Norte

$\left(\mathbf{U}^{\mathbf{N}}\right)$

$(-)$

\begin{tabular}{|c|c|c|c|}
\cline { 2 - 4 } \multicolumn{1}{c|}{} & \multicolumn{3}{|c|}{ Setor } \\
\cline { 2 - 5 } & Dem. Int & Dem.Fin. & Total $(\mathrm{Q})$ \\
\hline Produto & 1 & 36 & 71 \\
\hline $\mathrm{C}$ & 26 & 61 & $(26+61)$ \\
\hline Total $(\mathrm{X})$ & 31 & 66 & $(31+66)$ \\
\hline
\end{tabular}

Matriz de Insumos Nordeste

$\left(\mathrm{U}^{\mathrm{NE}}\right)$

$(-)$

\begin{tabular}{|c|c|c|c|}
\cline { 2 - 4 } \multicolumn{1}{c|}{} & \multicolumn{3}{|c|}{ Setor } \\
\cline { 2 - 4 } \multicolumn{1}{c|}{} & Dem. Int & Dem. Fin. & Total $(Q)$ \\
\hline Produto & 4 & 39 & 72 \\
\hline C & 27 & 62 & $(27+62)$ \\
\hline Total $(X)$ & 32 & 67 & $(32+67)$ \\
\hline
\end{tabular}

$(=)$

Matriz de Insumos do

Resto do Brasil

$\left(\mathbf{U}^{\mathrm{RB}}\right)$

\begin{tabular}{|c|c|c|c|}
\hline & \multicolumn{3}{|c|}{ Setor } \\
\hline & Dem. Intermed. & Demanda Final & Total $(Q)$ \\
\hline Produto & $\begin{array}{l}2 \text { e } 3,5 \text { a } 10, \\
11 \text { a } 16,17 \text { a } 25\end{array}$ & $\begin{array}{r}37 \text { e } 38,40 \text { a } 45 \\
46 \text { a } 51,52 \text { a } 60\end{array}$ & 73 a 75 \\
\hline $\mathrm{C}$ & 28 a 30 & $63 a 65$ & $(76-26-27-61-62)$ \\
\hline Total $(\mathrm{X})$ & $33 \times 35$ & 68,70 & $(77-21-32-66-67)$ \\
\hline
\end{tabular}

Figura 6.3 - Esquema de obtenção da matriz de produção - $U^{R B}$ - (produto $x$ setor) para 0 Resto do Brasil . 


\begin{tabular}{|c|c|c|c|c|c|c|c|}
\hline & \multicolumn{3}{|c|}{ DEMANDA INTERMEDIÁRIA } & \multicolumn{3}{|c|}{ DEMANDA FINAL } & \multirow{2}{*}{$\begin{array}{c}\text { TOTAL } \\
\text { (Q) }\end{array}$} \\
\hline & NORTE & NORD. & R.BR. & NORTE & NORD. & R.BR & \\
\hline NORTE & 1 & 2 & 5 a 7 & 36 & 37 & 40 a 42 & 71 \\
\hline NORDESTE & 3 & 4 & 8 a 10 & 38 & 39 & 43 a 45 & 72 \\
\hline RESTO DO BRASIL & 11 a 16 & 14 a 16 & 17 a 25 & $46-48$ & $49-51$ & 52 a 60 & 73 a 75 \\
\hline C & 26 & 27 & 28 a 30 & 61 & 62 & 63 a 65 & 76 \\
\hline TOTAL $\left(X^{\prime}\right)$ & 31 & 32 & 33 a 35 & 66 & 67 & 68 a 70 & 77 \\
\hline
\end{tabular}

Figura 6.4 - Esquema para obtenção da Matriz de insumos - $U^{\mathrm{RB}}$ - para o resto do Brasil, (Região Centro-Oeste, Sudeste e Sul agregadas), ( produto $\mathrm{x}$ setor)

Ressalta-se que estas numerações referem-se àquelas constantes na matriz de insumos na Figura 6.1 e, que as informações das matrizes do Resto do Brasil, na Figura 6.5, são assinaladas em cinza, pois seus valores são conhecidos de forma agregada, enquanto na Figura 6.6, elas encontram-se sem essa coloração, pois seus valores desconhecidos, na forma desagregada.

$3^{0}$ - estágio - Agregação das matrizes de insumos, Norte, Nordeste e Resto do Brasil.

Quadro 6.4 - Agregação das matrizes de insumos, Resto do Brasil, Norte e Nordeste.

\begin{tabular}{|c|c|c|c|c|}
\hline \multirow{3}{*}{ REGIÃO } & \multicolumn{4}{|c|}{ MATRIZ DE INSUMOS } \\
\hline & \multicolumn{2}{|c|}{ PRIMEIRA AGREGACĀO } & \multicolumn{2}{|c|}{ SEGLNDA AGREGACĀO } \\
\hline & IDENTIFICAÇĀO & DIMENSĀO & IDENTIFICAÇAOO & DIMENSĀO \\
\hline RESTO DO BRASIL & $\mathbf{U}^{\mathbf{R B}}$ & $77 \times 44$ & $\mathbf{U}^{\mathrm{RB}}$ & $43 \times 26$ \\
\hline NORTE & $\mathbf{U}^{\mathrm{n}^{\mathrm{N}}}$ & $77 \times 44$ & $\mathbf{U}^{\mathrm{N}}$ & $43 \times 26$ \\
\hline NORDESTE & $\mathrm{U}^{\mathrm{i} \mathrm{i}}$ & $77 \times 44$ & $\mathrm{U}^{\mathrm{NE}}$ & $+3 \times 26$ \\
\hline
\end{tabular}

Observação: a discriminação dos setores e produtos, das matrizes de insumo, para as regiões Norte e Nordeste, encontra-se no Anexo B desta pesquisa. 
$4^{O}$ - estágio - Obtenção da matriz de insumos para as regiões Centro-Oeste, Sudeste e Sul.

Matriz de Insumos do Resto do Brasil (U $\mathrm{U}^{\mathrm{RB}}$ )

$(=)$

\begin{tabular}{|c|c|c|c|}
\cline { 2 - 4 } \multicolumn{1}{c|}{} & \multicolumn{3}{c|}{ Setor } \\
\hline \multirow{4}{*}{ Produto Intermed. } & Demanda Final & Total $(Q)$ \\
\hline & 2 e 3, 5 a 10, & 37 e 38, 40 a 45 & \\
& 11 a 16, 17 a 25 & 46 a 51,52 a 60 & 73 a 75 \\
C & 28 a 30 & 63 a 65 & $(76-26-27-61-62)$ \\
\hline Total $(X)$ & 33 a 35 & 68 a 70 & $(77-21-32-66-67)$ \\
\hline
\end{tabular}

Matriz de Insumos do Centro-Oeste

$$
\begin{gathered}
\left(v^{\mathrm{CO}}\right) \\
(+)
\end{gathered}
$$

\begin{tabular}{|c|c|c|c|}
\cline { 2 - 4 } \multicolumn{1}{c|}{} & \multicolumn{3}{c|}{ Setor } \\
\cline { 2 - 4 } \multicolumn{1}{c|}{} & Dem. Int & Dem.Fin. & Total $(Q)$ \\
\hline Produto & 17 & 52 & 73 \\
\hline C & 28 & 63 & $(28+63)$ \\
\hline Total $(X)$ & 33 & 68 & $(33+68)$ \\
\hline
\end{tabular}

Matriz de Insumos do Sudeste

$$
\begin{gathered}
\left(\mathbf{V}^{\mathrm{SE}}\right) \\
(+)
\end{gathered}
$$

\begin{tabular}{|c|c|c|c|}
\cline { 2 - 4 } \multicolumn{1}{c|}{} & \multicolumn{3}{c|}{ Setor } \\
\cline { 2 - 4 } \multicolumn{1}{c|}{} & Dem. Int & Dem. Fin. & Total (Q) \\
\hline Produto & 21 & 59 & 74 \\
\hline C & 29 & 64 & $(29+64)$ \\
\hline Total (X) & 34 & 69 & $(34+69)$ \\
\hline
\end{tabular}

Matriz de Insumos do Sul

$$
\begin{aligned}
& \left(v^{s}\right) \\
& (+)
\end{aligned}
$$

\begin{tabular}{|c|c|c|c|}
\cline { 2 - 4 } \multicolumn{1}{c|}{} & \multicolumn{3}{c|}{ Setor } \\
\cline { 2 - 4 } \multicolumn{1}{c|}{ Dem. Int } & Dem.Fin. & Total $(Q)$ \\
\hline Produto & 25 & 60 & 75 \\
\hline C & 30 & 65 & $(30+65)$ \\
\hline Total $(X)$ & 32 & 70 & $(32+70)$ \\
\hline
\end{tabular}

Figura 6.5 - Esquema de obtenção da matriz de produção $-V^{\mathrm{RB}}$ - (produto $\mathrm{x}$ setor) para 0 Resto do Brasil. 


\begin{tabular}{|c|c|c|c|c|c|c|c|c|c|c|c|}
\hline & \multicolumn{4}{|c|}{ DEMANDA INTERMEDIÁRIA } & \multicolumn{6}{|c|}{ DEMANDA FINAL } \\
\cline { 2 - 15 } & $\mathrm{N}$ & $\mathrm{NE}$ & $\mathrm{CO}$ & $\mathrm{SE}$ & $\mathrm{S}$ & $\mathrm{N}$ & $\mathrm{NE}$ & $\mathrm{CO}$ & $\mathrm{SE}$ & $\mathrm{S}$ & $\begin{array}{c}\text { TOTAL } \\
\left(Q^{\prime}\right)\end{array}$ \\
\hline NORTE & 1 & 2 & 5 & 6 & 7 & 36 & 37 & 40 & 41 & 42 & 71 \\
\hline NORDESTE & 3 & 4 & 8 & 9 & 10 & 38 & 39 & 43 & 44 & 45 & 72 \\
\hline CENTRO-OESTE & 11 & 14 & 17 & 18 & 19 & 46 & 49 & 52 & 53 & 54 & 73 \\
\hline SUDESTE & 12 & 15 & 20 & 21 & 22 & 47 & 50 & 55 & 56 & 57 & 74 \\
\hline SUL & 13 & 16 & 23 & 24 & 25 & 48 & 51 & 58 & 59 & 60 & 75 \\
\hline C & 26 & 27 & 28 & 29 & 30 & 61 & 62 & 63 & 64 & 65 & 76 \\
\hline TOTAL (X') & 31 & 32 & 33 & 34 & 35 & 66 & 67 & 68 & 69 & 70 & 77 \\
\hline
\end{tabular}

Figura 6.6 - Esquema para obtenção das matrizes $U^{R}$ - insumo, completa, para todas as regiões: Norte, Nordeste, Centro-Oeste, Sudeste e Sul .

As Figuras 6.5 e 6.6, ilustram as matrizes obtidas através da aplicação da técnica dos coeficientes locacionais, no sentido de identificar o potencial de comércio interregional, bem como a aplicação do método biproporcional de matrizes (RAS), para calibragem das matrizes obtidas, técnicas apresentadas no capitulo 5 , desta pesquisa, itens 5.4 .1 e 5.4 .2 respectivamente. Portanto, neste estágio, as matrizes do Resto do Brasil são compatibilizadas, com as informações desagregadas de produção dos censos econômicos do IBGE, no sentido de subdividi-la nas outras três grandes regiões restantes: Centro-Oeste, Sudeste e Sul, representadas em cinza na Figura 6.6, e posteriormente, através das mesmas técnicas, obtém-se as matrizes inter-regionais, que estão representadas em branco, na Figura 6.6. 
$\mathbf{5}^{\mathrm{O}}$ - estágio - Obtenção das matrizes de produção agregadas, $\mathrm{V}^{\mathrm{RB}}$, (produto $\mathrm{x}$ setor), para o resto do Brasil (Centro-Oeste, Sudeste e Sul), através da dedução da matrizes de produção do Norte e Nordeste $\left(\mathrm{V}^{\mathrm{NE}} \mathrm{e} \mathrm{V}^{\mathrm{NE}}\right)$, das respectivas matrizes de produção do Brasil $\left(\mathrm{V}^{\mathrm{BR}} \mathrm{e}^{\mathrm{BR}}\right)$, Figura 6.7.

Matriz de Produção do Brasil

$\left(\mathrm{V}^{\mathrm{BR}}\right)$

$(-)$

\begin{tabular}{|c|c|c|}
\cline { 2 - 3 } \multicolumn{1}{c|}{} & Produto & $\begin{array}{c}\text { Total } \\
(\mathrm{X})\end{array}$ \\
\hline Setor & $\mathbf{8 4}$ & $\mathbf{3 6}$ \\
\hline $\begin{array}{c}\text { Total } \\
(\mathrm{Q})\end{array}$ & $77^{\prime}$ & \\
\hline
\end{tabular}

Matriz de Produção Norte

$\left(\mathrm{V}^{\mathrm{N}}\right)$

$(-)$

\begin{tabular}{|c|c|c|}
\cline { 2 - 3 } \multicolumn{1}{c|}{} & Produto & $\begin{array}{c}\text { Total } \\
(\mathrm{X})\end{array}$ \\
\hline Setor & $\mathbf{7 8}$ & $\mathbf{3 1}$ \\
\hline $\begin{array}{c}\text { Total } \\
(\mathrm{Q})\end{array}$ & $\mathbf{7 1}{ }^{\prime}$ & \\
\hline
\end{tabular}

Matriz de Produção Nordeste

$\left(\mathrm{V}^{\mathrm{NE}}\right)$

$(-)$

\begin{tabular}{|c|c|c|}
\cline { 2 - 3 } \multicolumn{1}{c|}{} & Produto & $\begin{array}{c}\text { Total } \\
(\mathrm{X})\end{array}$ \\
\hline Setor & 79 & $32^{\prime}$ \\
\hline $\begin{array}{c}\text { Total } \\
\text { (Q) }\end{array}$ & $62^{\prime}$ & \\
\hline
\end{tabular}

$(=)$

Matriz de Produção do Resto do Brasil $\left(V^{\mathrm{RB}}\right)$

\begin{tabular}{|c|c|c|}
\cline { 2 - 3 } \multicolumn{1}{c|}{} & Produto & $\begin{array}{c}\text { Total } \\
(\mathrm{X})\end{array}$ \\
\hline Setor & 83 & $33^{\prime}-35^{\prime}$ \\
\hline $\begin{array}{c}\text { Total } \\
(\mathrm{Q})\end{array}$ & $73^{\prime}-\mathbf{y 5}^{\prime}$ & \multicolumn{1}{|c}{} \\
\hline
\end{tabular}

Figura 6.7 - Esquema de obtenção da matriz de produção $-V^{\mathrm{RB}}$ - (setor $\mathrm{x}$ produto) para 0 Resto do Brasil . 
$6^{\circ}$ estágio - Agregação das linhas e colunas das matrizes de produção, Norte, Nordeste e Resto do Brasil.

Quadro 6.5 - Agregação das matrizes de produção, Resto do Brasil, Norte e Nordeste, 40 para 26 linhas e 77 para 43 colunas.

\begin{tabular}{|c|c|c|c|c|}
\hline \multirow{2}{*}{ REGIĀO } & \multicolumn{4}{|c|}{ MATRIZ PRODUCÃO } \\
\cline { 2 - 5 } & \multicolumn{2}{|c|}{ CONSOLIDADA } & \multicolumn{2}{c|}{ AGREGADA } \\
\cline { 2 - 5 } & IDNTIFICAÇÃO & DIMENSÃO & IDENTIFICAÇÃO & DIMENSÃO \\
\hline \multirow{2}{*}{ RESTO DO BRASIL } & $\mathbf{v}^{\mathrm{RB}}$ & $40 \times 77$ & $\mathbf{V}^{\mathrm{RB}}$ & $26 \mathrm{X} 43$ \\
\hline NORTE & & & $\mathrm{V}^{\mathrm{N}}$ & $26 \times 43$ \\
\hline NORDESTE & $\mathrm{V}^{\mathrm{N}}$ & $40 \times 77$ & $\mathbf{V}^{\mathrm{NE}}$ & $26 \times 43$ \\
\hline
\end{tabular}

A discriminação dos setores e produtos agregados para matriz de produção, para o Resto do Brasil, região Norte e Nordeste, encontram-se no anexo B, desta pesquisa. 
$7^{0}$ - estágio - Obtenção da matrizes de produção Centro-Oeste, Sudeste e Sul . A partir da matriz $\mathrm{V}^{\mathrm{RB}}$, obtida no estágio 3, derivam-se as matrizes de produção para as regiões CentroOeste, Sudeste e Sul $\left(V^{C O}, V^{S E}\right.$ e $\left.V^{S}\right)$.

Matriz de Produção do Resto do Brasil

$$
\begin{gathered}
\left(\mathbf{V}^{\mathrm{RB}}\right) \\
(=)
\end{gathered}
$$

\begin{tabular}{|c|c|c|}
\cline { 2 - 3 } \multicolumn{1}{c|}{} & Produto & Total $(X)$ \\
\hline Setor & $\mathbf{8 3}$ & $33^{\prime}-35^{\prime}$ \\
\hline Total (Q) & $\mathbf{7 3}-75^{\prime}$ & \multicolumn{1}{|c}{} \\
\hline
\end{tabular}

Matriz de Produção Centro-Oeste

(ve)

$(+)$

\begin{tabular}{|c|c|c|}
\cline { 2 - 3 } \multicolumn{1}{c|}{} & Produto & Total $(\mathrm{X})$ \\
\hline Setor & $\mathbf{8 0}$ & $\mathbf{3 3}$ \\
\hline Total $(\mathbf{Q})$ & $\mathbf{7 3}$ \\
\hline
\end{tabular}

Matriz de Produção Sudeste

$$
\begin{gathered}
\left(\mathbf{V}^{\mathrm{SE}}\right) \\
(+)
\end{gathered}
$$

\begin{tabular}{|c|c|c|}
\cline { 2 - 3 } \multicolumn{1}{c|}{} & Produto & Total (X) \\
\hline Setor & $\mathbf{8 1}$ & 34 \\
\hline Total (Q) & 74 \\
\hline
\end{tabular}

Matriz de Produção Sul $\left(V^{s}\right)$

\begin{tabular}{|c|c|c|}
\cline { 2 - 3 } \multicolumn{1}{c|}{} & Produto & Total $(X)$ \\
\hline Setor & $\mathbf{8 2}$ & 35 \\
\hline Total (Q) & $\mathbf{7 5}$ \\
\hline
\end{tabular}

Figura 6.8 - Esquema da obtenção das Matrizes de Produção Centro-Oeste, Sudeste e Sul 
$8^{0}$ - estágio - Obtenção da matriz de coeficientes de produção, conforme já descrito no item 6.3.1 deste capítulo, para todas regiões $\mathrm{D}^{\mathrm{N}}, \mathrm{D}^{\mathrm{NE}}, \mathrm{D}^{\mathrm{CO}}, \mathrm{D}^{\mathrm{SE}}$ e $\mathrm{D}^{\mathrm{S}}$. Através das matrizes de produção para as cinco regiões, obtém-se os coeficientes de produção, $d$, que compõem as matrizes $\mathrm{D}^{\mathrm{R}}$ (setor x produto), como se segue:

$$
d_{i j}=\frac{v_{i j}{ }^{R}}{Q_{i j}{ }^{R}}
$$

onde,

$i=1, \ldots, n \quad$ que indica o número de setores, $\mathrm{e}$

$j=1, \ldots, m \quad$ que indica o número de produtos.

Matricialmente tem-se:

$$
D_{i j}^{R}=V_{i j}^{R}\left(\hat{Q}_{i j}^{R}\right)^{-1}
$$

$9^{\circ}$ - estágio - Obtém-se, $Z$, matriz de insumo-produto de transações intersetoriais (setor x setor), através da composição em blocos, dos resultados de: $Z^{R}=D^{R} * U^{R}, Z^{C}=C^{R}$ e $Z^{X}=X^{R}$ ,conforme procedimentos descritos preliminarmente neste capítulo, ítem 6.31. 


\subsection{Especificações da matriz de insumos, inter-regional}

O Quadro 6.6, a seguir, apresenta as dimensões da matriz de insumos interregional, $\mathrm{U}^{\mathrm{R}}$, enquanto os Quadros 6.7 e 6.8 , discriminam suas linhas e colunas respectivamente.

Quadro 6.6 - Esquema e dimensão da matrizes de Uso para todas as regiōesNorte, Nordeste, Centro-Oeste, Sudeste e Sul (produto x setor)

\begin{tabular}{|c|c|c|c|c|c|c|c|c|c|c|c|}
\hline & $\begin{array}{l}\text { Norte } \\
1-26\end{array}$ & $\begin{array}{c}\text { Nordeste } \\
27-52\end{array}$ & $\begin{array}{l}\text { C. Oeste } \\
53-78\end{array}$ & $\begin{array}{l}\text { Sudeste } \\
79-104\end{array}$ & $\begin{array}{c}\text { Sul } \\
105-130\end{array}$ & $\begin{array}{c}\text { DF N } \\
131-135\end{array}$ & $\begin{array}{l}\text { DF NE } \\
136-140\end{array}$ & $\begin{array}{l}\text { DF CO } \\
141-145\end{array}$ & $\begin{array}{c}\text { DF SE } \\
146-150\end{array}$ & $\begin{array}{c}\text { DF S } \\
151-155\end{array}$ & $\begin{array}{l}\text { Totais } \\
156-168\end{array}$ \\
\hline $\begin{array}{c}\text { Norte } \\
1-43 \\
\end{array}$ & $43 \times 26$ & $43 \times 26$ & $43 \times 26$ & $43 \times 26$ & $43 \times 26$ & $43 \times 5$ & $43 \times 5$ & $43 \times 5$ & $43 \times 5$ & $43 \times 5$ & $43 \times 13$ \\
\hline $\begin{array}{l}\text { Nordeste } \\
44-86 \\
\end{array}$ & $43 \times 26$ & $43 \times 26$ & $43 \times 26$ & $43 \times 26$ & $43 \times 26$ & $43 \times 5$ & $43 \times 5$ & $43 \times 5$ & $43 \times 5$ & $43 \times 5$ & $43 \times 13$ \\
\hline $\begin{array}{l}\text { C.Oeste } \\
87-129 \\
\end{array}$ & $43 \times 26$ & $43 \times 26$ & $43 \times 26$ & $43 \times 26$ & $43 \times 26$ & $43 \times 5$ & $43 \times 5$ & $43 \times 5$ & $43 \times 5$ & $43 \times 5$ & $43 \times 13$ \\
\hline $\begin{array}{l}\text { Sudeste } \\
130-172 \\
\end{array}$ & $43 \times 26$ & $43 \times 26$ & $43 \times 26$ & $43 \times 26$ & $43 \times 26$ & $43 \times 5$ & $43 \times 5$ & $43 \times 5$ & $43 \times 5$ & $43 \times 5$ & $43 \times 13$ \\
\hline $\begin{array}{c}\text { Sul } \\
173-215 \\
\end{array}$ & $43 \times 26$ & $43 \times 26$ & $43 \times 26$ & $43 \times 26$ & $43 \times 26$ & $43 \times 5$ & $43 \times 5$ & $43 \times 5$ & $43 \times 5$ & $43 \times 5$ & $43 \times 13$ \\
\hline $\begin{array}{c}\mathrm{C} \\
216-226 \\
\end{array}$ & $11 \times 26$ & $11 \times 26$ & $11 \times 26$ & $11 \times 26$ & $11 \times 26$ & $11 \times 5$ & $11 \times 5$ & $11 \times 5$ & $11 \times 5$ & $11 \times 5$ & $11 \times 13$ \\
\hline $\begin{array}{c}\text { Totais } \\
227-233 \\
\end{array}$ & $7 \times 26$ & $7 \times 26$ & $7 \times 26$ & $7 \times 26$ & $7 \times 26$ & $7 \times 5$ & $7 \times 5$ & $7 \times 5$ & $7 \times 5$ & $7 \times 5$ & $7 \times 13$ \\
\hline
\end{tabular}

Quadro: elaborado pelo autor, com os resultados da pesquisa. 
Quadro 6.7 - Linhas da Matriz de Uso Inter-regional - Brasil 1985

\begin{tabular}{|c|c|}
\hline No.Linhas & Descrição \\
\hline $1-43$ & Produtos originários da região Norte \\
\hline $44-86$ & Produtos originários da região Nordeste \\
\hline $87-129$ & Produtos originários da região Centro Oeste \\
\hline $130-172$ & Produtos originários da região Sudeste \\
\hline $173-215$ & Produtos originários da região Sul \\
\hline 216 & Importações do Exterior \\
\hline 217 & Impostos \\
\hline 218 & Remunerações \\
\hline 219 & Salário Total \\
\hline 220 & Contribuiç̃̃es Sociais Efetivas \\
\hline 221 & Contribuições Sociais Fictícias \\
\hline 222 & Excedente Bruto \\
\hline 223 & Valor Adicionado a Custo de Fatores \\
\hline 224 & Imposto sobre Atividade \\
\hline 225 & Subsídio sobre Atividade \\
\hline 226 & Valor Adicionado a Preço Básico \\
\hline 227 & Soma das Linhas 1 a 43 \\
\hline 228 & Soma das Linhas 44 a 86 \\
\hline 229 & Soma das Linhas 87 a 129 \\
\hline 230 & Soma das Linhas 130 a 172 \\
\hline 231 & Soma das Linhas 173 a 215 \\
\hline 232 & Soma das Linhas 1 a 217 \\
\hline 233 & Linha $226+$ Linha 232 (Total Geral da Coluna) \\
\hline
\end{tabular}


Quadro 6.8 - Colunas da Matriz de Uso Inter-regional - Brasil 1985

\begin{tabular}{|c|c|}
\hline N. & Descrição \\
\hline $1-26$ & Insumos adquiridos pela região Norte \\
\hline $27-52$ & Insumos adquiridos pela região Nordeste \\
\hline 53-78 & Insumos adquiridos pela região Centro Oeste \\
\hline 79-104 & Insumos adquiridos pela região Sudeste \\
\hline $105-130$ & Insumos adquiridos pela região Sul \\
\hline 131 & Dummy Financeiro da região Norte \\
\hline 132 & Consumo da região Norte \\
\hline 133 & Formação Bruta de Capital Fixo da região Norte \\
\hline 134 & Variação de Estoque da região Norte \\
\hline 135 & Exportação do Exterior da região Norte \\
\hline 136 & Dummy Financeiro da região Nordeste \\
\hline 137 & Consumo da região Nordeste \\
\hline 138 & Formação Bruta de Capital Fixo da região Nordeste \\
\hline 139 & Variação de Estoque da região Nordeste \\
\hline 140 & Exportação do Exterior da região Nordeste \\
\hline 141 & Dummy Financeiro da região Centro-Oeste \\
\hline 142 & Consumo da região Centro-Deste \\
\hline 143 & Formação Bruta de Capital Fixo da região Centro-Oeste \\
\hline 144 & Variação de Estoque da região Centro-Oeste \\
\hline 145 & Exportação do Exterior da região Centro-Oeste \\
\hline 146 & Dummy Financeiro da região Sudeste \\
\hline 147 & Consumo da região Sudeste \\
\hline 148 & Formação Bruta de Capital Fixo da região Sudeste \\
\hline 149 & Variação de Estoque da região Sudeste \\
\hline 150 & Exportacão do Exterior da região Sudeste \\
\hline 151 & Dummy Financeiro da região Sul \\
\hline 152 & Consumo da região Sul \\
\hline 153 & Formação Bruta de Capital Fixo da região Sul \\
\hline 154 & Variação de Estoque da região Sul \\
\hline 155 & Exportação do Exterior da região Sul \\
\hline 156 & Soma das Colunas 1 a 26 \\
\hline 157 & Soma das Colunas 27 a 52 \\
\hline
\end{tabular}


Quadro 6.8 - ( continuação) Colunas da Matriz de Uso Inter-regional - Brasil 1985

\begin{tabular}{|l|l|}
\hline 158 & Soma das Colunas 53 a 78 \\
\hline 159 & Soma das Colunas 79 a 104 \\
\hline 160 & Soma das Colunas 105 a 130 \\
\hline 161 & Soma das Colunas 132 a 135 \\
\hline 162 & Soma das Colunas 137 a 140 \\
\hline 163 & Soma das Colunas 142 a 145 \\
\hline 164 & Soma das Colunas 147 a 150 \\
\hline 165 & Soma das Colunas 152 a 155 \\
\hline 166 & Soma das Colunas 156 a 160 \\
\hline 167 & Soma das Colunas 161 a 165 \\
\hline 168 & Soma das Colunas: $131,136,141,146,151,166$ e 167 (Total Geral da Linha) \\
\hline
\end{tabular}


6.5 A matriz inter-regional do Brasil, 1985, específicações e apresentação sintética.

O Quadro 6.9 apresenta as dimensões da matriz inter-regional aqui construída, em seguida os Quadros 6.10 e 6.11, discriminam suas linhas e colunas.

A Tabela 6.1 apresenta, de forma sintética, os valores desta matriz. A matriz completa encontra-se no Anexo A, desta pesquisa.

Quadro 6.9 - Esquema e dimensão da matrizes $(Z)$ Isard, para todas as regiões: Norte, Nordeste, Centro-Oeste, Sudeste e Sul (produto x setor)

\begin{tabular}{|c|c|c|c|c|c|c|c|c|c|c|c|}
\hline & $\begin{array}{c}\text { Norte } \\
1-26\end{array}$ & $\begin{array}{c}\text { Nordeste } \\
27-52\end{array}$ & $\begin{array}{c}\text { C. Oeste } \\
53-78\end{array}$ & $\begin{array}{c}\text { Sudeste } \\
79-104\end{array}$ & $\begin{array}{c}\text { Sul } \\
105-130\end{array}$ & $\begin{array}{c}\text { DF N } \\
131-135\end{array}$ & $\begin{array}{c}\text { DF NE } \\
136-140\end{array}$ & $\begin{array}{c}\text { DF CO } \\
141-145\end{array}$ & $\begin{array}{c}\text { DF SE } \\
146-150\end{array}$ & $\begin{array}{c}\text { DF S } \\
151-155\end{array}$ & $\begin{array}{c}\text { Totals } \\
156-168\end{array}$ \\
\hline $\begin{array}{c}\text { Norte } \\
1-26 \\
\end{array}$ & $26 \times 26$ & $26 \times 26$ & $26 \times 26$ & $26 \times 26$ & $26 \times 26$ & $26 \times 5$ & $26 \times 5$ & $26 \times 5$ & $26 \times 5$ & $26 \times 5$ & $26 \times 13$ \\
\hline $\begin{array}{c}\text { Nordeste } \\
27-52 \\
\end{array}$ & $26 \times 26$ & $26 \times 26$ & $26 \times 26$ & $26 \times 26$ & $26 \times 26$ & $26 \times 5$ & $26 \times 5$ & $26 \times 5$ & $26 \times 5$ & $26 \times 5$ & $26 \times 13$ \\
\hline $\begin{array}{c}\text { C.Oeste } \\
53-78 \\
\end{array}$ & $26 \times 26$ & $26 \times 26$ & $26 \times 26$ & $26 \times 26$ & $26 \times 26$ & $26 \times 5$ & $26 \times 5$ & $26 \times 5$ & $26 \times 5$ & $26 \times 5$ & $26 \times 13$ \\
\hline $\begin{array}{c}\text { Sudeste } \\
79-104 \\
\end{array}$ & $26 \times 26$ & $26 \times 26$ & $26 \times 26$ & $26 \times 26$ & $26 \times 26$ & $26 \times 5$ & $26 \times 5$ & $26 \times 5$ & $26 \times 5$ & $26 \times 5$ & $26 \times 13$ \\
\hline $\begin{array}{c}\text { Sul } \\
105-130 \\
\end{array}$ & $26 \times 26$ & $26 \times 26$ & $26 \times 26$ & $26 \times 26$ & $26 \times 26$ & $26 \times 5$ & $26 \times 5$ & $26 \times 5$ & $26 \times 5$ & $26 \times 5$ & $26 \times 13$ \\
\hline $\begin{array}{c}C \\
131-141 \\
\end{array}$ & $11 \times 26$ & $11 \times 26$ & $11 \times 26$ & $11 \times 26$ & $11 \times 26$ & $11 \times 5$ & $11 \times 5$ & $11 \times 5$ & $11 \times 5$ & $11 \times 5$ & $11 \times 13$ \\
\hline $\begin{array}{c}\text { Totais } \\
142-148\end{array}$ & $7 \times 26$ & $7 \times 26$ & $7 \times 26$ & $7 \times 26$ & $7 \times 26$ & $7 \times 5$ & $7 \times 5$ & $7 \times 5$ & $7 \times 5$ & $7 \times 5$ & $7 \times 13$ \\
\hline
\end{tabular}

Quadro: elaborado pelo autor, com os resultados da pesquisa 
Quadro 6.10 - Linhas da Matriz (Z) de Isard - Inter-regional - Brasil 1985

\begin{tabular}{|c|c|}
\hline Número de Linhas & Descrição \\
\hline $1-26$ & Produtos originários da região Norte \\
\hline $27-52$ & Produtos originários da região Nordeste \\
\hline $53-78$ & Produtos originários da região Centro Oeste \\
\hline $79-104$ & Produtos originários da região Sudeste \\
\hline $105-130$ & Produtos originários da região Sul \\
\hline 131 & Importações do Exterior \\
\hline 132 & Impostos \\
\hline 133 & Remuneraç̃̃es \\
\hline 134 & Salánio Total \\
\hline 135 & Contribuições Sociais Efetivas \\
\hline 136 & Constribuições Sociais Fictícias \\
\hline 137 & Excedente Bruto \\
\hline 138 & Valor Adicionado a Custo de Fatores \\
\hline 139 & Imposto sobre Atividade \\
\hline 140 & Subsídio sobre Atividade \\
\hline 141 & Valor Adicionado a Preço Básico \\
\hline 142 & Soma das Linhas 1 a 26 \\
\hline 143 & Soma das Linhas 27 a 52 \\
\hline 144 & Soma das Linhas 53 a 78 \\
\hline 145 & Soma das Linhas 79 a 104 \\
\hline 146 & Soma das Linhas 105 a 130 \\
\hline 147 & Soma das Linhas 1 a 132 \\
\hline 148 & Linha $140+$ Linha 147 (Total Geral da Coluna) \\
\hline
\end{tabular}


Quadro 6.11 - Colunas da Matriz (Z) de Isard - Inter-regional - Brasil 1985

\begin{tabular}{|c|c|}
\hline Número Coluna & Descrição \\
\hline $1-26$ & Insumos adquiridos pela região Norte \\
\hline $27-52$ & Insumos adquiridos pela região Nordeste \\
\hline $53-78$ & Insumos adquiridos pela região Centro Oeste \\
\hline $79-104$ & Insumos adquiridos pela região Sudeste \\
\hline $105-130$ & Insumos adquiridos pela região Sul \\
\hline 131 & Dummy Financeiro da região Norte \\
\hline 132 & Consumo da região Norte \\
\hline 133 & Formação Bruta de Capital Fixo da região Norte \\
\hline 134 & Variação de Estoque da região Norte \\
\hline 135 & Exportação do Exterior da região Norte \\
\hline 136 & Dummy Financeiro da região Nordeste \\
\hline 137 & Consumo da região Nordeste \\
\hline 138 & Formação Bruta de Capital Fixo da região Nordeste \\
\hline 139 & Variação de Estoque da região Nordeste \\
\hline 140 & Exportação do Exterior da região Nordeste \\
\hline 141 & Dummy Financeiro da região Centro Oeste \\
\hline 142 & Consumo da região Centro Oeste \\
\hline 143 & Formação Bruta de Capital Fixo da região Centro Oeste \\
\hline 144 & Variação de Estoque da região Centro Oeste \\
\hline 145 & Exportação do Exterior da região Centro Oeste \\
\hline 146 & Dummy Financeiro da região Sudeste \\
\hline 147 & Consumo da região Sudeste \\
\hline 148 & Formação Bruta de Capital Fixo da região Sudeste \\
\hline 149 & Variação de Estoque da região Sudeste \\
\hline 150 & Exportações do Exterior da região Sudeste \\
\hline 151 & Dummy Financeiro da região Sul \\
\hline 152 & Consumo da região Sul \\
\hline 153 & Formação Bruta de Capital Fixo da região \\
\hline 154 & Variação de Estoque da região Sul \\
\hline 155 & Exportacões do Exterior da região $\mathrm{Sul}$ \\
\hline 156 & Soma das Colunas 1 a 26 \\
\hline 157 & Soma das Colunas 27 a 52 \\
\hline 158 & Soma das Colunas 53 a 78 \\
\hline 159 & Soma das Colunas 79 a 104 \\
\hline
\end{tabular}


Quadro 6.11 - (continuação) Colunas da Matriz (Z) de Isard - Inter-regional - Brasil 1985

\begin{tabular}{|l|l|}
\hline 160 & Soma das Colunas 105 a 130 \\
\hline 161 & Soma das Colunas 132 a 135 \\
\hline 162 & Soma das Colunas 137 a 140 \\
\hline 163 & Soma das Colunas 142 a 145 \\
\hline 164 & Soma das Colunas 147 a 150 \\
\hline 165 & Soma das Colunas 152 a 155 \\
\hline 166 & Soma das Colunas 156 a 160 \\
\hline 167 & Soma das Colunas 161 a 165 \\
\hline 168 & Soma das Colunas: 131,136,141,146, 151,166 e 167 (Total Geral da Linha) \\
\hline
\end{tabular}




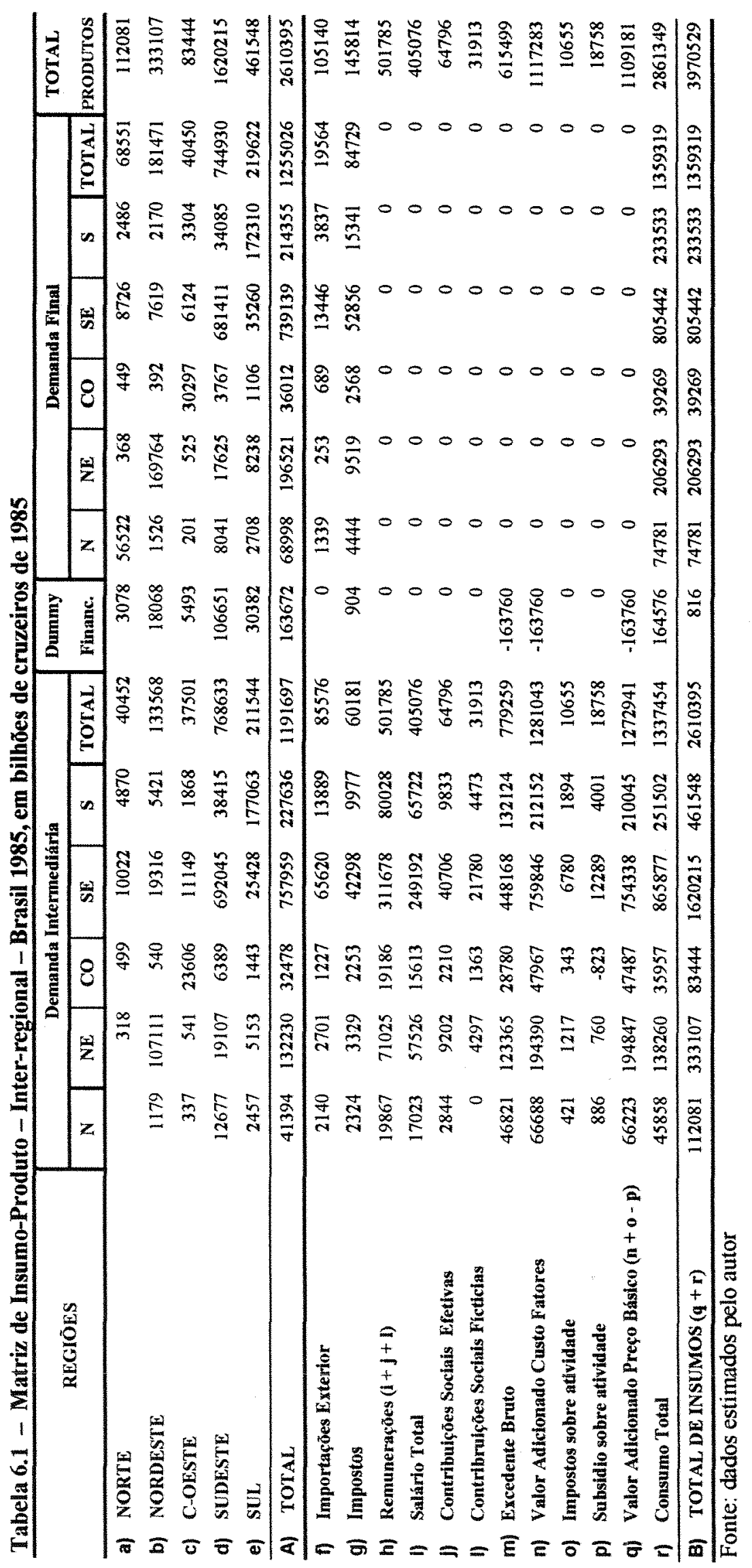




\section{MÉTOdos dE ANÁlise dA ESTRUTURA PRODUTIVA : ÍNDICES DE LIGAÇÕES, SETORES CHAVE E INTEGRAÇÃO REGIONAL}

Um grande número de diferentes e importantes métodos de análise das estruturas produtivas de insumo-produto vêm sendo desenvolvidas e aplicados. Apresentam-se neste capítulo algumas técnicas selecionadas para a análise da matriz inter-regional do Brasil, ressaltando-se que esta seleção se pautou por algumas características. Os métodos são, de forma geral, complementares, observando-se uma determinada ordem cronológic. Foram considerados aqueles mais adequados aos objetivos desta pesquisa.

A apresentação inicia-se com a proposta de Hasmussen (1956) e de Hirschman (1958), dos índices de encadeamentos para frente e para trás, que são complementados pelo método de Campo de Influência de Sonis e Hewings (1989 e 1995). A seguir apresentam-se as abordagens de Guilhoto, Hewings e Sonis (1996), através do chamado modelo GHS (1996), que combina métodos de multiplicadores e ligações em uma estrutura multirregional, uma integração de abordagens alternativas, fundamentais para identificar a interdependência entre setores e regiões.

Especificamente, no modelo GHS (1996), destaca-se neste capítulo, a mais recente versão do método de obtenção de índices puros de ligações, formulados inicialmente por Cella (1984) e Clements (1990), aperfeiçoados por Guilhoto et al. (1984) que, no modelo GHS sofre novo aperfeiçoamento, bem como as técnica de identificação da interdependência entre setores e regiões. Aborda-se, também a aplicação deste método GHS, para alguns países da Ásia e Estados Unidos, pesquisa desenvolvida por Guilhoto, Hewings e Sonis (1997). 


\subsection{Enfoque de Rasmussen e Hirschman}

A partir da matriz inversa de Leontief, representada em 7.1 por B (nxn), Hasmussen (1956) e Hirschman (1958) determinam quais são os setores com potencial de maior poder de encadeamento da economia, os chamados índices de ligações para trás, que demonstram o quanto determinado setor demanda de outros, e os índices de ligações para frente, que nos fornecem o quanto um setor é demandado por outros. Valores maiores que 1 , acima da média, indicam os setores chave para o crescimento da economia.

$$
B=(I-A)^{-1},
$$

onde identicamem-se,

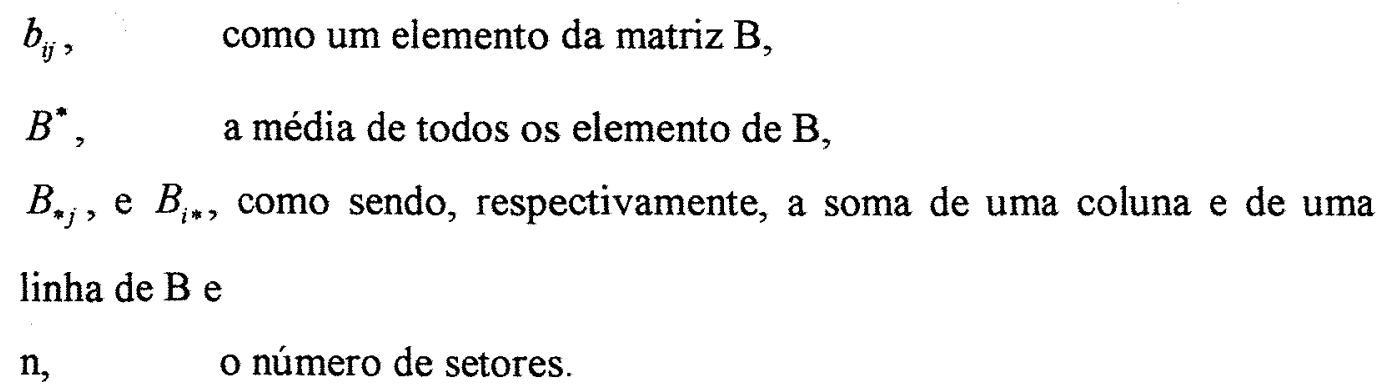

As formulações, a seguir, determinam os índices de ligações para trás e para frente.

Índices de ligações para trás

$$
U_{J}=\left[\frac{B_{*_{j}}}{n}\right] / B^{*},
$$

Índices de ligações para frente

$$
U_{i}=\left[\frac{B_{i *}}{n}\right] / B^{*}
$$


Este método não permite por si só, avaliar a influência de um setor/região e eventualmente pelos seus componentes, sobre outros do resto da economia., o que é possível de se alcançar através do enfoque de Campo de Influência apresentado a seguir.

\subsection{Enfoque do campo de influência}

A técnica da determinação de campo de influência, Sonis e Hewings (1989 e 1995), permite identificar quais as relações entre os setores que seriam mais importantes no processo produtivo. Esta técnica é uma complementação dos índices de ligações, uma vez que os mesmos não identificam claramente quais os principais elos de ligação na economia, ou seja, ..."quais seriam os coeficientes que, se alterados, teriam um maior impacto no sistema como um todo". Guilhoto, Sonis, Hewings e Martins (1994, p. 296).

Considerando, a matriz de, coeficientes diretos, $A=\left|a_{i j}\right|$ e definindo-se.

$$
E=\left|\varepsilon_{i j}\right|,
$$

como a matriz de coeficientes incrementais nos coeficientes diretos de insumo, temos as correspondentes matrizes inversas de Leontief, dadas por.

$$
B=[I-A]^{-1}=\left|b_{i j}\right|, \text { e por } B(\varepsilon)=[I-A-\varepsilon]^{-1}=\left|b_{i j}(\varepsilon)\right| \text {. }
$$

Conforme Sonis E Hewings(1989 e 1995), caso a variação seja pequena e só ocorra em um coeficiente direto, temos:

$$
\varepsilon_{i j}= \begin{cases}\varepsilon & i=i_{1}, j=j_{1} \\ 0 & i \neq i_{1} \text { ou } \neq j_{1}\end{cases}
$$

O campo de influência desta variação pode ser aproximado pela seguinte expressão: 


$$
F\left(\varepsilon_{i j}\right)=\frac{\left[B\left(\varepsilon_{i j}\right)-B\right]}{\varepsilon_{i j}},
$$

onde $F\left(\varepsilon_{i j}\right)$ é a matriz (nxn) do campo de influência do coeficiente $a_{i j}$.

É necessário, portanto que se associe uma valor, chamado de $S_{i j}$, a cada matriz $F\left(\varepsilon_{i j}\right)$, para se obter quais seriam os coeficientes que possuem o maior campo de influência. Este valor é dado por.

$$
S_{i j}=\sum_{k=1}^{n} \sum_{l=1}^{n}\left[f_{k l}\left(\varepsilon_{i j}\right)\right]^{2}
$$

Portanto, os coeficientes diretos de maior valor para $S_{i j}$, serão os de maior campo de influência dentro da economia como um todo.

\subsection{Modelo GHS, ligações em uma estrutura multirregional: indices puros de ligações e integração de abordagens alternativas.}

Guilhoto, Sonis e Hewings (1996), desenvolvem um importante trabalho, que consiste basicamente na integração das principais técnicas utilizadas na análise de estruturas de insumo-produto, objetivando decompor e distinguir o impacto de um setor/região na economia, sobre seus vários componentes. Para tal tratam de dois métodos; o enfoque de setores chave, associados inicialmente com Hirschman e Rasmussen, que são modificados por Cella, Rossi e Guilhoto, et.al., e o enfoque de ligações puras, identificado com as fontes de mudança na economia e os efeitos internos e externos dos multiplicadores de Miyazawa (1976).

A contribuição principal destes autores é a montagem de diferentes decomposições de matrizes, de maneira a realizar uma ligação formal destes dois enfoques: setores chave, e as fontes de mudança na economia. Particularmente para este 
trabalho, esta técnica é fundamental, no sentido de identificar os graus dos impactos de demanda final em determinadas regiões e sobre todas outras.

Os citados autores realizam uma consolidação destas abordagens, que toma por base a matriz A, como se segue:

$$
A=\left[\begin{array}{ll}
A_{i j} & A_{j r} \\
A_{r j} & A_{r r}
\end{array}\right],
$$

onde :

$A_{i j}$, e $A_{r r}$, representam matrizes quadradas de insumos diretos do setor $j$ e do resto da economia (economia menos setor $j$ ), respectivamente, $A_{j r}$, e $A_{r j}$, representam matrizes retangulares, dos insumos diretos adquiridos pelo setor $j$ do resto da economia e os insumos diretos adquiridos pelos resto da economia do setor $j$.

$$
B=(I-A)^{-1}=\left(\begin{array}{cc}
B_{j j} & B_{j r} \\
B_{r j} & B_{r r}
\end{array}\right)=\left(\begin{array}{cc}
\Delta_{i j} & 0 \\
0 & \Delta_{r r}
\end{array}\right)\left(\begin{array}{cc}
\Delta_{j} & 0 \\
0 & \Delta_{r}
\end{array}\right)\left(\begin{array}{cc}
I & A_{j r} \Delta_{r} \\
A_{r j} \Delta_{j} & I
\end{array}\right)
$$

e separam todos os componentes de (7.8), da seguinte forma:

$$
\begin{aligned}
& \Delta_{j}=\left(I-A_{j j}\right)^{-1} \\
& \Delta_{r}=\left(I-A_{j j}\right)^{-1} \\
& \Delta_{j j}=\left(I-\Delta_{j} A_{j r} \Delta_{r} A_{r j}\right)^{-1} \\
& \Delta_{r r}=\left(I-\Delta_{r} A_{r j} \Delta_{j} A_{j r}\right)^{-1}
\end{aligned}
$$


A partir de (7.8), é possível verificar-se como ocorre o processo de produção na economia, e como são derivados uma série de multiplicadores e de ligações da estrutura produtiva.

$$
\begin{aligned}
& \left(\begin{array}{cc}
\Delta_{j j} & 0 \\
0 & \Delta_{r r}
\end{array}\right) \\
& \left(\begin{array}{cc}
\Delta_{j} & 0 \\
0 & \Delta_{r}
\end{array}\right) \\
& \left(\begin{array}{cc}
I & A_{j r} \Delta_{r} \\
A_{r j} \Delta_{j} & I
\end{array}\right)
\end{aligned}
$$

A matriz representada em (7.15) separa a demanda final interna $I$, da demanda final externa. Isto pode ser detectado pela análise de suas linhas.

Partindo-se do modelo de Leontief,

$$
X=(I-A)^{-1} Y,
$$

mais as formulações (7.14) e (7.15), obtém-se importantes indicadores, que podem ser usados, segundo Guilhoto, Sonis e Hewings (1996), para:

a) classificar regiões de acordo com sua importância dentro de uma economia e

b) identificar como o processo de produção acontece na economia.

Da equação (7.8) e (7.16), obtém-se:

$$
\begin{aligned}
& \left(\begin{array}{l}
X_{j} \\
X_{r}
\end{array}\right)=\left(\begin{array}{cc}
\Delta_{j j} & 0 \\
0 & \Delta_{r r}
\end{array}\right)\left(\begin{array}{cc}
\Delta_{j} & 0 \\
0 & \Delta_{r}
\end{array}\right)\left(\begin{array}{cc}
I & A_{j r} \Delta_{r} \\
A_{r j} \Delta_{j} & I
\end{array}\right)\left(\begin{array}{l}
Y_{j} \\
Y_{r}
\end{array}\right) \mathrm{e} \\
& \left(\begin{array}{c}
X_{j} \\
X_{r}
\end{array}\right)=\left(\begin{array}{cc}
\Delta_{j j} & 0 \\
0 & \Delta_{r r}
\end{array}\right)\left(\begin{array}{cc}
\Delta_{j} & 0 \\
0 & \Delta_{r}
\end{array}\right)\left(\begin{array}{c}
Y_{j}+A_{j r} \Delta_{r} Y_{r} \\
A_{r j} \Delta_{j} Y_{j}+Y_{r}
\end{array}\right),
\end{aligned}
$$


onde pode-se destacar;

$$
A_{j r} A_{r} Y_{r}
$$

que indica o impacto direto na demanda final do resto da economia sobre a região $j$, o que representa o nivel de exportação na região $j$ necessário para atender as necessidades de produção do resto da economia e que

$$
A_{r j} A_{j} Y_{j}
$$

representa o impacto direto da demanda final da região $j$ sobre o resto da economia, ou seja, o nível de exportações no resto da economia necessário para atender as necessidades de produção do setor $j$, considerando um nível de demanda final dado por $Y_{\mathrm{j}}$. Ainda, a partir de (7.20), temos:

$\left(\begin{array}{l}X_{j} \\ X_{r}\end{array}\right)=\left(\begin{array}{cc}\Delta_{i j} & 0 \\ 0 & \Delta_{r r}\end{array}\right)\left(\begin{array}{c}\Delta_{j} Y_{j}+\Delta_{j} A_{j r} \Delta_{r} Y_{r} \\ \Delta_{r} A_{r j} \Delta_{j} Y_{j}+\Delta_{r} Y_{r}\end{array}\right)$

Que apresenta novas definições para os índices de ligações para trás (PBL), e para a frente (PFL), através de.

$$
\begin{aligned}
& P B L=\Delta_{r} A_{r j} \Delta_{j} Y_{j} \\
& P F L=\Delta_{j} A_{j r} \Delta_{r} Y_{r}
\end{aligned}
$$

O PBL, nos indicará, o impacto puro sobre o resto da economia, do valor da produção total na região j. Impacto puro porque, segundo Guilhoto, Sonis e Hewings (1996, p.17), ele está livre de:

a) da demanda de insumos que a região j produz para a região j e

b) os retornos do resto da economia para a região j e vice-versa. Por sua vez o PFL, indicará o impacto puro sobre a região $\mathrm{j}$, do valor da produção total no resto da economia $r$. 
Através ainda de (7.22), pode-se deduzir.

$$
\left(\begin{array}{c}
X_{j} \\
X_{r}
\end{array}\right)=\left(\begin{array}{c}
\Delta_{j j} \Delta_{j} Y_{j}+\Delta_{j j} \Delta_{j} A_{j r} \Delta_{r} Y_{r} \\
\Delta_{r r} \Delta_{r} A_{r j} \Delta_{j} Y_{j}+\Delta_{r r} \Delta_{r} Y_{r}
\end{array}\right)\left(\begin{array}{c}
X_{j}^{j}+X_{j}^{r} \\
X_{r}^{j}+X_{r}^{r}
\end{array}\right)
$$

O que possibilita a divisão do nível de produção da economia em dois componentes.

$$
\begin{aligned}
& X_{j}^{j}=\Delta_{j j} \Delta_{j} Y_{j} \mathrm{e} \\
& X_{j}^{r}=\Delta_{i j} \Delta_{j} A_{j r} \Delta_{r} Y_{r}
\end{aligned}
$$

Em $X_{j}^{j}$, obtém-se o valor da produção total na região $j$, proporcionado pela demanda final na região $j$, enquanto que $X_{j}^{r}$, fornece o valor da produção total na região $j$, devida à demanda final no resto da economia. Podemos, ainda, obter outros dois componentes.

$$
\begin{aligned}
& X_{r}^{j}=\Delta_{r r} \Delta_{r} A_{r j} \Delta_{j} Y_{j} \\
& X_{r}^{r}=\Delta_{r r} \Delta_{r} Y_{r}
\end{aligned}
$$

Onde $X_{r}^{j}$, fornece o valor da produção total no resto da economia, devido a demanda final na região $j$, enquanto $X_{r}^{r}$, fornece o valor da produção total no resto da economia, devido a demanda final no resto da economia.

Verifica-se, portanto, que estas técnicas fornecem um poderoso instrumental, que é utilizado para subsidiar sobremaneira esta pesquisa, por um lado, porque integra os principais métodos usados, e por outro porque, possibilita a decomposição dos impactos entre as regiões, permitindo analisar a integração da economia brasileira, considerando sua estrutura produtiva.. 
O modelo GHS foi aplicado por Guilhoto, Hewings e Sonis (1997) para identificar a interdependência, ligações e multiplicadores na Ásia através de um grupo de tabelas de insumo-produto para alguns países, mais os Estados Unidos, nos anos de 1975 e 1985. Quanto aos principais resultados, além de identificar os setores chave, os autores afirmam que o método permite, a detecção das fontes de mudanças na economia, pois foi possível separar, o impacto setor/região na economia.

No capitulo que se segue, são discutidos os resultados da aplicação destes métodos na estrutura inter-regional brasileira, ressaltando alguns desdobramentos possíveis do modelo GHS. 


\section{ANÁlise DA ESTRUTURA PRODUTIVA REGIONAL DA ECONOMIA BRASILEIRA EM 1985}

O objetivo deste capitulo é o de identificar a interdependência setorial e regional da economia brasileira em 1985, através da detecção de setores chaves, ligações inter-setoriais e inter-regionais, campo de influência e interação entre as regiões, cujos métodos estão apresentados no capítulo 7 deste trabalho. Para tal discute-se inicialmente os principais resultados da aplicação destas metodologias. Essa discussão envolve, quando possível, análises comparadas dos resultados da matriz nacional de 1985 frente aos obtidos da matriz inter-regional, construída neste trabalho para este período. E por fim, realiza-se uma análise integrada destes principais resultados.

\section{1 Índices de ligações de Rasmussen-Hirschman e a matriz inter-regional 1985}

A análise dos índices de ligações formuladas por Rasmussen (1956) e Hirschman (1958), conforme descrito no capitulo 7, revela o grau de integração setorial da economia para um determinado periodo. Ou seja identifica os setores-chave que a dinamizam tanto pelo grau de demanda por produtos de outros setores (índices de ligações para trás maiores que 1 ), como através do grau da oferta de produtos à outros setores (índices de ligações para frente maiores que 1). Portanto, conforme esta hipótese, as economias que apresentam o maior número de setores com índices nestas condições podem ser consideras as de melhor dinâmica e mais integradas ao sistema. Com uma abordagem mais restrita Mcgilvray (1977), elege como setores-chave aqueles com indices para frente e para trás maiores que 1 simultaneamente. 
Estes índices calculados para a estrutura da economia agregada e inter-regional do Brasil em 1985, ver Quadros 8.1 e 8.2 respectivamente, referem-se aos 26 setores selecionados neste trabalho, com destaque em cinza para índices maior que 1. Registra-se, também, sua ordem de importância na economia, do $1^{\circ}$ ao $26^{\circ}$ lugar para o agregado e do $1^{\circ}$ ao $130^{\circ}$ para as regiões ( 26 setores para cada uma das 5 regiões).

Quadro 8.1. Índices de ligações de Rasmussen - Hirschman, Brasil 1985

\begin{tabular}{|c|c|c|c|c|c|}
\hline $\bar{N}$ & SETORES & FRENTE & ORDEM & TRAS & ORDEM \\
\hline 1 & Agropecuária & 2279 & 11 & 0.816 & 23 \\
\hline 2 & Mineraçăo & 1.055 & 99 & 0.757 & 24 \\
\hline 3 & Minerais não Metálicos & 0.797 & 15 & 1.033 & 11 \\
\hline 4 & Metalurgia & 2.053 & 2 & 1211 & 3 \\
\hline 5 & Mecânica & 0.997 & 11 & 1003 & 1013 \\
\hline 6 & Material Elétrico & 0.702 & 17 & 0.986 & 15 \\
\hline 7 & Material de Transporte & 0.884 & 13 & 1.184 & 5 \\
\hline 8 & Madeira e Mobiliário & 0.642 & 19 & 1.002 & 1.14 \\
\hline 9 & Celulose, Papel e Gráfica & 0.933 & 12 & 1.011 & 12 \\
\hline 10 & Indústria da Borracha & 0.780 & 16 & 1056 & 9 \\
\hline 11 & Refino do Petróleo & 1.775 & 3 & 0.925 & 19 \\
\hline 12 & Químicos Diversos & 1,390 & 5 & 0.980 & 16 \\
\hline 13 & Farmacêutica & 0.534 & 26 & 0.957 & 18 \\
\hline 14 & Plásticos & 0.676 & 18 & 1033 & 10 \\
\hline 15 & Indústria Têxtil & 1190 & 7 & 1135 & 7 \\
\hline 16 & Vestuario e Calçados & 0.553 & 25 & 1.071 & 8 \\
\hline 17 & Indústria do Café & 0.591 & 22 & 1.230 & 1 \\
\hline 18 & Abate de Animais & 0.563 & 24 & 1.205 & 4 \\
\hline 19 & Fabricação de Açúcar & 0.631 & 21 & 1215 & 2 \\
\hline 20 & Outros Produtos. Alimentares & 0.805 & 14 & 1.165 & 6 \\
\hline 21 & Indústrias Diversas & 0.633 & 20 & 0.899 & 20 \\
\hline 22 & Energia, Agua, Saneam. e,Com.. & 1.030 & 10 & 0.836 & 22 \\
\hline 23 & Construção Civil & 0.577 & 23 & 0.978 & 17 \\
\hline 24 & Comércio & 1.375 & 6 & 0.732 & $\overline{25}$ \\
\hline 25 & Transportes & 1.079 & 8 & 0.876 & 21 \\
\hline 26 & Serviços & 1.479 & 4 & 0.704 & 26 \\
\hline
\end{tabular}

Fonte: dados estimados pelo autor 


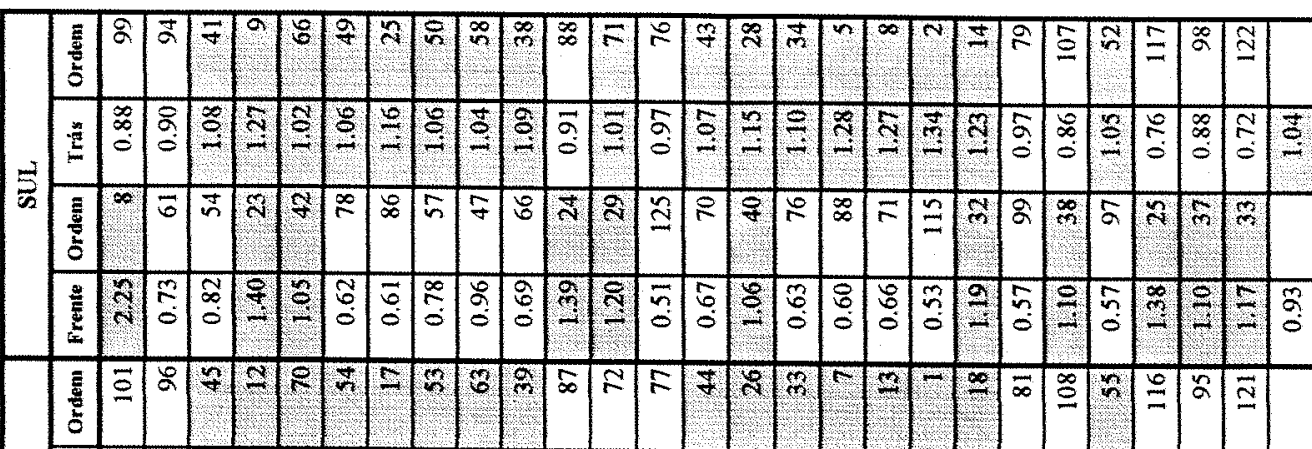

量

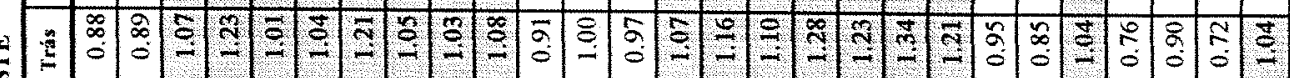

迹

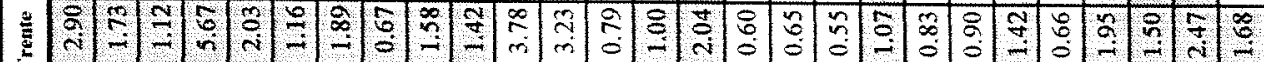

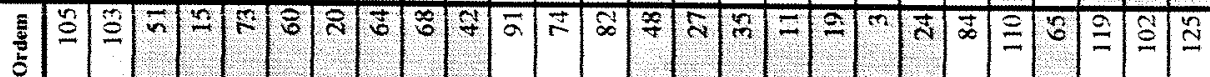

a

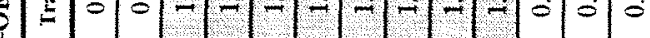

氮

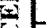

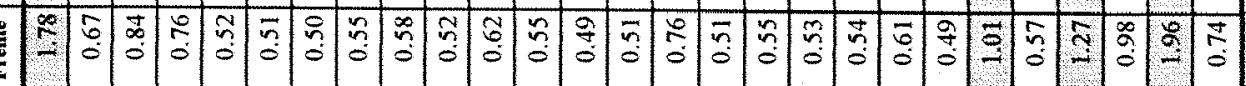

言

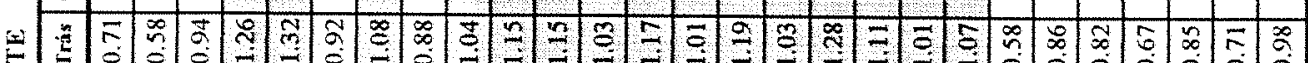

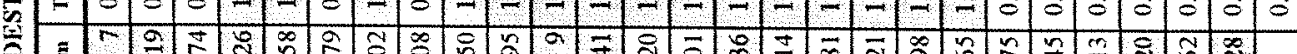

$=\frac{2}{2}$

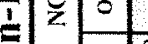

ती 约

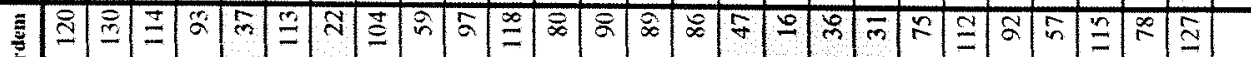

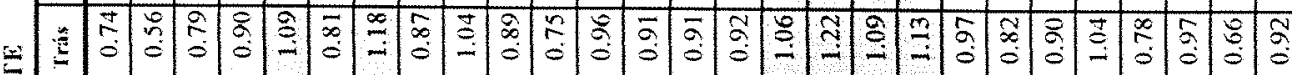

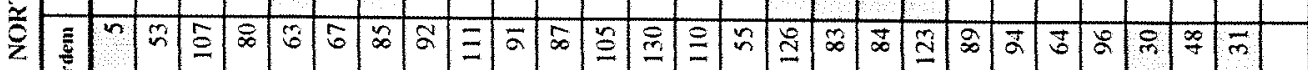

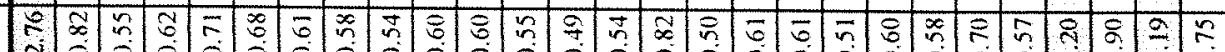

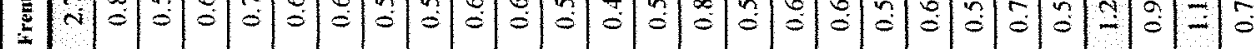




\subsubsection{Ligações para frente, Rasmussen-Hirschman, Brasil e regiões, 1985}

\section{a) Brasil - ligações para frente de Rasmussen-Hirschman}

Os resultados obtidos para a estrutura agregada do Brasil, discriminados no Quadro 8.1, podem ser melhor visualizados e comparados através da Figura 8.1, que destaca os 10 setores com fortes ligações para frente, ou seja com maior poder de oferta na economia. Pode-se destacar três níveis, e por ordem de importância, (1) Agropecuária e (4) Metalurgia, com valores mais significativos (maiores que 2 ). Em posição intermediária, (11) Refino de Petróleo, (26) Serviços, (12) Químicos Diversos, e (24) Comércio. E em um patamar mais abaixo (15) Indústria Têxtil, (25) Transportes, (2) Mineração e (22) Energia, Água, Saneamento e Comunicação.

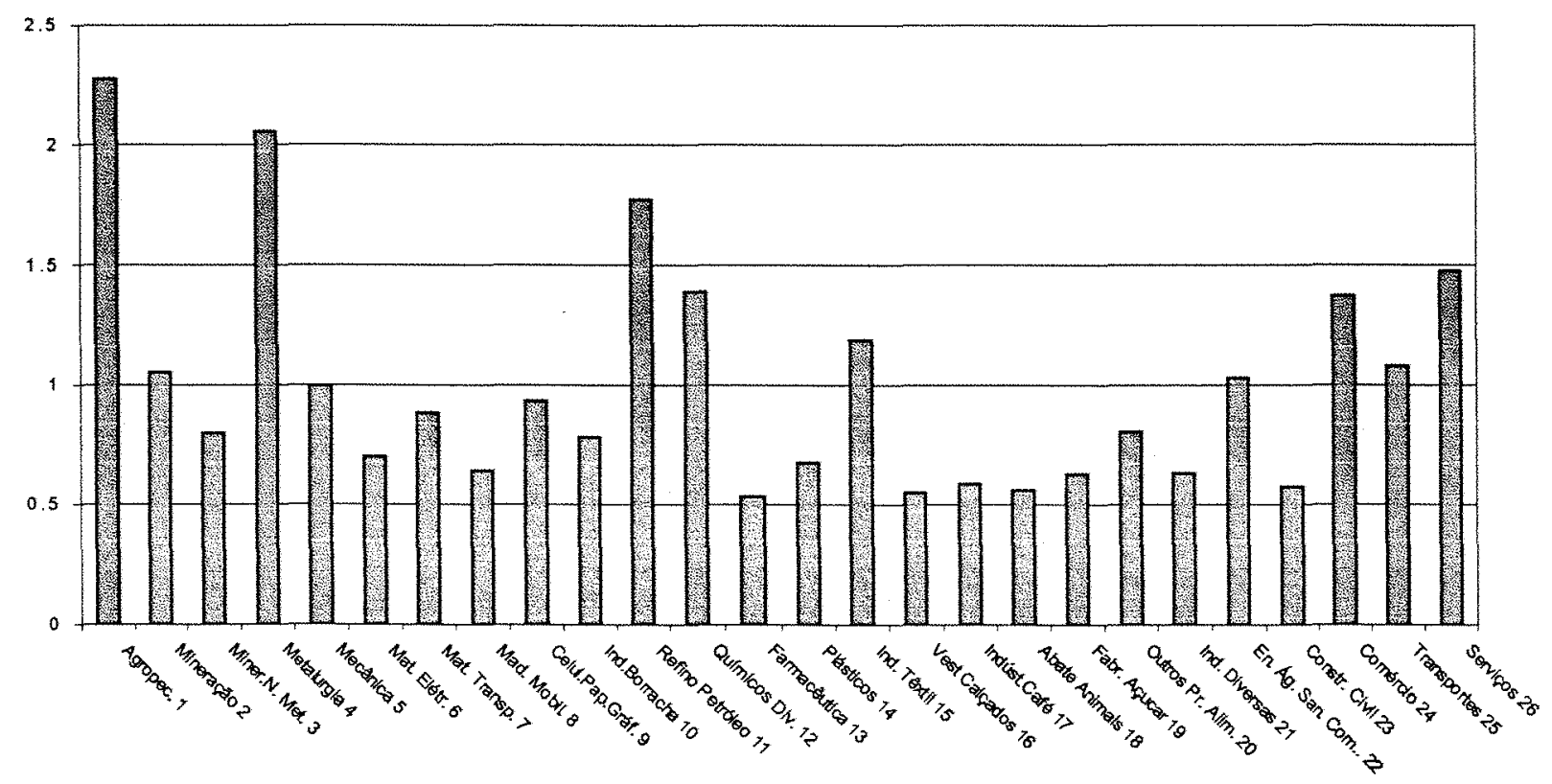

Figura 8.1 Índices de ligações para frente, Rasmussen-Hirschman, Brasil 1985

Esta situação sugere, dentro dos parâmetros para estes indicadores, uma estrutura de economia diversificada com dois setores pólos no setor primário, Mineração e Agropecuária, com destaque para a Agropecuária. A indústria de transformação apresenta 4 pólos de oferta, a Metalurgia, com maior grau, seguida dos setores de Refino de Petróleo, Químicos Diversos e Têxtil. Para o setor terciário, os destaques ficam com 
Comércio e Serviços seguidos de Transportes e Energia, Água, Saneamento e Comunicação. A seguir pode-se acompanhar a importância destes setores na economia inter-regional.

b) Região Norte - Ligações para frente-Rasmussen-Hirschman

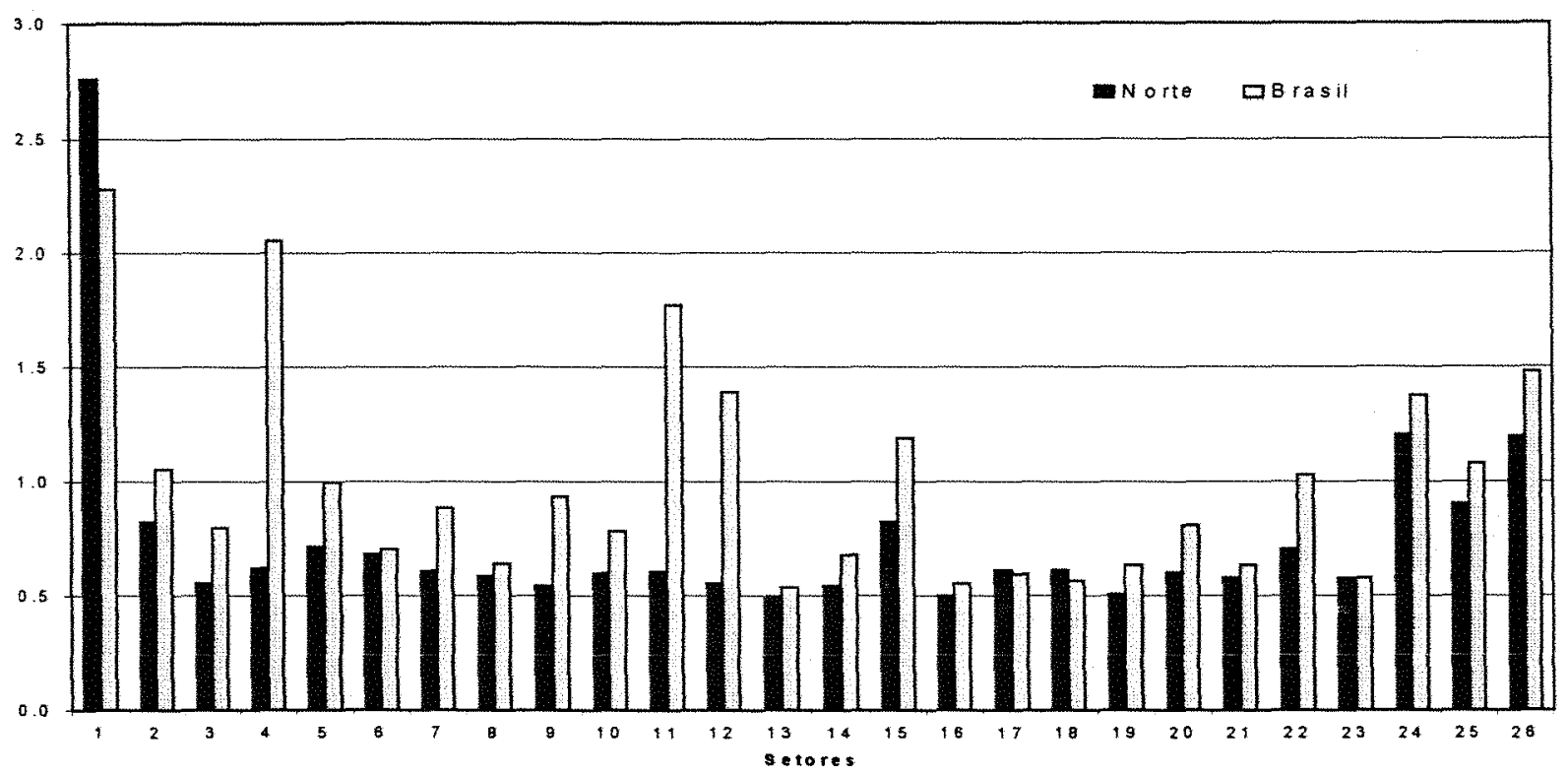

Figura 8.2 Índices de Ligações para frente Rasmussen-Hirschman - Norte x Brasil 1985

A região Norte, Quadro 8.2 e Figura 8.2, apresenta somente 3 setores relevantes quanto a ligações para a frente, o grande destaque fica para o setor (1) Agropecuária, com índice de 2,76, acima do valor nacional que situa-se em 2,27, abaixo apenas da região Sudeste, e em termos de classificação geral é o quinto maior índice para frente do Brasil. Bem abaixo apresentam-se os setores (24) Comércio, abaixo de todas as outras regiões e (26) Serviços apenas superior a região Sul. Portanto, seus valores são inferiores ao agregado nacional.

Esta região revela como grande setor dinâmico para frente apenas a Agropecuária e um grande vazio na indústria de transformação. E em segundo plano os pólos de Comércio e Serviços, provavelmente alavancados pelo ainda incipiente Turismo, na época. Incentivados, portanto, deveriam estes setores gerar maior integração 
e encadeamentos para frente, porém, a necessidade da criação de outros pólos no setor de transformação é clara neste procedimento de análise.

c) Região Nordeste - Ligações para frente-Rasmussen-Hirschman

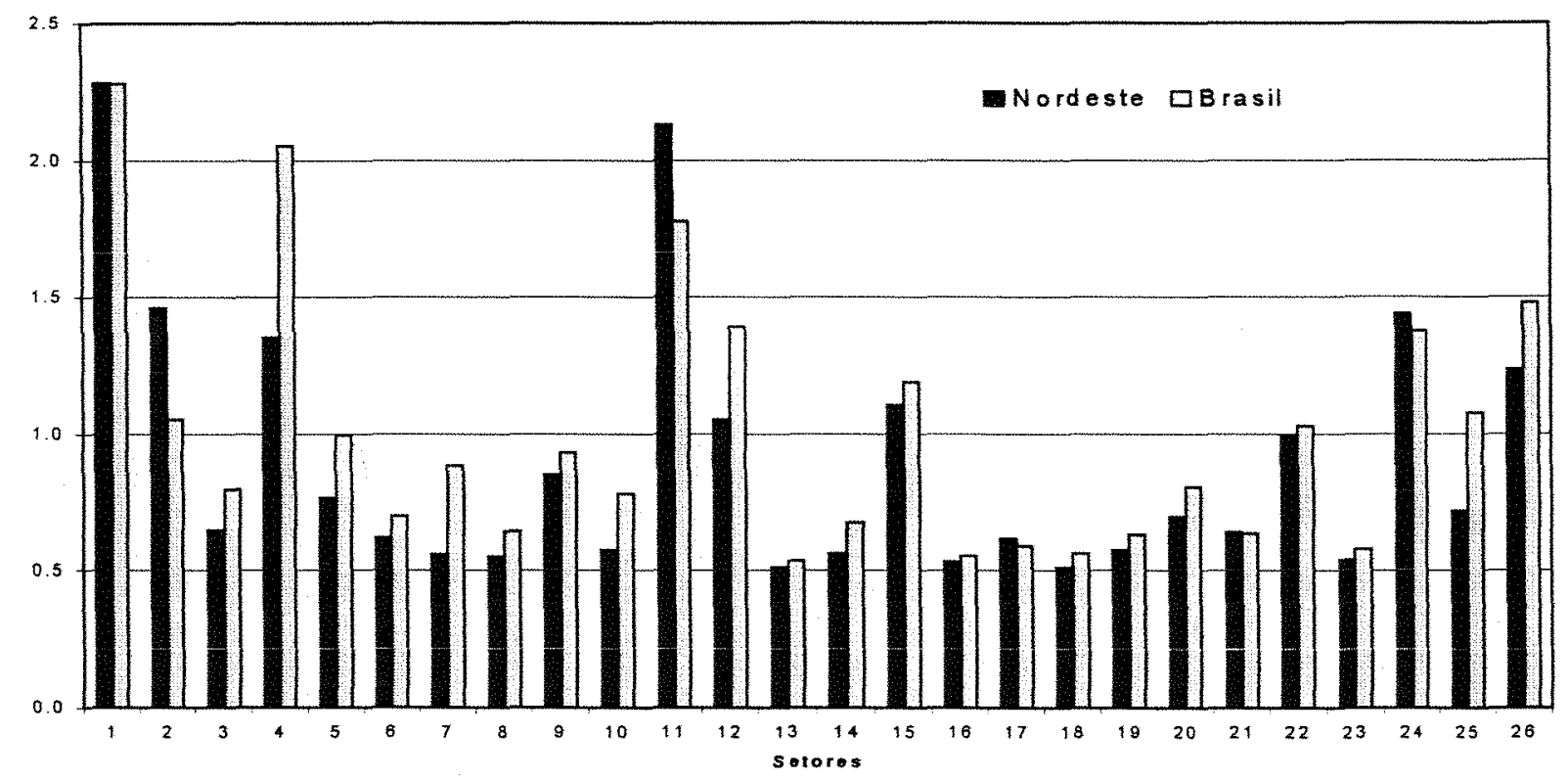

Figura 8.3 Índices de Ligações para frente Rasmussen-Hirschman - Nordeste x Brasil 1985

A região Nordeste mostra-se em uma situação melhor que a Região Norte, com maior quantidade e variedade de setores com ligações fortes para frente. Conforme podemos constatar na figura 8.3 e Quadro 8.2, a região Nordeste apresenta 8 setores com fortes ligações para frente. Acima dos valores para o agregado nacional identificam se 4 setores; (1) Agropecuária, que ocupa a sétima posição nacional em termos de ligações para a frente e terceira no setor, seguido de (11) Refino de Petróleo, nono colocado geral e segunda posição no setor. Em patamar intermediário (2) Mineração e (24) Comércio, ambos com a segunda classificação no setor. Os outros 4 setores são, (4) Metalurgia e (26) Serviços, terceira posição no setor. E em posição inferior (15) Indústria Têxtil e (12) Químicos Diversos, terceira e segunda classificação no setor respectivamente. 
Nota-se claramente que a região Nordeste em 1985 parece estar com sua estrutura econômica equilibrada em termos dos pólos de crescimento para frente, acompanhando, guardando as devidas proporções, a estrutura agregada brasileira, portanto uma região aparentemente preparada para crescer. Alterna a segunda posição brasileira com a região Sul, dependendo dos setores que se aborda.

d) Região Centro-Oeste - Ligações para frente-Rasmussen-Hirschman

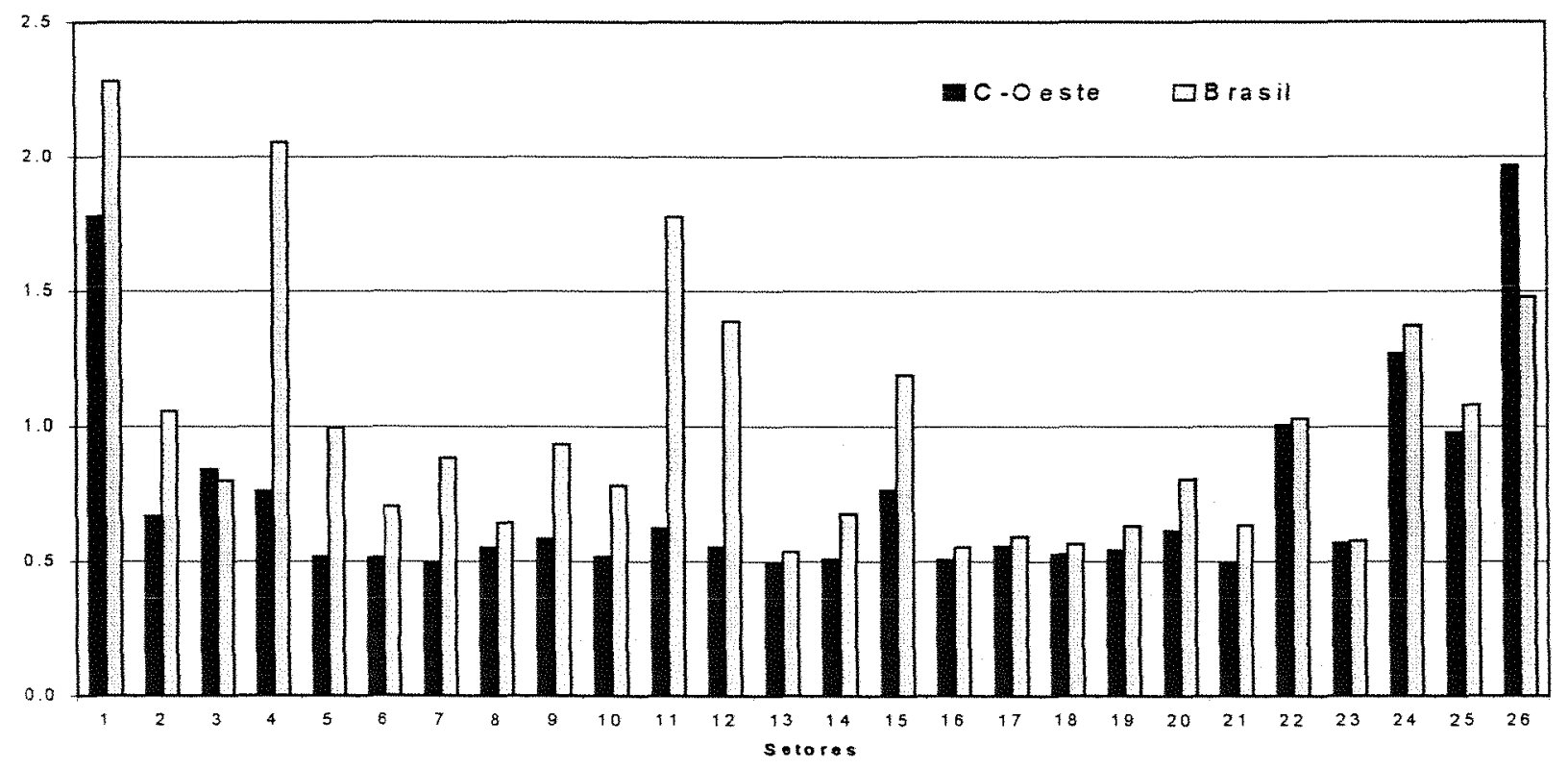

Figura 8.4 Índices de Ligações para frente Rasmussen-Hirschman-C-Oeste x Brasil, 1985

A região Centro-Oeste, Figura 8.4 e Quadro 8.2, apresenta-se em um nível pouco acima da região Norte, com apenas 4 setores significativos em termos de ligações para frente.

O setor com maior grau de integração de oferta nesta região é o de (26) Serviços, com valor de 1,96 , acima do índice nacional, décimo segundo na classificação geral brasileira, e segundo no setor, e o (1) Agropecuária, décimo quinto na ordem geral e lugar no próprio setor. Em uma faixa intermediária encontram-se os dois outros 
setores, (24) Comércio, e (22) Energia, Água, Saneamento e Comunicações, em classificação regular frente a outras regiões.

A exemplo da região Norte os números para esta região indicam necessidades de criação e incentivos de setores geradores de oferta e encadeamentos positivos para a economia regional.

\section{e) Região Sudeste- Ligações para frente-Rasmussen-Hirschman}

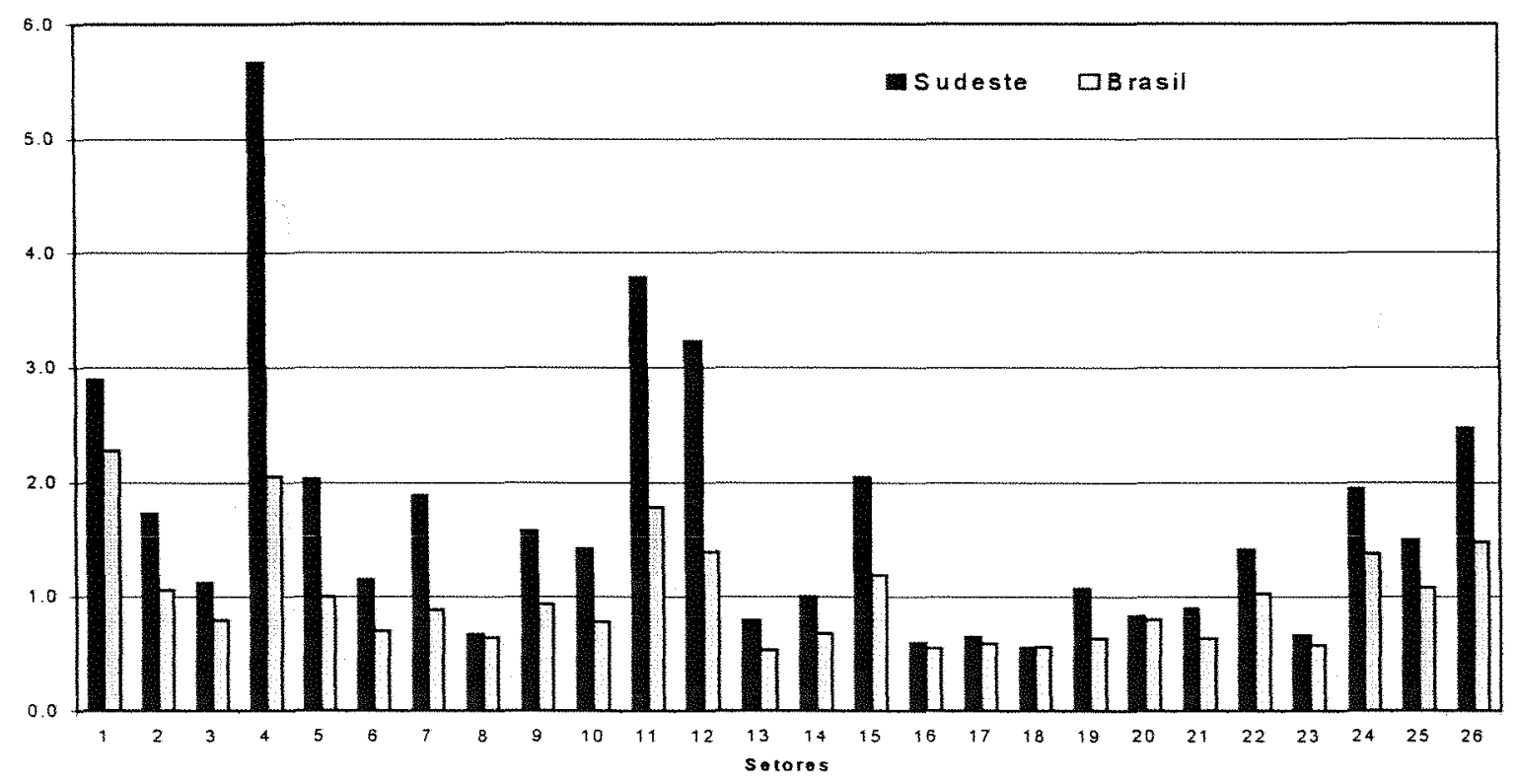

Figura 8.5 Índices de Ligações para frente Rasmussen-Hirschman - Sudeste x Brasil 1985

Na região Sudeste 17 são os setores com relevància para com as ligações para frente que conforme pode-se verificar na Figura 8.5, pois todos possuem índices superiores aos valores nacionais. Os destaques ficam para os setores (4) Metalurgia com indice de 5,67, o maior indice inter-setorial e inter-regional, seguido de 3,78 do setor (11) Refino de Petróleo, (12) Químicos Diversos e (12 ) Agropecuária, que ocupam a segunda, terceira e Quarta posições nesta estrutura.

Ainda em patamar elevado encontram-se os setores (26) Serviços, (15) Indústria Têxtil, com índice de 2,9 e 2,5 respectivamente. Os setores com indice entre 2,0 e 1,5; 
(5) Mecânica, (24) Comércio, (7) Material de Transporte, (2) Mineração, (9) Celulose, Papel e Gráfica, (25)Transportes, (10) Indústria da Borracha, (22) Energia, Água, Saneamento e Comunicação. E em um patamar mais baixo, (6) Material Elétrico, (3) Minerais não Metálicos e (19) Fabricação de Açúcar, apenas o setor da Indústria da Borracha, não ocupa a primeira posição dentro do setor em termos nacionais.

A dinâmica da economia brasileira é dada pela região Sudeste, como era de se esperar. Nota-se que apenas o setor (18) Abate de Animais, encontra-se pouco abaixo, e quase no mesmo nível do valor da economia nacional.

\section{f) Região Sul - Ligações para frente-Rasmussen-Hirschman}

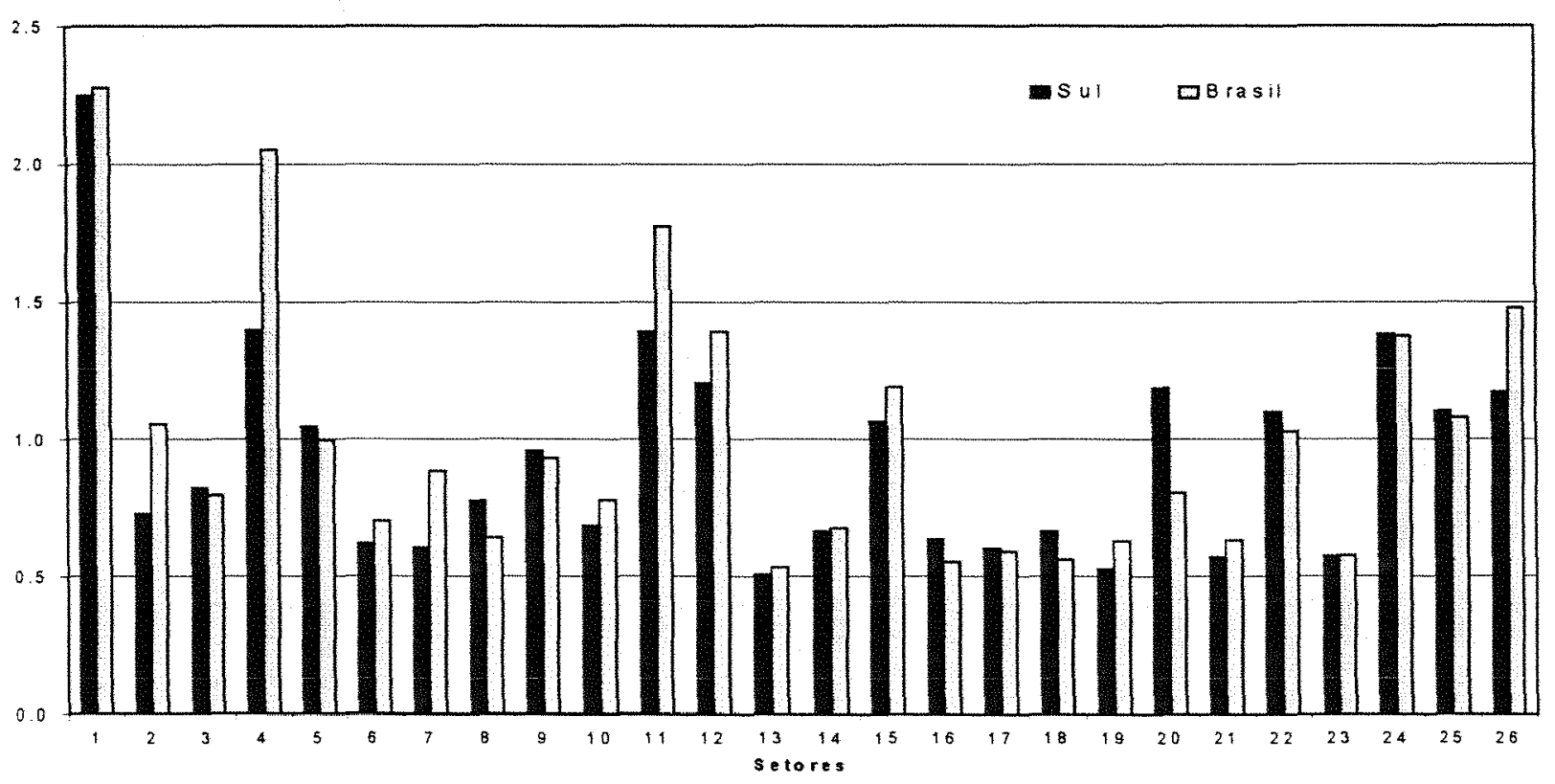

Figura 8.6 Índices de Ligações para frente Rasmussen-Hirschman - Sul x Brasil 1985

Ao observar o Quadro 8.2 e Figura 8.6, identifica-se a região Sul como a segunda região mais dinâmica do Brasil., quanto aos índices de ligações para frente, contando com 11 setores relevantes neste quesito. Os mais fortes são (1) Agropecuária, no patamar do agregado nacional. Em nivel intermediário (4) Metalurgia, segunda posição no setor, (11) Refino de Petróleo e (24) Comércio, terceira posição no setor. 
Em plano mais abaixo, apresenta o setor (12) Químicos Diversos, (20) Outros Produtos Alimentares, (25) Transportes, (22) Energia, Água, Saneamento e Comunicações e (5) Mecânica, todos ocupando a segunda posição no setor, (15) Industria Têxtil terceira no setor e (26) Serviços classificada em quinto lugar.

A exemplo da região Nordeste, mas com maior diversidade, é possível inferir que a região Sul acompanha a estrutura agregada nacional.

\section{g) Consolidação dos índices de Ligações para frente - Rasmussen-Hirschman, Brasil e regiões.}

Após identificação dos setores de maior dinâmica para frente, no Brasil e nas regiões brasileiras, conforme proposta de Rasmussen e Hirschman, esta seção se propõe a fornecer uma visão conjunta destes índices compilados no Quadro 8.3, especialmente quanto às importantes informações que o enfoque inter-regional fornece. A análise do agregado aponta para os setores mais dinâmicos da economia. Por outro lado, a análise inter-regional, além de localizar as regiões onde se encontram estes setores, identifica aqueles com importância específica para algumas regiões e que podem não constar do rol de setores dinâmicos do quadro nacional. 
Quadro 8.3 Índices de ligações para frente-Rasmussen e Hirschman - regiões e Brasil 1985

\begin{tabular}{|c|c|c|c|c|c|c|c|c|}
\hline \multicolumn{2}{|r|}{ Setores } & Norte & Nordeste & C-Oeste & Sudeste & Sul & Méd.Reg. & Brasil \\
\hline 1 & Agropecuária & 2760 & 2280 & 1779 & 2898 & 2250 & 2394 & 2279 \\
\hline 2 & Mineração & 0.823 & 1,460 & 0.667 & 1.727 & 0.730 & 1.081 & 1055 \\
\hline 3 & Miner N. Metálicos & 0.552 & 0.648 & 0.841 & 1.125 & 0.822 & 0.798 & 0.797 \\
\hline 4 & Metalurgia & 0.618 & 1351 & 0.761 & 5666 & 1.397 & 1959 & 2053 \\
\hline 5 & Mecànica & 0.713 & 0.766 & 0.518 & 2028 & 1049 & 1.015 & 0.997 \\
\hline 6 & Material Elétrico & 0.680 & 0.619 & 0.514 & 1156 & 0.620 & 0.718 & 0.702 \\
\hline 7 & Mat. Transporte & 0.607 & 0.558 & 0.496 & 1.887 & 0.606 & 0.831 & 0.884 \\
\hline 8 & Madeira Mobiliário & 0.585 & 0.551 & 0.548 & 0.672 & 0.776 & 0.627 & 0.642 \\
\hline 9 & Celul.Pap.Gráfica & 0.542 & 0.852 & 0.581 & 1575 & 0.960 & 0.902 & 0.933 \\
\hline 10 & Ind da .Borracha & 0.596 & 0.576 & 0.518 & 1.419 & 0.685 & 0.759 & 0.780 \\
\hline 11 & Refino Petróleo & 0.605 & 2128 & 0.621 & 3780 & 1390 & 1705 & 1.775 \\
\hline 12 & Quimicos Diversos & 0.553 & 1055 & 0.552 & 3235 & 1.205 & 1320 & 1390 \\
\hline 13 & Farmacèutica & 0.489 & 0.511 & 0.492 & 0.795 & 0.506 & 0.559 & 0.534 \\
\hline 14 & Plásticos & 0.543 & 0.561 & 0.509 & 0.999 & 0.666 & 0.656 & 0.676 \\
\hline 15 & Indústria Têxtil & 0.822 & 1105 & 0.763 & 2043 & 1.063 & 1.159 & 1,190 \\
\hline 16 & Vest. Calçados & 0.496 & 0.532 & 0.506 & 0.599 & 0.634 & 0.553 & 0.553 \\
\hline 17 & Indúst do Café & 0.612 & 0.616 & 0.554 & 0.648 & 0.602 & 0.606 & 0.591 \\
\hline 18 & Abate de Animais & 0.611 & 0.509 & 0.526 & 0.554 & 0.664 & 0.573 & 0.563 \\
\hline 19 & Fabr de Açúcar & 0.506 & 0.573 & 0.540 & 1.073 & 0.529 & 0.644 & 0.631 \\
\hline 20 & Outros Pr. Aliment. & 0.600 & 0.697 & 0.614 & 0.829 & 1.187 & 0.785 & 0.805 \\
\hline 21 & Indústrias Diversas & 0.578 & 0.638 & 0.491 & 0.895 & 0.572 & 0.635 & 0.633 \\
\hline 22 & En. Á. San. Com.. & 0.700 & 0.997 & 10007 & 1.416 & 1.099 & 1044 & 1030 \\
\hline 23 & Construção Civil & 0.575 & 0.538 & 0.568 & 0.663 & 0.573 & 0.583 & 0.577 \\
\hline 24 & Comércio & 1.202 & 1.439 & 1268 & 1947 & 1382 & 1448 & 1375 \\
\hline 25 & Transportes & 0.900 & 0.719 & 0.978 & 1.503 & 1102 & 1.041 & 1.079 \\
\hline 26 & Serviços & 1.194 & 1.234 & 1.965 & 2473 & 1,173 & 1.608 & 1.479 \\
\hline & Média & 0.749 & 0.904 & 0.738 & 1.677 & 0.932 & 1.000 & 1.000 \\
\hline
\end{tabular}

Fonte: dados estimados pelo autor

Neste contexto, destacam-se 6 setores com importância somente para uma região, e que não são identificados no agregado nacional, dos quais 5 pertencem a região Sudeste; (6) Material Elétrico, (7) Material de Transporte, (9) Celulose, Papel e Gráfica, (10) Indústria da Borracha e (19 Fabricação de Açúcar. E um para a região Sul (20) Outros Produtos Alimentares. Esta indicaçŏes podem nortear políticas específicas para tais setores.

Por outro lado estas desagregações podem fornecer a exata localização dos setores dinâmicos da estrutura agregada. Esta pesquisa identificou que os setores (1) 
Agropecuária, (26) Serviços e (24) Comércio, fortes para frente no agregado nacional, apresentam esta intensidade em todas as regiões brasileiras aqui estudadas.

Por sua vez os setores (4) Metalurgia, (11) Refino de Petróleo, (12) Químicos Diversos e (15) Indústria Têxtil, são dinâmicos para o Sudeste, Sul e Nordeste, enquanto (22) Energia, Água, Saneamento e Comunicação para Sudeste, Sul e CentroOeste, enquanto que (05) Mecânica e (25) Transportes para Sudeste e Sul, e (2) Mineração para Sudeste e Nordeste

\subsection{2 - Ligações para trás, Rasmussen-Hirschman, Brasil e regiões, 1985}

Os índices de ligações para trás aqui obtidos apresentam pequena amplitude, e de certa forma as regiões Centro-Oeste, Sudeste e Sul acompanham o agregado nacional, estes resultados são explicados para ambos os casos, através da conjugação de dois motivos, o primeiro consiste na consideração de mesma tecnologia da estrutura produtiva no modelo de insumo-produto adotado, e o segundo refere-se ao método de estimação dos valores de comércio inter-regional, explicitado na metodologia desta pesquisa., descrita no capítulo 6 .

Os resultados aqui apresentados, entretanto, permitiram algum tipo de análise, que podem ser corroborados com os obtidos com a aplicação dos método de campo de influência e de índices puros apresentados ainda neste capitulo. 


\section{a) Brasil - Ligações para trás - Rasmussen-Hirschman}

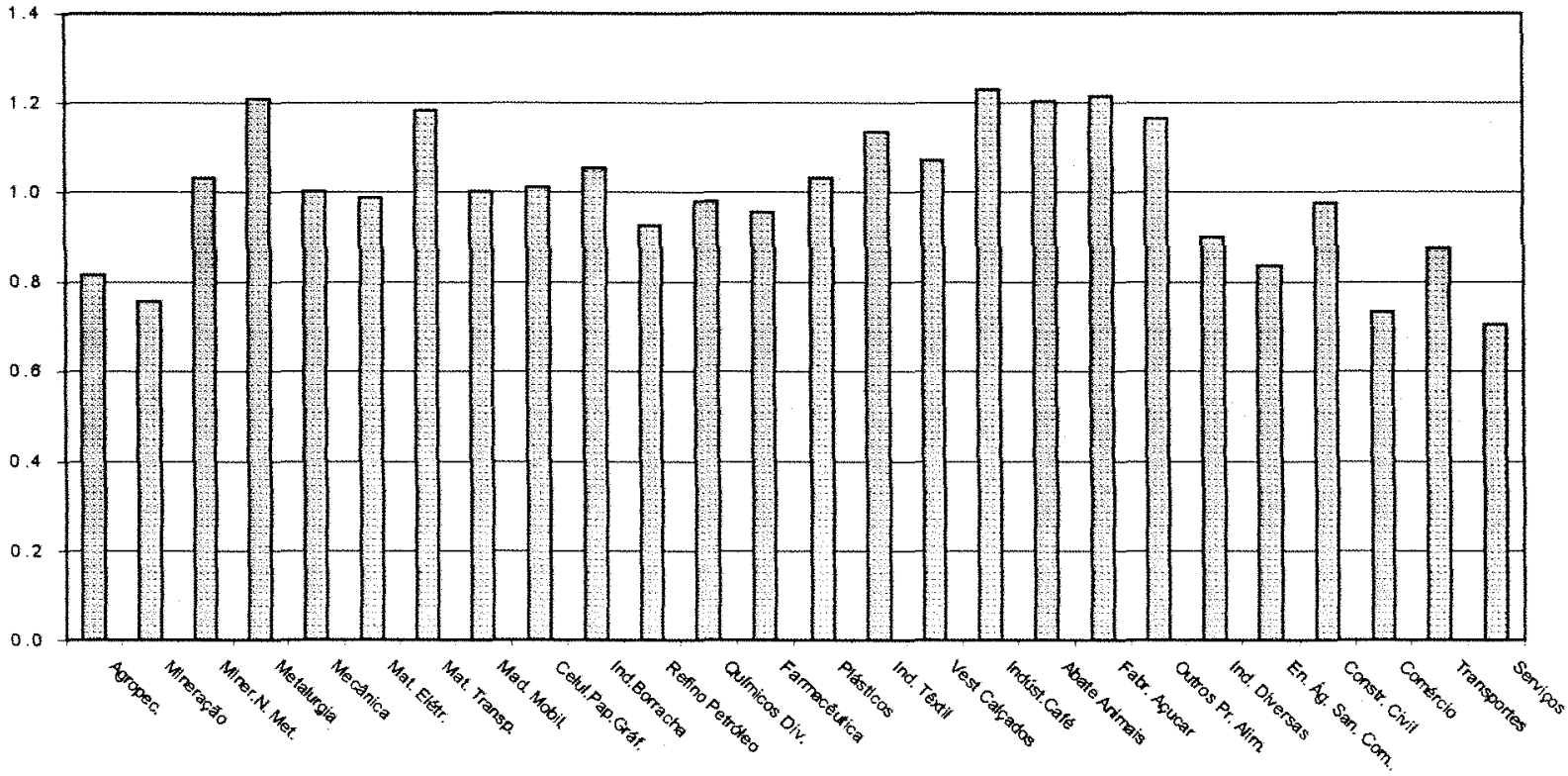

Figura 8.7 Índices de Ligações para trás Rasmussen-Hirschman - Brasil 1985

A estrutura agregada da economia brasileira apresentou, em 1985, 14 setores com forte ligações para trás, conforme Quadro 8.1, ou seja setores com alto poder de demanda por insumos na economia.

A Figura 8.7 permite constatar que estes setores estão circunscritos a uma pequena amplitude $(1,002$ até 1,230$)$. A estrutura econômica neste quesito mostra-se diversificada. Pode-se distinguir dentro desta amplitude três níveis de importância, os setores (17) Indústria do Café , (19) Fabricação do Açúcar, (4) Metalurgia, e (18) Abate de Animais. Um grupo intermediário composto pelos setores (7) Material de Transporte, (20) Outros Produtos Alimenticios e (15) Indústria Têxtil. E em patamar inferior (16) Vestuário e Calçados, (10) Indústria da Borracha, (14) Plásticos, (3) Minerais não Metálicos, (9) Celulose Papel e Gráfica, (5) Mecânica e (8) Madeira e Mobiliário. 
A seguir efetua-se a comparação da estrutura da economia brasileira com os resultados obtidos para as cinco regiões estudadas, seguindo a ordem de importância, ou seja, as regiões com maior número de setores com ligações relevantes para trás.

\section{b) Região Sudeste - Ligações para trás - Rasmussen-Hirschman}

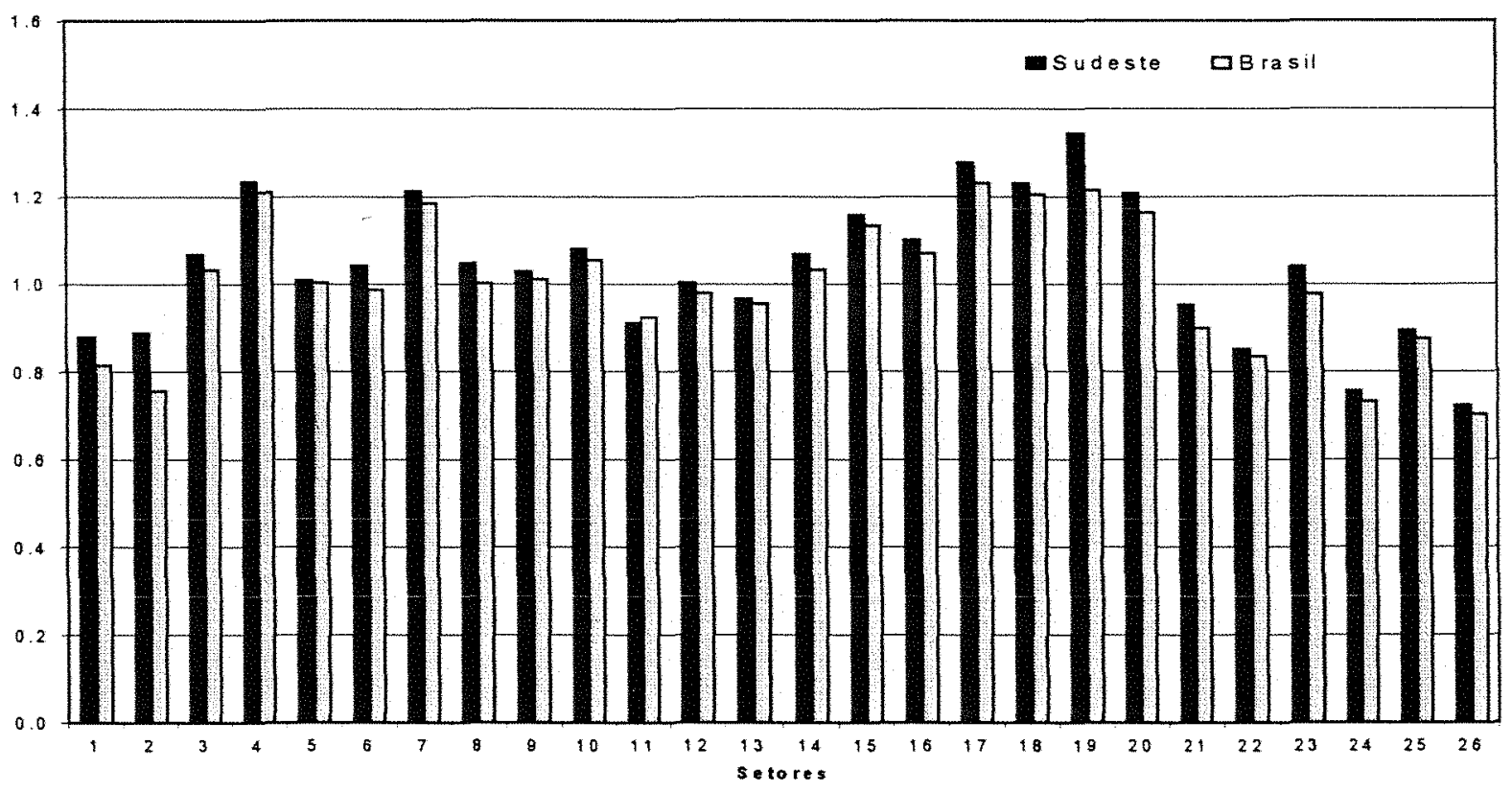

Figura 8.8 Índices de Ligações para trás Rasmussen-Hirschman - Sudeste x Brasil 1985

A região Sudeste apresenta 17 setores com fortes ligações para trás, o maior número dentre as regiões brasileiras, e maior média, 1,04. Apresenta uma amplitude ligeiramente superior a nacional $(1,003$ ate 1,34$)$. Pode-se distinguir três grupos, os mais elevados, (19) Fabricação de Açúcar, maior indice nacional, (17) Indústria do Café, (4) Metalurgia, (18) Abate de Animais, (7) Material de Transporte e (20) Outros Produtos Alimentares, que alternam-se em ordem de importância no setor com a região Sul, com destaque para o setor de Materiais de Transportes. Um grupo intermediário formado por (15) Industria Têxtil e (16) Vestuário e Calçados, primeiro no setor. E em uma posição mais baixa (10) Indústria da Borracha, (14) Plásticos, (3) Minerais não Metálicos, (8) Madeira e Mobiliário, (6) Material Elétrico, (23) Construção Civil, (9) Celulose, Papel e Gráfica, (5) Mecânica e (12) Químicos Diversos. 
A região Sudeste apresenta o maior número de setores com ligações para trás, mas atinge a mesma média da região Sul, 1.04, conforme pode-se constatar a seguir.

c) Região Sul - Ligações para trás - Rasmussen-Hirschman

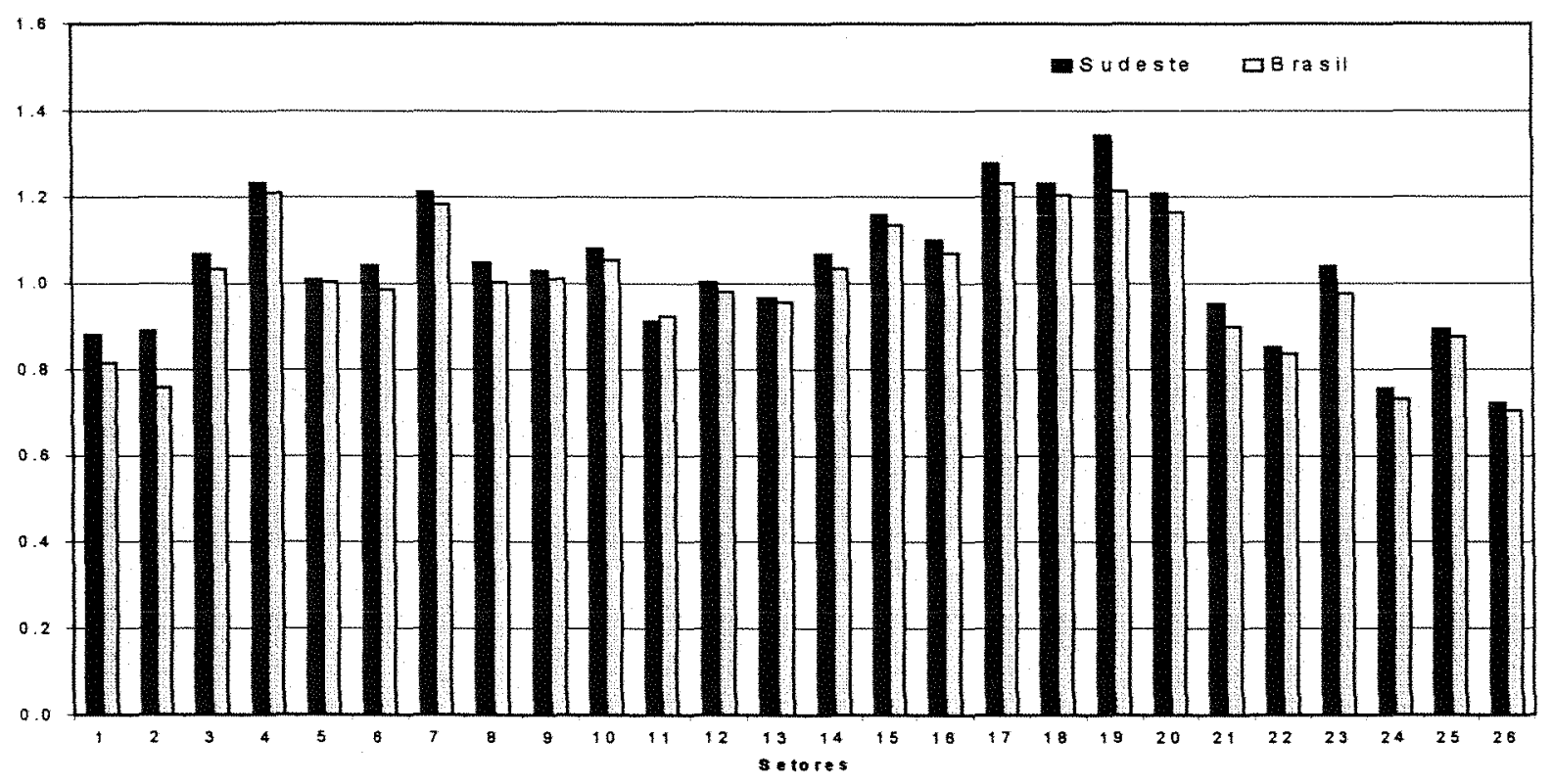

Figura 8.9 Índices de Ligações para trás Rassmussen-Hirschman - Sul x Brasil 1985

A região Sul, apresenta 16 setores relevantes quanto a ligações para trás, somente abaixo da região Sudeste, mas com a mesma média. A amplitude dos índice é de (1,02 até 1,335). Os setores com os maiores índices são (19) Fabricação de Açúcar, segundo índice na classificação geral, (17) Indústria do Café, (18) Abate de Animais, (4) Metalurgia e (20). Outros Produtos Alimentaress, todos classificados no primeiro lugar do setor. Em posição intermediária situam-se os setores (7) Material de Transporte e (15) Indústria Têxtil. E em posições mais baixas, (3) Minerais não Metálicos, (14) Plásticos, (8) Madeira e Mobiliário, (6) Material Elétrico e (23) Construção Civil, classificados em primeiro lugar no setor, (16) Vestuário e Calçados, (10) Indústria da 
Borracha, classificados em segundo e (9) Celulose, Papel e Gráfica e (5) Mecânica, classificados em terceiro lugar do setor.

d) Região Centro-Oeste - Ligações para trás - Rasmussen-Hirschman

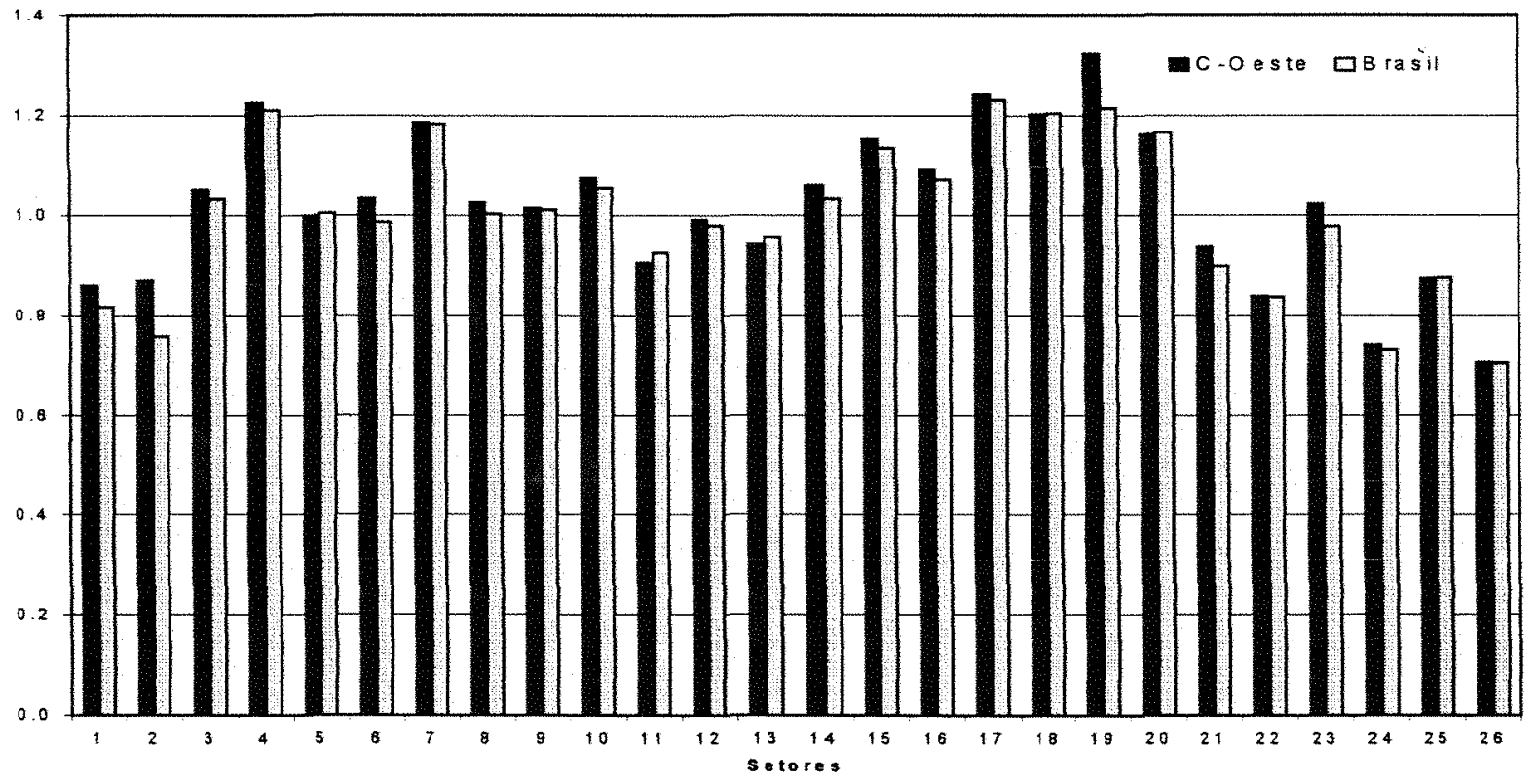

Figura 8.10 İndices de Ligações para trás Rasmussen-Hirschman - C.Oeste x Brasil 1985

A região Centro-Oeste apresenta 15 setores com fortes ligações para trás, com média de 1,02 e amplitude de $(1,013$ até 1,323). Os setores com maiores índices, são (19) Fabricação de Açúcar, (17) Indústria do Café, (4) Metalurgia e (18) Abate de Animais. Em posição intermediária, (7) Material de Transporte, (20) Outros Produtos Alimentares e (15) Industria Têxtil. Em posição mais baixa, (16) Vestuário e Calçados, (10) Indústria da Borracha, (14) Plásticos, (3) Minerais não Metálicos, (6) Material Elétrico, (8) Madeira e Mobiliário, (23) Construção Civil e (9) Celulose, Papel e Gráfica. 
e) Região Nordeste - Ligações para trás - Rasmussen-Hirschman

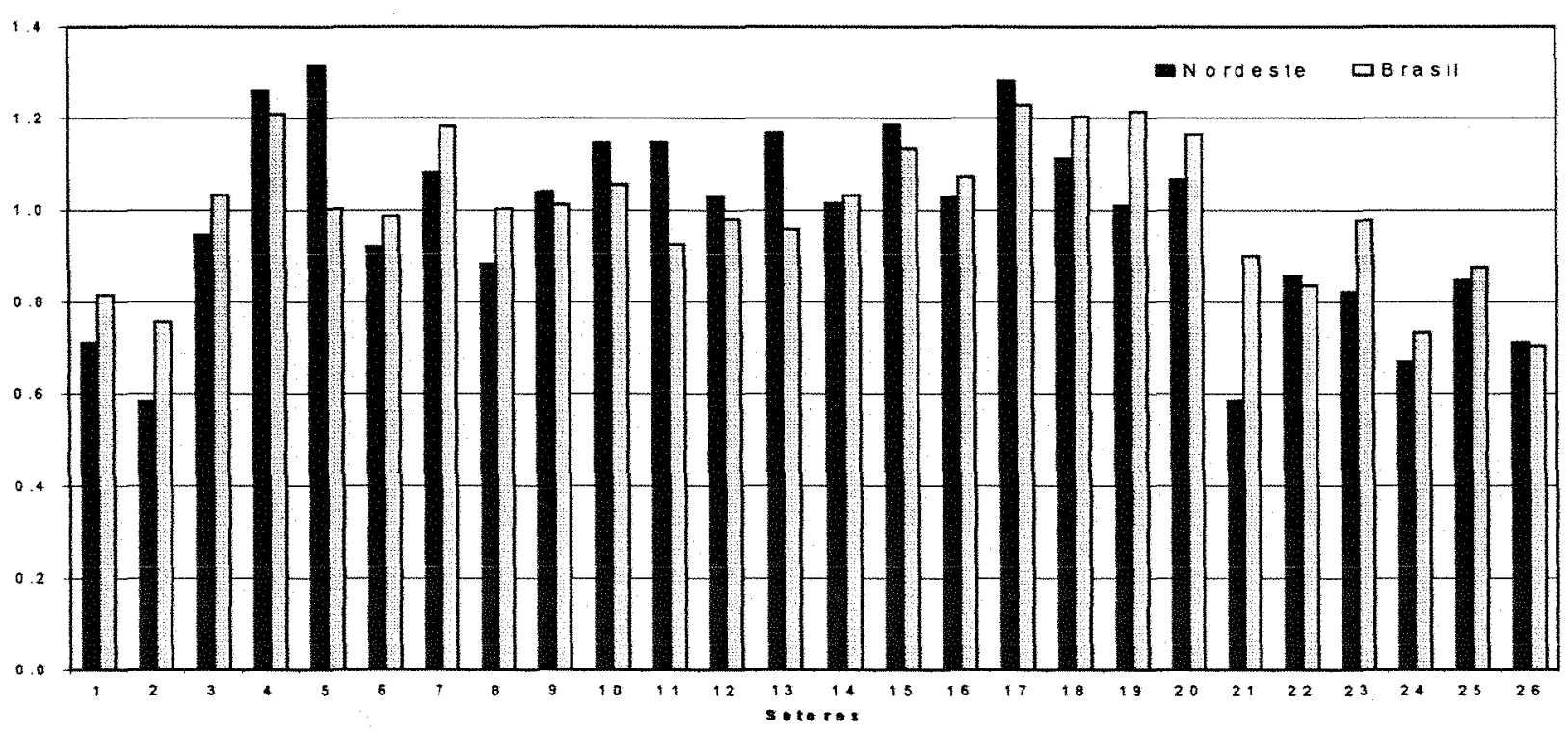

Figura 8.11 Índices de Ligações para trás Rasmussen-Hirschman - Nordeste x Brasil 1985

Em um patamar abaixo, como quarta região brasileira quanto as ligações para trás, identifica-se a região Nordeste, com 15 setores relevantes que apresentam uma média de 0,98 . A amplitude dos índices é de $(1,01$ até 1,31$)$. Os setores que apresentam maiores indices são (5) Mecânica, quarta colocação em toda a economia nacional e primeira do setor, (17) Indústria do Café e (4) Metalurgia, os dois classificados em segundo lugar no setor. No grupo intermediário, (15) Industria Têxtil, (13) Farmacêutica, (11) Refino de Petróleo, (10) Indústria da Borracha, primeiro lugar no setor e (18) Abate de Animais. Em uma posição inferior, (9) Celulose, Papel e Gráfica, (12) Químicos Diversos, primeiro lugar no setor, (16) Vestuário e Calçados, (14) Plásticos , (19) Fabricação de Açúcar, (7) Material de Transporte e (20) Outros Produtos Alimentícios. 
f) Região Norte - Ligações para trás - Rasmussen-Hirschman

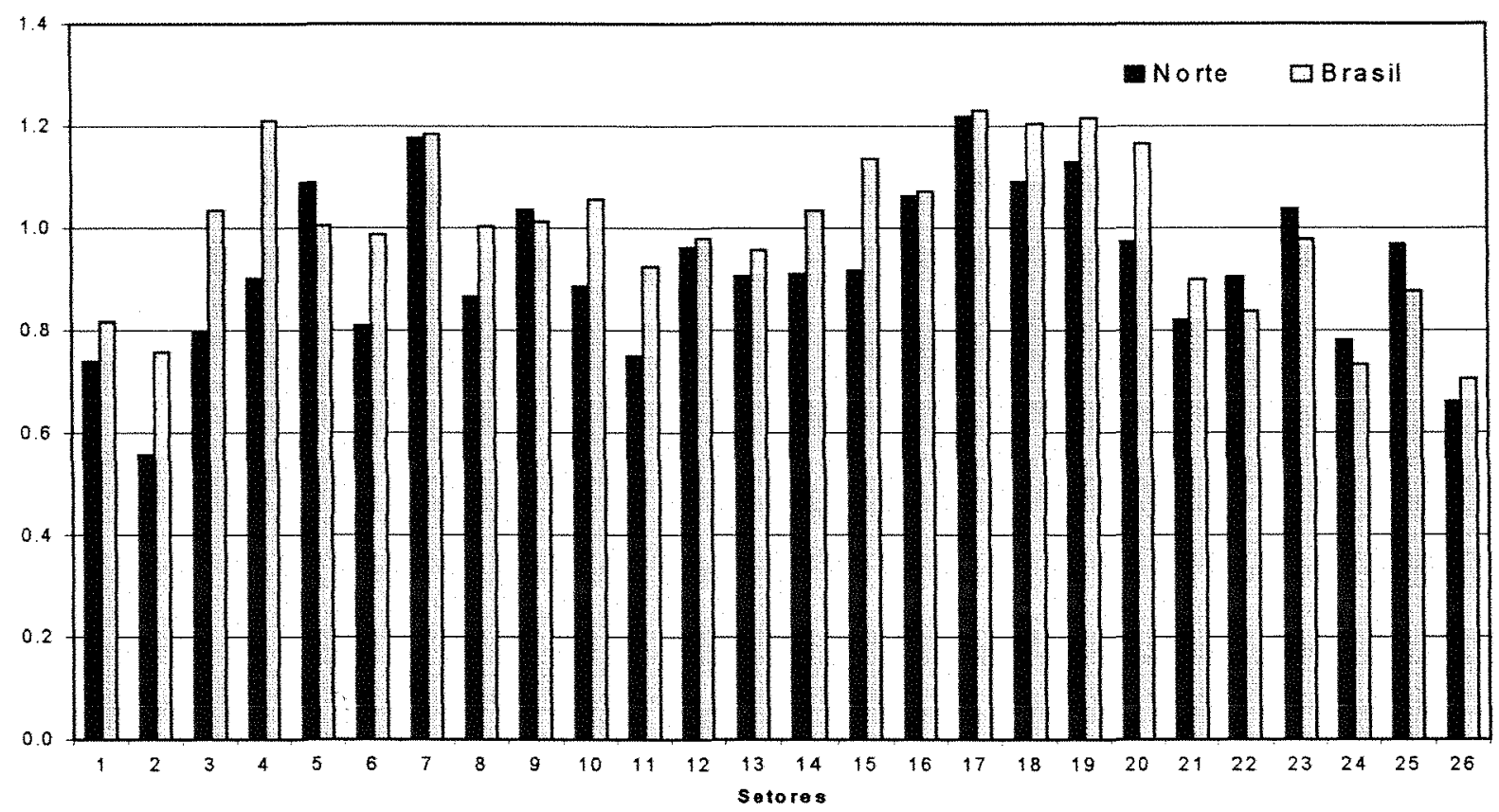

Figura 8.12 Índices de Ligações para trás Rasmussen-Hirschman - Norte x Brasil 1985

A região Norte apresenta somente 9 setores com ligações fortes para trás, com média 0,92 , a maioria abaixo dos valores nacionais. A exemplo dos resultados para a estrutura agregada, a amplitude de variação é $(1,03$ até 1,21$)$. O setor (17) Indústria do Café apresenta o maior índice, no mesmo patamar que o agregado nacional. Em nivel intermediário, (7) Material de Transporte também a nivel nacional e (19) Fabricação de Açúcar. Em posição inferior, (18) Abate de Animais, (5) Mecânica, (16) Vestuário e Calçados, (23) Construção Civil e (9) Celulose, Papel e Gráfica.

A exemplo das ligações para a frente a região Norte não apresenta dinâmica quanto a capacidade de demanda na economia. 
g) Consolidação dos índices de Ligações para trás - Rasmussen-Hirschman, Brasil e regiões.

A análise regionalizada permite identificar os setores mais dinâmicos para cada região. No caso específico das ligações para trás, ver Quadro 8.4, identificam-se para o Brasil 05 setores que não são considerados na análise nacional, porém são relevantes para determinadas regiões.

Quadro 8.4 - Índices de ligações para trás - Rasmussen e Hirschman - regiões, média reg. e Brasil - 1985

\begin{tabular}{|c|c|c|c|c|c|c|c|c|}
\hline \multicolumn{2}{|c|}{\begin{tabular}{|c|} 
Setores \\
\end{tabular}} & \multirow{2}{*}{\begin{tabular}{|l|} 
Norte \\
0.738 \\
\end{tabular}} & \multirow{2}{*}{\begin{tabular}{|r|} 
Nordeste \\
0.712 \\
\end{tabular}} & \multirow{2}{*}{\begin{tabular}{r|} 
C-Oeste \\
0.859
\end{tabular}} & \multirow{2}{*}{\begin{tabular}{|r|} 
Sudeste \\
0.880
\end{tabular}} & \multirow{2}{*}{\begin{tabular}{l|} 
Sul \\
0.883
\end{tabular}} & \multirow{2}{*}{\begin{tabular}{r|} 
Méd.Reg. \\
0.815 \\
\end{tabular}} & \multirow{2}{*}{\begin{tabular}{|c|} 
Brasil \\
0.816 \\
\end{tabular}} \\
\hline 1 & Agropecuária & & & & & & & \\
\hline 2 & Mineraçào & 0.557 & 0.584 & 0.872 & 0.890 & 0.896 & 0.760 & 0.757 \\
\hline 3 & Miner.N. Metalicos & 0.794 & 0.944 & 1.053 & 1.067 & 1.079 & 0.987 & 1.033 \\
\hline 4 & Metalurgia & 0.901 & 1260 & 1.224 & 1.233 & 1.266 & 1,171 & 1.211 \\
\hline 5 & Mecânica & 1.088 & 1317 & 1,000 & 1.009 & 1009 & 1.087 & 1.003 \\
\hline 6 & Material Elétrico & 0.809 & 0.919 & 1.035 & 1042 & 1.058 & 0.973 & 0.986 \\
\hline 7 & Mat. Transporte & 1.176 & 1.082 & 1.187 & 1213 & 1462 & 1,164 & 1.184 \\
\hline 8 & Madeira Mobiliário & 0.865 & 0.882 & 1.027 & 1.048 & 1057 & 0.976 & 1002 \\
\hline 9 & Celul.Pap.Gráfica & 1036 & 1040 & 1.014 & 1030 & 1.036 & 1.031 & 1011 \\
\hline 10 & Ind da .Borracha & 0.886 & 1.149 & 1.076 & 1.082 & 1.085 & 1.055 & 1.056 \\
\hline 11 & Refino Petróleo & 0.749 & 1.149 & 0.906 & 0.912 & 0.911 & 0.925 & 0.925 \\
\hline 12 & Químicos Diversos & 0.962 & 1031 & 0.990 & 1.003 & 1.004 & 0.998 & 0.980 \\
\hline 13 & Farmacèutica & 0.907 & 1.168 & 0.944 & 0.968 & 0.972 & 0.992 & 0.957 \\
\hline 14 & Plästicos & 0.911 & 1015 & 1060 & 1.068 & 1,070 & 1,025 & 1.033 \\
\hline 15 & Indústria Tèxtil & 0.917 & 1,186 & 1152 & 1.159 & 1.151 & 1,113 & 1.135 \\
\hline 16 & Vest. Calçados & 1,061 & 1.030 & 1.092 & 1.101 & 1.096 & 1076 & 1071 \\
\hline 17 & Indust do Café & 1.218 & 1282 & 1.241 & 1.280 & 1.285 & 1.261 & 1.230 \\
\hline 18 & Abate de Animais & 1091 & 1,112 & 1203 & 1.231 & 1.272 & 1182 & 1.205 \\
\hline 19 & Fabr de Açúcar & 1.130 & 1.010 & 1.323 & 1345 & 1.336 & 1.220 & 1.215 \\
\hline 20 & Outros Pr. Aliment. & 0.973 & 1067 & 1.162 & 1.208 & 1.231 & 1128 & 1165 \\
\hline 21 & Indústrias Diversas & 0.820 & 0.585 & 0.936 & 0.954 & 0.966 & 0.852 & 0.899 \\
\hline 22 & En. Ag. San. Com.. & 0.903 & 0.857 & 0.838 & 0.852 & 0.855 & 0.861 & 0.836 \\
\hline 23 & Construção Civil & 1.037 & 0.822 & 1.024 & 1.040 & 1.052 & 0.995 & 0.978 \\
\hline 24 & Comércio & 0.781 & 0.669 & 0.741 & 0.756 & 0.756 & 0.741 & 0.732 \\
\hline 25 & Transportes & 0.968 & 0.847 & 0.875 & 0.895 & 0.885 & 0.894 & 0.876 \\
\hline 26 & Serviços & 0.661 & 0.711 & 0.705 & 0.723 & 0.723 & 0.704 & 0.704 \\
\hline & Média & 0.921 & 0.978 & 1.021 & 1.038 & 1.043 & 1.000 & 1.000 \\
\hline
\end{tabular}

Fonte: dados estimados pelo autor 
Estes setores são (23) Construção Civil para as regiões Sul, Sudeste, Norte e Centro-Oeste, (6) Material Elétrico para as regiões Sul, Sudeste e Centro-Oeste, (12) Químicos Diversos para Nordeste e Sul, (13) Farmacêutica e (11) Refino de Petróleo para o Nordeste.

Por sua vez, os setores relevantes para todas as regiões são (5) Mecânica, (7) Material de Transporte, (9) Celulose Papel e Gráfica, (16) Vestuário e Calçados, (17) Indústria de Café, (18) Abate de Animais e (19) Fabricação de Açúcar.

Os setores (4) Metalurgia, (10) Indústria da Borracha, (14) Plásticos, (15) Indústria Têxtil e (20) Outros produtos Alimentares, são relevantes para 4 regiões simultaneamente; as regiões Nordeste, Centro-Oeste, Sudeste e Sul.

Considerando os setores fortes para 3 regiões, temos para as regiões CentroOeste, Sudeste e Sul, (3) Mineral não Metálicos, (6) Material Elétrico e (8) Madeira e Mobiliário. Enquanto o setor (12) Químicos Diversos é relevante para Nordeste, Sudeste e Sul.

\subsubsection{Setores chave, Brasil e regiões, 1985}

\subsubsection{Brasil e os setores chave}

Considerando o critério restrito para seleção de setores-chave proposta por Mcgilvray (1977), identificou-se, através da organização dos índices constantes do Quadro 8.5, para a estrutura agregada brasileira, apenas 02 setores com índices de ligações para frente e para trás maiores que 1 simultaneamente, (4) Metalurgia e (15) Indústria Têxtil. A proposta é de que tais setores deveriam ser considerados como prioritários quando da implementação de investimentos, pois apresentam maior possibilidade de desencadear efeitos para trás e frente no sistema econômico.. A seguir, apresentam-se os resultados da aplicação destes critérios para a matriz inter-regional brasileira em 1985. Novamente salienta-se a relevância da análise regionalizada destes indicadores. 


\subsubsection{As regiões brasileiras e os setores-chave}

Quadro 8.5 - Setores-chave, ligações de Rasmussen-Hirschman - Brasil e Regiões-1985

\begin{tabular}{|c|c|c|c|c|c|c|c|c|c|c|c|c|c|}
\hline \multicolumn{2}{|r|}{ REGIŌES } & \multicolumn{2}{|c|}{ NORTE } & \multicolumn{2}{|c|}{ NORDESTE } & \multicolumn{2}{|c|}{ C-OESTE } & \multicolumn{2}{|c|}{ SUDESTE } & \multicolumn{2}{|c|}{ SUL } & \multicolumn{2}{|c|}{ BRASIL } \\
\hline No. & SETORES & Frente & Trás & Frente & Trás & Frente & Trás & Frente & Trás & Frente & Trás & Frente & Trás \\
\hline 1 & Agropecuária & 2.76 & 0.74 & 228 & 0.71 & 1,78 & 0.86 & 290 & 0.88 & 2.25 & 0.88 & 2.28 & 0.82 \\
\hline 2 & Mineração & 0.82 & 0.56 & 146 & 0.58 & 0.67 & 0.87 & 1,73 & 0.89 & 0.73 & 0.90 & 1.06 & 0.76 \\
\hline 3 & Minerais não Matálicos & 0.55 & 0.79 & 0.65 & 0.94 & 0.84 & 1,051 & 1.12 & 107 & 0.82 & 1.08 & 0.80 & 1.03 \\
\hline 4 & Metalurgia & 0.62 & 0.90 & 1,35 & 1.26 & 0.76 & 1.22 & 5.67 & 123 & 1.40 & 1.27 & 2.05 & 1.21 \\
\hline 5 & Mecânica & 0.71 & 1.09 & 0.77 & 1,32 & 0.52 & 1.00 & 2.03 & 101 & 1.05 & 102 & 1.00 & 1.00 \\
\hline 6 & Material Elátrico & 0.68 & 0.81 & 0.62 & 0.92 & 0.51 & 1.04 & 116 & 104 & 0.62 & 106 & 0.70 & 0.99 \\
\hline 7 & Material de Transporte & 0.61 & 1.18 & 0.56 & 1.08 & 0.50 & 1.19 & 1.89 & 1.21 & 0.61 & 1.16 & 0.88 & 1.18 \\
\hline 8 & Madeira e Mobiliário & 0.58 & 0.87 & 0.55 & 0.88 & 0.55 & 1.03 & 0.67 & 105 & 0.78 & 1.06 & 0.64 & 1.00 \\
\hline 9 & Celulose, Papel e Gráf. & 0.54 & 1.04 & 0.85 & 104 & 0.58 & 101 & 1.58 & 1.03 & 0.96 & 1.04 & 0.93 & 1.01 \\
\hline 10 & Ind. Da Borracha & 0.60 & 0.89 & 0.58 & 1,15 & 0.52 & 1.07 & 1.42 & 1.08 & 0.69 & 1.09 & 0.78 & 1.06 \\
\hline 11 & Refino do Petróleo & 0.60 & 0.75 & 2.13 & 1.15 & 0.62 & 0.91 & 3.78 & 0.91 & 139 & 0.91 & 1.77 & 0.93 \\
\hline 12 & Químicos Diversos & 0.55 & 0.96 & 1.05 & 1.03 & 0.55 & 0.99 & 3.231 & 1.01 & 1.20 & 1.01 & 1,39 & 0.98 \\
\hline 13 & Farmacèutica & 0.49 & 0.91 & 0.51 & 1.17 & 0.49 & 0.94 & 0.79 & 0.97 & 0.51 & 0.97 & 0.53 & 0.96 \\
\hline 14 & Plásticos & 0.54 & 0.91 & 0.56 & 1.01 & 0.51 & 1.06 & 1.00 & 1.07 & 0.67 & 107 & 0.68 & 1.03 \\
\hline 15 & Ind. Têxtil & 0.82 & 0.92 & 1.10 & 1.19 & 0.76 & 1.15 & 2.04 & 1.16 & 1.06 & 1.15 & 1.19 & 1,13 \\
\hline 16 & Vestuário e Calçados & 0.50 & 106 & 0.53 & 103 & 0.51 & 109 & 0.60 & 1.10 & 0.63 & 1,10 & 0.55 & 1.07 \\
\hline 17 & Indústria do Café & 0.61 & 122 & 0.62 & 128 & 0.55 & 1.24 & 0.65 & 1.28 & 0.60 & 1.28 & 0.59 & 1.23 \\
\hline 18 & Abate de Animais & 0.61 & 1.09 & 0.51 & 1.11 & 0.53 & 120 & 0.55 & 1.23 & 0.66 & 1.27 & 0.56 & 1.21 \\
\hline 19 & Fabricação de Açucar & 0.51 & 1,13 & 0.57 & 101 & 0.54 & 132 & 1.07 & 1.34 & 0.53 & 1,34 & 0.63 & 1.21 \\
\hline 20 & Outros Prod. Aliment. & 0.60 & 0.97 & 0.70 & 1.07 & 0.61 & 1.16 & 0.83 & 1.21 & 119 & 123 & 0.80 & 116 \\
\hline 21 & Indústrias Diversas & 0.58 & 0.82 & 0.64 & 0.58 & 0.49 & 0.94 & 0.90 & 0.95 & 0.57 & 0.97 & 0.63 & 0.90 \\
\hline 22 & En., Água, San,COm. & 0.70 & 0.90 & 1.00 & 0.86 & 1.01 & 0.84 & 1.42 & 0.85 & 1,10 & 0.86 & 1.03 & 0.84 \\
\hline 23 & Construçào Civil & 0.57 & 1.04 & 0.54 & 0.82 & 0.57 & 1.02 & 0.66 & 104 & 0.57 & 1.05 & 0.58 & 0.98 \\
\hline 24 & Comércio & 120 & 0.78 & 1.44 & 0.67 & 1.27 & 0.74 & 195 & 0.76 & 1.38 & 0.76 & 1.38 & 0.73 \\
\hline 25 & Transportes & 0.90 & 0.97 & 0.72 & 0.85 & 0.98 & 0.87 & 1.50 & 0.90 & 1.10 & 0.88 & 1.08 & 0.88 \\
\hline 26 & Serviços & 1.19 & 0.66 & 1.23 & 0.71 & 1.96 & 0.70 & 2.47 & 0.72 & 1.17 & 0.72 & 1.48 & 0.70 \\
\hline & Média & 0.75 & 0.92 & 0.90 & 0.98 & 0.74 & 1.02 & 1.68 & 1.04 & 0.93 & 1.04 & 1.00 & 1.00 \\
\hline
\end{tabular}

Fonte: dados estimados pelo autor

Estendendo esta análise para matriz inter-regional construída para 1985, a região Sudeste, apresenta um maior número de setores e maior intensidade dos índices de ligação para frente e para trás, simultaneamente, seguida pela região Sul e Nordeste, enquanto as regiões Centro-Oeste e Norte não apresentam setores-chave sob este critério 
O Quadro 8.5 apresenta os índices de ligações de forma a permitir, rapidamente, a identificação visual dos setores-chave das regiões brasileiras. A região Sudeste apresenta 10 setores-chave considerando a matriz inter-regional: (4) Metalurgia, (12) Químicos Diversos, (15) Indústria Têxtil, (5) Mecânica, (7) Material de Transporte, (9) Celulose, Papel e Gráfica, (10) Indústria da Borracha, (6) Material Elétrico, (3) Minerais não Metálicos e (19) Fabricação de Açúcar.

Pode-se verificar que, neste critério, a região Sudeste apresenta-se como pólo dinâmico da economia brasileira, especialmente na indústria de transformação, pois a média de seus indices para frente suplantam as das outras regiões, deve-se observar, inclusive, que é a única região a apresentar média dos indices para a frente maior que a média dos indices para trás, sugerindo provocar dinâmica na economia com maior grau pela oferta.

Com a metade de setores-chave, a região Sul se coloca como a segunda região brasileira como pólo dinâmico, em número de setores, apresenta como diferença da região Sudeste, o setor (20) Outros Produtos Alimentares. Os quatro setores restantes são (4) Metalurgia, (12) Químicos Diversos, (15) Industria Têxtil e (5) Mecânica.

A região Nordeste apresenta-se como pólo diferenciado das demais regiões, no setor de (11) Refino de Petróleo, os demais setores são (4) Metalurgia, (15) Indústria Têxtil e (12) Químicos Diversos.

O Quadro 8.6 apresentado a seguir, mostra claramente os setores característicos para com índices para a frente ou para trás na economia brasileira, como por exemplo, os característicos para frente, Agropecuária, Mineração, Comércio, Serviços, etc., e para trás Vestuário e Calçados, Indústria do Café, Abate de Animais, dentre outros. Porém, é interessante identificar os setores importantes fora deste padrão, como os setores, Refino de Petróleo e Químicos Diversos, que são relevantes para trás na região Nordeste, quando sua característica normal é a de ligação para frente, o mesmo acontece com a Indústria da Borracha, Celulose, Papel e Gráfica, dentro outras para a região Sudeste. 
Quadro 8.6. Comparação das ligações para frente e trás - Rasmussen-Hirschman 1985

\begin{tabular}{|c|c|c|c|c|c|c|c|c|c|c|c|c|c|c|c|c|c|}
\hline & \multirow{2}{*}{ SETORES } & \multicolumn{6}{|c|}{ Frente } & \multicolumn{6}{|c|}{ Trás } & \multicolumn{2}{|c|}{ Frente } & \multicolumn{2}{|c|}{ Trás } \\
\hline & & $\mathbf{N}$ & $\mathrm{NE}$ & $\mathrm{CO}$ & $\mathrm{SE}$ & $\mathbf{S}$ & BR & $\mathrm{N}$ & $\mathrm{NE}$ & $\mathrm{CO}$ & SE & $\mathbf{S}$ & $B R$ & Me.R & BR & Me.R & BR \\
\hline 1 & Agropec. & 276 & 228 & 1,78 & 290 & 225 & 228 & 0.74 & 0.71 & 0.86 & 0.88 & 0.88 & 0.82 & 2,39 & 228 & 0.81 & 0.82 \\
\hline 2 & Mineração & 0.82 & 1,46 & 0.67 & 1,73 & 0.73 & 106 & 0.56 & 0.58 & 0.87 & 0.89 & 0.90 & 0.76 & 108 & 106 & 0.76 & 0.76 \\
\hline 3 & Miner.N. Met. & 0.55 & 0.65 & 0.84 & 1,12 & 0.82 & 0.80 & 0.79 & 0.94 & 105 & 107 & 108 & 103 & 0.80 & 0.80 & 0.99 & 100 \\
\hline 4 & Metalurgia & 0.62 & 1.35 & 0.76 & 3.67 & 1,40 & 2,05 & 0.90 & 426 & 1.22 & 123 & 1.27 & 121 & 196 & 205 & 1.18 & 121 \\
\hline 5 & Mecânica & 0.71 & 0.77 & 0.52 & 2.03 & 1.05 & 1.00 & 1.09 & 1,32 & 1.00 & 1,01 & 102 & 1.00 & 101 & 1.00 & 109 & 1.00 \\
\hline 6 & Mat. Elétr. & 0.68 & 0.62 & 0.51 & 1,16 & 0.62 & 0.70 & 0.81 & 0.92 & 1.04 & 104 & 1,06 & 0.99 & 0.72 & 0.70 & 0.97 & 0.99 \\
\hline 7 & Mat. Transp. & 0.61 & 0.56 & 0.50 & 1.89 & 0.61 & 0.88 & 1,18 & 1.08 & $(19)$ & 1.21 & 1.16 & 1,18 & 0.83 & 0.88 & 1,16 & 1,18 \\
\hline 8 & Mad. Mobil. & 0.58 & 0.55 & 0.55 & 0.67 & 0.78 & 0.64 & 0.87 & 0.88 & 1.03 & 1.05 & 1,06 & 1.00 & 0.63 & 0.64 & 0.98 & 1.00 \\
\hline 9 & Celul.Pap.Graf. & 0.54 & 0.85 & 0.58 & 158 & 0.96 & 0.93 & 1.04 & 1,04 & 1.01 & 1.03 & 104 & 1.01 & 0.90 & 0.93 & 103 & 1,01 \\
\hline 10 & Ind.Borracha & 0.60 & 0.58 & 0.52 & 1,42 & 0.69 & 0.78 & 0.89 & 115 & 1.07 & 108 & 1,09 & 1,06 & 0.76 & 0.78 & 1.06 & 106 \\
\hline 11 & Refino Petróleo & 0.60 & 2,13 & 0.62 & 378 & 1,39 & 1.77 & 0.75 & 1,15 & 0.91 & 0.91 & 0.91 & 0.93 & 1,70 & 1.77 & 0.93 & 0.93 \\
\hline 12 & Quimicos Div. & 0.55 & 1.05 & 0.55 & 3.23 & 120 & 1.39 & 0.96 & 103 & 0.99 & 1.00 & 1.00 & 0.98 & 1,32 & 1,39 & 1.00 & 0.98 \\
\hline 13 & Farmacêutica & 0.49 & 0.51 & 0.49 & 0.79 & 0.51 & 0.53 & 0.91 & 1,17 & 0.94 & 0.97 & 0.97 & 0.96 & 0.56 & 0.53 & 0.99 & 0.96 \\
\hline 14 & Plásticos & 0.54 & 0.56 & 0.51 & 1.00 & 0.67 & 0.68 & 0.91 & 1.01 & 1.06 & 1.07 & 107 & 1,03 & 0.66 & 0.68 & 1.02 & 103 \\
\hline 15 & Ind. Tèxtil & 0.82 & 110 & 0.76 & 204 & 1,06 & 1,19 & 0.92 & 1,19 & 1,16 & 1,16 & 115 & 1,13 & 1,16 & 119 & 1,11 & 1,13 \\
\hline 16 & Vest Calçados & 0.50 & 0.53 & 0.51 & 0.60 & 0.63 & 0.55 & 1.06 & 1,03 & 1.09 & 1,10 & 1.10 & 1.07 & 0.55 & 0.55 & 1,08 & 1.07 \\
\hline 17 & Indúst.Café & 0.61 & 0.62 & 0.55 & 0.65 & 0.60 & 0.59 & 122 & 1,28 & 1.24 & 128 & 1.28 & 1,23 & 0.61 & 0.59 & 1,26 & 1.23 \\
\hline 18 & Abate Animais & 0.61 & 0.51 & 0.53 & 0.55 & 0.66 & 0.56 & 109 & 1,11 & 1,20 & 123 & 127 & 121 & 0.57 & 0.56 & 1,18 & 121 \\
\hline 19 & Fabr. Açucar & 0.51 & 0.57 & 0.54 & 1.07 & 0.53 & 0.63 & 1,13 & 1.01 & 132 & 1.34 & 1,34 & 121 & 0.64 & 0.63 & 123 & 1,21 \\
\hline 20 & Outros Pr. Alim. & 0.60 & 0.70 & 0.61 & 0.83 & 1,19 & 0.80 & 0.97 & 1.07 & 1,16 & 1,21 & 1,23 & 1.16 & 0.79 & 0.80 & 113 & 1.16 \\
\hline 21 & Ind. Diversas & 0.58 & 0.64 & 0.49 & 0.90 & 0.57 & 0.63 & 0.82 & 0.58 & 0.94 & 0.95 & 0.97 & 0.90 & 0.64 & 0.63 & 0.85 & 0.90 \\
\hline 22 & En. Ag. S.Com. & 0.70 & 1.00 & 1.01 & 1.42 & 1,10 & 103 & 0.90 & 0.86 & 0.84 & 0.85 & 0.86 & 0.84 & 1.04 & 1.03 & 0.86 & 0.84 \\
\hline 23 & Constr. Civil & 0.57 & 0.54 & 0.57 & 0.66 & 0.57 & 0.58 & 104 & 0.82 & 102 & 104 & 105 & 0.98 & 0.58 & 0.58 & 0.99 & 0.98 \\
\hline 24 & Comercio & 120 & 1.44 & 1.27 & 1.95 & 1,38 & 1,38 & 0.78 & 0.67 & 0.74 & 0.76 & 0.76 & 0.73 & 1.45 & 1.38 & 0.74 & 0.73 \\
\hline 25 & Transportes & 0.90 & 0.72 & 0.98 & 1.50 & 1.10 & 1.08 & 0.97 & 0.85 & 0.87 & 0.90 & 0.88 & 0.88 & 1.04 & 108 & 0.89 & 0.88 \\
\hline 26 & Serviços & 149 & 1.23 & 1.96 & 2.47 & 1.17 & 1.48 & 0.66 & 0.71 & 0.70 & 0.72 & 0.72 & 0.70 & 161 & 1.48 & 0.70 & 0.70 \\
\hline & Média & 0.75 & 0.90 & 0.74 & 1.68 & 0.93 & 1.00 & 0.92 & 0.98 & 1.02 & 1.04 & 1.04 & 1.00 & 1.00 & 1.00 & 1.00 & 1.00 \\
\hline
\end{tabular}

Fonte: dados estimados pelos autor

A proposta de análise do campo de influência que se apresenta a seguir, permite identificar as ligações entre os setores aqui apontados. Posteriormente, os resultados do índices puros são apresentados, como outra alternativa para identificação de setores chaves, com características diferenciadas. 


\subsection{Campo de Influência, Brasil e regiões, 1985}

O método de determinação de campo de influência, proposto por Sonis e Hewings (1989 e 1984), apresentado no capitulo 7 desta pesquisa, complementa as análise dos índices de ligações de Rasmussen- Hirschman, na medida que identifica as relações entre os setores chaves da estrutura econômica estudada, ou seja revelando os elos da economia.

Guilhoto(1995, p.32), aponta para a importância do uso do campo de influência, no sentido de se verificar, quais seriam os coeficientes que, se alterados, teriam um maior impacto no sistema como um todo, ou seja, eles demonstram como se distribuem as mudanças dos coeficientes diretos no sistema econômico como um todo, possibilitando com isso a determinação das mais importantes relações inter-setoriais no processo produtivo

Especificamente para este trabalho, a técnica de campo de influência é extremamente importante, pois possibilita desvendar as relações de comércio intra e inter-regionais para a estrutura da economia brasileira em 1985 .

Os resultados obtidos estão compilados nas duas figuras apresentadas a seguir: a Figura 8.13, que sintetiza o campo de influência para a estrutura agregada brasileira de 1985 e a 8.14, que faz o mesmo para a estrutura inter-regional brasileira de 1985.

Preliminarmente à análise, esclarece-se que o campo de influência estudado para a estrutura agregada brasileira, considerou os 150 primeiros índices obtidos, plotados nos 26 setores aqui estudados, enquanto que para a análise inter-regional foram selecionados os primeiros 600 índices, considerando os 26 setores para cada uma das 05 regiões estudadas. As figuras discriminam nos eixos os setores considerados nesta pesquisa.

A identificação na Figura 8.13, dos setores (4) Metalurgia e (15) Indústria Têxtil, considerados como setores chave na análise via indices de Rasmussen-Hirschman, é facilmente realizada, em maior grau para a Metalurgia que relaciona-se com todos os 26 setores considerados. Destaca-se também o setor (1) Agropecuário 
Ainda na figura 8.13, visualizam-se dois quadrantes, que revelam a realização de intercâmbios entre os setores (7) Material de Transporte, (9) Celulose, Papel e Gráfica e (10) Indústria da Borracha, entre eles e com o setor (11) Refino de Petróleo. Enquanto o segundo quadrante, relaciona novamente os setores (7), (9) e (10) com os setores (17) Indústria do Café, (18) Abate de Animais, (19) Indústria do Açúcar e (20) Outros Produtos Alimentares.

Todos estes setores apresentaram índices de ligações maiores que 1, ou seja maior que a média, e no conceito menos restrito podem ser considerados setores chaves na economia e apresentam os maiores coeficientes de influência para a economia brasileira em 1985 .

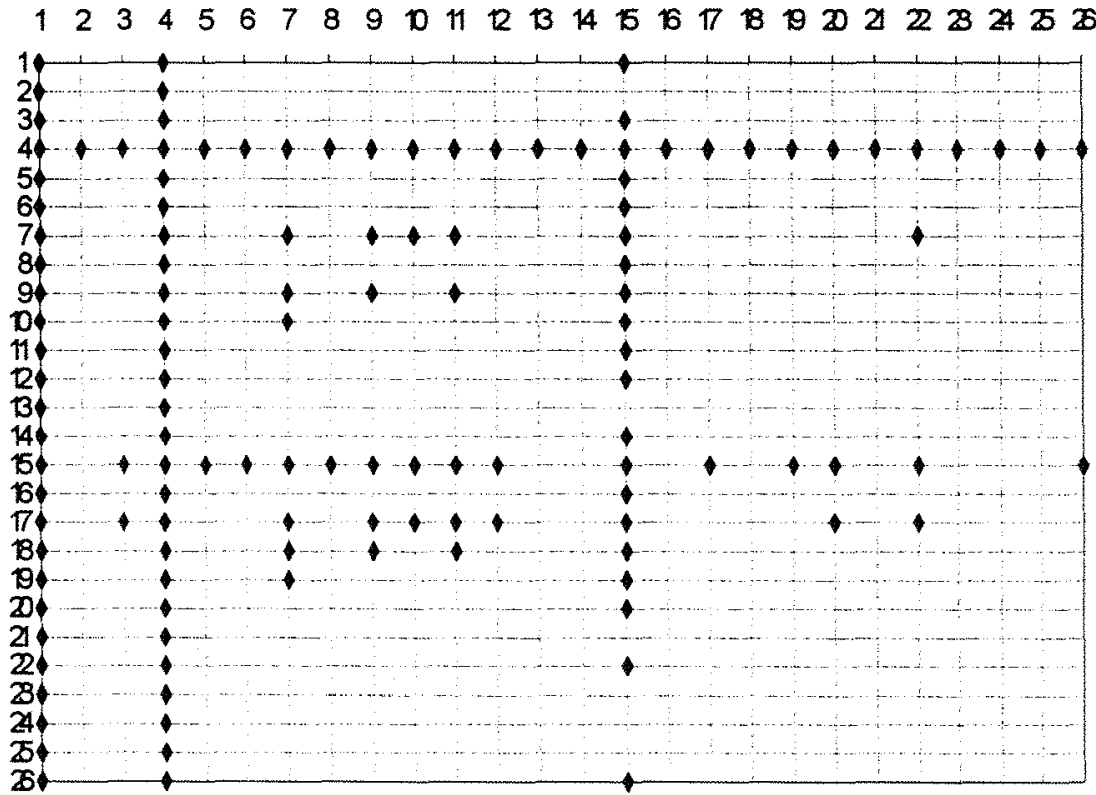

Figura 8.13 - Campo de Influência - Brasil 1985 
A Figura 8.14, apresenta um grande número de informações e possibilita diversos tipos de análises A preocupação por ora é a de destacar aquelas que se julga mais importantes e circunscritas no escopo desta pesquisa. De forma geral, o campo de influência para a estrutura inter-regional brasileira para 1985 revela a existência de mercados intra e inter-regionais bem delíneados, que complementam algumas das inferências já realizadas

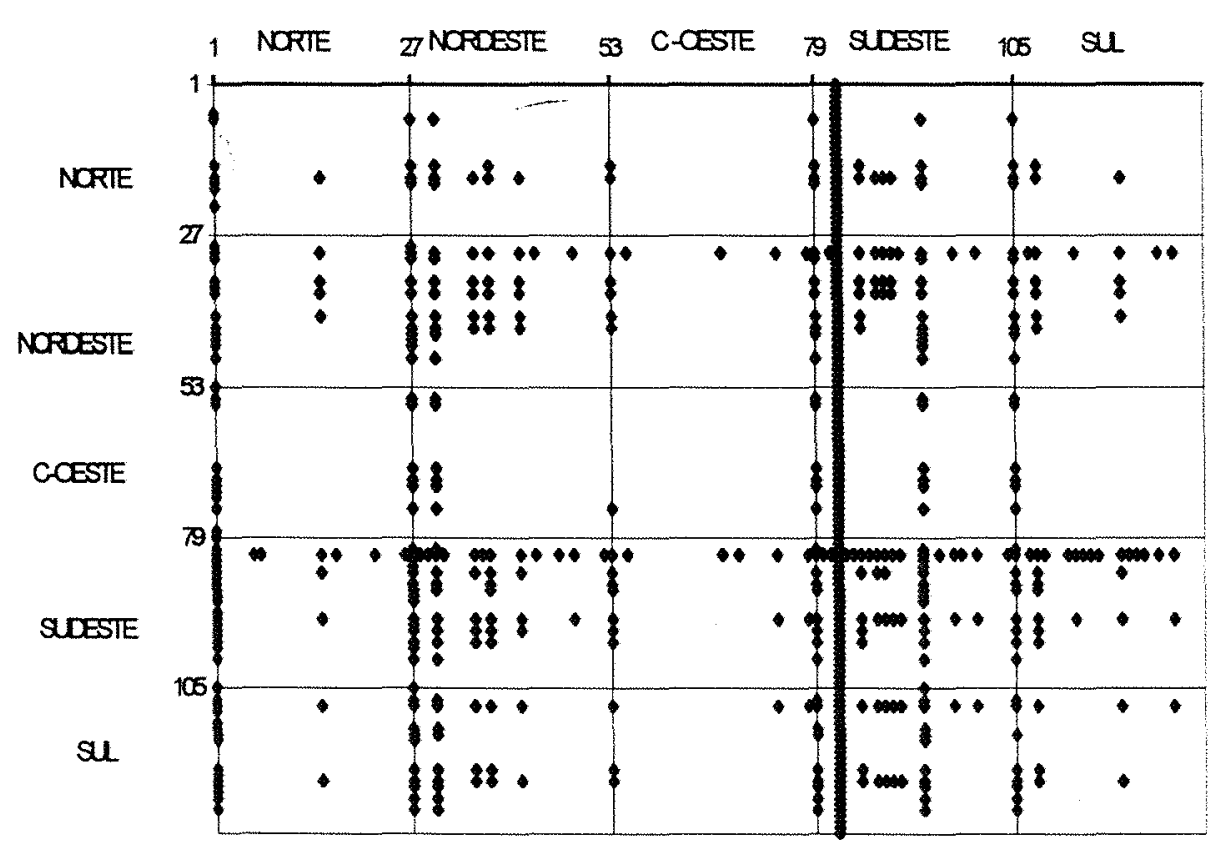

Figura 8.14 - Campo de Influência - Estrutura Inter-regional - Brasil 1985

Além da região Sudeste, que se mostra claramente dinâmica em todos os sentidos, a região Nordeste revela-se com alguns setores dinâmicos tanto intra como inter-regionalmente, guardando-se as devidas proporções e evidenciando suas características particulares, que são corroboradas pelos indicadores de ligações até aqui verificados. Quando comparada com a região Sul, nota-se claramente que esta revela 
pequena dinâmica interna dos seus setores, inclusive o intercâmbio entre as duas parece ser mais relevante que a própria dinâmica interna da região Sul.

A região Norte apresenta dinâmica fraca internamente e basicamente relaciona-se com as regiões Nordeste e Sudeste. Já a região Centro-Oeste não apresenta dinâmica interna, dentro das condições deste tipo de análise e encontra-se dependente em maior grau da região Sudeste .

A análise da estrutura inter-regional brasileira através do campo de influência, para este número de coeficientes, revela portanto qual o alcance dos índices de ligações obtidos no item anterior, em termos de comércio intra e inter-regional. É importante a revelação do mercado da região Nordeste, apresentando uma ligeira superioridade com relação a região Sul, tanto do mercado interno como na estrutura inter-regional.. Identifica-se, inclusive, uma certa relação com a região Norte, revelando um possivel mercado, ou pólo de desenvolvimento mais descentralizado com relação a região Sudeste.

$\mathrm{Na}$ seção seguinte os índices puros são apresentados, como alternativa de análise, considerando a contribuição dos setores na produção da economia.

\section{3 Índices Puros de ligações e a matriz inter-regional brasileira, 1985}

O método de apuração de índices puros, elaborado por Guilhoto et.al.(1996), conforme explicitado no capitulo 7 , refere-se a obtenção do grau de importância dos valores da produção de cada setor para determinada economia

Os índices puros de ligações para frente, demonstram em valor de produção, o impacto puro da produção total do restante da economia em determinado setor. Enquanto os indices puro de ligações para trás revelam o impacto puro do valor da produção total de determinado setor na economia. A soma dos dois indices revela os setores dinâmicos, ou chaves, de determinada economia. 


\subsection{1 Índices puros, Brasil, 1985}

O Quadro 8.7 apresenta os valores, por setor, dos índices puros de ligações para a frente, para trás e total, referentes a matriz brasileira de 1985, com destaque para os valores acima da média por região. São apresentadas, também, a participação das ligações para frente e para trás, nos valores totais, bem como a classificação destes valores na economia.

É possivel, portanto, identificar os setores chaves da economia brasileira para o período estudado, observando, os índices totais acima da média nacional, e a participação das ligações para frente e para trás, nestes totais. A Figura 8.7, ilustra estas proporções.

\section{Quadro 8.7 - Índices Puros de Ligações - Brasil 1985}

\begin{tabular}{|c|c|c|c|c|c|c|c|c|c|}
\hline & SETORES & Frente & Ordem & Trás & Ordem & Total & Ordem & $(\%)$ Frente & (\%)Trás \\
\hline I & Agropecuária & 19556708 & 1 & 51101.37 & 10 & 246668.45 & 2 & 79.28 & 20.72 \\
\hline 2 & Mineração & 34212.06 & 13 & 6932.66 & 23 & 41144.73 & 21 & 83.15 & 16.85 \\
\hline 3 & Minerais não Metálicos & 45493.48 & 12 & 4895.00 & 25 & 50388.48 & 19 & 90.29 & 9.71 \\
\hline 4 & Metalurgia & 159048.20 & 2 & 27002.11 & 14 & 186050.31 & 6 & 85.49 & 14.51 \\
\hline 5 & Mecânica & 49595.49 & 11 & 39227.14 & 12 & 88822.63 & 12 & 55.84 & 44.16 \\
\hline 6 & Material Elátrico & 23118.74 & 17 & 46876.00 & 11 & 69994.74 & 14 & 33.03 & 66.97 \\
\hline 7 & Material de Transporte & 33617.55 & 14 & 62768.80 & 6 & 96386.35 & 10 & 34.88 & 6512 \\
\hline 8 & Madeira e Mobiliario & 15802.95 & 19 & 26277.66 & 15 & 42080.61 & 20 & 37.55 & 62.45 \\
\hline 9 & Celulose Papel e Gráfica & 50869.53 & 10 & 12428.31 & 21 & 63297.84 & 16 & 80.37 & 19.63 \\
\hline 10 & Indústria da Borracha & 22757.51 & 18 & 2069.90 & 26 & 24827.42 & 25 & 91.66 & 8.34 \\
\hline 11 & Refino de Petróleo & 123229.66 & 3 & 30992.71 & 13 & 15422237 & 7 & 7990 & 20.10 \\
\hline 12 & Quimicos Diversos & 76656.62 & 5 & 24175.35 & 16 & 100831.97 & 9 & 76.02 & 23.98 \\
\hline 13 & Farmacètutica & 4624.93 & 24 & 22606.49 & 18 & 27231.42 & 24 & 16.98 & 83.02 \\
\hline 14 & Plásticos & 28766.13 & 16 & 4997.12 & 24 & 33763.25 & 22 & 85.20 & 14.80 \\
\hline 15 & Indústria Textil & 69144.79 & 8 & 22763.29 & 17 & 91908.08 & II & 75.23 & 24.77 \\
\hline 16 & Vestuário e Calçados & 4293.37 & 25 & $58201 \times 72$ & 9 & 62495.09 & 17 & 6.87 & 93.13 \\
\hline 17 & Indüstria do Café & 1471.76 & 26 & 58438.89 & 7 & 59910.65 & 18 & 2.46 & 97.54 \\
\hline 18 & Abate de Animais & 8349.23 & 22 & 78364.76 & 5 & 86713.99 & 13 & 9.63 & 9037 \\
\hline 19 & Fabricação de Açucar & 8086.68 & 23 & 20902.18 & 19 & 28988.86 & 23 & 27.90 & 72.10 \\
\hline 20 & Outros Produtos Alimentares & 28905.30 & 15 & 208713.6 & 1 & 23761890 & 3 & 12.16 & 87.84 \\
\hline 21 & Indústrias Diversas & 15765.26 & 20 & 7432.84 & 22 & 23198.11 & 26 & 67.96 & 32.04 \\
\hline 22 & Energia, Ag.San..Com. & 53643.88 & 9 & 12658.94 & 20 & 66302.83 & 15 & 8091 & 19.09 \\
\hline 23 & Construção Civil & 14429.20 & 21 & 184886.9 & 3 & 199316.20 & 5 & 7.24 & 92.76 \\
\hline 24 & Comércio & 112382.33 & 4 & 91084.03 & 4 & 203466,37 & 4 & 55.23 & 44.77 \\
\hline 25 & Transportes & 70722.73 & 7 & 58284.72 & 8 & 129007.45 & 8 & 54.82 & 45.18 \\
\hline 26 & Serviços & 74968.09 & 6 & 196818.8 & 2 & 271786.96 & 1 & 53.20 & 46.80 \\
\hline & Média & 50981.64 & & 52342.37 & & 103324.00 & & 53.20 & +6.80 \\
\hline
\end{tabular}

Fonte: dados estimados pelo autor 


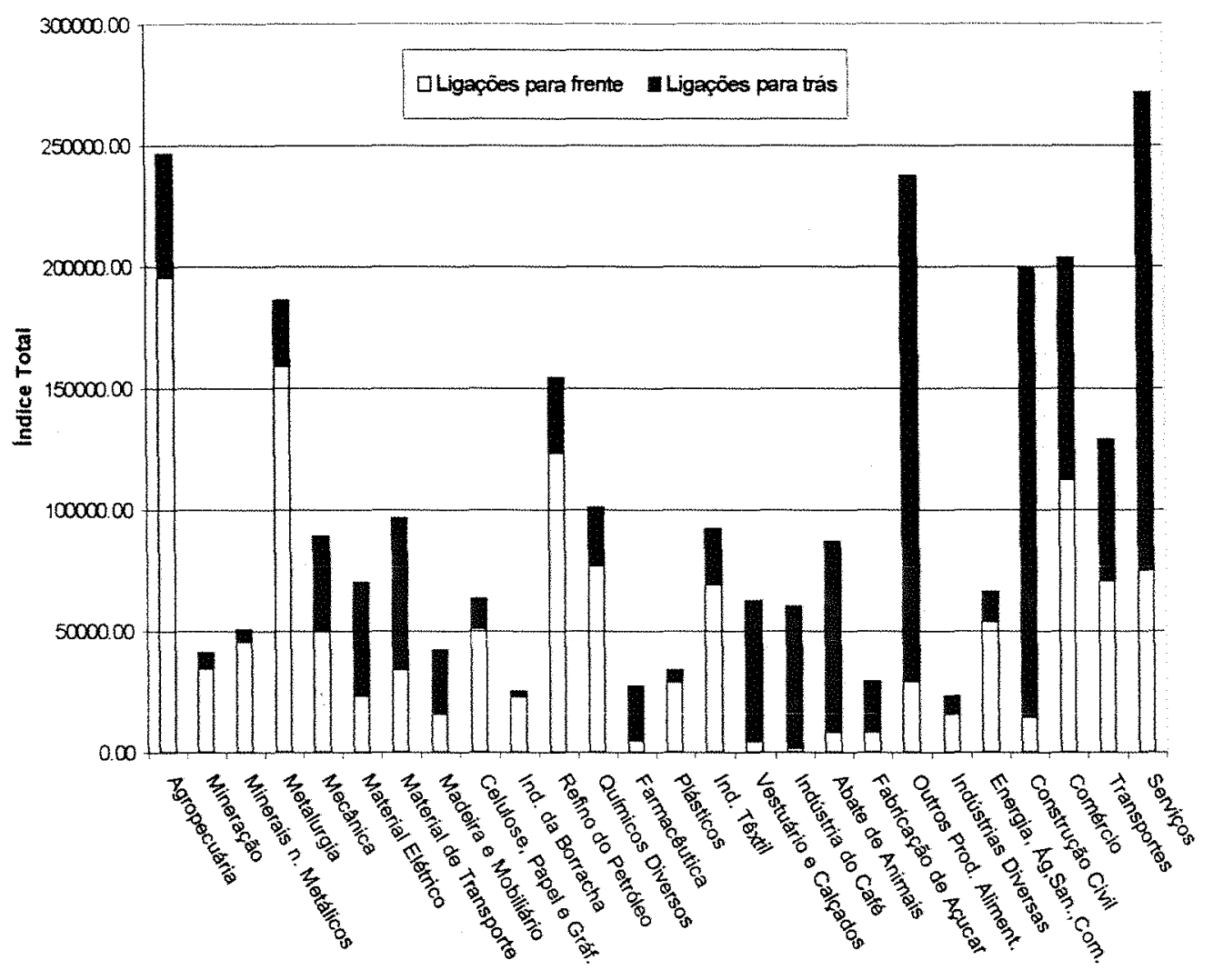

Figura 8.15 - Índices puros de ligações, para frente, trás e total - Brasil 1985

O Brasil apresentou em 1985, em um exame do Quadro 8.7 e Figura 8.15, 09 setores chave;(1) Agropecuária, (4) Metalurgia, (11) Refino de Petróleo, (12) Químicos Diversos, (20) Outros Produtos Alimentícios, (23) Construção Civil, (24) Comércio, (25) Transportes e (26) Serviços. Os destaques em termos de composição para frente ficam com (1) Agropecuária 79\%, (4) Metalurgia 85\%, (11) Refino de Petróleo 80\%, (12) Químicos Diversos 76\%, (15) Indústria Têxtil 75\%, (22) Energia, Água, Saneamento e Comunicação 81\%. E para trás, (20) Outros Produtos Alimentícios 87\% e (23) Construção Civil com 93\%. 


\subsubsection{As regiões brasileiras e os índices puros}

Os Quadros 8.8 e 8.9 apresentam os valores puros de ligações para frente, para trás e total, calculados para a estrutura inter-regional brasileira em 1985, aos moldes do quadro nacional, referido anteriormente.

Quadro 8.8 - Índices Puros de Ligações - Norte e Nordeste - 1985

\begin{tabular}{|c|c|c|c|c|c|c|c|c|c|c|c|}
\hline \multirow{2}{*}{\multicolumn{2}{|c|}{ SETORES }} & \multicolumn{5}{|c|}{ NORTE } & \multicolumn{5}{|c|}{ NORDESTE } \\
\hline & & Frente & Trás & Total & $\begin{array}{c}\%) \\
\text { Fr. }\end{array}$ & $\begin{array}{l}(\%) \\
\mathrm{Tr} .\end{array}$ & Frente & Trás & Total & $\begin{array}{l}(\%) \\
\text { Fr. }\end{array}$ & $\begin{array}{c}(\%) \\
\text { Tr. }\end{array}$ \\
\hline 1 & Agropececuária & 10456 & 3305 & 13761 & 760 & 24.0 & 17628 & 7215 & 24843 & 710 & 29.0 \\
\hline 2 & Mineração & 3767 & 338 & 4105 & 91.8 & 8.2 & 12275 & 12401 & 24676 & 497 & 503 \\
\hline 3 & Miner.Não Metalico & 856 & 122 & 978 & 87.5 & 12.5 & 2730 & 2874 & 5604 & 48.7 & 51.3 \\
\hline 4 & Metalurgia & 655 & 179 & 834 & 78.5 & 21.5 & 5879 & 8030 & 13909 & 423 & 57.7 \\
\hline 5 & Mecànica & 578 & 318 & 896 & 64.5 & 35.5 & 1774 & 2887 & 4661 & 38.1 & 61.9 \\
\hline 6 & Material Elárico & 2090 & 3564 & 5654 & 37.0 & 63.0 & 836 & 1765 & 2601 & 32.1 & 67.9 \\
\hline 7 & Material de Transporte & 876 & 410 & 1286 & 68.1 & 31.9 & 572 & 783 & 1355 & 42.2 & 57.8 \\
\hline 8 & Madeira e Mobiliário & 1242 & 1228 & 2470 & 50.3 & 49.7 & 683 & 1345 & 2028 & 33.7 & 66.3 \\
\hline 9 & Celuiole .Papel e Grafica & 295 & 522 & 817 & 36.1 & 63.9 & 2167 & 2453 & 4620 & 46.9 & 53.1 \\
\hline 10 & Indústria da Borracha & 526 & 25 & 551 & 95.5 & 4.5 & 302 & 391 & 693 & 43.6 & 56.4 \\
\hline 11 & Refino de Petróleo & 470 & 82 & 552 & 85.1 & 14.9 & 16852 & 22155 & 39007 & 432 & 56.8 \\
\hline 12 & Químicos Diversos & 205 & 137 & 342 & 59.9 & 40.1 & 5789 & 8073 & 13862 & 41.8 & 58.2 \\
\hline 13 & Farmacèutica & 11 & 111 & 122 & 9.0 & 91.0 & 201 & 1606 & 1807 & 11.1 & 88.9 \\
\hline 14 & Plásticos & 279 & 57 & 336 & 83.0 & 17.0 & 1353 & 1748 & 3101 & 43.6 & 56.4 \\
\hline 15 & Indústria Têxtil & 293 & 317 & 610 & 48.0 & 52.0 & 5665 & 8421 & 14086 & 402 & 59.8 \\
\hline 16 & Vestuario e Calçados & 14 & 218 & 232 & 6.0 & 94.0 & 280 & 4626 & 4906 & 5.7 & 94.3 \\
\hline 17 & Indúsria do.Café & 108 & 592 & 700 & 15.4 & 84.6 & 109 & 2010 & 2119 & 5.1 & 94.9 \\
\hline 18 & Abate de Animais & 113 & 1062 & 1175 & 9.6 & 90.4 & 266 & 4955 & 5221 & 5.1 & 94.9 \\
\hline 19 & Fabricação de Açucar & 8 & 78 & 86 & 9.3 & 90.7 & 708 & 4363 & 5071 & 14.0 & 86.0 \\
\hline 20 & Outros Produtos Alimentares & 570 & 1805 & 2375 & 24.0 & 76.0 & 2847 & 17788 & 20635 & 13.8 & 86.2 \\
\hline 21 & Ind.ủstria Diversas & 404 & 231 & 635 & 63.6 & 36.4 & 1495 & 1531 & 3026 & 49.4 & 50.6 \\
\hline 22 & Energia Água San. e Comunic. & 1204 & 508 & 1712 & 70.3 & 29.7 & 5461 & 6265 & 11726 & 46.6 & 53.4 \\
\hline 23 & Construção Civil & 662 & 19878 & 20540 & 3.2 & 96.8 & 2018 & 24322 & 26340 & 7.7 & 92.3 \\
\hline 24 & Comércio & 3385 & 2173 & 5558 & 60.9 & 39.1 & 12732 & 16470 & 29202 & 43.6 & 56.4 \\
\hline 25 & Transportes & 2712 & 2164 & 4876 & 55.6 & 44.4 & 3491 & 7670 & 11161 & 31.3 & 68.7 \\
\hline 26 & Serviços & 2790 & 5762 & 8552 & 51.5 & 48.5 & 7015 & 34074 & 41089 & 171 & 82.9 \\
\hline & Média & 1329 & 1737 & 3067 & 51.5 & 48.5 & 4274 & 7931 & 12206 & 35.0 & 65.0 \\
\hline
\end{tabular}

Fonte: dados estimados pelo autor 
Quadro 8.9 - Índices Puros de Ligações - Centro-Oeste, Sudeste e Sul - 1985

\begin{tabular}{|c|c|c|c|c|c|c|c|c|c|c|c|c|c|c|c|c|}
\hline \multirow{2}{*}{\multicolumn{2}{|c|}{ SETORES }} & \multicolumn{5}{|c|}{ CENTRO-OESTE } & \multicolumn{5}{|c|}{ SUDESTE } & \multicolumn{5}{|c|}{ SUL } \\
\hline & & \multirow{2}{*}{\begin{tabular}{|c|}
$\begin{array}{c}\text { Frent } \\
\mathrm{e}\end{array}$ \\
10341 \\
\end{tabular}} & \multirow{2}{*}{\begin{tabular}{r|} 
Trás \\
2456 \\
\end{tabular}} & \multirow{2}{*}{\begin{tabular}{c|} 
Total \\
12797 \\
\end{tabular}} & \multirow{2}{*}{$\begin{array}{l}\%) \\
\text { Fr. } \\
80.8 \\
\end{array}$} & \multirow{2}{*}{\begin{tabular}{c|}
$\%)$ \\
Tr. \\
19.2 \\
\end{tabular}} & \multirow{2}{*}{\begin{tabular}{r|} 
Frente \\
43640 \\
\end{tabular}} & \multirow{2}{*}{$\begin{array}{l}\text { Trás } \\
17466 \\
\end{array}$} & \multirow{2}{*}{\begin{tabular}{c|} 
Total \\
61106 \\
\end{tabular}} & \multirow{2}{*}{\begin{tabular}{c|}
$(\%)$ \\
Fr. \\
71.4 \\
\end{tabular}} & $\begin{array}{l}\%) \\
\text { Tr. } \\
\end{array}$ & Frente & \multirow{2}{*}{\begin{tabular}{r|} 
Trás \\
9457 \\
\end{tabular}} & \multirow{2}{*}{$\begin{array}{l}\text { Total } \\
49158 \\
\end{array}$} & \multirow{2}{*}{\begin{tabular}{c|}
$(\%)$ \\
Fr. \\
80.8 \\
\end{tabular}} & \multirow{2}{*}{$\begin{array}{l}(\%) \\
\mathrm{Tr} . \\
19.2 \\
\end{array}$} \\
\hline 1 & Agropec. & & & & & & & & & & 28.6 & 39701 & & & & \\
\hline 2 & Mineração & 1090 & 1208 & 2298 & 47.4 & 52.6 & 22229 & 26414 & 48643 & 45.7 & 54.3 & 2422 & 398 & 2820 & 85.9 & 14.1 \\
\hline 3 & Miner.N. M. & 64 & 1801 & 365 & 46.5 & 53.5 & 039 & 25257 & 48296 & 47.7 & 52.3 & 5058 & 764 & 822 & 86.9 & 13.1 \\
\hline 4 & Meta & 577 & 804 & 1381 & 41.8 & 58.2 & 97326 & 113784 & 211110 & 46.1 & 53.9 & 7616 & 2731 & 10347 & 73.6 & 26.4 \\
\hline 5 & Meca & 54 & 168 & 222 & 24.3 & 75.7 & & 47678 & 73244 & 34.9 & 651 & 80 & 326 & & 43.0 & 57.0 \\
\hline 6 & Mat I & 97 & 343 & 440 & 22.0 & 78.0 & 02 & 41623 & 56125 & 25.8 & 74.2 & 1505 & 4308 & 5813 & 25.9 & 74.1 \\
\hline 7 & Mat I & 25 & 103 & 128 & 19.5 & 80.5 & 753 & 67575 & 92328 & 26.8 & 73.2 & 1268 & 4335 & 500 & 22.6 & 77.4 \\
\hline 8 & Mad. I & 218 & 574 & 792 & 27.5 & 72.5 & 41 & 91 & 32 & 27.7 & 72.3 & 88 & 6532 & 10960 & 40.4 & 59.6 \\
\hline 9 & Celul.Pap.Gr & 295 & 390 & 685 & 43.1 & 56.9 & 551 & 32860 & 59511 & 44.8 & 55.2 & 6633 & 1717 & 50 & 79.4 & 20.6 \\
\hline 10 & cha & & 56 & 06 & .2 & 52.8 & & & & 48.0 & 52.0 & & 244 & 24 & 86.6 & 13.4 \\
\hline 11 & Ref. P & 525 & 704 & 1229 & 42.7 & 57.3 & 117 & 81745 & 144362 & 43.4 & 56.6 & 12327 & 4096 & 16423 & 751 & 24.9 \\
\hline 12 & Quim & 300 & 447 & 47 & 40.2 & 59.8 & & & & 44.6 & 53.4 & 8450 & 2147 & 10597 & 79.7 & 20.3 \\
\hline 13 & Farn & - & 111 & 137 & 19.0 & 81.0 & 72 & 19739 & 24011 & 17.8 & 82.2 & 197 & 779 & 976 & 20.2 & 79.8 \\
\hline 14 & Plást & 56 & 72 & 128 & 43.8 & 56.3 & 964 & 493 & 157 & 45.6 & 54.4 & 847 & 631 & 478 & 81.9 & 18.1 \\
\hline 15 & Ind. T & 288 & 534 & 822 & 35.0 & 65.0 & 866 & & & 42.4 & 57.6 & 7712 & 2646 & & 74.5 & 25.5 \\
\hline 16 & Vest Calca & 2 & 491 & 519 & 5.4 & 94.6 & 352 & 37676 & 28 & 3.5 & 96.5 & 1405 & 19436 & 20841 & 6.7 & 93.3 \\
\hline 17 & Indt & 4 & 16 & 649 & 5.1 & 94.9 & 60 & & 09 & 4.8 & 95.2 & 148 & 4624 & 4772 & 3.1 & 96.9 \\
\hline 18 & Abat & 202 & 175 & 1377 & 14.7 & 85.3 & 2301 & 03 & 19204 & 12.0 & 88.0 & 3412 & 16521 & 19933 & 17.1 & 82.9 \\
\hline 19 & Fabr. & 66 & 159 & 225 & 29.3 & 70.7 & 347 & 25 & 16872 & 31.7 & 68.3 & 348 & 368 & 716 & 48.6 & 51.4 \\
\hline 20 & Outros Pr. A & 965 & 931 & 896 & 19.7 & 80.3 & 9292 & 55664 & 56 & 14.3 & 85.7 & 14722 & 8420 & 63142 & 233 & 767 \\
\hline 21 & Ind. Diversa & 10 & 20 & 30 & 33.3 & 66.7 & 9029 & 569 & 22598 & 40.0 & 60.0 & 1043 & 753 & 1796 & 58.1 & 41.9 \\
\hline 22 & En. Ag. San. & 2180 & 2587 & 4767 & 45.7 & 543 & 24577 & 30079 & 54656 & 45.0 & 55.0 & 8916 & 2069 & & 81.2 & 18.8 \\
\hline 23 & Constr. Civil & 430 & 5039 & 5469 & 7.9 & 921 & 8166 & 99662 & 107828 & 7.6 & 92,4 & 1693 & 18967 & 20660 & 8.2 & 91.8 \\
\hline 24 & Comercio & 3872 & 7011 & 10883 & 35.6 & 64.4 & 46517 & 83081 & 129598 & 35.9 & 64.1 & 17654 & 13363 & 31017 & 56.9 & 43.1 \\
\hline 25 & Transportes & 2060 & 3582 & 5642 & 36.5 & 63.5 & 29844 & 53817 & 83661 & 357 & 64,3 & 12122 & 8727 & 20849 & 58.1 & 419 \\
\hline 26 & Servicos & 6421 & 12647 & 19068 & 337 & 663 & 51661 & 165775 & 217436 & 23.8 & 762 & 9923 & 26647 & 36570 & 27.1 & 72.9 \\
\hline & Média & 1222 & 1808 & 3030 & 40.3 & 59.71 & 24420 & 45998 & 70419 & 34.7 & 65.3 & 6842 & 7961 & 14804 & 46.2 & 53. \\
\hline
\end{tabular}

Fonte: dados estimados pelo autor

\section{a) Índices puros de ligações - Região Norte}

A região Norte, ver Quadro 8.8 e Figura 8.16, apresenta 07 setores chave, ou seja, valores dos índices puros totais maiores que a média inter-regional, são eles: (1)

Agropecuária, (2) Mineração, (9) Material Elétrico, (23) Construção Civil, (24) Comércio, (25) Transportes e (26) Serviços. O setor de (2) Mineração, tem seu valor quase que representado totalmente, pela parcela para frente, $92 \%$, enquanto o setor (23) Construção Civil, apresenta um indice de ligação puro total, quase que totalmente para trás, 97\%. Em termos de ligações para frente, destacam-se a Agropecuária, com $76 \%$ do total, Comércio $71 \%$, E para as ligações para trás, o setor de Material Elétrico, com $63 \%$ do valor total do indice. 


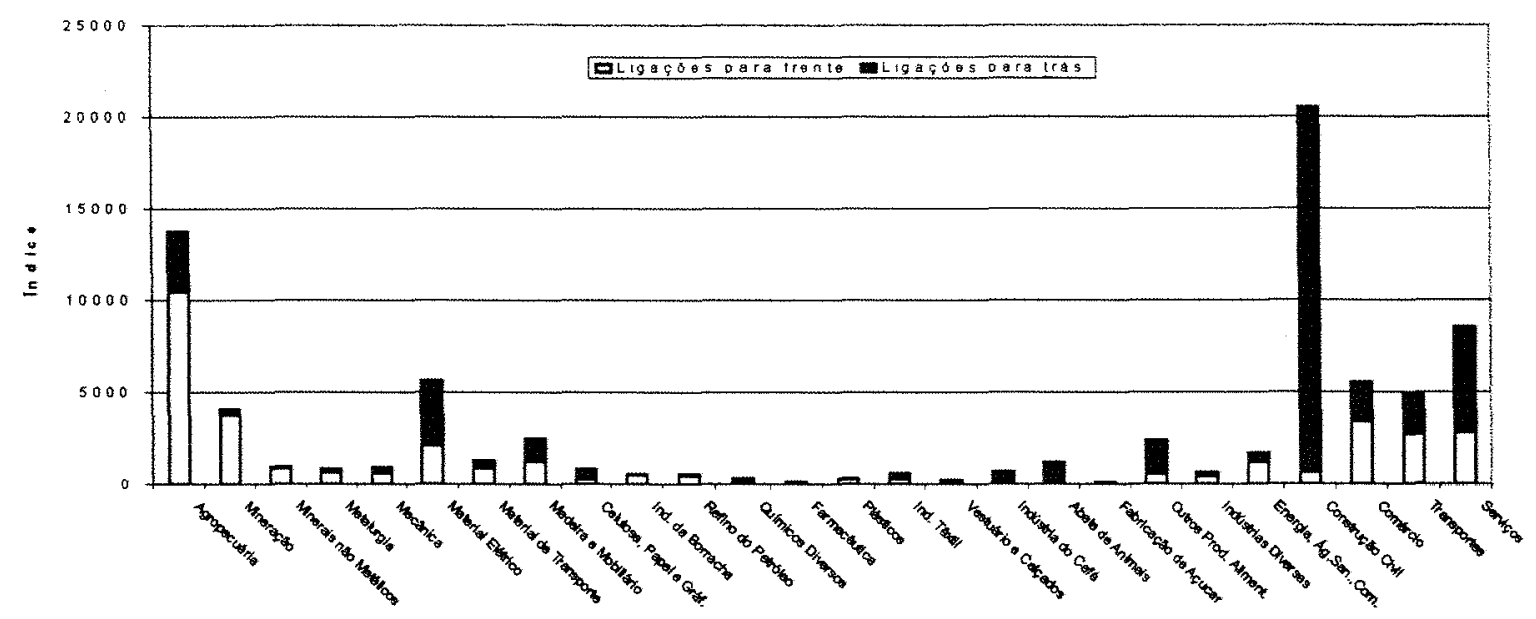

Figura 8.16 - Índices puros de ligações para frente, trás e total, região Norte, 1985

\section{b) Índices puros de ligações - Região Centro-Oeste}

Esta região apresenta 08 setores chave: (1) Agropecuária, (3) Minerais Não Metálicos, (22) Energia, Água, Saneamento e Comunicações, (24) Comércio, (25) Transportes e (26) Serviços. O setor (1) Agropecuária apresenta maior participação para frente, $80 \%$ enquanto todos outros setores concentram-se nas ligações para trás, com destaque para (20) Outros Produtos Alimentares, 80\%, e (23) Construção Civil, com $92 \%$. A média das ligações para trás,é de $60 \%$, ver Figura 8.17 .

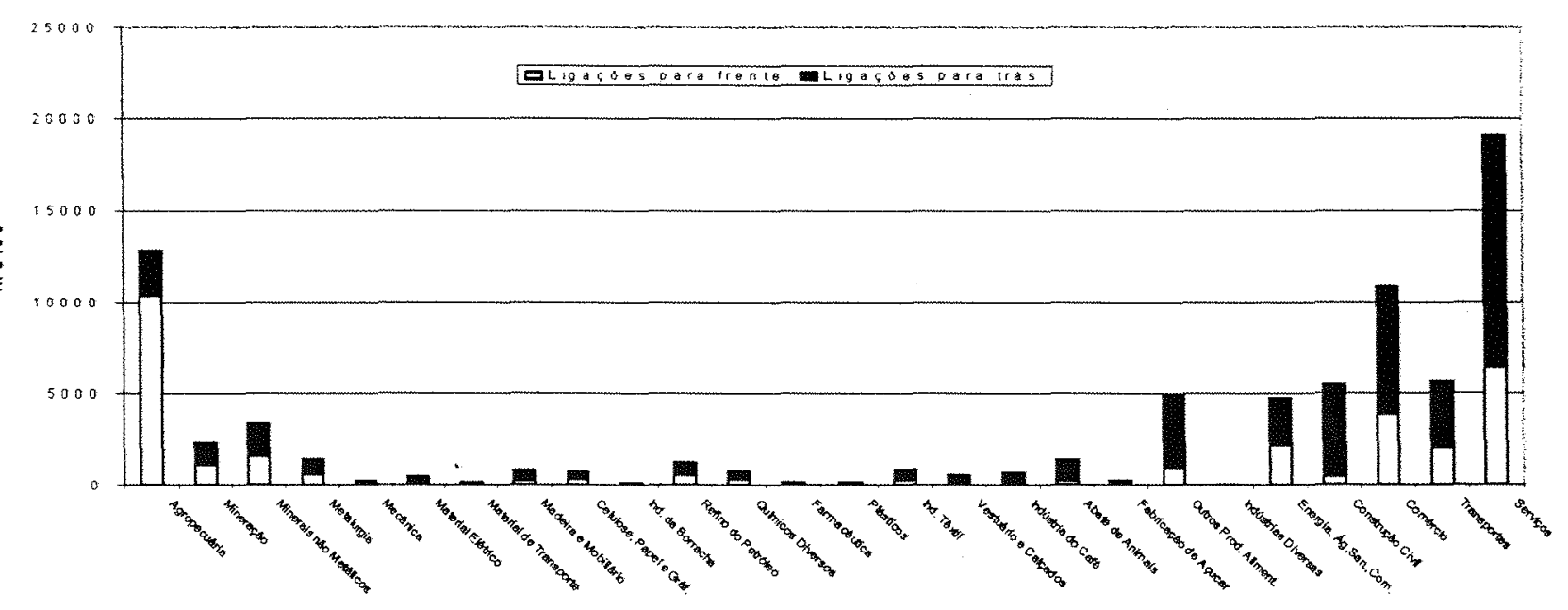

Figura 8.17 - Índices puros de ligações para frente, trás e total, região C-Oeste, 1985 


\section{c) Índices puros de ligações - Região Nordeste}

A região Nordeste, conforme pode ser visto na Figura 8.18, apresenta 10 setores chave, são eles: (1) Agropecuária, (2) Mineração, (4) Metalurgia, (11) Refino de Petróleo, (12) Químicos Diversos, (15) Indústria Têxtil, (20) Ouros Produtos Alimentares, (23) Construção Civil, (24) Comércio e (26) Serviços.

O setor (1) Agropecuário é fortemente ligado para frente $71 \%$, já o setor (20) Outros Produtos Alimentares contém maior participação para trás, $86 \%$, o que ocorre de forma semelhante para Construção (23) Civil e setor (26) Serviços.

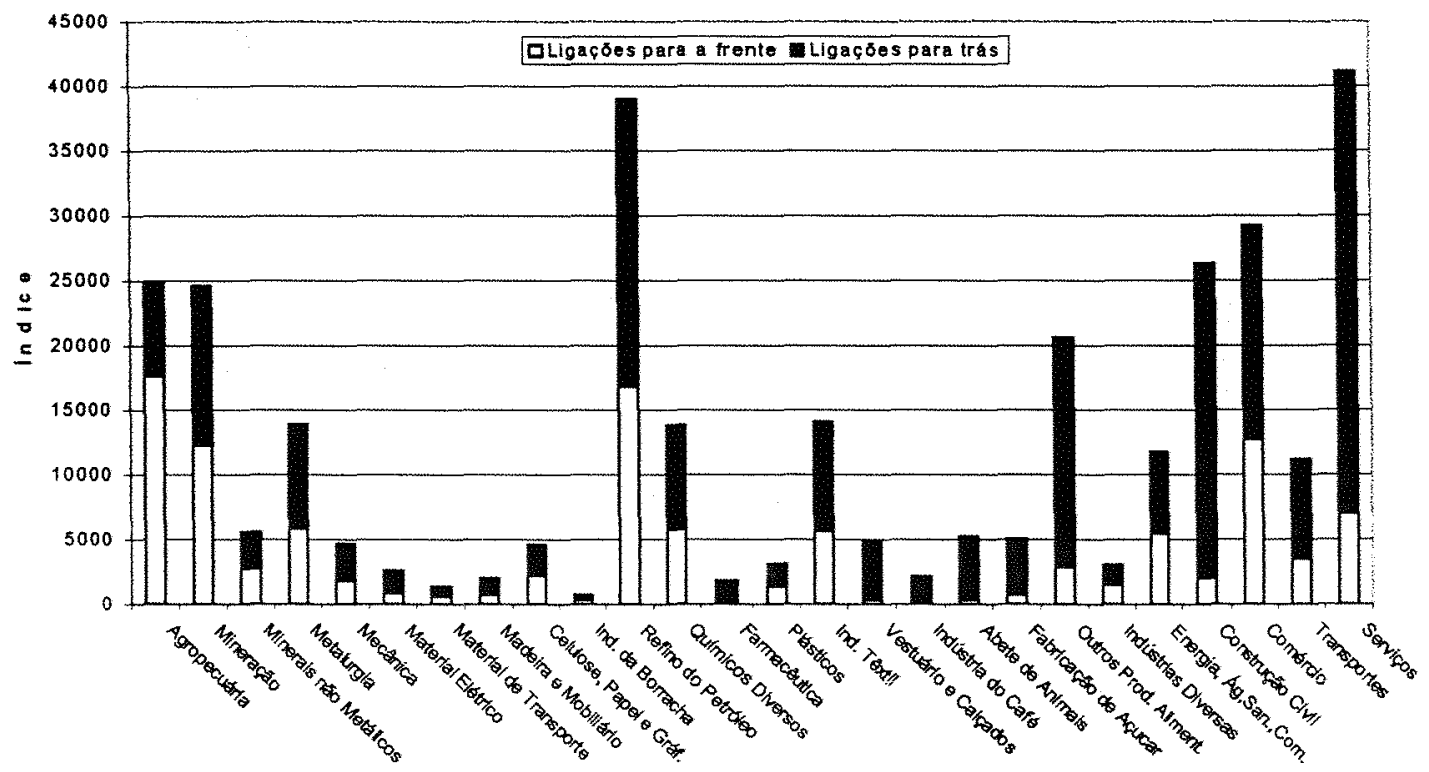

Figura 8.18 - Índices puros de ligações, para frente, para trás e total -Região Nordeste 1985 
d) Índices puros de ligações - região Sudeste

Os setores dinâmicos nesta região são 09 , conforme ilustra a Figura 8.19, (4) Metalurgia, (5) Mecânica, (7) Material de Transporte, (11) Refino de Petróleo, (12) Químicos Diversos, (23) Construção Cívil, (24) Comércio, (25) Transportes e (26) Serviços. Todos estes setores possuem fortes ligações para trás, com destaque para a (23) Construção Civil com 92\% , (26) Serviços 76\% e (7) Material de Transportes, $73 \%$.

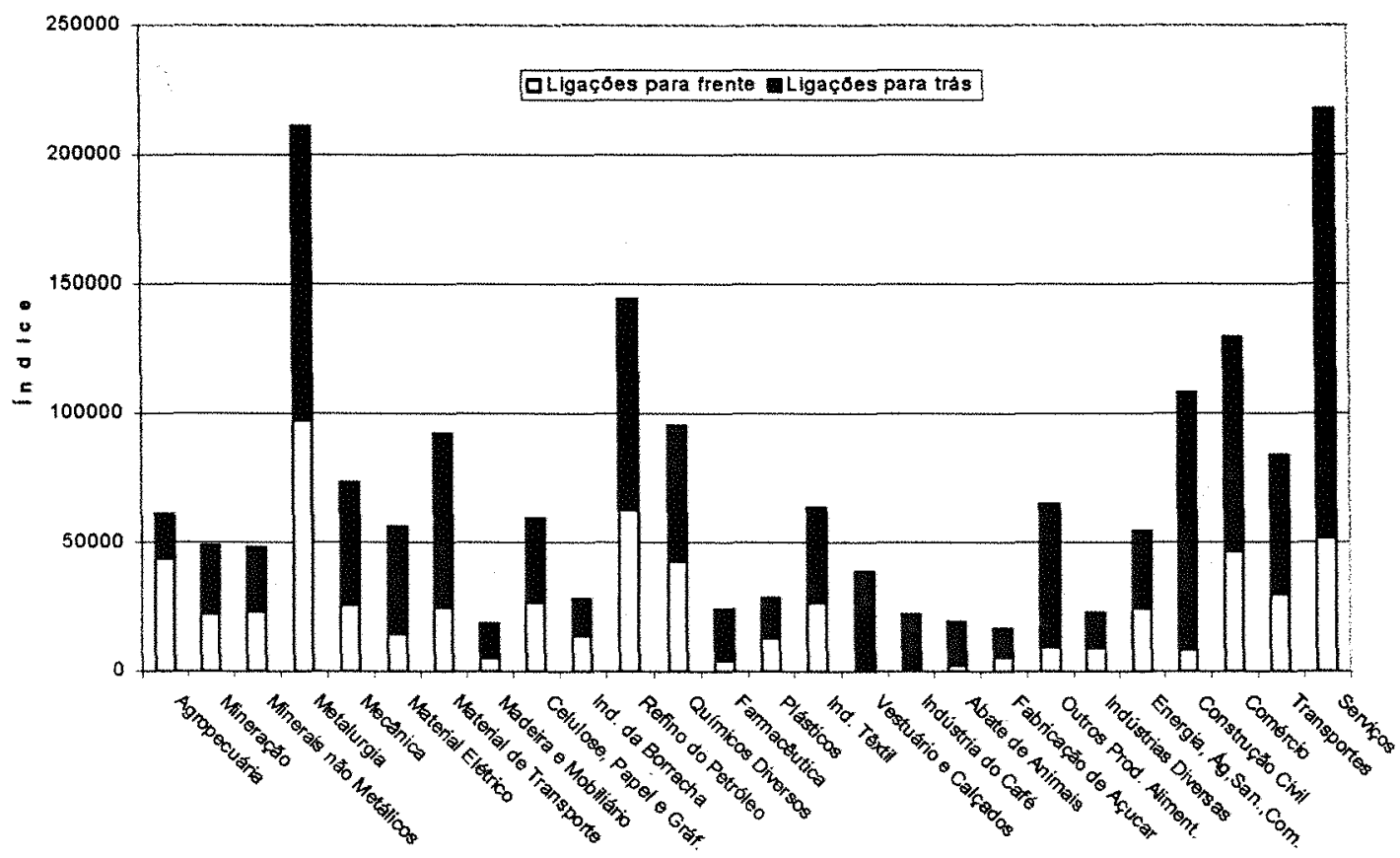

Figura 8.19. - Índices puros de ligações, para frente, para trás e total -Região Sudeste - 1985 


\section{e) Índices puros de ligações - Região Sul}

A região Sul a exemplo do Sudeste, apresenta 09 setores chave, conforme Figura 8.10: (1) Agropecuária, (11) Refino de Petróleo, (16) Vestuário e Calçados, (18) Abate de Animais, (20) Outros Produtos Alimentares, (23) Construção Civil, (24) Comércio, (25) Transportes e (26) Serviços. Os destaques para ligações forte para frente ficam para (1) Agropecuária, $81 \%$ e (11) Refino de Petróleo 75\%. Em termos de ligações para trás (16) Vestuário e Calçados com 93\%, (18) Abate de Animais 83\%, (20) Outros Produtos Alimentares 77\%, (23) Construção Civil 92\% e (26) Serviços73\%.

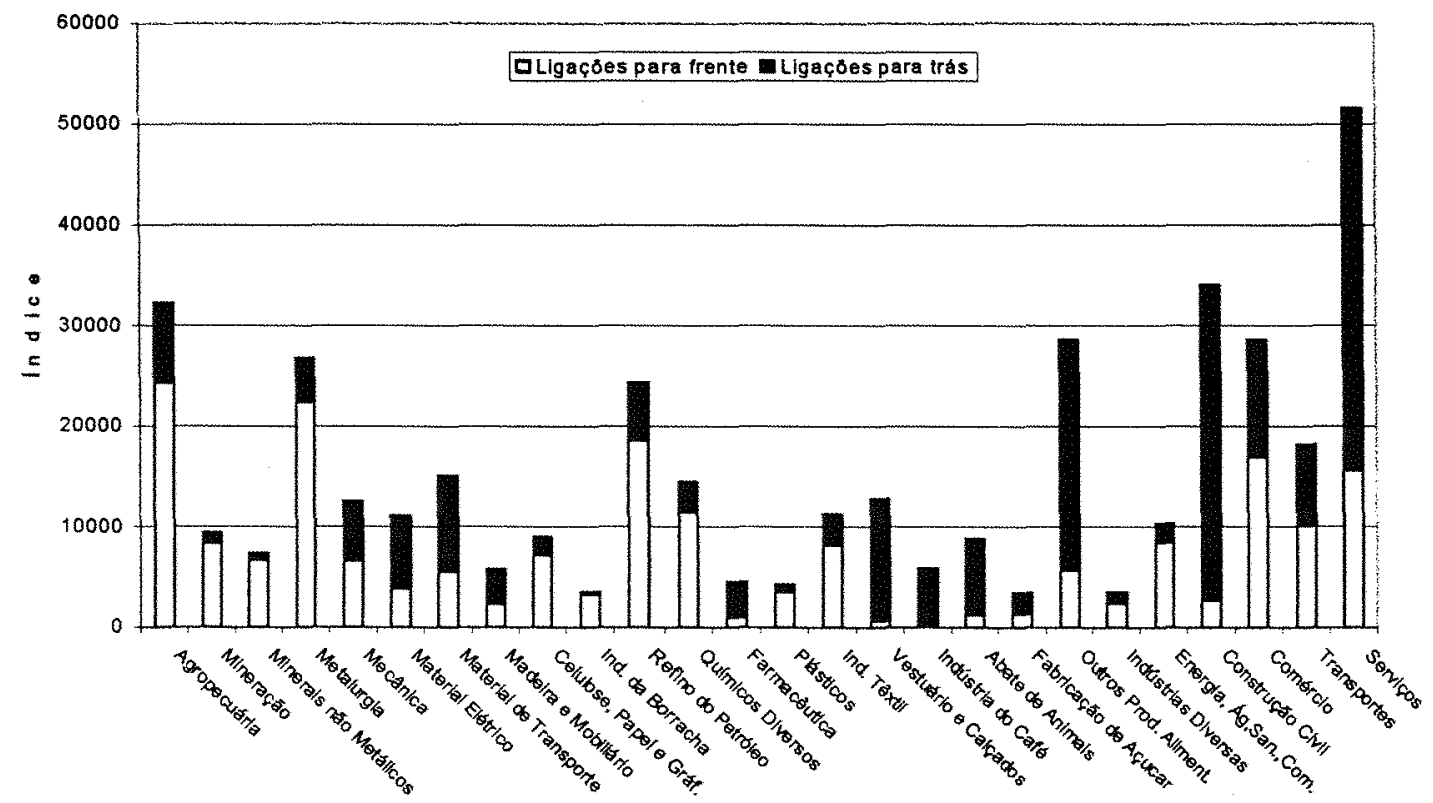

Figura 8.20 - Índices puros de ligações, para frente, para trás e total -região Sul - 1985 


\subsubsection{Consolidação dos índices puros para frente, para trás, Brasil e regiões, 1985}

\section{a) Ligações puras para a frente - consolidadas para as regiões}

A exemplo da análise que se realizou com os índices de Rasmussen e Hirschman, é possível agora efetuar uma comparação entre as ligações do agregado nacional com as regiões.

Os setores (1) Agropecuária, (24) Comércio e (26) Serviços são relevantes, em termos de ligações para frente, para todas as regiões e para o agregado nacional. A seguir, os setores (22) Energia, Água, Saneamento e Comunicação e (25) Comércio, são fortes nas ligações para frente em quase todas as regiões, somente não o sendo para 0 setor (22) da região Norte e (25) para a região Nordeste.

Os setores (4) Metalurgia, (11) Refino de Petróleo, (12) Químicos Diversos e (15) Indústria Têxtil, revelam-se fortes para frente para o agregado nacional e para as regiões, Nordeste, Sudeste e Sul. Enquanto o setor (2) Mineração é relevante neste quesito sómente para as regiões Norte e Nordeste.

Os setores que não aparecem como relevantes para o agregado, mas apresentam-se importantes nas ligações para frente em algumas regiões, são, na Região Sudeste: (5) Mecânica, (7) Material de Transporte, (9) Celulose, Papel e Gráfica. Para a região Centro-Oeste, são: (3) Minerais Não Metálicos e para a região Sul (20), Outros Produtos Alimentares.

\section{b) Ligações puras para trás, consolidadas para as regiões}

Os setores (23) Construção Civil, (24) Comércio, (25) Transportes e (26) Serviços apresentam ligações fortes para trás para o agregado nacional e para todas as regiões brasileiras, no período estudado. Em seguida identifica-se o setor (20) Outros Produtos Alimentares, relevante para quase todas as regiões, sómente não o é para o Norte. 
O setor (1) Agropecuário é relevante também neste quesito para as regiões Norte, Centro-Oeste e Sul, apesar de não se apresentar como tal para o agregado nacional, assim como ocorre com os setores: (4) Metalurgia, (11) Refino de Petróleo e (12) Químicos Diversos, que se revelam importantes nas ligações para a trás nas regiões Nordeste e Sudeste. Os setores (2) Mineração e (15) Indústria Têxtil são fortes, para trás, exclusivamente para a região Nordeste. Da mesma forma, os setores (5) Mecânica é forte só para a região Sudeste, (6) Material Elétrico para região Norte e (22) Energia, Água, Saneamento e Comunicação para o Centro-Oeste .

O setor (18) Abate de Animais é relevante somente para a região Sul, enquanto o setor (7) Material de Transporte o é para a região Sudeste.

\subsubsection{Setores chave, comparação com a média da economia, Brasil e regiões, 1985}

A região Sudeste mostra-se bastante superior, na comparação dos valores registrados dos índices puros de cada região com suas respectivas médias da economia como um todo por setor, ver Quadro 8.10. A região Sudeste apresenta todos seu valores acima da média nacional, para todos os índices puros para frente, trás e total. A região Sul é apenas superior a média nos setores (1) Agropecuária, (8) Madeira e Mobilário, (16) Vestuário e Calçados, (18) Abate de Animais, (20) Outros Produtos Alimentares,

(22) Energia, Água, Saneamento, Comércio e Transportes, e acima da média nacional para frente nos setores Minerais não Metálicos e Mecânica. A região Nordeste, por sua vez, apresenta a Mineração com índice maior que a média nacional, para frente, para trás e total e Fabricação de Açúcar,relevante, para frente e trás 


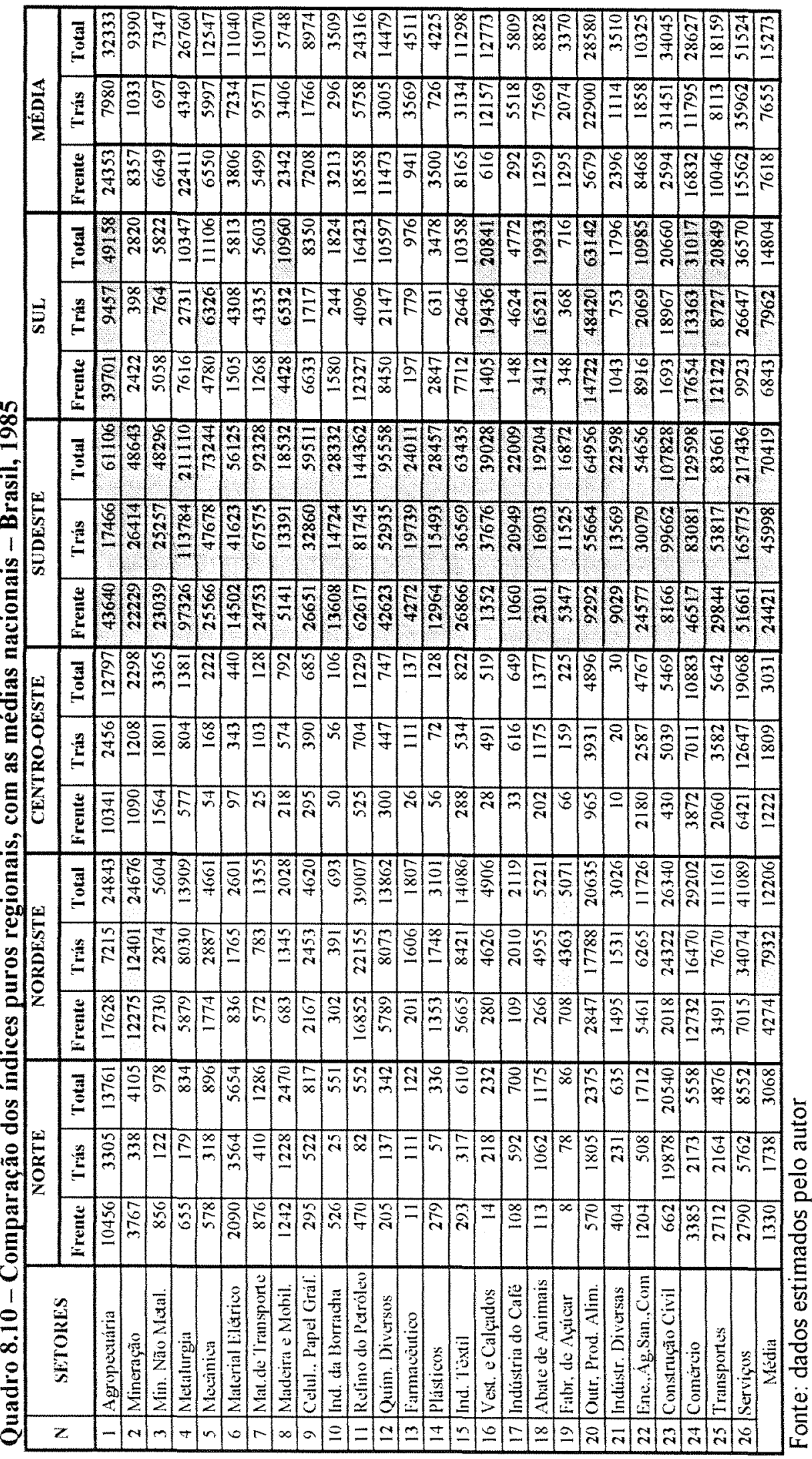




\subsection{Comparação e consolidação dos índices de Rasmussen/Hirschman e Puros}

Antes de apresentarmos a comparação entre os índices de ligações calculados, é fundamental salientar, que os índices de Rasmussen e Hirschman e as os de ligações puras, apresentam resultados, que se complementam, segundo Guilhoto (1995), para os índices de Rasmussen/Hirschman e campo de influência, os setores chave identificam a estrutura interna da economia, independentemente do valor da produção total na economia. Por outro lado, o índice puro considera, além da estrutura interna, o nível de produção de cada setor da economia, o citado autor

"Em resumo, pode-se fazer a seguinte distinção: os enfoques de Rasmussen/Hirschman e de campo de influência identificam o que pode se referir como sendo o potencial dos impactos de mudanças em um dado setor, enquanto que os indices Puro avaliam os efeitos realizados através da consideração do volume de atividade"(Guilhoto, 1995, p.48).

Portanto, não deve-se esperar os mesmos setores chaves, como resultados destas técnicas. O objetivo desta seção é o de apresentar uma breve comparação, Quadro 8.11, e destacar os setores chave, comuns entre estas duas abordagens, através do Quadro 8.12.

Confrontando-se os resultados dos índices de ligações obtidos até aqui, registrados no Quadro 8.11, observa-se que existe uma certa similaridade nos resultados de setores relevantes para frente, em ambos os métodos, revelando, portanto importantes tanto pelo ponto de vista do volume de produção, como de impactos de mudança na economia A diferença se encontra nas ligações para trás, onde os índices puros concentram-se de forma mais intensa nos setores de serviços, enquanto o outro método capta ligações para trás de forma mais acentuada nos setores de transformação, inclusive a indústria alimentícia. Além disto, nesta comparação, percebe-se que os índices puros identificam maior número de setores com ligações fortes para trás. 
Rasmussen/Hirschman, e os índices puros totais acima da média para cada região. Percebe-se o maior número de setores chaves no critério de índices puros, inclusive com ,praticamente, todos os setores relacionados a comércio e serviços sendo considerados dinâmicos em todas as regiões.

Em termos de consolidação nestes critérios mais restritos, identificam-se os setores chave, somente nas regiões Nordeste, Sudeste e Sul.

É interessante perceber que a região Nordeste, mesmo sendo a região que apresenta os mais baixos indicadores sócio-econômicos do Brasil, alguns apresentados no capitulo 2 deste trabalho, apresenta quatro setores chave, Metalurgia, Refino de Petróleo, Químicos Diversos e Indústria Têxtil, ratificando algumas indicações anteriores, inclusive do enfoque via campo de influência. Cabe a região Sul a maior dinâmica do setor de Outros Produtos Alimentares, e a região Sudeste 04 importantes setores: Metalurgia, Mecânica, Material de Transporte e Químicos Diversos, fundamentais para a base do desenvolvimento da economia. A análise consolidada do agregado nacional, aponta apenas para o setor de Metalurgia.

A análise do quanto estes setores chave podem estar relacionados com a economia como um todo, pode ser feita em parte, através do campo de influência, mas seguramente o enfoque GHS, permite a análise da integração destes mercados, através de identificação dos impactos das demandas finais de cada região por setor.

O próximo item desta pesquisa, apresenta alguns resultados da aplicação da proposta do GHS e alguns de seus possíveis desdobramentos 


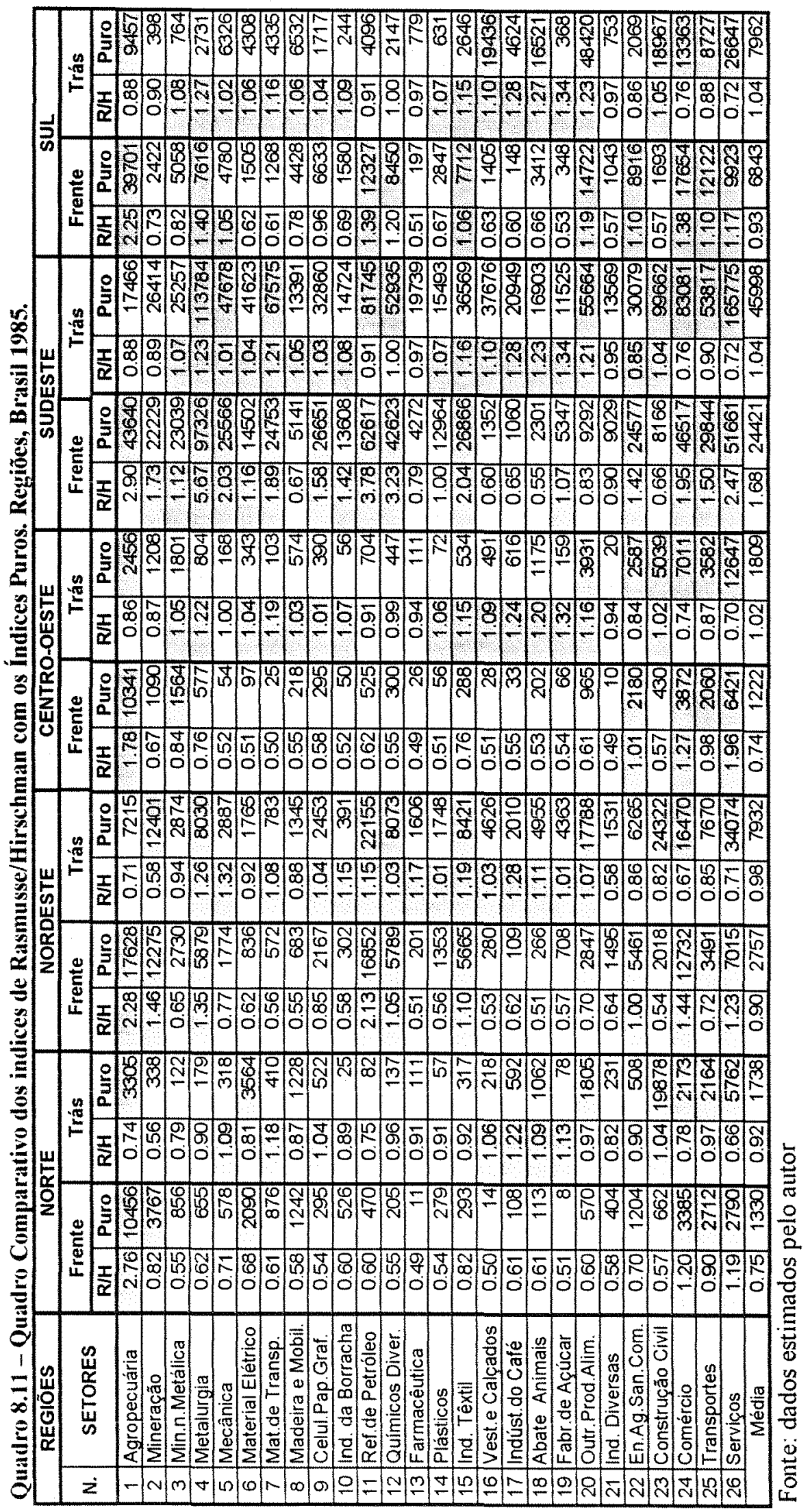


Quadro 8.12 Setores chave consolidados - Rasmussen/Hirschman e Puros.

Brasil e regiões, 1985

\begin{tabular}{|c|c|c|c|c|c|c|c|c|c|c|c|c|c|}
\hline \multirow{2}{*}{\multicolumn{2}{|c|}{ Setores }} & \multicolumn{2}{|c|}{ NORTE } & \multicolumn{2}{|c|}{ NORDESTE } & \multicolumn{2}{|c|}{ C-OESTE } & \multicolumn{2}{|c|}{ SUDESTE } & \multicolumn{2}{|c|}{ SUL } & \multicolumn{2}{|c|}{ BRASIL } \\
\hline & & $\mathrm{R} / \mathrm{H}$ & PURO & $R / \mathbf{H}$ & PURO & $\mathrm{R} / \mathbf{H}$ & PURO & $\mathbf{R} / \mathbf{H}$ & PURO & $\mathrm{R} / \mathbf{H}$ & PURO & $\mathbf{R} / \mathbf{H}$ & PURO \\
\hline 1 & Agropecuária & & $\bar{X}$ & & $\bar{X}$ & & $\mathbf{X}$ & & & & $\bar{X}$ & & $\mathbf{X}$ \\
\hline 2 & Mineraçăo & & $\mathrm{X}$ & & $\mathbf{X}$ & & & & & & & & \\
\hline 3 & Min.n.Metálica & & & & & & $\mathbf{X}$ & $\mathbf{X}$ & & & & & \\
\hline 4 & Metalurgia & & & $\mathbf{X}$ & $\mathbf{X}$ & & & $\bar{X}$ & $\mathbf{X}$ & $\bar{X}$ & & $\mathbf{X}$ & $\mathbf{X}$ \\
\hline 5 & Mecânica & & & & & & & $\bar{X}$ & $\mathbf{X}$ & $\mathbf{X}$ & & & \\
\hline 6 & Material Elétrico & & $\mathbf{X}$ & & & & & $\overline{\mathbf{X}}$ & & & & & \\
\hline 7 & Mat.de Transp. & & & & & & & $\bar{x}$ & $\mathbf{X}$ & & & & \\
\hline 8 & Madeira e Mobil. & & & & & & & & & & & & \\
\hline 9 & Celul.Pap.Graf. & & & & & & & $\mathbf{X}$ & & & & & \\
\hline 10 & Ind. da Borracha & & & & & & & $\bar{X}$ & & & & & \\
\hline 11 & Ref.de Petróleo & & & $\mathbf{X}$ & $\bar{X}$ & & & & $\mathbf{X}$ & & $\mathrm{X}$ & & $\mathbf{X}$ \\
\hline 12 & Quimicos Diver. & & & $\mathbf{X}$ & $\mathbf{X}$ & & & $\mathbf{X}$ & $\mathbf{X}$ & $x$ & & & $X$ \\
\hline 13 & Farmacèutica & & & & & & & & & & & & \\
\hline 14 & Plásticos & & & & & & & & & & & & \\
\hline 15 & Ind. Tèxtil & & & $\mathbf{X}$ & $\mathbf{X}$ & & & $\mathrm{X}$ & & $\mathbf{X}$ & & $\mathbf{X}$ & \\
\hline 16 & Vest.e Calçados & & & & & & & & & & $\bar{X}$ & & \\
\hline 17 & Indust.do Café & & & & & & & & & & & & \\
\hline 18 & Abate Animais & & & & & & & & & & $\bar{X}$ & & \\
\hline 19 & Fabr.de Açicar & & & & & & & $\mathbf{X}$ & & & & & \\
\hline 20 & Outr.Prod.Alim. & & & & $\mathbf{X}$ & & $\bar{x}$ & & & $\mathbf{X}$ & $\bar{X}$ & & $\mathbf{X}$ \\
\hline 21 & Ind. Diversas & & & & & & & & & & & & \\
\hline 22 & En.Ag San.Com. & & & & & & $\mathrm{X}$ & & & & & & \\
\hline 23 & Construção Civil & & $\bar{X}$ & & $\mathbf{X}$ & & $\mathbf{X}$ & & $\mathbf{X}$ & & $\bar{X}$ & & $\mathbf{X}$ \\
\hline 24 & Comercio & & $\bar{X}$ & & $\bar{x}$ & & $\mathbf{X}$ & & $\mathrm{X}$ & & $\mathbf{X}$ & & $\mathbf{X}$ \\
\hline 25 & Transportes & & $\mathbf{X}$ & & & & $\mathrm{X}$ & & $\mathbf{X}$ & & $\mathrm{X}$ & & $\mathbf{X}$ \\
\hline 26 & Serviços & & $\bar{x}$ & & $\bar{X}$ & & $\mathrm{X}$ & & $\bar{X}$ & & $\mathrm{X}$ & & $\bar{X}$ \\
\hline
\end{tabular}

Fonte: dados estimados pelo autor 
8. 5 Interação entre as regiões brasileiras e impactos da demanda final sobre a produção: uma aplicação do método GHS.

A proposta do método GHS, apresentada no capítulo 7, consiste na identificação e dimensionamento das interações entre regiões, no sentido de determinar o nível de integração em determinados sistemas econômico e evidenciar a dependência dos mercados.

A aplicação do método GHS possibilitou, neste trabalho, além da consecução dos propósitos traçados acima, a realização de desagregações intersetoriais e interregionais relativas às produções induzidas pelas demandas finais, aspectos fundamentais para o propósito desta pesquisa.

Inicialmente, esta seção apresenta e discute o quadro agregado da integração inter-regional brasileira conforme método original GHS e, posteriormente, seus desdobramentos.

\subsubsection{Interação entre as regiões brasileiras. Enfoque região $\mathrm{x}$ resto do Brasil}

A análise da interação entre as regiões brasileiras, é realizada através dos resultados da aplicação do método GHS, Tabela 8.1, primeiramente e complementada pela abordagem sobre a participação das produções das regiões na produção nacional, Tabela 8.2.

\section{a) Análise pelo método GHS}

Os resultados apresentados na Tabela 8.1 resultantes da aplicação das equações (7.25) e (7.26), decompõem a produção de cada região quanto à parcela induzida pela sua própria demanda final e à gerada pelas demais regiões do sistema econômico, aqui denominada demanda final do resto do Brasil.

Observar que os totais da produção das regiões, apresentados na tabela 8.1, referem-se aos mesmos valores da produção registrados na matriz inter-regional do Brasil, Tabela 7.1. 
Tabela 8.1 - Composição da produção das regiões brasileiras segundo indução da demanda final própria e do resto do Brasil, em bilhões de cruzeiros de 1985

\begin{tabular}{|c|c|c|c|c|c|}
\hline \multirow{3}{*}{ Região (j) } & \multicolumn{4}{|c|}{ Producão induzida pela demanda final } & \multirow{3}{*}{$\begin{array}{c}\text { Total } \\
\text { Produção }\end{array}$} \\
\hline & \multicolumn{2}{|c|}{ da região (j) } & \multicolumn{2}{|c|}{ do resto Brasil } & \\
\hline & Valor & $(\%)$ & Valor & $(\%)$ & \\
\hline Norte & 92.433 & 82,47 & 19.648 & 17,53 & 112.081 \\
\hline Nordeste & 290.527 & 87,22 & 42.580 & 12,78 & 333.107 \\
\hline Centro-Oeste & 63.956 & 76,64 & 19.489 & 23,36 & 83.445 \\
\hline Sudeste & 1.485 .865 & 91,71 & 134.350 & 8,29 & 1.620 .215 \\
\hline Sul & 404.816 & 87,71 & 56.732 & 12,29 & 461.548 \\
\hline
\end{tabular}

Fonte: dados estimados pelo autor

A análise dos resultados, apresentados na Tabela 8.1, permite classificar as regiões de acordo com seu grau de dependência no sistema produtivo. Neste sentido, a região Sudeste apresenta cerca de $92 \%$ de sua produção induzida pela sua demanda final e o restante, $8 \%$, pela demanda final do resto da economia, ou seja, pelas demandas finais das outras regiões brasileiras. Isto se explica, em grande parte, pela forte dinâmica interna da região, ratificada pelas análises dos índices de ligações e setores chaves e, principalmente, através do campo de influência, já apresentadas no presente trabalho.

As regiões Sul e Nordeste demonstram uma estrutura razoavelmente dinâmica, em consonância com os resultados até aqui verificados, com cerca de $88 \%$ de suas produções induzidas pelas suas demandas finais, seguidas pelas região Norte, com $82 \%$, e, bem abaixo, a região Centro-Oeste, com cerca de $23 \%$ de sua produção gerada pelas demandas finais de outras regiões, o que revela um maior grau de dependência econômica desta Porém estas inferências requerem uma análise e avaliação mais detidas, principalmente quanto aos desdobramentos em termos de grau de participação das regiões e setores, o que é realizado na seção seguinte.

\section{b) Participações das produções das regiões na produção nacional}

Um aspecto fundamental, que não pode deixar de ser evidenciado, refere-se à participação destas produções regionais na produção total nacional,. Conforme as porcentagens constantes da tabela 8.2 , a região Sudeste participa com $62 \%$ do valor da 
produção total do Brasil, bem acima do Sul e Nordeste, as mais próxima regiões concorrentes com cerca de $18 \%$ e $13 \%$ respectivamente, enquanto o Norte, com aproximadamente $4 \%$ e Centro-Oeste $3 \%$, situam-se em um patamar bem abaixo.

Tabela 8.2 -Participação da produção das regiões brasileiras segundo indução da demanda final própria e do resto do Brasil, no total de produção do Brasil, em bilhões de cruzeiros de 1985

\begin{tabular}{|c|c|c|c|c|c|c|}
\hline \multirow{3}{*}{ Região (j) } & \multicolumn{4}{|c|}{ Producão induzida nela Demanda Final } & \multirow{2}{*}{\multicolumn{2}{|c|}{$\begin{array}{c}\text { Produção Total do } \\
\text { Brasil }\end{array}$}} \\
\hline & \multicolumn{2}{|c|}{ da região (i) } & \multicolumn{2}{|c|}{ Do resto do Brasil } & & \\
\hline & Valor & (\%)Total Brasil & Valor & $(\%)$ Total Brasil & Valor & $(\%)$ \\
\hline Norte & \multicolumn{2}{|c|}{92.433} & \multicolumn{2}{|c|}{19.648} & 112.081 & 4,29 \\
\hline Nordeste & \multicolumn{2}{|c|}{290.527} & \multicolumn{2}{|c|}{42.580} & 333.107 & 12,76 \\
\hline Centro-Oeste & \multicolumn{2}{|c|}{63.956} & \multicolumn{2}{|c|}{19.489} & 83.445 & 3,20 \\
\hline Sudeste & \multicolumn{2}{|c|}{1.485 .865} & \multicolumn{2}{|c|}{134.350} & 1.620 .215 & 62,07 \\
\hline Sul & \multicolumn{2}{|c|}{404.816} & \multicolumn{2}{|c|}{56.732} & 461.548 & 17,68 \\
\hline Total & \multicolumn{2}{|c|}{2.337 .597} & \multicolumn{2}{|c|}{272.799} & 2.610 .396 & 100,00 \\
\hline
\end{tabular}

Fonte: dados estimados pelo autor

A participação da região Sudeste na produção induzida por outras regiões, demonstrada anteriormente, representa, ainda conforme as informações da Tabela 8.2, cerca de $5,2 \%$ da produção total nacional, o maior valor dentre as regiões. A região Sul apresenta também uma razoável participação, 2,17\%. A regiões Norte e Centro-Oeste registram proporções pequenas, cada uma com $0,75 \%$ da produção nacional.

Cabe salientar, portanto, que a análise aqui realizada refere-se ao grau de interação das regiões na economia e que não se deve perder de vista a participação relativa das regiões na produção nacional, como o caso da região Sudeste. A parcela da sua produção induzida pelo resto do Brasil, representa apenas $8 \%$ de sua produção total, porém este valor representa $5 \%$ da produção total da economia, a maior participação dentre as regiões, valor, inclusive, maior do que a produção total da região Norte e da região Centro-Oeste, comparando-as individualmente. 


\subsubsection{Interação regional. Desagregações}

A demanda final para cada região requer e/ou ou induz volumes de produção que se distribuem pela economia obedecendo a padrões produtivos, as chamadas estruturas econômicas intersetoriais e inter-regionais, ou seja, as demandas finais desencadeiam efeitos diretos e indiretos, induzindo produções diferenciadas conforme estes padrões. O desdobramento do modelo GHS permitiu a realização de algumas desagregações importantes.

\subsubsection{Desagregações regionais das produções induzidas pelas demandas finais}

A Tabela 8.3 apresenta nas linhas, a produção de cada região brasileira e registra, nas colunas, qual a região que deu origem a estas produções. Estes resultados desagregam, portanto, a produção das regiões, pela origem das demandas finais. Notar, que os valores dos totais das produções das regiões, são próximos aos registrados na Tabela 8.1, as diferenças representam arredondamentos.

Tabela 8.3 - Produção das regiões brasileiras induzidas pela demandas finais das regiões, em bilhões de cruzeiros de 1985

\begin{tabular}{lrrrrrrrrrrrr}
\hline Regióes & Norte & \multicolumn{1}{c}{$\%$} & \multicolumn{1}{c}{ Nordeste } & $\%$ & \multicolumn{1}{c}{ C-Oeste } & $\%$ & Sudeste & $\%$ & \multicolumn{1}{c}{ Sul } & $\%$ & Total & $\%$ \\
\hline Norte & 92.432 & 82,48 & 807 & 0,72 & 548 & 0,49 & 12.461 & 10.12 & 5.820 & 5.19 & 112.068 & 100,00 \\
Nordeste & 2.512 & 0,75 & 290.529 & 87,22 & 1.006 & 0,30 & 29.416 & 8.83 & 9.628 & 2,89 & 333.091 & 100,00 \\
C-Oeste & 637 & 0,76 & 1.069 & 1,28 & 63.961 & 76,67 & 15.118 & 18,12 & 2.642 & 3,17 & 83.427 & 100,00 \\
Sudeste & 23.261 & 1,44 & 33.559 & 2,07 & 9.837 & 0,61 & 1.485 .860 & 91,71 & 67.687 & 4,18 & 1.620 .204 & 100,00 \\
Sul & 3.801 & 0,82 & 8.428 & 1,83 & 1.829 & 0,40 & 42.662 & 9,24 & 404.811 & 87,71 & 461.531 & 100,00 \\
\hline Total & 122.643 & 4,70 & 334.392 & 12,81 & 77.181 & 2,96 & 1.585 .517 & 60,70 & 490.588 & 18.79 & 2.610 .321 & 100.00 \\
\hline
\end{tabular}

Fonte: dados estimados pelo autor

Como exemplo, seguindo a primeira linha, a região Norte produziu 92.432 bilhões de cruzeiros em 1985, induzidos pela sua própria demanda final, 807 milhões pela demanda final do Nordeste, 548 bilhões pela do Centro-Oeste e assim por diante. 
Nota-se, que a região Sudeste apresenta a maior participação nas demandas finais de outras regiões, seguida pela região Sul e Nordeste.

\subsubsection{Desagregações setoriais das produções induzidas pelas demandas finais}

Os resultados obtidos, conforme os procedimentos descritos na seção anterior, permitem calcular a participação de cada setor nas produções das regiões, produções estas classificadas por região indutora. Utilizando-se do mesmo exemplo realizado anteriormente, conforme a Tabela 8.3 , foi possível detectar qual a participação da Agropecuária, Mineração, etc., no valor de 92.432 bilhões de cruzeiros em 1985, induzidos pela sua própria demanda final, da mesma forma para os 807 milhões, induzidos pela demanda final do Nordeste e, assim por diante, conforme as regiões indutoras.

Estas participações estão organizadas em figuras, construidas com as porcentagens iguais ou maiores que $3 \%$, por convenção. A seguir, são apresentadas e discutidas estas figuras, inicialmente considerando os resultados das induções das próprias regiões, e a seguir, aqueles induzidos externamente à região considerada, ou seja pelas outras regiões.

\subsection{Impactos da demanda final própria}

Nesta seção, apresenta-se a distribuição da produção das regiões conforme suas próprias demandas finais. O propósito é o de identificar a característica da estrutura produtiva. de cada uma delas.

A figura 8.21 ilustra o impacto da demanda final de cada região, sobre seus setores produtivos. Como exemplo, tomando a primeira barra, da referida figura, ela indica que a produção do setor Agropecuário da região Norte, representa $13 \%$ do total da produção induzida pela região Norte, por sua vez o setor de Mineração, $3 \%$, o de Material Elétrico $9 \%$, e assim por diante. 
De forma geral, analisando a Figura 8.21 , os setores de Agropecuária, Construção Civil, Comércio, Transporte e Serviços são aqueles que apresentam a maior parcela na produção, em todas as demandas finais próprias das regiões. Observa-se, que dentre as regiões, a Sudeste apresenta a menor indução no setor de Agropecuária, enquanto a região Sul, registra a menor participação no setor de Serviços.

As regiões Sul, Sudeste e Nordeste apresentam participação, semelhante na produção de Refino de Petróleo, em média 5\% de suas demandas finais.

Os setor de Outros Produtos Alimentares, também é induzido, por quase todas as regiões, exceto região Norte. A participação mais relevante é a da região Sul, com 13\% de produção para sua demanda final.

É interessante observar, nesta análise comparada, que as regiões Sul e Sudeste, destacam-se, pela indução dos seu setores de Metalurgia, Mecânica e Indústria Têxtil. Enquanto, particularmente, os setores de Vestuário e Calçados e Abate de Animais são característicos da demanda final da região Sul, e os setores de Material de Transporte e Químicos Diversos, o são para a região Sudeste.

Por fim, pode-se destacar o setor de material elétrico, com importante parcela na demanda final da região Norte. 


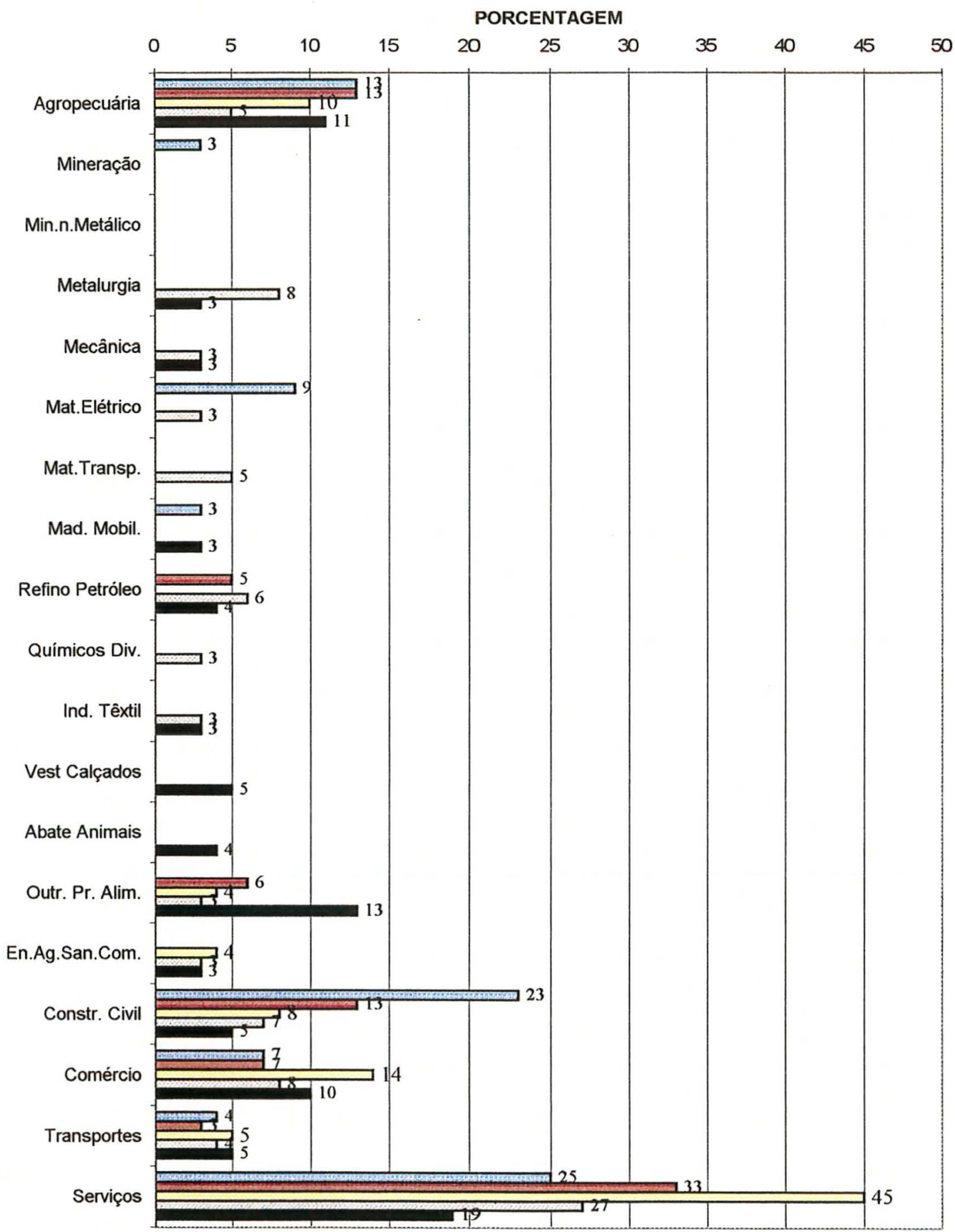

GNORTE ENORDESTE QC-OESTE QSUDESTE QSUL

Figura 8.21 - Produção, por região e setor, induzida pela demanda final própria, em (\%), Brasil, 1985 


\subsection{Impactos da demanda de outras regiões}

Discutem-se, nesta seção, os impactos na produção, por setor, de cada região, causados pela indução externa, ou seja, induzidos por outras regiões. Da mesma forma, que a análise efetuada para a demanda própria, foram geradas figuras, agora organizadas para cada uma das regiões estudadas.

As figuras ilustram, de que forma a produção das regiões, induzidas externamente, se distribuem pelos setores, indicando, inclusive, a região indutora por setor.

Como exemplo, através da Figura 8.22 , identifica-se como a produção da região Norte, induzida por outras regiões, se distribue nos setores de sua economia. A primeira barra da referida figura, indica, que $40 \%$ da demanda final da região Nordeste sobre a região Norte, é exercida no setor Agropecuário, 17\% no de Mineração, 6\% no setor de Mecânica, 3\%, sobre o setor de Transportes e assim por diante. Deve-se observar, que estas porcentagens somadas, por região indutora, não chegam a $100 \%$, em virtude de considerar-se, sómente, aquelas iguais ou maiores que $3 \%$.

\section{a) Região Norte}

As demandas finais de outras regiões, basicamente, induzem os setores da Agropecuária e Mineração da região Norte, Figura 8.22, representando cerca de $60 \%$ de suas demandas. A região Sul aciona em maior grau, a produção da Agropecuária nortista, $57 \%$ de sua demanda total para com a região.

Em um segundo plano, o setor de Material Elétrico, onde se agregam os eletrônicos, apresenta-se como um segmento importante na demanda final de outras regiões, com destaque para a região Sudeste, com $13 \%$ de participação de sua demanda total..

Os setores Comércio, Transportes e Serviços são acionados de maneira mais ou menos regular entre as regiões, em média com $5 \%$ de suas demandas finais. 
O setor de Madeira e Mobiliário, representa cerca de $4 \%$ da demanda do Centro-Oeste, enquanto os setores de Mecânica, Industria da Borracha e Indústria Diversas, são induzidos, aapenas, pela região Nordeste, fato interessante na análise, pois os únicos setores pertencentes ao setor secundário da região Norte são induzidos pela região vizinha. $\mathrm{O}$ que é também identificado na discussão da região Nordeste, a seguir.

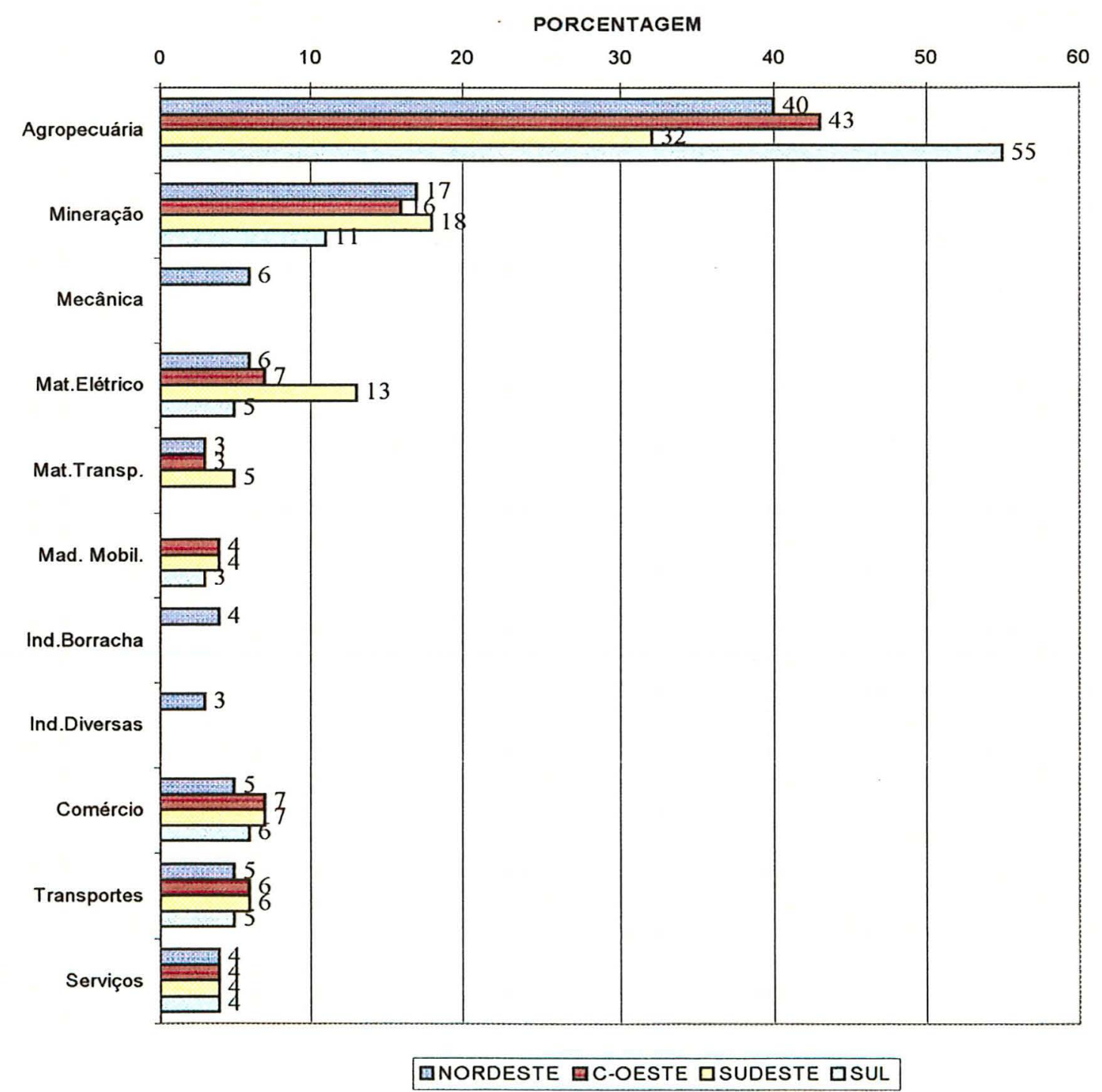

Figura 8.22 - Produção setorial da região Norte, induzida pela demanda final de outras regiões em (\%), Brasil, 1985 


\section{b) Região Nordeste}

Cerca da metade das demandas finais de outras regiões para com a produção no Nordeste é realizada nos setores de Refino de Petróleo e Mineração, Figura 8.23.

A estrutura econômica do Nordeste mostra-se diversificada, incorporando um setor importante de transformação, a Metalurgia , com destaque para a participação da Região Norte, com $22 \%$ de sua demanda final.

O setor de Químicos Diversos, apresenta relativa dinâmica na região, com cerca de $6 \%$ das demandas finais de todas outras regiões.

Os setores de Comércio e Serviços relacionam-se com três regiões o Norte, Sudeste e Sul.

A região Norte é a única que apresenta importante grau de demanda pelos setores de Mecânica, Material Elétrico, e de Transporte, assim como pela indústria de Plásticos do Nordeste, sugerindo a existência, em 1985, de um pólo de desenvolvimento na região, conforme se identificou na análise sobre a região Norte. 


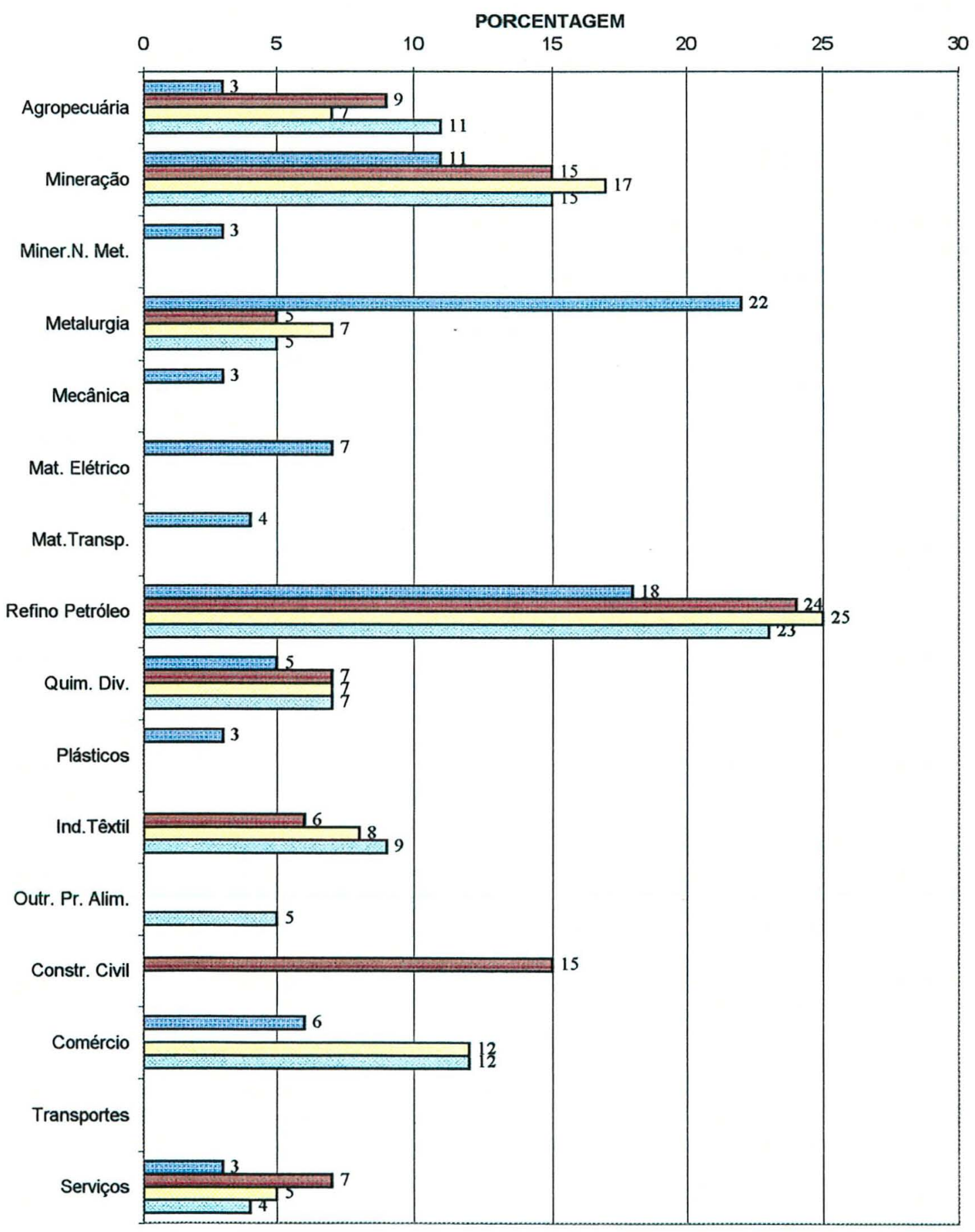

INORTE IC-OESTE QSUDESTE QSUL

Figura 8.23 - Produção setorial da região Nordeste, induzida pela demanda final de outras regiões em (\%), Brasil, 1985 


\section{c) Centro-Oeste}

A região Centro-Oeste apresenta 9 setores sendo acionados pelas demandas finais de outras regiões, o que se verifica através da figura 8.24.

O destaque é o setor Agropecuário, importante na composição da demanda final do Sudeste em 53\% e 33\% para a região Nordeste, a seguir o setor de Serviços, mostra-se relevante para todas as outras regiões, com destaque para a região Sul, com $40 \%$ de sua demanda final.

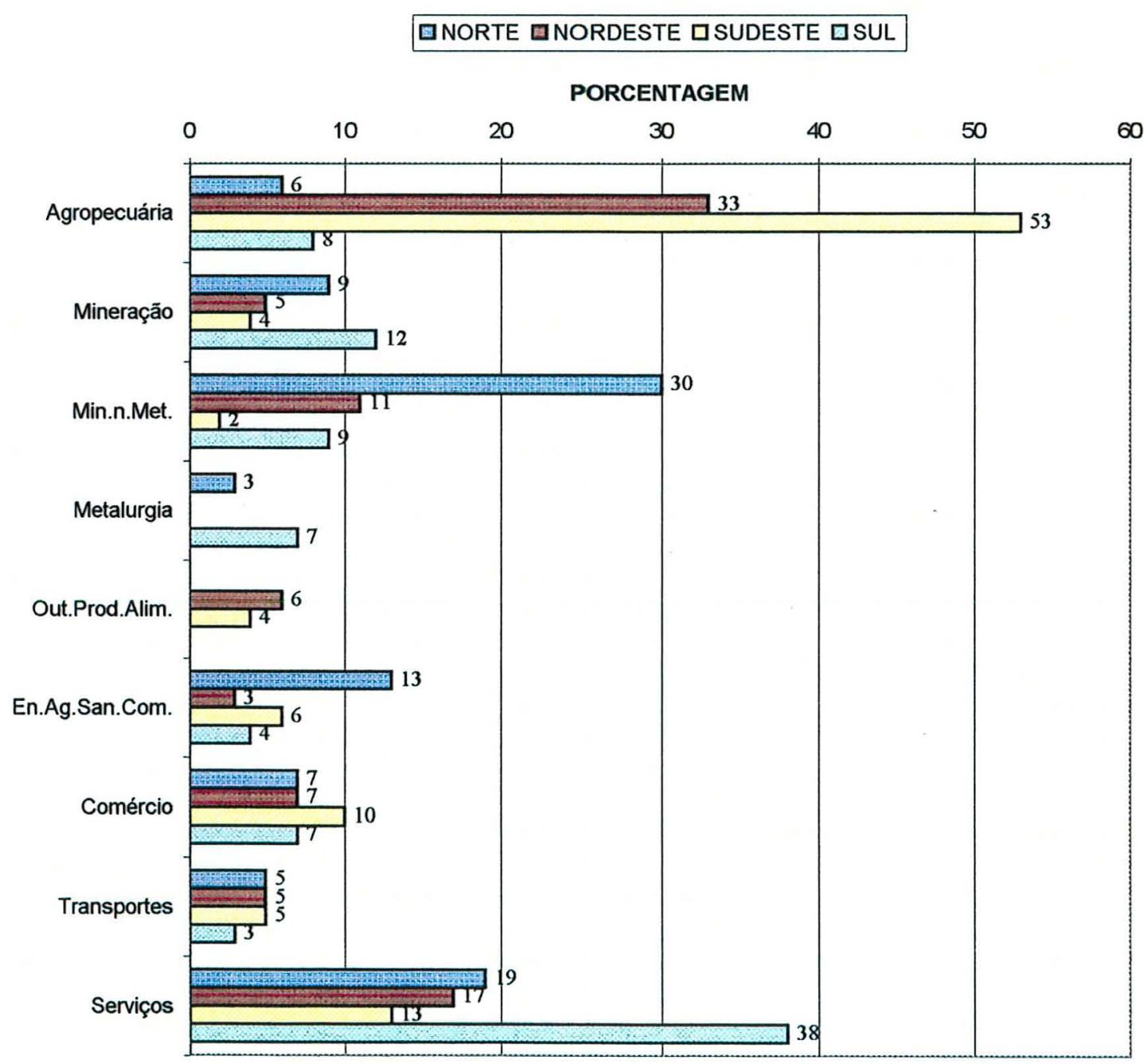

Figura 8. 24 - Produção setorial da região Centro-Oeste, induzida pela demanda final das outras regiões em (\%), Brasil, 1985 
Em termos de importância, destacam-se os setores de Minerais não Metálicos, com maior indução da região Norte, cerca de $30 \%$ de sua demanda final, seguidos de Mineração, Comércio, Energia, Água, Saneamento e Comunicações e Transportes.

\section{d) Região Sudeste}

A região Sudeste é acionada em 17 setores, ver Figura 8.25. Destes, 7 são acionados por todas as outras regiões brasileiras, de forma simultânea, são eles: os setores de Metalurgia, Refino de Petróleo, Material de Transporte, Serviços, Comércio, Mecânica e Mineração. Nota-se, ao observar-se a Figura 8.25, uma distribuição regular da produção da região Sudeste, entre seus setores, tanto os extrativos, de transformação, como os de serviços.

Os grandes destaque ficam para com os setores de Metalurgia e Refino de Petróleo, que constituem-se em setores chave para a dinâmica nas economias.

Esta análise, identifica a estrutura diversificada da região Sudeste, que, por sua vez ratifica as aquelas já realizadas neste trabalho, através de outras técnicas, bem como, revela o grau de dependência, por setor, das outras regiões brasileiras 


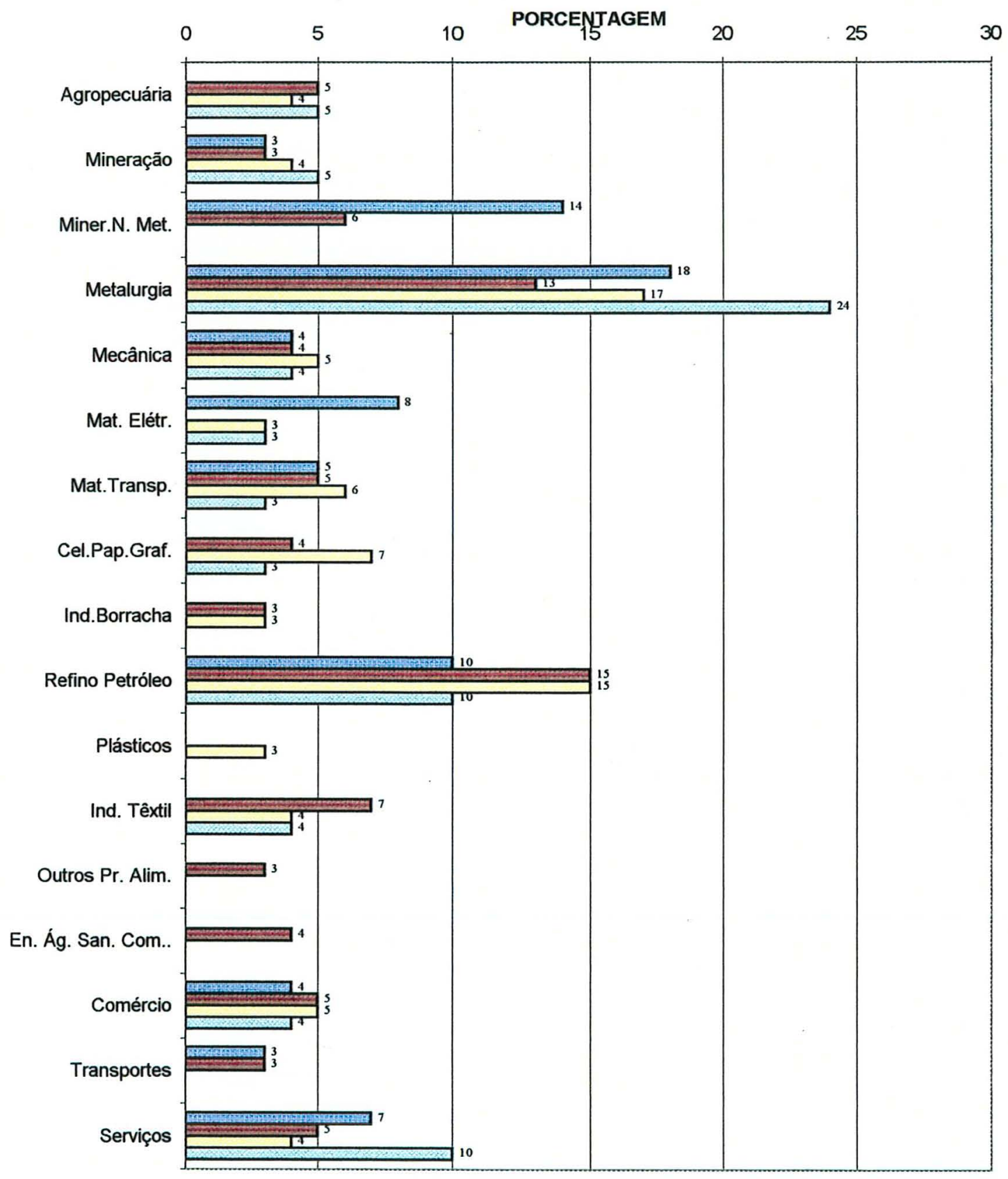

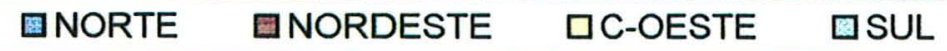

Figura 8.25 - Produção setorial da região Sudeste, induzida pela demanda final de outras regiões em (\%), Brasil, 1985 


\section{e) Região Sul}

Os setores de Agropecuária e de Outros Produtos Alimentares, representam, em média, $20 \%$ das demandas de outras regiões, sobre a produção da região Sul.

Os destaques, desta indução ficam com as regiões Sudeste e Nordeste com participação de $33 \%$ e 19\%, respectivamente, salienta-se, também, que a Agropecuária e Outros Produtos Alimentares, representam $54 \%$ do total da demanda final que a região Sudeste tem sobre a região Sul, enquanto a da região Nordeste representa, $34 \%$.

Outro setor que ocupa relativa parcela sobre as sua demandas finais, via demanda das outras regiões, é o Refino de Petróleo.

A região Sul revela-se uma região dinâmica, como se percebe ao longo deste trabalho, fundamentalmente nos setores ligados à alimentação, mas, também, possui uma determinada diversificação no setor de serviços e da transformação.

Ressalta-se a importância da análise mais aprofundada sobre estas informações no sentido de identificar a interação das estruturas produtivas regionais, inclusive com a necessidade de uma análise temporal, para acompanhar as modificações nestas estruturas. 


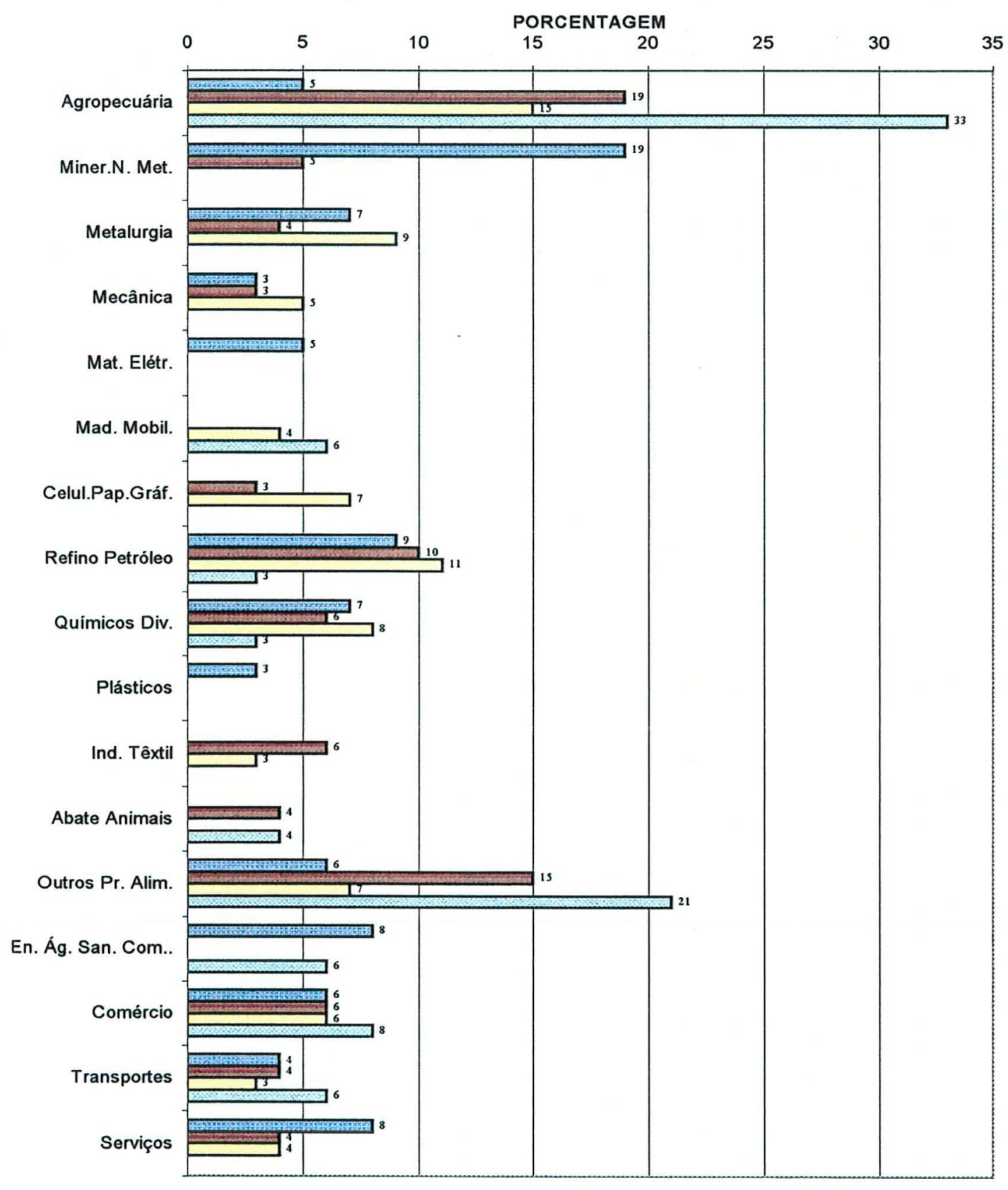

INORTE $\square$ NORDESTE $\square$ C-OESTE $\square$ SUDESTE

Figura 8.26 - Produção setorial da região Sul induzida, pela demanda final das outras regiões em (\%), Brasil, 1985 


\section{CONCLUSÕES}

A metodologia de insumo-produto para estudos regionais mostra-se extremamente útil, com aplicações cada vez mais apropriadas às diferentes economias, revelando crescente evolução na criação e adaptações dos seus métodos.

O esforço da presente pesquisa orienta-se em duas dimensões integradas: a construção de uma matriz inter-regional brasileira, que, por si só, revela uma aplicação destes modelos, o que caracteriza a primeira dimensão, e ao mesmo tempo, fornece a base para algumas análises, as quais também experimentam outros tipos de métodos, o que qualifica a segunda dimensão.

A contribuição principal é a identificação das inter-relações dos setores entre as regiões brasileiras para o período. À guisa de conclusão destacam-se os seguintes resultados.

A análise dos índices de ligações de Rasmussen/Hirschman para o agregado brasileiro, através do critério restrito, aponta para Metalurgia e Têxtil como setores chave da economia brasileira. A pesquisa permitiu revelar que tais setores são dinâmicos nas regiões Sudeste, Nordeste e Sul e, além disso, identificou setores dinâmicos para cada uma das regiões, o que pode subsidiar políticas específicas. Como exemplo, a região Nordeste apresenta, também, como dinâmicos, os setores de Refino de Petróleo e Químicos Diversos. Da mesma, forma a região Sul, com Mecânica e Outros Produtos Alimentares e a região Sudeste, com Minerais não Metálicos, Mecânica, Material Elétrico, Material de Transporte, Celulose Papel e Gráfica e Indústria da Borracha. 
Ao considerar-se o critério mais amplo, identificam-se os setores relevantes nos encadeamentos para frente e para trás para estas e outras regiões, conforme se constata nas informações contidas no capítulo 8 deste trabalho. A análise desagregada revela os setores específicos para cada região, o que não é possível na análise agregada.

O enfoque do campo de influência complementa a análise das ligações de Rasmussen e Hirschman e permite a visualização dos elos mais fortes entre setores e regiões. $\mathrm{O}$ destaque fica para a o grau de dinâmica apresentada pela região Nordeste, acima da Centro-Oeste, Norte e, conforme o setor, também da região Sul, que é confirmada pelos índices de ligações e resultados das interações entre as regiões obtidos quando da aplicação do método GHS.

Os resultados dos índices puros, análise alternativa que considera o valor de produção, apresentam um leque maior de setores dinâmicos .Identificam-se 09 setores no agregado e a análise inter-regional aponta em que regiões estão localizados. Os setores de Construção Civil, Comércio, Transporte e Serviços são dinâmicos, de forma geral, em todas as regiões, enquanto a Agropecuária só não o é para a região Sudeste. Os setores Metalurgia e Químicos Diversos apresentam-se como dinâmicos nas regiões Sudeste e Nordeste, enquanto Outros Produtos Alimentares nas regiões Nordeste, Centro-Oeste e Sul, e, por fim o setor de Refino de Petróleo no Nordeste, Sudeste e Sul.

Além destas localizações, a análise inter-regional identifica os seguintes setores dinâmicos: Mineração para Norte e Nordeste, Mineral não Metálico para o Centro-Oeste, Metalurgia para Nordeste e Sudeste, Mecânica e Material de Transporte para o Sudeste, Têxtil para Nordeste, Vestuário e Calçados e Abate de Animais para o Sul e Energia, Água, Saneamento e Comunicações para o Centro-Oeste.

A análise dos índices puros permite, também, a constatação da grande supremacia da região Sudeste, frente à média nacional em cada setor. Tanto nos índices para frente como para trás, todos seus valores apresentam-se maiores que esta média. A região Sul, na sequềncia, possui oito setores acima da média nas ligações para trás. São eles: Agropecuária, Madeira e Mobiliário, Vestuário e Calçados, Abate de Animais, 
Outros Produtos Alimentares, Energia, Água, Saneamento e Comunicação, Comércio e Transportes. E dois acima da média das ligações para frente, Minerais não Metálicos e Mecânica. Por fim, a região Nordeste com o setor de Mineração com valor maior que a média nacional tanto para frente como para trás e Fabricação de Açúcar com valor acima da média, para trás, da economia nacional.

O método GHS e seus desdobramentos, revelam que a região Sudeste mostrase quase que inteiramente independente do resto do Brasil. A. sua dinâmica basta para o seu desenvolvimento. Por outro lado a sua integração na economia é fundamental para a sobrevivência de outras regiões.

A análise da produção, de acordo com a demanda final própria e para outras regiões, permite identificar a grande dinâmica da economia da região Sudeste. A sua demanda própria é bem distribuída dente os setores de Serviços, Metalurgia, Material de Transportes, Refino de Petróleo, enquanto as outras regiões brasileiras acionam os setores de Metalurgia, Refino de Petróleo e Comércio de forma mais acentuada.

A região Sul apresenta uma demanda própria, relativamente, bem distribuida dentre os setores, especificamente na Agropecuária, Outros Produtos Alimentares, Comércio e Transportes e sua economia é acionada por outras regiões de forma mais forte na Agropecuária, Outros Produtos Alimentares, Refino de Petróleo, Metalurgia e Comércio.

As outras regiões, de forma geral, possuem uma demanda própria que recai com maior incidência na Agropecuária, Construção Civil e Serviços. Em termos de demanda de outros setores, a região Norte é requisitada para produção nos setores de Agropecuária, Mineração, Material Elétrico e Comércio, enquanto a região Nordeste é mais acionada nos setores de Refino de Petróleo e Químicos Diversos. É interessante registrar a demanda exercida pela região Norte quanto à produção do setor de Metalurgia do Nordeste.

A região Centro-Oeste tem no setor de Agropecuária a maior demanda de outras regiões, seguido dos setores de Mineral não Metálico e Serviços./ 
A pesquisa trouxe, como uma das principais identificações, a deteç̧ão de uma certa dinâmica na estrutura econômica da região Nordeste, talvez devido à maturação de investimentos realizados na década anterior. Destaca-se, também a existência de determinado pólo de desenvolvimento entre regiões Norte e Nordeste, possibilitado pela aplicação da abordagem GHS e campo de influência. Esta constatação demonstra um rearranjo em termos de desenvolvimento em uma nação de dimensões continentais.

Mesmo considerando todas as limitações, já explicitadas ao longo deste trabalho, o trabalho desenvolvido revelou inúmeras possibilidades de análise, dentre elas a aplicações dos multiplicadores, a expansão dos desdobramentos do GHS, para análise mais detalhadas sobre efeitos diretos das demandas finais, bem como investigações específicas sobre as relações intersetoriais e inter-regionais reveladas pelo campo de influência.

A título de sugestão, estruturas inter-regionais mais atuais, deveriam ser elaboradas, tão logo novos censos econômicos sejam divulgados $\mathrm{A}$ análise temporal enriqueceria sobremaneira algumas conclusões desta pesquisa, bem como contribuiria para o aperfeiçoamento e uso de novos métodos para construção e análises de estruturas inter-regionais. 


\section{ANEXOS}

Anexo A - Matriz inter-regional do Brasil, 1985

Anexo B - Agregações de setores e produtos 
Anero A: MATRIZ INTER-REGIONAL DE INSUMO - PRODUTO - BRASL - 1985 (bithöes de cruscirces) (onntinuan)

\begin{tabular}{|c|c|c|c|c|c|c|c|c|c|c|c|c|c|c|c|c|c|c|}
\hline & & REGOOES & & & & & & & & & & & & No: & RTB & & & \\
\hline & & SETORES & 1 & 2 & \begin{tabular}{|l|l|}
3 & 4 \\
\end{tabular} & $4|5|$ & 6 & 7 & 8 & \begin{tabular}{|l|l}
9 & \\
\end{tabular} & 10 & & 12 & & & 15 & 16 & \\
\hline & 1 & Azzopecuaria & 1738 & & 260 & $\begin{array}{ll}0 & 0\end{array}$ & 1 & & $648 \mathrm{t}$ & 133.2 & 245 & & 94 & 9 & 0 & 49 & 6 & 373 \\
\hline & 2 & Minetagāo & 109 & 28 & 7849 & 490 & 8 & 0 & i & I & 0 & 0 & 0 & 0 & 0 & 0 & 0 & 0 \\
\hline & 3 & Minerais nöo Metslicos & 7 & & 463 & 33 & 5 & 1 & 1. & 1 & 0 & 0 & 0 & 1 & 0 & 0 & 0 & 0 \\
\hline & 4 & Metafurgia & 23 & 18 & 262 & 6250 & 24 & 15 & 4 & 3 & 0 & 1 & 0 & 0 & 2 & 1 & 1 & 0 \\
\hline & 5 & Mecànica & $\$ 7$ & 73 & 236 & 667 & 24 & 12 & 46 & 60 & 3 & 6 & 4 & 0 & 5 & 5 & 0 & 1 \\
\hline & 6 & Maletial Eletrico & $\$$ & 2 & 32 & 261 & 1151 & 2 & 2 & 3 & 0 & 0 & 0 & 0 & 0 & 0 & 0 & 0 \\
\hline & 7 & Malerial de Transporte & 0 & 0 & 01 & 11 & 1 & 181 & 0 & 0 & 0 & 0 & 0 & 0 & 0 & 0 & 0 & 0 \\
\hline & 8 & Madeira e Mob & 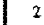 & 2 & $0 \quad 1$ & 10 & 82 & & 191 & 2 & 0 & 0 & 2 & 0 & 0 & 0 & 0 & 0 \\
\hline & 9 & Celubse, Paptel & 4 & 0 & 26 & 6. 8 & $\$ 1$ & 0 & 0 & 28 & 0 & 0 & 0 & 0 & 0 & 0 & 0 & 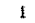 \\
\hline & 10 & Ind da I & 0 & 0 & 00 & 054 & 2 & 24 & I & 0 & 3 & 0 & 0 & 0 & 0 & 0 & 0 & 0 \\
\hline & 11 & Refmo & 67 & 13 & 41 & 12 & 1 & 0 & 9 & 13 & 0 & 7 & 3 & 0 & 13 & 4 & 0 & 0 \\
\hline & 12 & Quimicos Divetsos & 96 & 1 & 00 & 00 & 1 & 0 & 2 & 9 & 0 & 3 & 2 & 2 & 10 & 3 & 0 & 0 \\
\hline N & 13 & Farmascutica & 7 & 0 & 00 & 00 & 0 & 0 & 0 & 0 & 0 & 0 & 0 & 0 & 0 & 0 & 0 & 0 \\
\hline 0 & 14 & plastico & 19 & a & 025 & 251 & 54 & I & 5 & 0 & 0 & 0 & I & 0 & 0 & 9 & $\mathfrak{I}$ & 2 \\
\hline $\mathbf{R}$ & 15 & Ind. T & 44 & 13 & 00 & 00 & 3 & 0 & 2 & 0 & 0 & 0 & 0 & 0 & & 285 & 41 & 0 \\
\hline $\mathbf{T}$ & 16 & - Calqados & 9 & 0 & 00 & 00 & 2 & 0 & 0 & 0 & 0 & 0 & 0 & 0 & 0 & 0 & 3 & 0 \\
\hline $\mathrm{E}$ & 17 & Indis: & 5 & 0 & 00 & 0. 2 & 0 & 1 & 0 & 0 & 0 & 0 & 0 & 0 & 0 & 0 & & 128 \\
\hline & 18 & Abate & 3 & 0 & 00 & 00 & 0 & 0 & 0 & 0 & 0 & 0 & 0 & 2 & 0 & & 26 & 0 \\
\hline & 19 & le $A_{\text {f ucar }}$ & 1 & 0 & 00 & 00 & 0 & 0 & 0 & 0 & 0 & 0 & 1 & 0 & 0 & 0 & 0 & 0 \\
\hline & 20 & d. Aliment & 289 & 0 & 10 & 01 & 1 & 0 & 1. & 0 & 0 & 0 & 0 & 7 & 0 & 0 & 0 & 4 \\
\hline & 21 & Incustrias Divetsas & 18 & 7 & 196 & 616 & 18 & 0 & 3 & 12 & 1 & 1 & 0 & 0 & 0 & 2 & 0 & 0 \\
\hline & 22 & ua, San, e Com & 30 & 17 & 115 & 54 & 11 & $s$ & 20 & 7 & 2 & 3 & 2 & 0 & 4 & 3 & 0 & 1. \\
\hline & 23 & Construçào Civil & 12 & 2 & $\begin{array}{ll}1 & 0\end{array}$ & $\begin{array}{ll}0 & 0\end{array}$ & 2 & 1 & 1. & 1 & 0 & 0 & 0 & 0 & 0 & 0 & 0 & 0 \\
\hline & 24 & Comácio & 626 & 53 & 4228 & 2858 & 183 & 103 & 104 & 38 & 14 & & 14 & 8 & 5 & 24 & 9 & 45 \\
\hline & 25 & Transpotter & 218 & 19 & 3917 & 177 & 128 & & 198 & 42 & 2 & & 8 & 2 & 0 & 2 & 1 & 9 \\
\hline & 26 & Serviços & 652 & & 3821 & 2119 & 148 & 62 & 91 & 39 & 7 & & 15 & 4 & $\mathbf{8}$ & 24 & 4 & 8 \\
\hline & 1 & Agropecurds is & 0 & 0 & $0 \quad 0$ & 00 & 0 & 0 & 0 & 0 & 0 & 0 & 0 & 0 & 0 & 0 & 0 & 0 \\
\hline & 2 & Mire & 2 & 0 & 20 & 0.0 & 0 & 0 & 0 & 0 & 0 & 0 & 0 & 0 & 0 & 0 & 0 & 0 \\
\hline & 3 & Mixe & 0 & 0 & 10 & 0.0 & 0 & 0 & 0 & 0 & 0 & 0 & 0 & 0 & 0 & 0 & 0 & 0 \\
\hline & 4 & Metain & 2 & 6 & 132 & 311 & 10 & 5 & 2 & 0 & 0 & 0 & 0 & 0 & 0 & 0 & 0 & D \\
\hline & 5 & Mecẩni & 1 & 1 & 01 & 112 & 14 & 1 & 0 & 0 & 0 & 0 & 0 & 0 & 0 & 0 & 0 & 0 \\
\hline & 6 & Mater & 0 & 0 & 01 & 10 & 45 & 0 & 0 & 0 & 0 & 0 & 0 & 0 & 0 & 0 & 0 & 0 \\
\hline & 7 & Mater & 0 & 0 & $0 \quad 1$ & 16 & 0 & 87 & 0 & 0 & 0 & 0 & 0 & 0 & 0 & 0 & 0 & 0 \\
\hline & s & Made & 0 & 0 & 00 & 00 & 17 & 0 & 0 & 0 & 0 & 0 & 0 & 0 & 0 & 0 & 0 & 0 \\
\hline & 9 & Coluto & 0 & 0 & 03 & 32 & 3 & 0 & 0 & 0 & 0 & 0 & 0 & 0 & 0 & 0 & 0 & 0 \\
\hline$N$ & 10 & Ind d & 0 & 0 & 00 & 00 & 0 & 4 & 0 & 0 & 2 & 0 & 0 & 0 & 0 & 0 & 0 & 0 \\
\hline 0 & 11 & Refin & 21 & 13 & 31 & 11 & 0 & 0 & 12 & 0 & 0 & 0 & 2 & 0 & 2 & 2 & 0 & 0 \\
\hline$R$ & 12 & Qulm & 37 & I & 01 & 10 & 0 & 0 & 4 & 0 & 0 & 0 & 2 & 0 & 2 & 2 & 0 & 0 \\
\hline D & 13 & Farm & 18 & 0 & 00 & 00 & 0 & 0 & 0 & 0 & 0 & 0 & 1 & 0 & 0 & 0 & 0 & 0 \\
\hline E & 14 & $\mathrm{P}$ & 2 & 0 & 0 II & 110 & 9 & 0 & 1 & 0 & 0 & 0 & 0 & 0 & 0 & 0 & 0 & 0 \\
\hline $\mathbf{S}$ & 15 & Find. & 1 & 2 & 00 & 0.0 & 0 & 0 & 0 & 0 & 0 & 0 & 0 & 0 & 0 & 12 & 0 & 0 \\
\hline$T$ & 16 & Vestu & 0 & 0 & 00 & $\begin{array}{ll}0 & 0\end{array}$ & i & 0 & 0 & 0 & 0 & 0 & 0 & 0 & 0 & 0 & 0 & 0 \\
\hline E & 17 & Ifridist & 0 & 0 & $\begin{array}{ll}0 & 0\end{array}$ & 00 & 0 & 0 & 0 & 0 & 0 & 0 & 0 & 0 & 0 & 0 & 0 & 0 \\
\hline & 18 & Abat & 0 & 0 & 00 & $\begin{array}{ll}0 & 0\end{array}$ & 0 & 0 & 0 & 0 & 0 & 0 & 0 & 0 & 0 & 0 & 0 & 0 \\
\hline & 19 & $F_{2}$ & 0 & 0 & 00 & 00 & 0 & 0 & 0 & 0 & 0 & 0 & I & 0 & 0 & 0 & 0 & 0 \\
\hline & 20 & Outro & 5 & 0 & 00 & 00 & o & 0 & 0 & 0 & 0 & 0 & 0 & 0 & 0 & 0 & 0 & 0 \\
\hline & 21 & Indus & 0 & 0 & 00 & 00 & 0 & 0 & 0 & 0 & 0 & 0 & 0 & 0 & 0 & 0 & 0 & 0 \\
\hline & 22 & $\mathrm{r}_{*} \mathrm{eCon}$ & 0 & 0 & 00 & 00 & 0 & 0 & 0 & 0 & 0 & 0 & 0 & 0 & 0 & 0 & 0 & 0 \\
\hline & 23 & Civil & 0 & 0 & 00 & 00 & 0 & 0 & 0 & 0 & 0 & 0 & 0 & 0 & 0 & 0 & 0 & 0 \\
\hline & 24 & Comer & 4 & 2 & I I & 10 & I & 1 & 2 & 0 & 0 & 0 & 0 & 0 & 0 & 0 & 0 & 0 \\
\hline & 25 & frans & 0 & 0 & 00 & 00 & 0 & 0 & 0 & 0 & 0 & 0 & 0 & 0 & 0 & 0 & 0 & 0 \\
\hline & 26 & Serviços & 0 & 0 & $\begin{array}{ll}0 & 0 \\
\end{array}$ & $0 \quad 0$ & 0 & 0 & a & 0 & 0 & 0 & 0 & 0 & 0 & 0 & 0 & 0 \\
\hline & 1. & Axto & 0 & 0 & 00 & 00 & 0 & 0 & 0 & 0 & 0 & 0 & 0 & 0 & 0 & 0 & 0 & 0 \\
\hline & 2 & $\mathrm{Min}$ & 6 & 0 & 10 & 00 & 0 & 0 & 0 & 0 & 0 & 0 & 0 & 0 & 0 & 0 & 0 & 0 \\
\hline & 3 & Mine & 2 & 0 & 10 & 00 & 0 & 0 & 0 & 0 & 0 & 0 & 0 & 0 & 0 & 0 & 0 & 0 \\
\hline & 4 & Met & 0 & 0 & 00 & $0 \quad 1$ & 0 & 0 & 0 & 0 & 0 & 0 & 0 & 0 & 0 & 0 & 0 & 0 \\
\hline & 5 & Mec & 0 & 0 & 00 & 00 & 0 & 0 & 0 & 0 & 0 & 0 & 0 & 0 & 0 & 0 & 0 & 0 \\
\hline & 6 & Mat & 0 & 0 & 00 & 00 & $\tau$ & 0 & 0 & 0 & 0 & 0 & 0 & 0 & 0 & 0 & 0 & 0 \\
\hline $\mathrm{c}$ & 7 & Mat & 0 & 0 & 00 & 00 & 0 & 0 & 0 & 0 & 0 & 0 & 0 & 0 & 0 & 0 & 0 & 0 \\
\hline$E$ & 8 & Ma & 0 & 0 & $\begin{array}{ll}0 & 0\end{array}$ & 00 & 2 & 0 & 0 & 0 & 0 & 0 & 0 & 0 & 0 & 0 & 0 & 0 \\
\hline $\mathrm{N}$ & 9 & 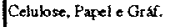 & 0 & 0 & 00 & 00 & 0 & 0 & 0 & 0 & 0 & 0 & 0 & 0 & 0 & 0 & 0 & 0 \\
\hline $\mathrm{T}$ & 10 & In & 0 & 0 & 00 & 00 & 0 & 0 & 0 & 0 & 0 & 0 & 0 & 0 & 0 & 0 & 0 & 0 \\
\hline $\mathrm{R}$ & $\boldsymbol{I}$ & I & 2 & 0 & 00 & 00 & 0 & 0 & 0 & 0 & 0 & 0 & 0 & 0 & 0 & 0 & 0 & 0 \\
\hline $\mathrm{O}$ & 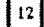 & 10 & 5 & 0 & 00 & 00 & 0 & 0 & 0 & 0 & 0 & 0 & 0 & 0 & o & 0 & 0 & 0 \\
\hline & 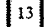 & 5 & 1 & 0 & 00 & 00 & 0 & 0 & 0 & 0 & 0 & 0 & 0 & 0 & 0 & 0 & 0 & 0 \\
\hline 0 & 14 & Pisticic & 0 & 0 & $0 \quad 0$ & 0.0 & 0 & 0 & 0 & 0 & 0 & 0 & 0 & 0 & 0 & 0 & 0 & 0 \\
\hline $\mathrm{E}$ & 15 & frod. Ts & 0 & 0 & 00 & 00 & 0 & 0 & 0 & 0 & 0 & 0 & 0 & 0 & 0 & 1 & 0 & 0 \\
\hline$S$ & 16 & $\mathrm{v}$ & 0 & 0 & $\begin{array}{lll}0 & 0\end{array}$ & 00 & o & 0 & 0 & 0 & 0 & 0 & 0 & 0 & 0 & 0 & 0 & $a$ \\
\hline $\mathrm{T}$ & 17 & Ir & 0 & 0 & 00 & 0.0 & o & 0 & 0 & 0 & 0 & 0 & 0 & 0 & 0 & 0 & 0 & 0 \\
\hline $\mathrm{E}$ & 18 & 1 & 0 & 0 & 00 & 00 & 0 & 0 & 0 & 0 & 0 & 0 & 0 & 0 & 0 & 0 & 0 & 0 \\
\hline & 19 & fi & 0 & 0 & $\begin{array}{ll}0 & 0\end{array}$ & 00 & $a$ & 0 & 0 & 0 & 0 & 0 & 0 & 0 & 0 & 0 & 0 & 0 \\
\hline & 20 & 0 & 2 & 0 & 00 & 00 & 0 & 0 & 0 & 0 & 0 & 0 & 0 & 0 & 0 & 0 & 0 & 0 \\
\hline & 21 & Indústrt & 0 & 0 & 00 & 00 & 0 & 0 & 0 & 0 & 0 & 0 & 0 & 0 & 0 & 0 & 0 & 0 \\
\hline & 22 & Energ & I & 1 & 00 & 00 & 0 & 0 & I & 0 & 0 & 0 & 0 & 0 & 0 & 0 & 0 & 0 \\
\hline & 23 & con & 0 & 0 & 00 & 00 & o & 0 & 0 & 0 & 0 & 0 & 0 & 0 & 0 & 0 & 0 & 0 \\
\hline & 24 & & 3 & 0 & 00 & $\begin{array}{ll}0 & 0\end{array}$ & o & 0 & 0 & 0 & 0 & 0 & 0 & 0 & 0 & 0 & 0 & 0 \\
\hline & 2 & & 0 & 0 & 00 & 0 & 0 & 0 & & & ( & 0 & 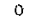 & 0 & 0 & 0 & 0 & 0 \\
\hline & & & 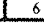 & 0 & $0 \quad 0$ & $\begin{array}{l}0 \\
0\end{array}$ & 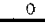 & 0 & 0 & U & 5 & & & & & & & \\
\hline
\end{tabular}




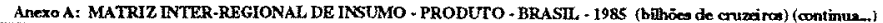

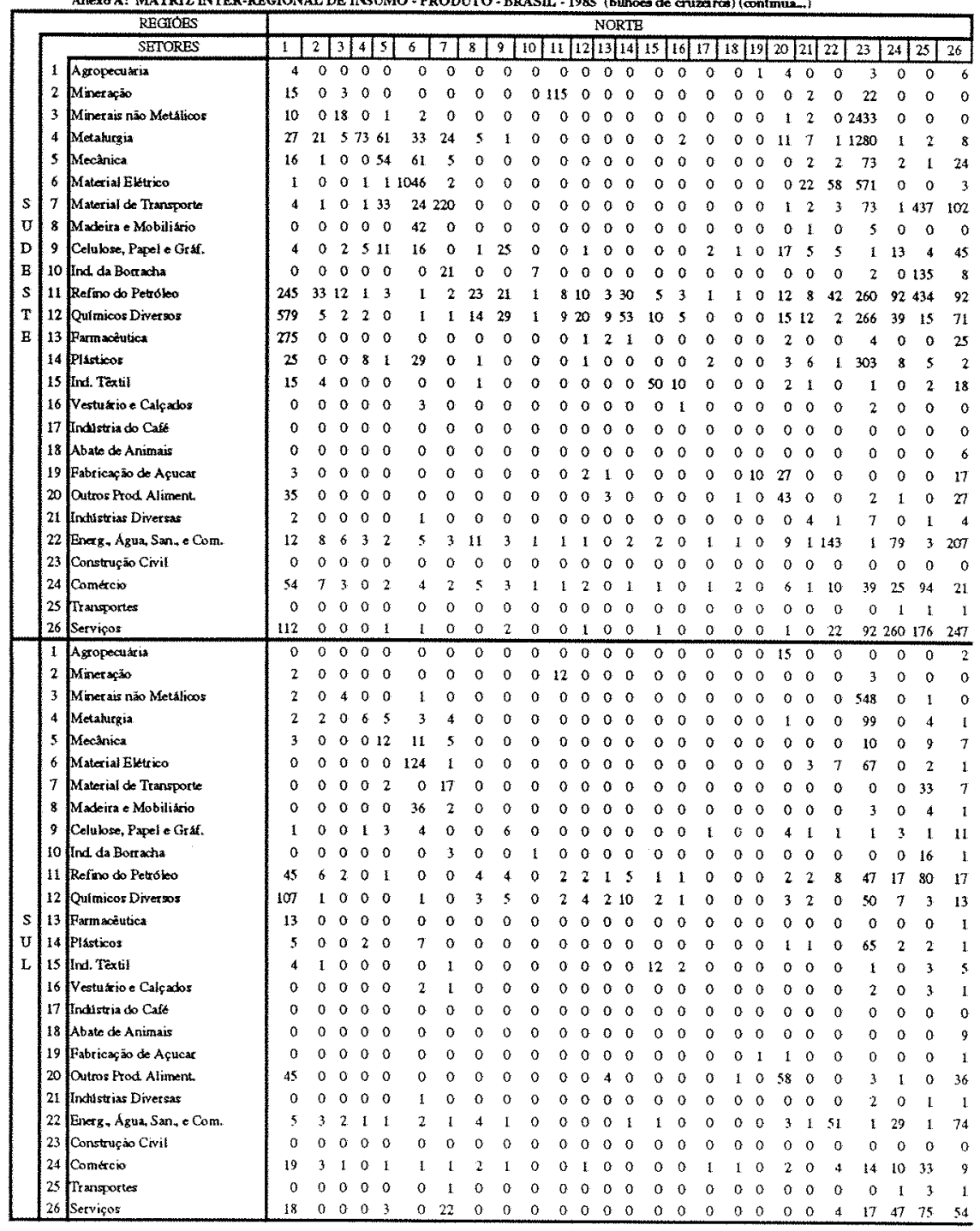


Anexo A: MATRIZ INTER-REGIONAL DE INSUMO - PRODUTO - BRASIL - 1985 (bilhōes de cruzairou) (continuam)

\begin{tabular}{|c|c|c|c|c|c|c|c|c|c|c|c|c|c|c|c|c|c|c|}
\hline & & KEGIOES & & & & & & & & & & & & & & H. & STE & \\
\hline & & SETORES & 1 & 2 & 3 & 4 & 5 & \begin{tabular}{l|l}
6 & 7 \\
\end{tabular} & & 8 & & 10 & 11) & 12 & 13 & 14 & 15 & 116 \\
\hline & 1 & Aszopecuárix & 1 & o & 0 & 0 & 0 & 0 & 0 & 19 & 0 & 0 & 0 & l. & 0 & 0 & & 01 \\
\hline & 2 & Miner asa ăo & 0 & 0 & 0 & 5 & 0 & 00 & 0 & 0 & 0 & 0 & 0 & 0 & 0 & o & & $\begin{array}{ll}0 & 0 \\
0 & -1\end{array}$ \\
\hline & 3 & Minerais nāo Me & 0 & 0 & 0 & 1 & 0 & 00 & 0 & 0 & 0 & 0 & 0 & 0 & 0 & 0 & & $0 \quad 0$ \\
\hline & 4 & Metalurgia & 0 & 0 & 0 & 1 & 0 & 00 & 0 & 0 & 0 & 0 & 0 & 0 & 0 & 0 & & $0 \quad 0$ \\
\hline & 5 & ceanica & I & 0 & 0 & 2 & 34 & $\theta$ & 1 & 0 & 0 & 0 & 0 & 0 & 0 & 0 & & 00 \\
\hline & 6 & aterial Ebtrico & 0 & 0 & 0. & 3 & 5 & 10 & 0 & 0 & 0 & 0 & 0 & 0 & 0 & 0 & & 00 \\
\hline & 7 & aterial de Transporte & 0 & 0 & 0 & 0 & 0 & 02 & 2 & 0 & 0 & 0 & 0 & 0 & 0 & 0 & & $0 \quad 0$ \\
\hline & 8 & Weira e Mobiliarrio & 0 & 0 & 0 & 0 & 0 & 00 & 0 & 0 & 0 & 0 & 0 & 0 & 0 & 0 & & 00 \\
\hline & 9 & lubse, Papel e Graf. & 0 & 0 & 0 & 1 & 1 & 10 & 0 & 0 & 1 & 0 & 0 & 0 & 0 & 0 & & 0 \\
\hline & 10 & I da Borracha & 0 & 0 & 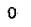 & 0 & 7 & 00 & 0 & 0 & 01 & & 0 & 0 & 0 & 0 & & 02 \\
\hline & 11 & froo do Petrobo & 0 & 0 & 0 & 0 & 0 & 00 & 0 & 0 & 0 & 0 & 0 & 0 & 0 & 0 & & a \\
\hline & 12 & Imico & 0 & 0 & 0 & 0 & 0 & 00 & 0 & 0 & 0 & 0 & 0 & 0 & 0 & o & & 0 \\
\hline$N$ & 13 & mastutica & 0 & 0 & 0 & 0 & 0 & 00 & 0 & 0 & 0 & 0 & 0 & 0 & 0 & 0 & & a \\
\hline 0 & 14 & isticos & 0 & 0 & 0 & 0 & 0 & 00 & 0 & 0 & 0 & 0 & 0 & 0 & 0 & 0 & & $0 \quad 0$ \\
\hline $\mathbf{R}$ & 15 & 1. Texti & 0 & 0 & 0 & 0 & 0 & 00 & 0 & 0 & 0 & 1 & 0 & 0 & 0 & 0 & & 1 \\
\hline $\mathrm{T}$ & 16 & stuario e Calyado & 0 & 0 & 0 & 0 & 0 & 00 & 0 & 0 & 0 & 0 & 0 & 0 & 0 & 0 & & 0 \\
\hline F & 7 & tistu & 0 & 0 & 0 & 0 & 0 & 00 & 0 & 0 & 0 & 0 & 0 & 0 & 0 & 0 & & 0 \\
\hline & 18 & late of & 0 & 0 & 0 & 0 & 0 & 00 & 0 & 0 & 0 & 0 & 0 & o & 0 & 0 & & 0 \\
\hline & 19 & ucar & 0 & 0 & 0 & 0 & 0 & 00 & 0 & 0 & 0 & 0 & 0 & o & 0 & 0 & & 0 \\
\hline & 20 & tros & 0 & 0 & 0 & 0 & 0 & 00 & 0 & 0 & 0 & 0 & 0 & 0 & 0 & 0 & & 0 \\
\hline & 21 & histu & 0 & 0 & 0 & 19 & 1 & 0 & 0 & 0 & 0 & 0 & 0 & 0 & 0 & 0 & & 0 \\
\hline & 22 & ag. & 0 & 0 & 0 & 0 & 0 & 0 & 0 & 0 & 0 & 0 & 0 & 0 & 0 & 0 & & 0 \\
\hline & 23 & Const & 0 & 0 & 0 & 0 & 0 & 00 & 0 & 0 & 0 & 0 & 0 & 0 & 0 & 0 & & 0 \\
\hline & 24 & mac & 0 & 0 & 0 & 0 & 0 & 00 & 0 & 0 & 0 & 0 & 0 & 0 & 0 & 0 & & 0 \\
\hline & 25 & fitans & 4 & 0 & 1 & 0 & 0 & 00 & 0 & $\mathfrak{l}$ & 0 & 0 & 0 & 0 & 0 & 0 & & 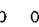 \\
\hline & 26 & yeos & 0 & 0 & 0 & 1 & 0 & 00 & 0 & 0 & 0 & 0 & 0 & 0 & 0 & 0 & & 00 \\
\hline & 1 & gopecuária & 48 & 65 & 53 & $\overline{33}$ & I & 0 & 03 & $\overline{32}$ & $\overline{252}$ & & & 227 & $\overline{22}$ & & 1760 & \\
\hline & 2 & then & 992 & 21218 & & 462 & 12 & 40 & 0 & 0 & 9 & & 665 & 100 & 1 & 1 & & 0 \\
\hline & 3 & Miner & 11 & 1139 & & 101 & $\mathfrak{1}$ & 15 & $\sigma$ & 4 & 0 & 0 & $\tau$ & 11 & 10 & 1 & & 1. \\
\hline & 4 & Mets: & 20 & 523 & 343 & 13081 & 1632 & 29665 & 65 & 36 & 15 & 2 & 140 & $2 \mathrm{~L}$ & 1 & 2 & & 74 \\
\hline & 5 & Mecâr & 793 & & 58 & 563 & 344 & 27 & 92 & 20 & 8 & 5 & 106 & 46 & 2 & 11 & 79 & 914 \\
\hline & 6 & Mater & 1 & 5 & 1 & 62 & 204 & 125 & 9 & 0 & 0 & 0 & 3 & 0 & 0 & 0 & & 1 \\
\hline & 7 & Malet & 1 & 3 & 0 & 1 & 3 & 120 & 20 & 1 & 0 & 0 & 1 & 0 & 0 & 0 & & $\begin{array}{ll}1 & 0 \\
1 & -1\end{array}$ \\
\hline & 8 & Madei & 25 & 0 & 1 & 7 & 3 & 6 & 810 & & 0 & 0 & 9 & 16 & 0 & 0 & & 08 \\
\hline & 3 & Celubs & 22 & 27 & 79 & 14 & 5 & 20 & 1 & & 326 & 0 & 54 & 46 & 19 & 32 & 4 & 436 \\
\hline$N$ & 10 & $d \mathrm{~d} d \mathrm{x}$ & 0 & 0 & 0 & 3 & 22 & 0 & 7 & 1 & 03 & 37 & 0 & 0 & 0 & 0 & & $\begin{array}{ll}0 & 31\end{array}$ \\
\hline 0 & 11 & fino & 644 & 51 & 90 & 112 & 12 & 13 & 4.2 & 21 & 463 & 346 & 509 & 954 & 66 & 329 & 232 & 259 \\
\hline $\mathrm{k}$ & 12 & Quimiox & 978 & 16 & 32 & 33 & 2 & 12 & 31 & 19 & 401 & 18 & 486 & 232 & 36 & 258 & 19 & 749 \\
\hline $\mathrm{D}$ & 13 & $m$ & 19 & 0 & 0 & 0 & 0 & 0 & 0 & 0 & 0 & 0 & 1 & 0 & 35 & 1 & & 20 \\
\hline B & 14 & stic & 22 & 0 & 2 & 3 & 0 & 4 & 12 & 27 & 1 & 0 & 16 & 19 & $T$ & 16 & 15 & $5 \quad 12$ \\
\hline $\mathrm{s}$ & 15 & Iind. Textil & 117 & 1 & 1 & 1 & 1 & 0 & 02 & 26 & 21 & 15 & 2 & 6 & 0 & & $255 ?$ & 2604 \\
\hline $\mathrm{T}$ & 16 & estudat & 29 & 0 & 0 & 0 & $£$ & 0 & 0 & $\mathfrak{I}$ & 0 & 2 & 1 & I & 0 & 0 & & 9223 \\
\hline E & 17 & Indists & 8 & 0 & 0 & 0 & 0 & 0 & 0 & 0 & 0 & 0 & 0 & 0 & 0 & 0 & & 0 \\
\hline & 18 & A & 0 & 0 & 0 & 0 & 0 & 0 & 0 & 0 & 0 & 0 & 0 & 2 & 17 & 0 & & 187 \\
\hline & 19 & btic & 7 & 6 & 1 & 5 & 2 & 0 & 0 & 0 & 0 & 0 & 12 & 222 & 1 & 1 & & I \\
\hline & 20 & Outros & 866 & 8 & 0 & 5 & 1 & 0 & 0 & 0 & 5 & 0 & 21 & & 123 & 1 & 1. & 53 \\
\hline & 21 & Indust & & 318 & 1 & 189 & 28 & 0 & 0 & 0 & 20 & 1 & 604 & 2 & 0 & 2 & & 018 \\
\hline & 22 & Ereag , Agна, San, e & 119 & $44 i$ & & 366 & 25 & 23 & 52 & 28 & 31 & 6 & 436 & 320 & 5 & 22 & 124 & $4 \quad 18$ \\
\hline & 23 & Constrn & 1 & 0 & 0 & 0 & 0 & 0 & 0 & 0 & 0 & 0 & 0 & 0 & 0 & 0 & & 00 \\
\hline & 24 & Comete & 7481 & 11412 & & 2331 & $12 \mathrm{I}$ & 442 & $23 \mathrm{ll}$ & & 943 & & 683 & 229 & 65 & 43 & & 1.117 \\
\hline & 25 & Trantro & 344 & $15 s$ & $\$ 7$ & 63 & 13 & 13 & 6. & 53 & 21 & 6 & 103 & 49 & 11 & 4 & 13 & 420 \\
\hline & 26 & Serviços & $m 1$ & 13713 & 38 & 108 & 99 & 3530 & $30 \quad 6$ & 68 & 74 & 9 & 309 & 181 & 46 & 56 & 200 & 0151 \\
\hline & 1 & xopec & 3 & 0 & - & $\overline{1}$ & 0 & 0 & 0 & 5 & I. & $\overline{0}$ & 0 & & 0 & 0 & & 0 \\
\hline & 2 & $M$ & 1 & 3 & 0 & 10 & 0 & 0 & a & 0 & o & 0 & 3 & & 0 & o & & 0 \\
\hline & 3 & Minet ai & 0 & 1 & 0 & 7 & 1 & 0 & 0 & 0 & 0 & 0 & 1 & & 0 & 0 & & 0 \\
\hline & 4 & Metahurgi & 0 & 0 & 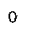 & 1 & I & 0 & 0 & 0 & 0 & 0 & 0 & 0 & 0 & 0 & & 0 \\
\hline & 5 & Mecầnic & 0 & 0 & 0 & o & I & 0 & 0 & 0 & 0 & 0 & 0 & 0 & 0 & o & & 0 \\
\hline & 6 & Mater & 0 & 0 & 0 & 0 & 0 & 0 & 0 & 0 & 0 & 0 & 0 & 0 & 0 & 0 & & 0 \\
\hline c & 7 & $M$ & 0 & 0 & 0 & 0 & 0 & 0 & 0 & 0 & 0 & 0 & 0 & 0 & 0 & 0 & & 0 \\
\hline$E$ & 8 & M & 0 & 0 & 0 & 0 & 0 & 0 & 0 & 0 & 0 & 0 & 0 & 0 & 0 & o & & 0 \\
\hline $\mathrm{N}$ & 9 & $\mathrm{c}$ & 0 & 0 & 0 & 0 & 0 & 0 & 0 & 0 & 2 & 0 & 0 & 0 & o & 0 & & 0 \\
\hline$T$ & 10 & & 0 & 0 & 0 & 0 & 0 & 0 & 0 & 0 & 0 & 0 & 0 & 0 & o & 0 & & 0 \\
\hline$R$ & 11 & & 3 & 0 & I & 1. & 0 & 0 & 0 & 0 & 0 & 0 & 9 & & o & 0 & & 0 \\
\hline 0 & 12 & o & 3 & 0 & 0 & 0 & 0 & 0 & 0 & 0 & 0 & 0 & 1 & & o & 0 & & 0 \\
\hline & 13 & $\mathrm{~F}$ & 2 & 0 & 0 & 0 & 0 & 0 & 0 & 0 & 0 & 0 & 0 & & & o & & 0 \\
\hline 0 & 14 & & 0 & 0 & 0 & 0 & 0 & 0 & 0 & 0 & 0 & 0 & 0 & & & o & & 0 \\
\hline $\mathrm{E}$ & 15 & I & 0 & 0 & 0 & 0 & 0 & 0 & 0 & 0 & 0 & 0 & 0 & & o & 0 & & 3 \\
\hline s & 16 & & 0 & 0 & 0 & 0 & 0 & 0 & 0 & 0 & 0 & 0 & 0 & & 0 & 0 & & U. \\
\hline$T$ & 17 & & 0 & 0 & 0 & 0 & 0 & 0 & 0 & 0 & 0 & 0 & 0 & & & o & & 0 \\
\hline & 18 & & 0 & 0 & 0 & 0 & 0 & 0 & 0 & 0 & 0 & 0 & 0 & & O & o & & 0 \\
\hline & 19 & & 0 & 0 & 0 & 0 & 0 & 0 & 0 & 0 & 0 & 0 & 0 & & 0 & 0 & & 0 \\
\hline & 20 & & 13 & 0 & 0 & 0 & 0 & o & 0 & 0 & 0 & 0 & 0 & & & 0 & & 0 \\
\hline & 21 & & 0 & 0 & 0 & 0 & 0 & 0 & 0 & 0 & 0 & 0 & 0 & & & 0 & & 0 \\
\hline & 22 & & 0 & 0 & 0 & 0 & 0 & 0 & 0 & 0 & 0 & 0 & 0 & & & 0 & & 0 \\
\hline & 23 & & 0 & 0 & 0 & 0 & 0 & 0 & 0 & 0 & 0 & 0 & 0 & & & 0 & & 0 \\
\hline & 2 & & 2 & 0 & 0 & 0 & 0 & 0 & 0 & 0 & 0 & 0 & & & & & & 0 \\
\hline & & & 8 & 0 & 0 & 0 & 0 & 0 & & & 0 & & & & & & & \\
\hline & & $\mid \mathrm{S}$ & & 0 & 0 & $\theta$ & 0 & 6 & 0 & & & & & & & & & \\
\hline
\end{tabular}


Anexo A : MATRIZ NTER-REGIONAL DE INSUMO - PRODUTO - BRASIL - 1985 (bithöes de cruatira) (continuan-)

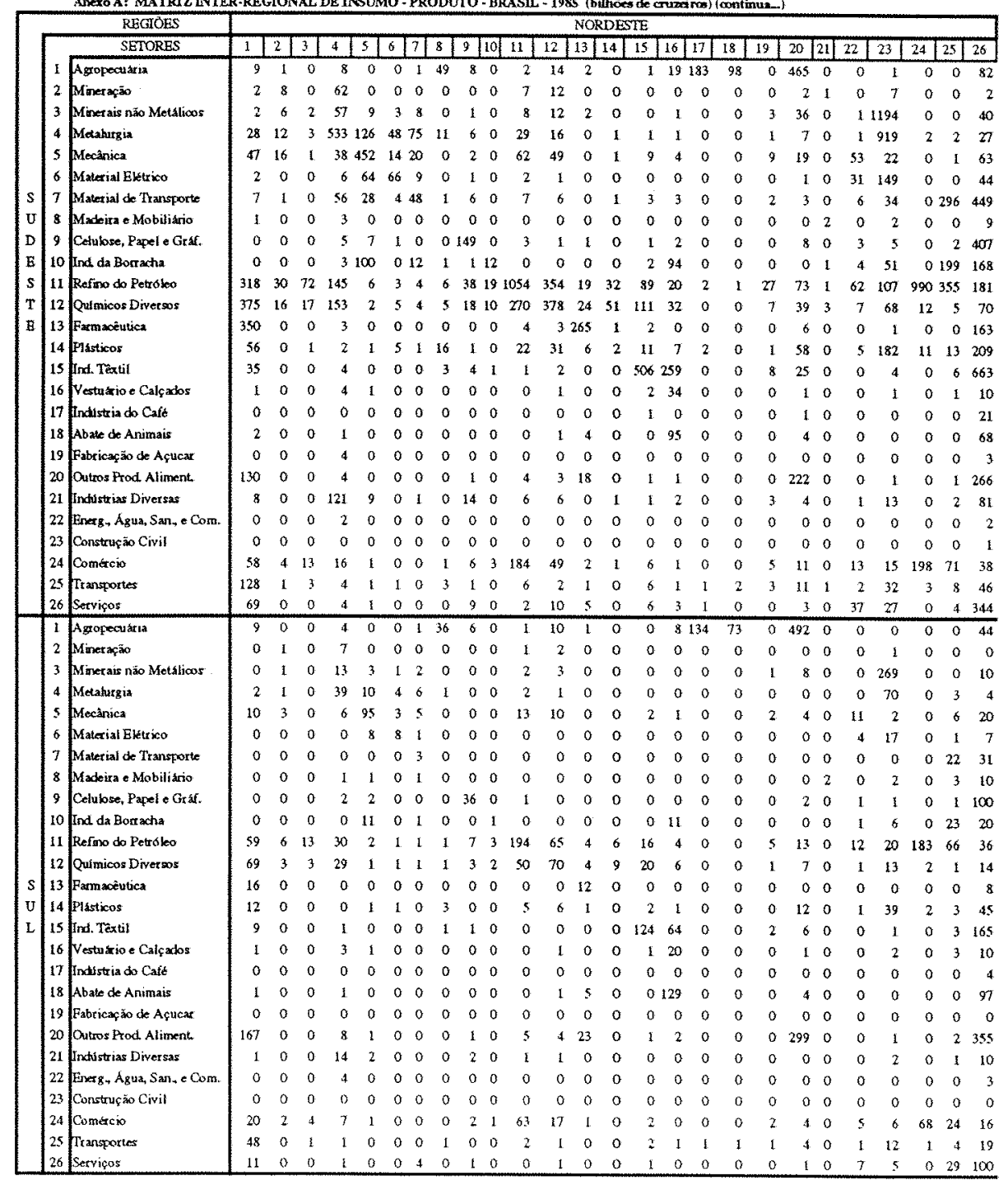


Anero A: MATRIZ NTERR-REGIONAL DE INSUMO - PRODUTO - BRASIL - 1985 (bilhöes de cruzeiros) foontinua

\begin{tabular}{|c|c|c|c|c|c|c|c|c|c|c|c|c|c|c|c|c|c|c|}
\hline & & KEGOES & & & & & & & & & & & & NTI & 5 & $\overline{\mathrm{OE}}$ & STE & \\
\hline & & SETORES & 1. & 2 & 3 & 4 & 5 & & & & 9[1]] & 11] & 121 & 13 : & $4[1$ & 5] 1 & 16 & \\
\hline & 1 & Agropecuáriata & 84 & 0 & 0 & 1 & 0 & 0 & 0 & 3 & 00 & 0 & 0 & 0 & 0 & $\overline{0}$ & 0 & 0 \\
\hline & 2 & Mineração & 25 & 4 & 43 & 4 & 0 & 0 & 0 & 0 & 00 & 0 & 2 & 0 & 0 & 0 & 0 & 0 \\
\hline & 3 & Minerais nāo Metalicos: & $\mathfrak{l}$ & 0 & 2 & 0 & 0 & 0 & 0 & 0 & 00 & 0 & 0 & 0 & 0 & 0 & 0 & 0 \\
\hline & 4 & Metahurgia & 0 & 0 & 0 & 0 & 0 & 0 & 0 & 0 & 00 & 0 & 0 & 0 & 0 & 0 & 0 & 0 \\
\hline & $s$ & Mecânica & 0 & 0 & 0 & 0 & 0 & 0 & 0 & 0 & 00 & 0 & 0 & 0 & 0 & 0 & 0 & 0 \\
\hline & 6 & Material Eletrico & 0 & 0 & 1 & 0 & 0 & 6 & 0 & 0 & 00 & 0 & 0 & 0 & 0 & 0 & 0 & 0 \\
\hline & 7 & Material de Transporte & 0 & 0 & 0 & 0 & 0 & 0 & 0 & 0 & 00 & 0 & 0 & 0 & 0 & 0 & 0 & 0 \\
\hline & 8 & Madeira e Mobiliario & I & 0 & 0 & 0 & 0 & 0 & 0 & 5 & 00 & 0 & 0 & 0 & 0 & 0 & 0 & 0 \\
\hline & 9 & Cetubse. Papel o Grat. & 0 & 0 & 0 & 0 & 0 & 0 & 0 & 0 & 00 & 0 & 0 & 0 & 0 & 0 & 0 & 0 \\
\hline & to & Find da Borracha & 0 & 0 & 0 & 0 & 0 & 0 & 0 & 0 & 00 & 0 & 0 & 0 & 0 & 0 & 0 & 0 \\
\hline & 11 & Refino do Petróleo & 0 & 0 & 0 & 0 & 0 & 0 & 0 & 0 & 00 & 0 & 0 & 0 & 0 & 0 & 0 & 0 \\
\hline & 12 & Qulmicos Div & 0 & 0 & 0 & 0 & 0 & 0 & 0 & 0 & 00 & 0 & 0 & 0 & 0 & 0 & 0 & 0 \\
\hline & 13 & Farm acsutic & 0 & 0 & 0 & 0 & 0 & 0 & 0 & 0 & 00 & 0 & 0 & 0 & 0 & 0 & 0 & 0 \\
\hline 0 & 14 & Plasticos & 0 & 0 & 0 & 0 & 0 & 0 & 0 & 0 & 00 & 0 & 0 & 0 & 0 & 0 & 0 & 0 \\
\hline $\mathrm{R}$ & 15 & Ind. Tezruit & 0 & 0 & 0 & 0 & 0 & 0 & 0 & 0 & 00 & 0 & 0 & 0 & 0 & 0 & 0 & 0 \\
\hline $\mathrm{T}$ & 16 & Vesturio Calcados & 0 & 0 & 0 & 0 & 0 & 0 & 0 & 0 & 00 & 0 & 0 & 0 & 0 & 0 & 0 & 0 \\
\hline & 17 & Endistia do Calte & 0 & 0 & 0 & 0 & 0 & 0 & 0 & 0 & 00 & 0 & 0 & 0 & 0 & 0 & 0 & I \\
\hline & 18 & Abate & 0 & 0 & 0 & 0 & 0 & 0 & 0 & 0 & 00 & 0 & 0 & 0 & 0 & 0 & 0 & 0 \\
\hline & 19 & Pabrica & 0 & 0 & 0 & 0 & 0 & 0 & 0 & 0 & 00 & 0 & 0 & 0 & 0 & 0 & 0 & 0 \\
\hline & 20 & Outros & 0 & 0 & 0 & 0 & 0 & 0 & 0 & 0 & 00 & 0 & 0 & 0 & 0 & 0 & 0 & c \\
\hline & 21 & Inchustria & 0 & 0 & 0 & 0 & 0 & 0 & 0 & 0 & 00 & 0 & 0 & 0 & 0 & 0 & 0 & 0 \\
\hline & 22 & Energ, Agua, San, e Com. & 0 & 0 & 0 & 0 & 0 & 0 & 0 & 0 & 00 & 0 & 0 & 0 & 0 & 0 & 0 & 0 \\
\hline & 23 & Construção Civil & 0 & 0 & 0 & 0 & 0 & 0 & 0 & 0 & 00 & 0 & 0 & 0 & 0 & 0 & 0 & 0 \\
\hline & 24 & Comitrcio & 4 & 0 & 0 & 0 & 0 & 0 & 0 & 0 & 00 & 0 & 0 & 0 & 0 & 0 & 0 & 0 \\
\hline & 25 & Transportes & 5 & $i$ & 2 & 0 & 0 & 0 & 0 & 0 & 00 & 0 & 0 & 0 & 0 & 0 & 0 & 0 \\
\hline & 26 & Serviços & 0 & 0 & 0 & 0 & 0 & 0 & o & 0 & 00 & 0 & 0 & 0 & 0 & 0 & 0 & 0 \\
\hline & 1 & Agropecustitio & 37 & 0 & 0 & 0 & 0 & 0 & 0 & 1 & 00 & 0 & 0 & 0 & 0 & 0 & 0 & 0 \\
\hline & 2 & Minet & 3 & 1 & 5 & I & 0 & 0 & 0 & 0 & 00 & & 0 & 0 & 0 & 0 & 0 & 0 \\
\hline & 3 & Minezais não & 0 & 0 & 1 & 0 & 0 & 0 & 0 & 0 & 00 & 0 & 0 & 0 & 0 & 0 & 0 & 0 \\
\hline & 4 & Metahurgia & 0 & 0 & 1 & 5 & 0 & 1 & 0 & 0 & 00 & 0 & 0 & 0 & 0 & 0 & 0 & 0 \\
\hline & 5 & Mechnica & 0 & 0 & 0 & 0 & 0 & 0 & 0 & 0 & 00 & 0 & 0 & 0 & 0 & 0 & 0 & 0 \\
\hline & 6 & Materia & 0 & 0 & 0 & 0 & 0 & 0 & 0 & 0 & 00 & 0 & 0 & 0 & 0 & 0 & 0 & 0 \\
\hline & 7 & Material & 0 & 0 & 0 & 0 & 0 & 0 & 0 & 0 & 00 & 0 & 0 & 0 & 0 & 0 & 0 & 0 \\
\hline & 8 & Madeir & 0 & 0 & 0 & 0 & 0 & 0 & 0 & 0 & 00 & 0 & 0 & 0 & 0 & 0 & 0 & 0 \\
\hline & 9 & Celubose & 0 & 0 & 0 & 0 & 0 & 0 & 0 & 0 & 00 & 0 & 0 & 0 & 0 & 0 & 0 & 0 \\
\hline N & 10 & End da & 0 & 0 & 0 & 0 & 0 & 0 & 0 & 0 & 00 & 0 & 0 & 0 & 0 & 0 & 0 & 0 \\
\hline 0 & HI & Reforo & 26 & 2 & 7 & 1 & 0 & 0 & 0 & 2 & I 1 & & 6 & 1 & 2 & 4 & 1 & 0 \\
\hline $\mathrm{R}$ & 12 & Quim: & 23 & 0 & 2 & 1 & 0 & 0 & 0 & 0 & 10 & 1 & 2 & 0 & 2 & 3 & 0 & 0 \\
\hline D & 13 & Farma & 0 & 0 & 0 & 0 & 0 & 0 & 0 & 0 & 00 & 0 & 0 & 0 & 0 & 0 & 0 & 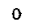 \\
\hline E. & 14 & Pistic & I & 0 & 0 & 0 & 0 & 0 & 0 & 0 & 00 & 0 & 0 & 0 & 0 & 0 & 0 & 0 \\
\hline$s$ & 15 & frd. Textil & 1 & 0 & 0 & 0 & 0 & 0 & 0 & 0 & 00 & 0 & 0 & 0 & 0.1 & 19 & $z$ & 0 \\
\hline$T$ & 16 & Vettu & 0 & 0 & 0 & 0 & 0 & 0 & 0 & 0 & 00 & 0 & 0 & 0 & 0 & 0 & 0 & 0 \\
\hline $\mathrm{E}$ & 17 & Indist & 0 & 0 & 0 & 0 & 0 & 0 & 0 & 0 & 00 & 0 & 0 & 0 & 0 & 0 & 0 & 0 \\
\hline & 18 & Abate & 0 & 0 & 0 & 0 & 0 & 0 & 0 & $o$ & 00 & 0 & 0 & 0 & 0 & 0 & 0 & 0 \\
\hline & 19 & Fabric & 0 & 0 & 0 & 0 & 0 & 0 & 0 & 0 & 00 & 0 & 0 & 0 & 0 & o & 0 & 0 \\
\hline & 20 & Outros & 4 & 0 & 0 & 0 & 0 & 0 & 0 & 0 & 00 & 0 & 0 & 0 & 0 & 0 & 0 & 0 \\
\hline & 21 & Indiust & 0 & 0 & 0 & 0 & 0 & 0 & 0 & 0 & 00 & 0 & 0 & 0 & 0 & 0 & 0 & 0 \\
\hline & 22 & Ener: & 0 & 0 & 0 & 0 & 0 & 0 & 0 & 0 & 00 & 0 & 0 & 0 & 0 & 0 & 0 & 0 \\
\hline & 23 & Const & 0 & 0 & 0 & 0 & 0 & 0 & 0 & 0 & 00 & 0 & 0 & 0 & 0 & 0 & 0 & 0 \\
\hline & 24 & Come & 18 & 1 & I & 1 & 0 & 1 & 0 & 1 & 10 & 2 & 1 & 0 & 0 & 1 & 1 & 0 \\
\hline & 25 & Trans & 3 & 0 & I & 0 & 0 & 0 & 0 & 0 & 00 & 0 & 0 & 0 & 0 & 0 & 0 & 0 \\
\hline & 26 & Serviços & 0 & 0 & 0 & 0 & 0 & 0 & 0 & 0 & 00 & 0 & 0 & 0 & 0 & 0 & 0 & 0 \\
\hline & 1 & Agra & 87 & 0 & 2 & 6 & 0 & 0 & 03 & 80 & 30 & 0 & 19 & 1 & 0 & 9 & & $\overline{\mid T T}$ \\
\hline & 2 & $\mathrm{Mi}$ & 79 & 121 & 121 & 12 & 0 & 1. & 0 & 0 & 10 & 0 & 8 & 0 & 0 & 0 & 0 & 0 \\
\hline & 3 & Mirx & 33 & 143 & 386 & 10 & 1 & $\theta$ & 1 & 4 & 30 & 3 & 5 & 2 & 0 & 1 & l & 1 \\
\hline & 4 & Mets & 20 & 16 & 12 & 571 & 10 & 25 & $5 \mathrm{i}$ & io & 30 & 2 & 3 & 1 & 1 & 2 & 1 & 0 \\
\hline & 5 & Mec & 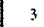 & 8 & 4 & 2 & 2 & 1 & 0 & I. & 10 & 1 & 1 & 0 & 0 & 1 & 0 & 0 \\
\hline & 6 & Mate & L & 0 & 1 & 0 & 1 & 6 & 0 & 0 & 00 & 0 & 0 & 0 & 0 & 0 & 0 & 0 \\
\hline c & $T$ & Mater & 0 & 0 & 0 & 0 & 0 & 0 & 1 & 0 & 00 & 0 & 0 & 0 & 0 & 0 & 0 & 0 \\
\hline E & 8 & Made & 4 & I & I & 1 & 0 & 1 & 0 & $4 !$ & 10 & 0 & 0 & 0 & 0 & 0 & 0 & 0 \\
\hline $\mathrm{N}$ & 9 & Celuto & $z$ & 2 & 10 & 1 & 0 & $i$ & 0 & 22 & & 1 & 1 & 1 & 0 & 1 & I & 1 \\
\hline $\mathrm{T}$ & 10 & find. & 0 & 1 & I & 0 & 0 & 0 & 0 & 0 & 02 & 0 & 0 & 0 & 0 & 0 & 1 & \\
\hline $\mathrm{R}$ & 11 & 1 & 98 & $T$ & 19 & 2 & 0 & 1 & 0 & 3 & 21 & 18 & 5 & 1 & 1. & 2 & 1 & 0 \\
\hline 0 & 12 & Qutr & 116 & 1 & 4 & 1 & 0 & 0 & 0 & t. & 10 & 3 & 5 & 1 & 1. & 2 & 0 & 0 \\
\hline & 13 & $\mathrm{~F}_{\mathrm{Nu}}$ & 0 & 0 & 0 & 0 & 0 & 0 & 0 & 0 & 00 & 0 & 0 & 1 & 0 & 0 & 0 & 0 \\
\hline 0 & 14 & Flas & 4 & 0 & $\mathfrak{t}$ & 0 & 0 & 1 & 0 & 2 & 00 & 0 & 0 & 0 & 0 & 1 & 2 & 0 \\
\hline$E$ & 15 & Inc & 17 & 1 & 3 & 0 & 0 & 0 & 0 & 6 & 12 & 1 & 0 & 0 & 1. 9 & 98. 0 & 63 & 1. \\
\hline s & 16 & Ves & i & 0 & 0 & 0 & 0 & 0 & 0 & 1 & 00 & 0 & 0 & 0 & 0 & 4 & 7 & 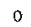 \\
\hline $\mathrm{T}$ & 17 & Inx & 1 & 0 & 0 & 0 & 0 & 0 & 0 & 0 & 00 & 0 & 0 & 0 & 0 & o & 0 & $\$ 9$ \\
\hline E & 18 & AB & 2 & 0 & 0 & 0 & 0 & 0 & 0 & 0 & 00 & 0 & 0 & 0 & 0 & 0 & 6 & o \\
\hline & 19 & & 0 & 0 & 0 & 0 & 0 & 0 & 0 & 0 & 00 & 0 & 3 & 0 & 0 & 0 & 0 & o \\
\hline & 20 & our & 343 & 1 & 1 & 0 & 0 & 0 & 0 & 0 & 10 & 1 & 2 & 2 & 0 & 0 & 0 & 2 \\
\hline & 21. & Ind & 0 & a & 0 & 0 & 0 & 0 & 0 & 0 & 00 & 0 & 0 & 0 & 0 & 0 & 0 & 0 \\
\hline & 22 & Enere & 60 & 31 & 57 & 17 & 3 & 4 & 1 & & 121 & 7 & 7 & 1 & & 7 & 4 & 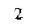 \\
\hline & 23 & $c_{0}$ & 0 & 6 & 4 & 1 & 0 & i & 0 & & 10 & 1 & 1 & 0 & & 1 & 0 & 0 \\
\hline & 24 & & 486 & 38 & 51 & 21 & 7 & & 13 & & 262 & 20 & & & & 25 & 17 & 7 \\
\hline & 2 & & & 46 & & 20 & 2 & & & & & & & 4 & & 7 & & \\
\hline & & Servicos & & & & & & & & & & & & & & & & \\
\hline
\end{tabular}


Anexo A: MATRIZ INTER-REGIONAL DE INGUMO - PRODUTO -BRASLL - 1985 (bilhöes de cruzainos) (montinus-

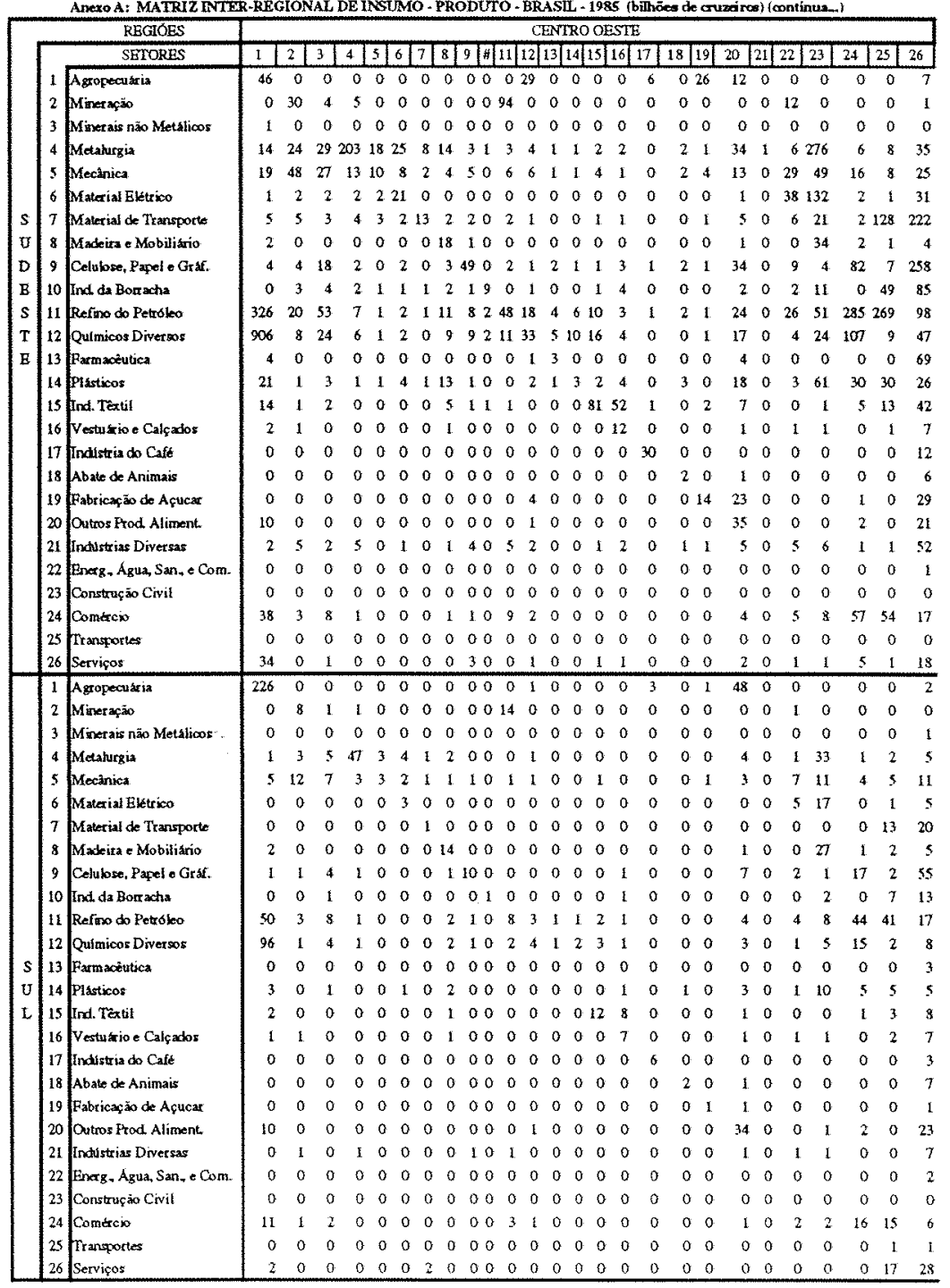




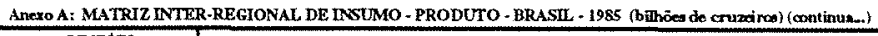

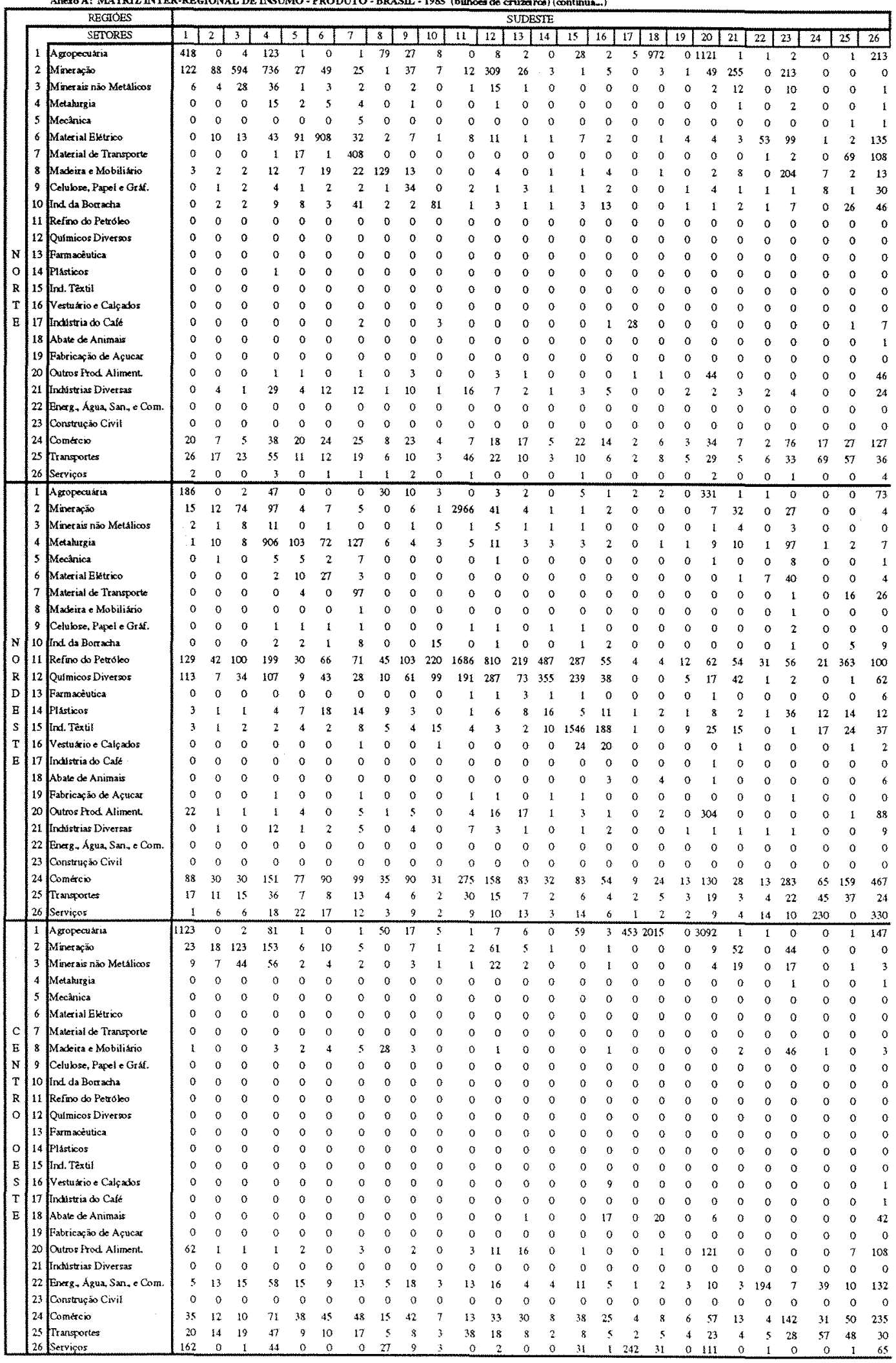


Anero A: MATRIZ INTER-REGIONAL DE INSUMO - PRODUTO - BRASIL - 1985 (billhée de cruzcires) (continus.

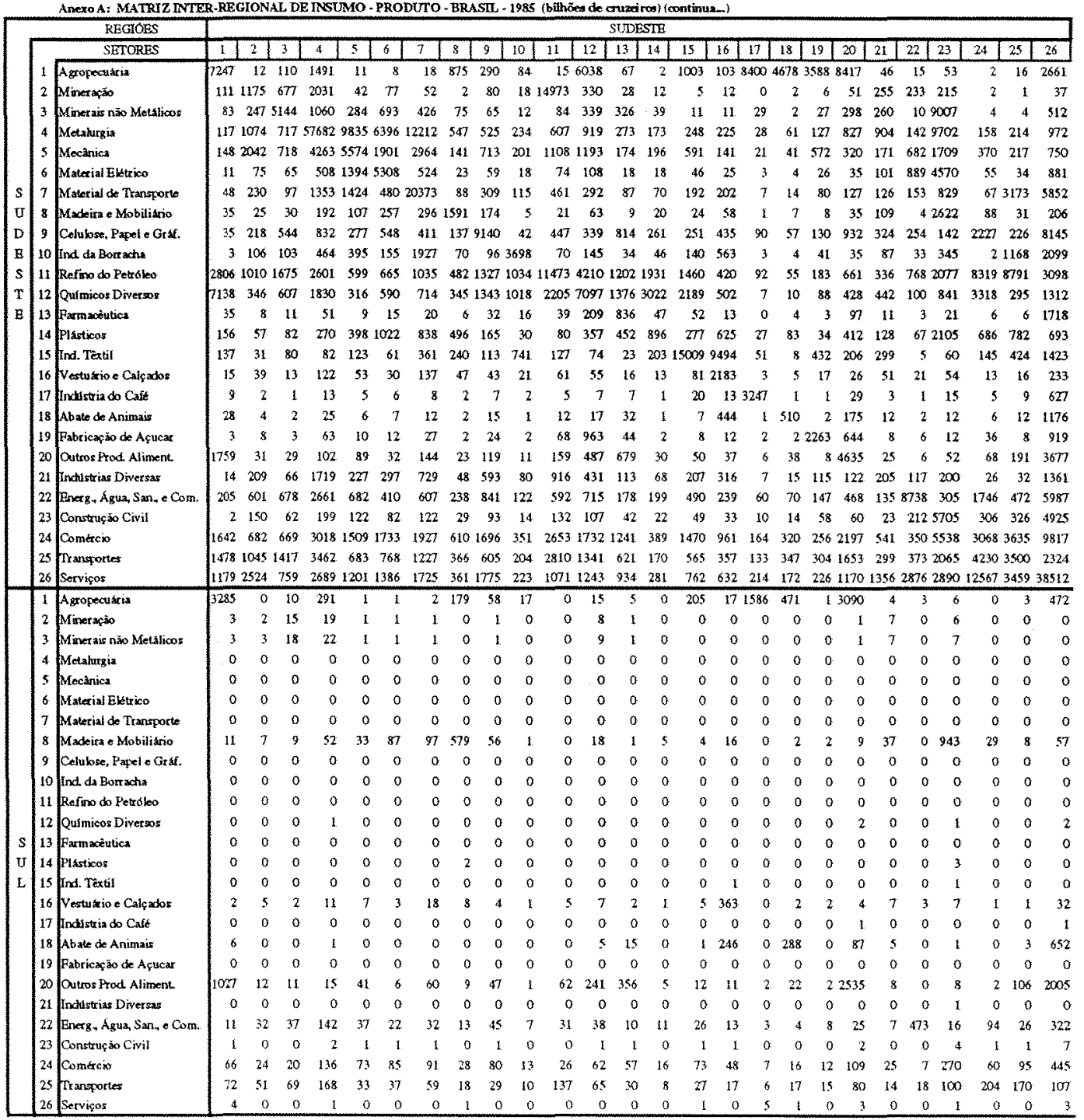


Anmx A: MATRI Z INTER-REGIONAL, DE INSUMO - PRODUTO - BRASIL - 1985 (bilhöes de cruxinas) (continua

\begin{tabular}{|c|c|c|c|c|c|c|c|c|c|c|c|c|c|c|c|c|c|c|}
\hline & & REGIOES & & & & & & & & & & & & SUL & & & & \\
\hline & & SETORES & 1 & 2 & 3 & 4 & 5 & 6 & 7 & 8 & 9 & 10 & 11 & 12 & 13 & 14 & 15 & 16 \\
\hline & 11 & Agropecutaiz & 326 & 0 & I & 10 & 0 & 0 & 0 & 70 & 7 & 1 & 0 & 1 & 0 & 0 & 7 & 1 \\
\hline & 2 & Mineracăo & 95 & 9 & 138 & 58 & 6 & 6 & 2 & 1 & 9 & 1 & 2 & 58 & 1 & 1. & 0 & 3 \\
\hline & 3 & Minetais náo Metalicos & 5 & 0 & 7 & 3 & 0 & 0 & 0 & 0 & 1 & 0 & 0 & 3 & 0 & 0 & 0 & 0 \\
\hline & 4 & Metahurgis & 0 & 0 & 0 & 1 & 0 & 1 & 0 & 0 & 0 & 0 & 0 & 0 & 0 & 0 & 0 & 0 \\
\hline & 5 & Mectaica & 0 & 0 & 0 & 0 & 0 & 0 & 0 & 0 & 0 & 0 & 0 & 0 & 0 & 0 & 0 & 0 \\
\hline & 6 & Material Elxtrico & 0 & 1. & 3 & 3 & 20 & 112 & 2 & 2 & 2 & 0 & 1 & 2 & 0 & 0 & 2 & 1 \\
\hline & 7 & Material de Trannporte & 0 & 0 & 0 & 0 & 4 & 0 & 26 & 0 & 0 & 0 & 0 & 0 & 0 & 0 & 0 & 0 \\
\hline & 8 & Madeira e Mobilikrio & 2 & 0 & 0 & 1 & 2 & 2 & 1 & 114 & 3 & 0 & 0 & 1 & 0 & $a$ & 0 & 2 \\
\hline & 9 & Celubse, Papel e Grat. & 0 & 0 & 0 & 0 & 0 & 0 & 0 & 0 & s & 0 & 0 & 0 & 0 & 0 & 0 & 1 \\
\hline & 10 & Ind da Borzachat & 0 & 0 & 0 & 1 & 2 & 0 & 3 & 1 & 0 & 10 & 0 & 1 & 0 & 0 & 1 & 8 \\
\hline & 11 & Refiso do Petróleo & 0 & 0 & 0 & 0 & 0 & 0 & 0 & 0 & 0 & 0 & 0 & 0 & 0 & 0 & 0 & 0 \\
\hline & 12 & Quimicos Diversos & 0 & 0 & 0 & 0 & 0 & 0 & 0 & 0 & 0 & 0 & 0 & 0 & 0 & 0 & o & 0 \\
\hline $\mathbf{N}$ & 13 & Farmatutica & 0 & 0 & 0 & 0 & 0 & 0 & 0 & 0 & 0 & 0 & 0 & 0 & 0 & 0 & 0 & 0 \\
\hline 0 & 14 & Plasticos & 0 & 0 & 0 & 0 & 0 & 0 & 0 & 0 & 0 & 0 & 0 & 0 & 0 & 0 & 0 & 0 \\
\hline $\mathbf{R}$ & 15 & Ind. Textil & 0 & 0 & 0 & 0 & 0 & 0 & 0 & 0 & 0 & 0 & 0 & 0 & 0 & 0 & 0 & 0 \\
\hline $\mathrm{T}$ & 16 & Vestuxicioe Calç abos & 0 & 0 & 0 & 0 & 0 & 0 & 0 & 0 & 0 & 0 & 0 & 0 & 0 & 0 & 0 & 0 \\
\hline $\mathbf{E}$ & 17 & Indistria do Cals & 0 & 0 & 0 & 0 & 0 & 0 & 0 & 0 & 0 & 0 & 0 & 0 & 0 & 0 & 0 & 0 \\
\hline & ${ }^{18}$ & Abate de Animais & 0 & 0 & 0 & 0 & 0 & 0 & 0 & 0 & 0 & 0 & 0 & 0 & 0 & 0 & 0 & 0 \\
\hline & 19 & Fabricacágo de $A_{\text {fucar }}$ & 0 & 0 & 0 & 0 & 0 & 0 & 0 & 0 & 0 & 0 & 0 & 0 & 0 & 0 & 0 & 0 \\
\hline & 20 & Ostros Frod. Aliment. & 0 & 0 & 0 & 0 & 0 & 0 & 0 & 0 & 1 & o & 0 & 1 & 0 & 0 & 0 & 0 \\
\hline & 21 & Industrias Diversas & 0 & 0 & 0 & 2 & 1 & 2 & I. & $\mathfrak{l}$ & 3 & 0 & 3 & 1 & 0 & 0 & 1 & 3 \\
\hline & 22 & Energ, Agua, $S_{2}$, e Com. & 0 & 0 & 0 & 0 & 0 & 0 & 0 & 0 & 0 & 0 & 0 & 0 & 0 & 0 & 0 & 0 \\
\hline & 23 & Construqąo Civil & 0 & 0 & 0 & 0 & 0 & 0 & 0 & 0 & o & 0 & 0 & 0 & 0 & 0 & 0 & 0 \\
\hline & 24 & Comarcio & 16 & 1 & I. & 3 & 5 & 3 & 2 & 7 & 6 & 0 & 1 & 3 & I & 1 & 6 & 8 \\
\hline & 25 & Transportes & 20 & 2 & 5 & 4 & 2 & 2 & I. & 5 & 2 & 0 & 9 & 4 & 0 & I & $z$ & 4 \\
\hline & 26 & Serviços & 1 & 0 & 0 & 0 & 0 & 0 & 0 & 1 & 0 & 0 & 0 & 0 & 0 & 0 & 0 & 0 \\
\hline & 1 & Agropecal deta & 145 & 0 & 0 & 4 & 0 & 0 & 0 & 26 & 2 & 0 & 0 & 1 & 0 & 0 & $I$ & 0 \\
\hline & 2 & Minerasăbo & 12 & 1. & 17 & 8 & 1 & 1. & 0 & 0 & 2 & o & 558 & 8 & 0 & 0 & 0 & 1 \\
\hline & ${ }^{3}$ & Miner ais näo Metálioos & 1 & 0 & 2 & 1 & 0 & 0 & 0 & 0 & $\alpha$ & o & 0 & 1 & 0 & 0 & 0 & 0 \\
\hline & 4 & Metalurgia & 1 & 1. & 2 & 72 & 23 & 9 & 8 & 5 & 1 & 0 & $\mathfrak{l}$ & 2 & 0 & 1 & 1 & I \\
\hline & 5 & Mecanica & 0 & 0 & 0 & 0 & 1 & 0 & 0 & 0 & 0 & 0 & 0 & 0 & 0 & 0 & 0 & 0 \\
\hline & 6 & Material Elétrico & 0 & 0 & 0 & 0 & 2 & 3 & 0 & 0 & 0 & 0 & 0 & 0 & 0 & 0 & 0 & 0 \\
\hline & $\gamma$ & Material de Transprotte & 0 & 0 & 0 & 0 & $£$ & 0 & 6 & 0 & o & 0 & 0 & 0 & 0 & 0 & 0 & 0 \\
\hline & 8 & Madeira e Mobiliário & 0 & 0 & 0 & 0 & 0 & 0 & 0 & 0 & 0 & 0 & 0 & 0 & 0 & 0 & 0 & 0 \\
\hline & 9 & Celulose, Papel e Graf. & 0 & 0 & 0 & 0 & 0 & 0 & 0 & 0 & 0 & 0 & 0 & 0 & 0 & 0 & 0 & 0 \\
\hline $\mathrm{N}$ & 10 & Ind da Bort acha & 0 & 0 & 0 & 0 & 0 & 0 & 0 & 0 & 0 & 2 & 0 & 0 & 0 & 0 & 0 & 1 \\
\hline o) & 11 & Refito do Petrobo & $10 t$ & 4 & 23 & 16 & $T$ & 8 & 4 & 40 & 26 & 27 & 317 & 152 & & & 73 & 32 \\
\hline $\mathrm{R}$ & 12 & Quimicos Diversos & 88 & 1 & 8 & 8 & $z$ & 5 & 2 & 9 & 15 & 12 & 36 & 54 & 3 & 79 & $6 \mathfrak{I}$ & 22 \\
\hline D & 13 & Farm anêutica & 0 & 0 & 0 & 0 & 0 & 0 & 0 & 0 & 0 & 0 & 0 & 0 & 0 & 0 & 0 & 0 \\
\hline $\mathrm{E}$ & 14 & Plasticos & 2 & 0 & 0 & 0 & 2 & 2 & 1 & 8 & 1 & 0 & 0 & 1 & 0 & 4 & 1 & 7 \\
\hline s & 15 & Ind. Têxul & 2 & 0 & 0 & 0 & $\mathfrak{l}$ & 0 & 0 & 4 & 1 & 2 & I & 1 & 0 & 2 & 394 & 112 \\
\hline r & 16 & Vertuario Calçados & 0 & 0 & 0 & 0 & 0 & 0 & 0 & 0 & 0 & 0 & 0 & 0 & 0 & 0 & 6 & 12 \\
\hline $\mathrm{E}$ & 17 & Indistria do Caft & 0 & 0 & 0 & 0 & 0 & 0 & 0 & 0 & 0 & 0 & 0 & 0 & 0 & 0 & 0 & 0 \\
\hline & 18 & Abate de Animais & 0 & 0 & 0 & 0 & 0 & 0 & 0 & 0 & 0 & 0 & 0 & 0 & 0 & 0 & 0 & 2 \\
\hline & 19 & Fabricaçắ de Açucar & 0 & 0 & 0 & 0 & 0 & 0 & 0 & 0 & 0 & 0 & 0 & 0 & 0 & 0 & o & 0 \\
\hline & $20 \mid$ & Outros Ftod Alumenth & 17 & 0 & 0 & 0 & 1 & 0 & 0 & 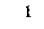 & 1 & 0 & 1 & 3. & 1 & 0 & 1 & 0 \\
\hline & $2 \mathrm{I}$ & Inchistrias Diversas & 0 & 0 & 0 & 1 & 0 & 0 & 0 & 0 & 1 & 0 & 1 & 1 & 0 & 0 & 0 & 1 \\
\hline & 22 & Energ, Agua, $\mathrm{San}_{+}+\mathrm{Com}$ & 0 & 0 & 0 & 0 & 0 & 0 & 0 & 0 & 0 & 0 & 0 & 0 & 0 & 0 & o & 0 \\
\hline & 23 & Construçăso Civil & 0 & 0 & 0 & 0 & 0 & 0 & 0 & 0 & 0 & 0 & 0 & 0 & 0 & 0 & 0 & 0 \\
\hline & 24 & Comécis & 69 & 3 & 7 & 12 & 17 & 11 & 6 & $3 \mathrm{~L}$ & 22 & 4 & 52 & 30 & 4 & 7 & 21 & 32 \\
\hline & ${ }^{25}$ & Franspoties & 13 & 1 & 3 & 3 & 2 & 1 & 1 & 3 & 2 & o & 6 & 3 & 0 & 0 & 2 & 2 \\
\hline & 26 & Servicos & 1 & 1 & 1 & 1 & 5 & 2 & 1 & 3 & 2 & 0 & 2 & 2 & I & 1 & 4 & 4 \\
\hline & 1 & Agropecuaria & 6 & 0 & 0 & 0 & 0 & 0 & 0 & 0 & 0 & 0 & 0 & 20 & 0 & 0 & o & 0 \\
\hline & 2 & Miner acias & 52 & 4 & 59 & 18 & 2 & 2 & 1 & 0 & 4 & 0 & I & $2 T$ & I & 0 & o & 2 \\
\hline & 3 & Mùer ais năo Metálicos & 19 & 2 & 35 & 7 & 2 & 2 & 1 & 1 & 2 & 0 & 1 & 10 & 0 & 0 & 0 & 2 \\
\hline & 4 & Metakurgia & 2 & 1. & 1 & 21 & 23 & IS & 9 & 8 & 2 & 0 & 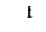 & 3 & 0 & 1 & I. & 2 \\
\hline & 5 & Mecânica & 0 & 0 & 0 & 0 & I & 0 & 0 & 0 & 0 & 0 & 0 & 0 & 0 & 0 & 0 & 0 \\
\hline & 6 & Material Eketrico & 0 & 0 & 0 & 0 & 1 & 3 & 0 & 0 & 0 & 0 & 0 & 0 & 0 & 0 & 0 & 0 \\
\hline c & 7 & Material de Transporte & 0 & 0 & 0 & 0 & 0 & 0 & 0 & 0 & o & 0 & 0 & 0 & 0 & 0 & 0 & 0 \\
\hline E & 8 & Madeina e Mobiliário & 0 & 0 & 0 & 0 & 0 & 0 & 0 & 0 & 0 & 0 & 0 & 0 & 0 & 0 & 0 & 0 \\
\hline $\mathrm{N}$ & 9 & Calutose, Papel e Grar. & 0 & 0 & 0 & 0 & 0 & 0 & o & 0 & 5 & 0 & 0 & 0 & 0 & 0 & 0 & $\mathfrak{I}$ \\
\hline $\mathrm{T}$ & 10 & Ind da Boracha & 0 & 0 & 0 & 0 & 0 & 0 & 0 & 0 & 0 & 2 & 0 & 0 & 0 & 0 & 0 & 2 \\
\hline $\mathrm{R}$ & 11 & Refino do Petroleo & 6 & 0 & 1 & 0 & 0 & 0 & 0 & $i$ & 1 & 0 & 4 & 2 & 0 & 1 & 1 & 0 \\
\hline 0 & 12 & Químicas Diversos & $y$ & 0 & 0 & 0 & 0 & o & o & 0 & 0 & 0 & $\mathbf{i}$ & 2 & 0 & $\mathfrak{l}$ & I & 0 \\
\hline & 13 & Farmacutica & 0 & 0 & 0 & 0 & 0 & 0 & 0 & 0 & 0 & 0 & 0 & 0 & 0 & 0 & 0 & 0 \\
\hline 0 & 14 & Plásticos & 0 & 0 & 0 & 0 & 0 & 0 & 0 & $\mathrm{I}$ & 0 & 0 & 0 & 0 & 0 & 0 & 0 & I \\
\hline E & 15 & Ind. Têxuil & 0 & 0 & 0 & 0 & 0 & 0 & 0 & I & 0 & 0 & 0 & 0 & 0 & 0 & 15 & 21 \\
\hline s & 16 & Vesturio Calçados & 0 & 0 & 0 & 0 & 0 & 0 & 0 & 0 & 0 & 0 & 0 & 0 & 0 & 0 & 1 & $\mathfrak{I}$ \\
\hline $\mathrm{T}$ & 17 & Indistria do Café & 0 & 0 & 0 & 0 & 0 & $o$ & 0 & 0 & 0 & 0 & 0 & 0 & 0 & 0 & 0 & 0 \\
\hline $\mathrm{E}$ & 18 & Atrate de Animais & 0 & 0 & 0 & 0 & 0 & o & 0 & 0 & 0 & 0 & 0 & 0 & 0 & 0 & 0 & 0 \\
\hline & 19 & Fabricarä́o de Açucar & o & 0 & 0 & 0 & 0 & 0 & 0 & 0 & 0 & 0 & 0 & 3 & 0 & 0 & 0 & 0 \\
\hline & 20 & Outros Prod Aliment. & 0 & 0 & 0 & 0 & 0 & 0 & o & 0 & 0 & 0 & 0 & 0 & 0 & 0 & 0 & 0 \\
\hline & 21 & Irdustrias Divetsas & 0 & 0 & 0 & 0 & 0 & 0 & 0 & 0 & 0 & 0 & 0 & 0 & 0 & 0 & 0 & 0 \\
\hline & 22 & Energ, Agua, San, e Com. & 0 & 0 & 0 & 0 & 0 & 0 & 0 & 0 & $o$ & 0 & 0 & 0 & 0 & 0 & 0 & 0 \\
\hline & 23 & Construţ̧ ấ Ciril & 0 & 0 & 0 & 0 & 0 & 0 & 0 & 0 & o & 0 & 0 & 0 & 0 & 0 & 0 & 0 \\
\hline & 24 & Comerein & 5 & 1 & 1 & 0 & $\mathfrak{l}$ & 0 & 0 & 1 & r. & 0 & 3 & I. & 0 & 0 & 1 & I \\
\hline & 25 & Transportes & 0 & 0 & 0 & 0 & 0 & 0 & 0 & 0 & 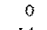 & 0 & 0 & 0 & 0 & 0 & 0 & 0 \\
\hline & 261 & Servicos & 39 & 11 & 1 & $s$ & 10 & 6 & 4 & 14 & 14 & 1 & 8 & 9 & & & $\$$ & 16 \\
\hline
\end{tabular}


Anexo A: MATRIZ INTER-REGIONAL DE INSUMO - PRODUTO - BRASL - 1985 (bilhöes de cruzana) (continuz-?

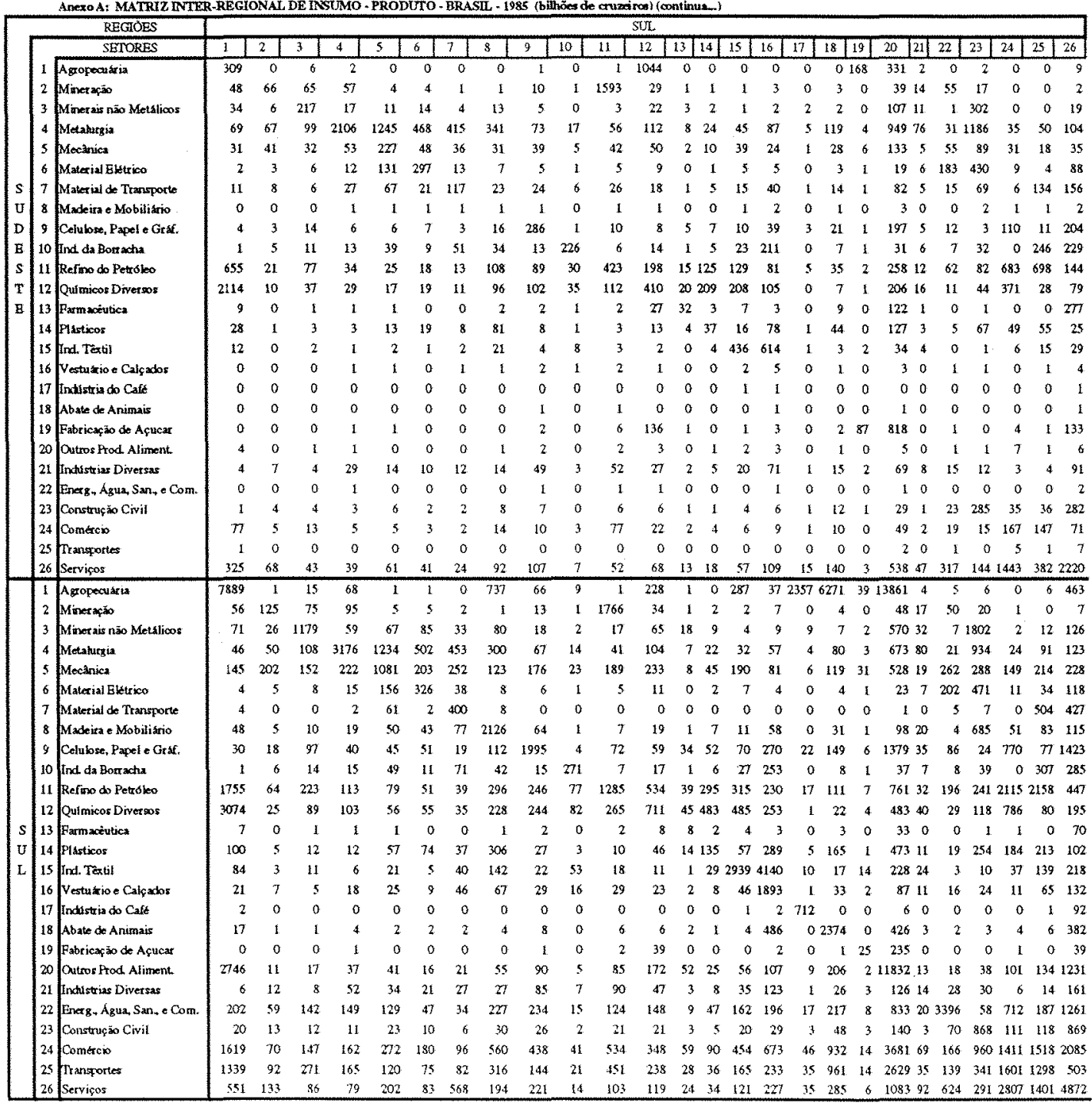


Anexo A: MATRIZ INTER-REGIONAL DE INSUMO - PRODUTO - BRASIL - 1995 (bahöes de crumirco) (continun-)

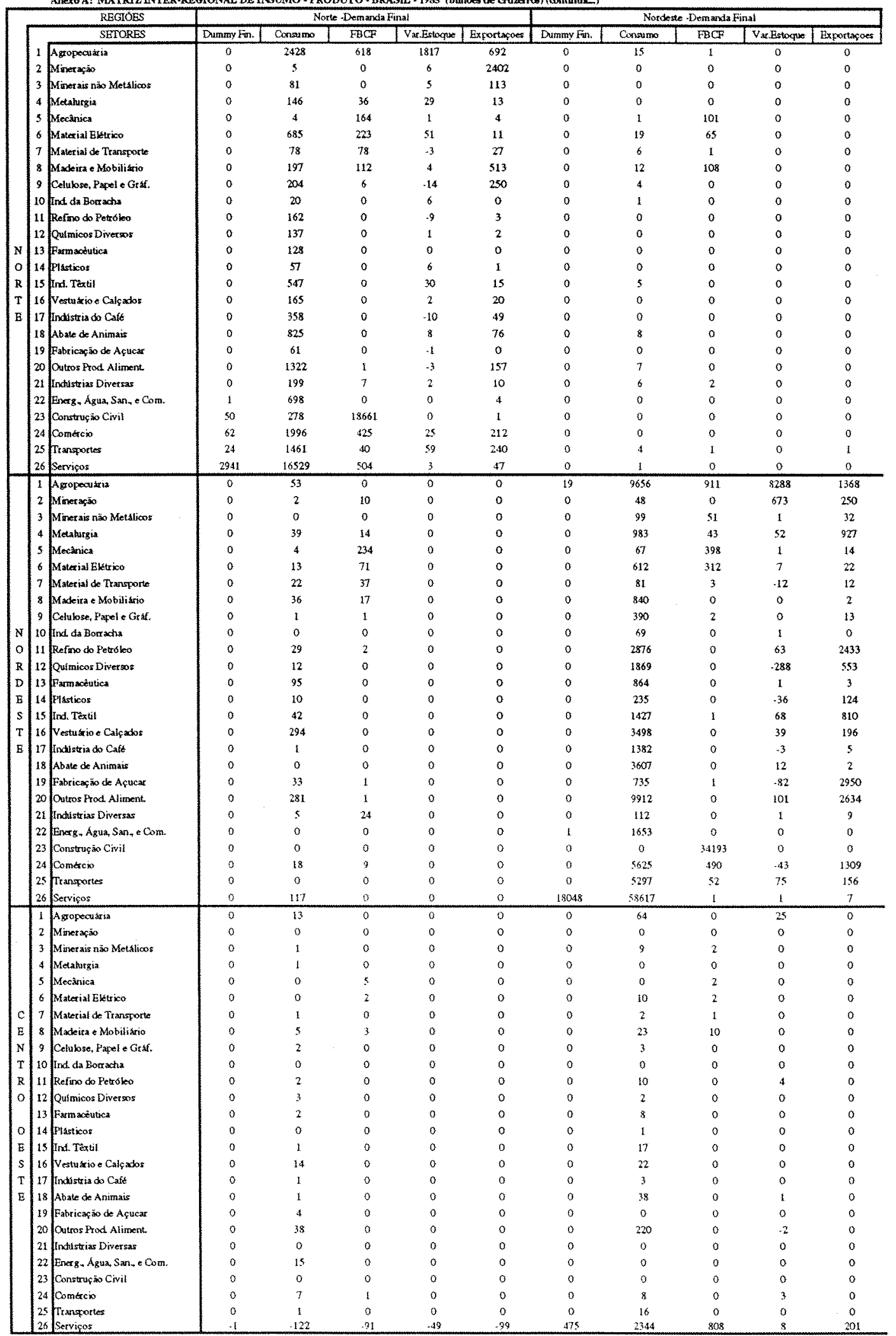


Anexo A: MATRIZ INTER-REGIONAL DE INSUMO - PRODUTO - BRASIL - 1985 (bỉhö̌s de cruzeciroes) (continua -)

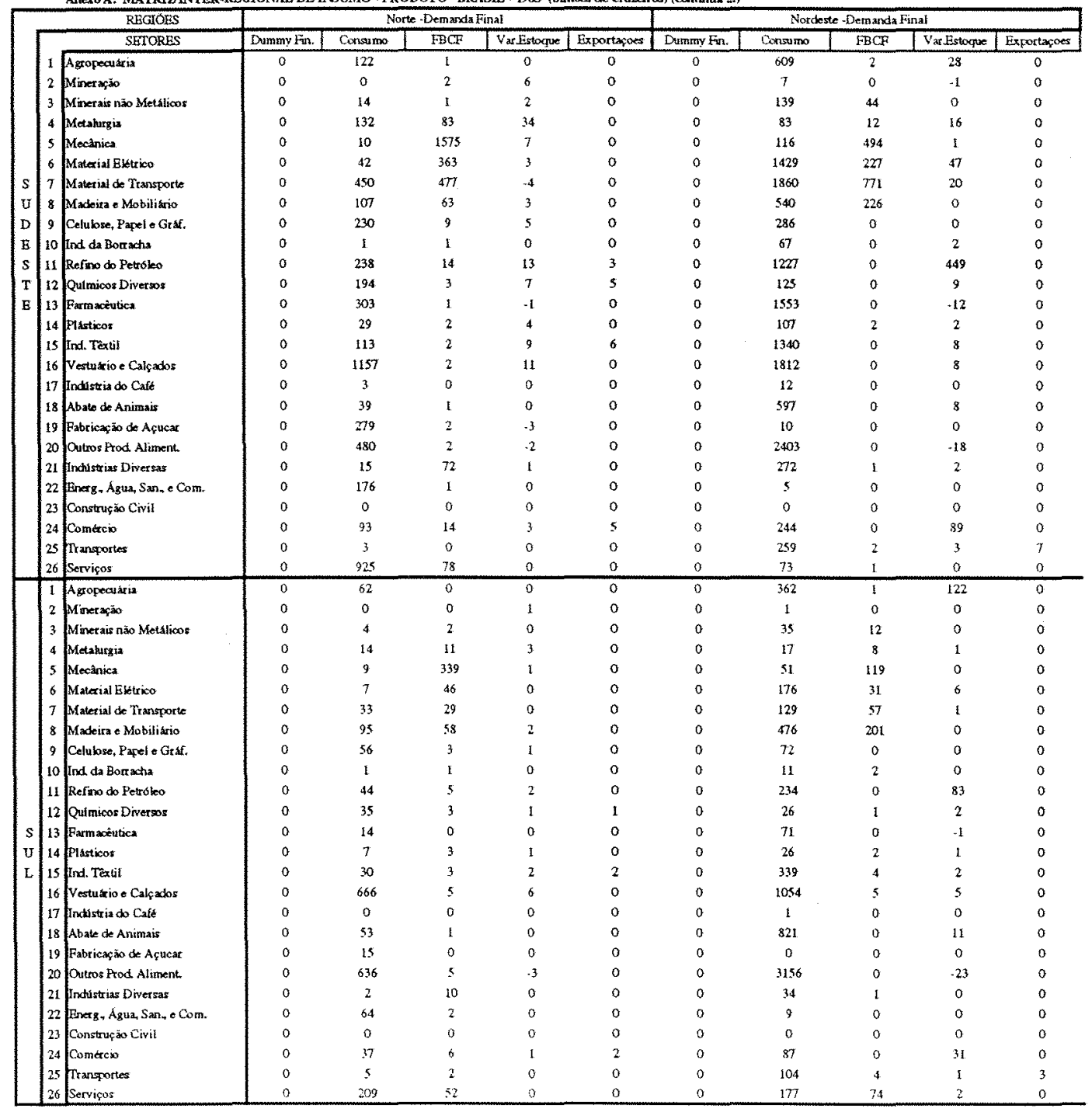


Anexo A: MATREZ ENTER-REGIONAL DE INSUMO - PRODUTO - BRASIL - 1985 (bitsez

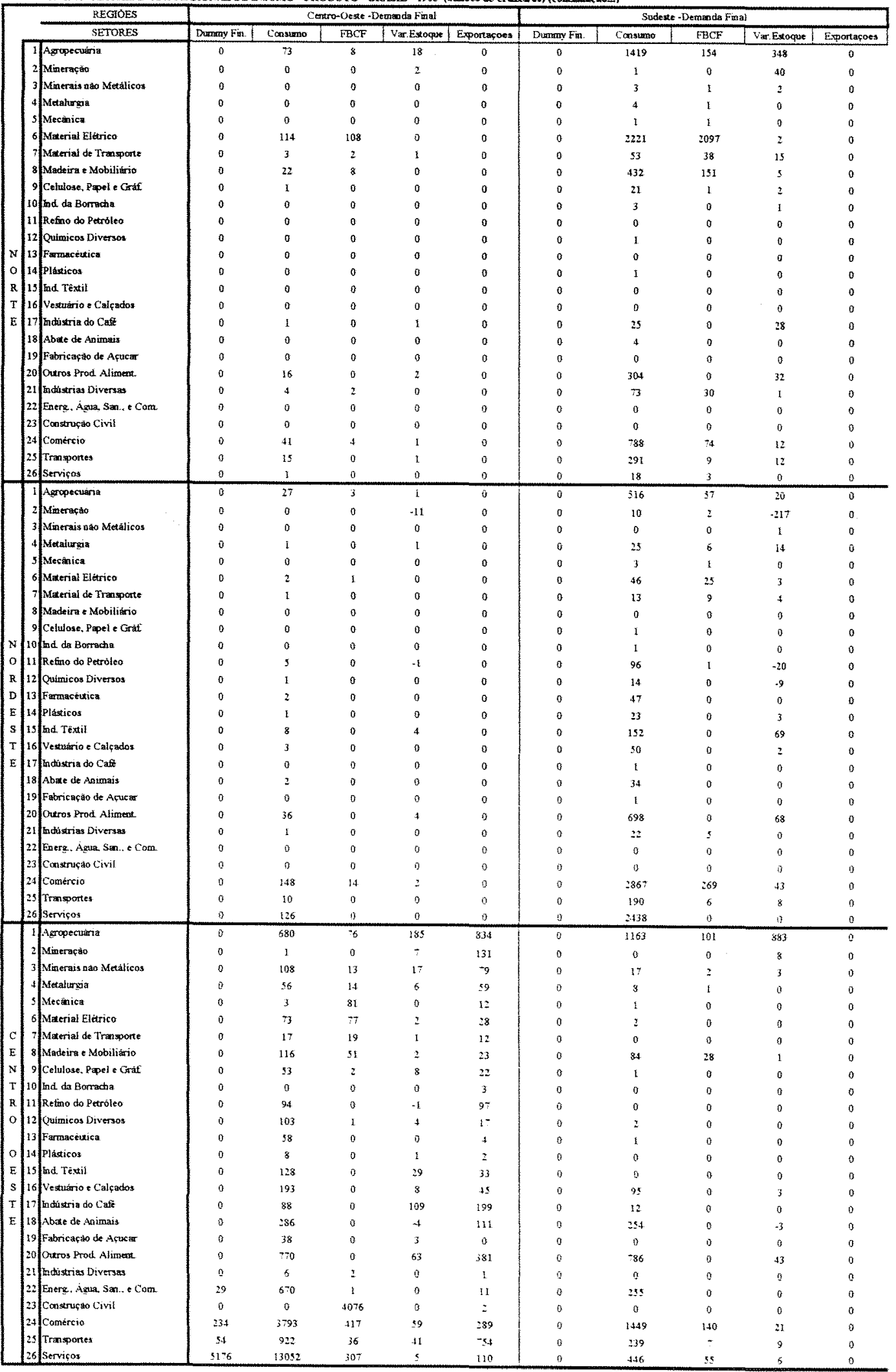




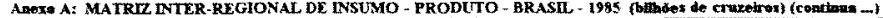

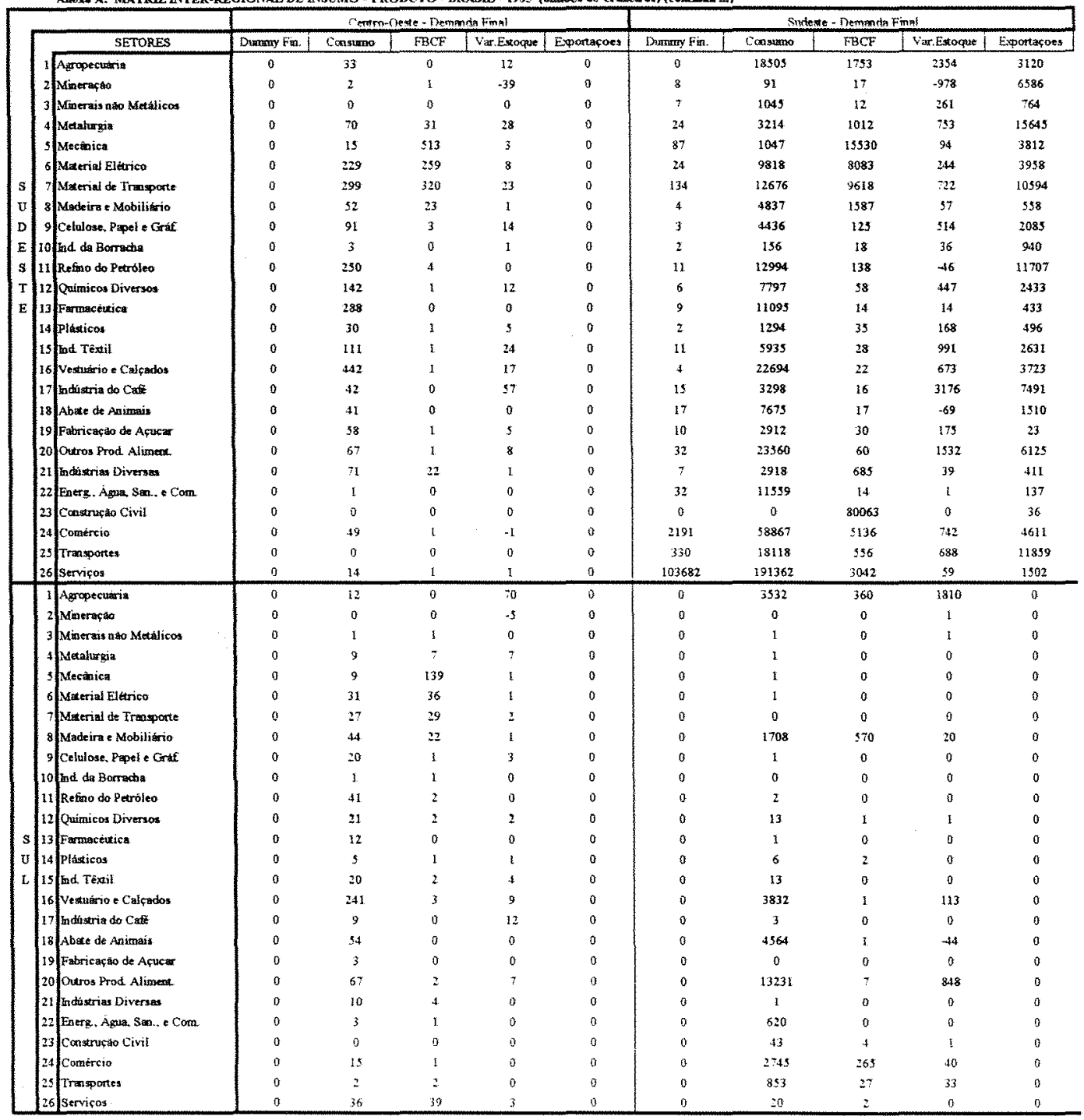




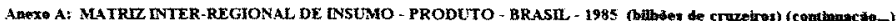

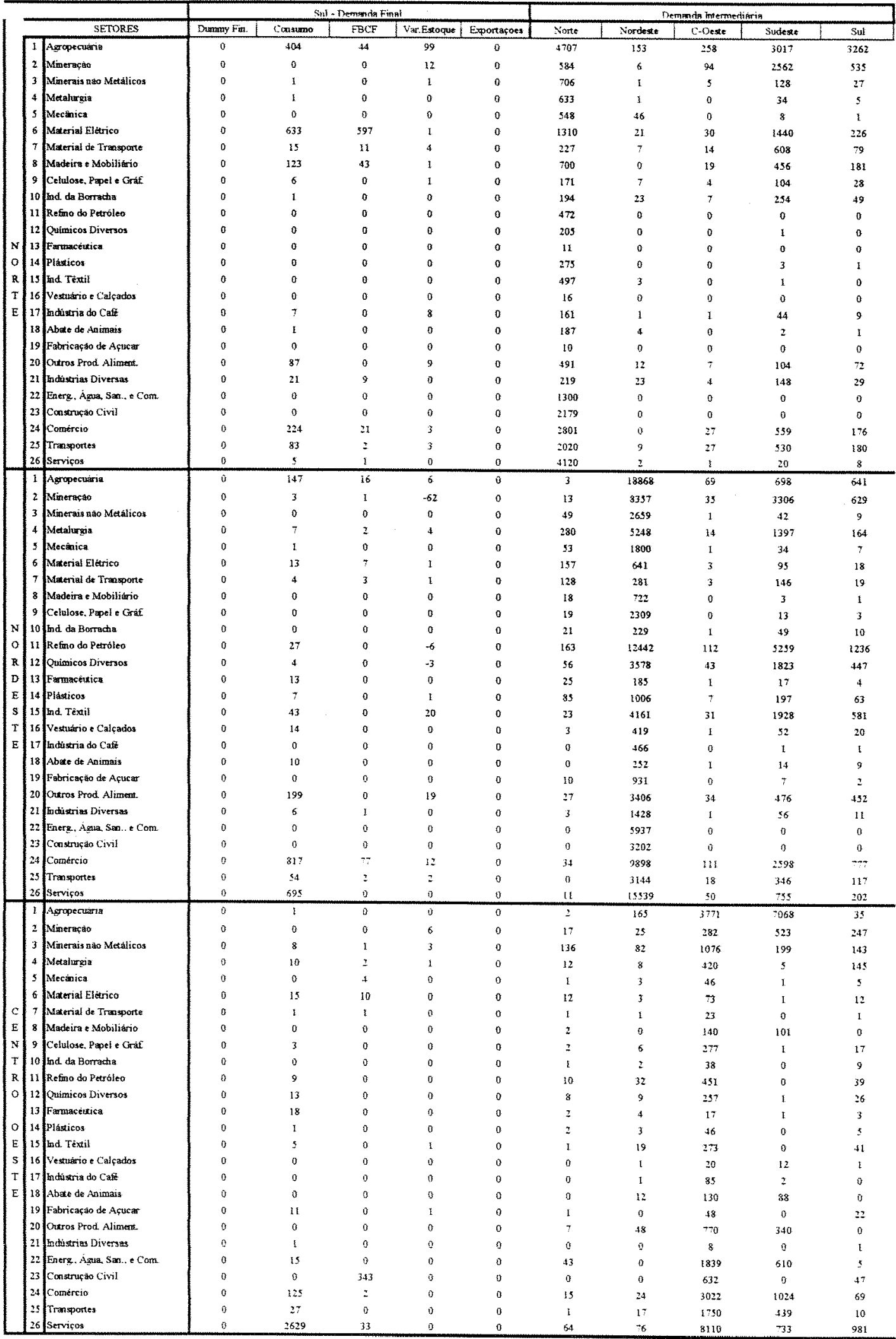




\begin{tabular}{|c|c|c|c|c|c|c|c|c|c|c|c|c|}
\hline \multirow{28}{*}{$\begin{array}{l} \\
\\
\\
S \\
U \\
D \\
\text { E } \\
S \\
\mathrm{~T} \\
\mathrm{E}\end{array}$} & & REGIOES & \multicolumn{5}{|c|}{ Sul - Derianda Final } & \multicolumn{5}{|c|}{ Demanda Intermediaria - Total } \\
\hline & & SETORES & Dummy Frn. & Consumo & $\mathrm{FBCF}$ & Vax.Entoque & Exportafoes & Norle & Nordeste & C.Oeste & Sudeste & Sul \\
\hline & $1 p$ & Agropecuadria & a & so & 0 & 3 & 0 & 18 & 944 & 128 & 45252 & 1875 \\
\hline & $2 \mathrm{~A}$ & Minet açào & 0 & 8 & 1 & -195 & 0 & 159 & 105 & 147 & 20429 & 2015 \\
\hline & 3 & Minetais näo Metalicar & 0 & 59 & 1 & 18 & 0 & 2467 & 1385 & 3 & 19054 & 799 \\
\hline & 4 & Metalurgia & 0 & 547 & 122 & 170 & 0 & 1563 & 1849 & 719 & 104923 & 7790 \\
\hline & 51 & Mecânica & 0 & 86 & 804 & 7 & 0 & 241 & 883 & 301 & 26921 & 1109 \\
\hline & 161 & Material Eketrico & 0 & 1548 & 1053 & 41 & 0 & 3704 & $3 \pi$ & 237 & 14874 & 1246 \\
\hline & 7 & Material de Transporte & 0 & 523 & 296 & 27 & 0 & 904 & 961 & 430 & 36248 & 899 \\
\hline & 8 & Madeira e Mobiliario & 0 & 8 & 2 & $\alpha$ & 0 & 48 & 20 & 65 & 8016 & 22 \\
\hline & 96 & Cetulose, Papel e Gtat. & 0 & $\$ 70$ & 5 & 20 & 0 & 157 & 595 & 491 & 27258 & 993 \\
\hline & 10 & Ind da Borracha & 0 & 15 & 1 & 6 & 0 & 174 & 649 & 179 & 11834 & 1220 \\
\hline & {$[11 \mathrm{~F}$} & Refino do Petróko & 0 & 835 & 11 & a & 0 & 1346 & 4008 & 1278 & 58313 & 4023 \\
\hline & 12 & Quimicos Divetsos & 0 & 672 & 3 & 41 & 0 & 1159 & 1680 & 1255 & 37479 & 4297 \\
\hline & 13 & Farmacêtutics & 0 & 2710 & 1 & 3 & 0 & 311 & 802 & 85 & 3268 & s01 \\
\hline & 14 & Plarticos & 0 & 69 & 2 & 10 & 0 & 396 & 641 & 228 & 11216 & 691 \\
\hline & 15 & Ind. Tèxtil & 0 & 168 & 2 & 29 & 0 & 103 & 1522 & 229 & 29953 & 1206 \\
\hline & 16 & Vestukitio e Cals ados & 0 & 10 & 2 & 0 & 0 & 7 & 56 & 30 & 3371 & 28 \\
\hline & 17 & Indistria do $C_{3}$ fes & 0 & 4 & 0 & 0 & 0 & 1. & 24 & 44 & 4049 & 4 \\
\hline & 18 & Abale de Animais & 0 & $s$ & 1 & 0 & 0 & 7 & 175 & 9 & 2524 & 7 \\
\hline & 19 & Fabricaşa de Açucstr & 0 & 622 & 2 & 41 & 0 & 62 & 9 & 73 & 5150 & 1200 \\
\hline & 20 & Outros Ftoct Aliment. & 0 & 45 & 2 & 1 & 0 & 114 & 652 & 72 & 12488 & 42 \\
\hline & 21 & Industrias Diversas & 0 & 289 & 58 & 4 & 0 & 21 & 775 & 104 & 8233 & 543 \\
\hline & 22 & Enag, Agua, San, e Com. & 0 & 11 & 1 & 0 & 0 & 508 & 5 & 2 & 27587 & 12 \\
\hline & 23 & Construçào Crril & 0 & 0 & $\$ 602$ & 0 & 0 & 0 & 1 & 0 & 12899 & 765 \\
\hline & 24 & Comarcio & 0 & $\$ 14$ & 7 & -1 & 0 & 235 & 697 & 209 & 48169 & 738 \\
\hline & 25 & Transportes & 0 & 53 & 1 & 0 & 0 & 3 & 265 & 0 & 32348 & 20 \\
\hline & 26 & Servicos & o & 16650 & 211 & 2 & 0 & 918 & $\$ 27$ & 70 & 82189 & 6370 \\
\hline & 1 & Agropecustia & 0 & 4836 & 396 & 1213 & 2429 & 18 & 818 & 282 & 9725 & 32353 \\
\hline & 2 & Miner açäa & 2 & 25 & 5 & .194 & 669 & 17 & 13 & 25 & 66 & 2336 \\
\hline & 3 & Minet ais não Metaticos & 3 & 394 & 46 & 95 & 192 & 558 & 314 & 2 & 76 & 4310 \\
\hline & 4 & Metahurgia & \& & 493 & 218 & 274 & 1265 & 127 & 144 & 114 & I & 8246 \\
\hline & 5 & Mečannica & 3 & 446 & 4316 & $\$ 2$ & 980 & 58 & 193 & 82 & I & $\$ 169$ \\
\hline & 6 & Material Eletrico & 1 & 1756 & 1239 & 50 & 514 & 205 & 47 & 33 & 1 & 1467 \\
\hline & 7 & Material de Transporte & 0 & 1317 & 384 & 91 & 761 & 59 & 56. & 35 & 0 & 1423 \\
\hline & 8 & Madeita o Mobiliatio & 2 & 2275 & 698 & 38 & 571 & 48 & 20 & 55 & 2064 & 3633 \\
\hline & 9 & Celulose, Papele Grati. & 2 & 1190 & 33 & 142 & 513 & 39 & 148 & 105 & I & 6940 \\
\hline & 10 & Ind da Borracha & 0 & 52 & $n$ & 9 & 126 & 21 & 75 & 27 & 0 & 1499 \\
\hline & 11 & Refino do Petróko & 5 & 2645 & 58 & -5 & 2173 & 248 & 745 & 200 & 2 & 11728 \\
\hline & 12 & Quínicos Diversos & 3 & 1470 & 53 & 87) & 476 & 216 & 314 & 151 & 9 & 7991 \\
\hline$s$ & 13 & Farmactutica & 1 & 667 & 1 & 1 & 21 & 14 & 37 & 4 & 1 & 148 \\
\hline $\mathrm{u}$ & 14 & Plasticos & I & 288 & 44 & 38 & $\$ 24$ & 86 & 137 & 38 & 7 & 2609 \\
\hline $\mathrm{L}$ & 15 & Ind. Textil & $s$ & 1234 & 71 & 205 & 703 & 30 & 379 & 39 & 4. & 8225 \\
\hline & 16 & Vestuxio e Calçados & 5 & 8527 & 95 & 270 & 2209 & II & 45 & 22 & 502 & 2626 \\
\hline & 17 & findistria do Cafe & 2 & 719 & $\mathfrak{I}$ & 785 & 1712 & 0 & 5 & 9 & 2 & 819 \\
\hline & 18 & Abate de Animais & 18 & 3942 & 9 & .38 & 2059 & 10 & 239 & 10 & 1313 & 3746 \\
\hline & 19 & Fabriçąa de de Açucar & 1 & 183 & 1 & 12 & 1 & 3 & 0 & 3 & 0 & 351 \\
\hline & 20 & Dutros Frodt Aliment & 93 & 11660 & 87 & 749 & 8256 & 150 & 869 & 74 & 6607 & 17119 \\
\hline & 21 & Inchistrias Diversas & 3 & $\$ 15$ & 125 & 8 & 83 & 5 & 35 & 15 & 1 & 996 \\
\hline & 22 & Energ, Agux, San, e Com. & 75 & 3705 & 27 & 2 & 59 & 183 & 9 & 4 & 1485 & 86.35 \\
\hline & 23 & Construçăo Civil & 0 & 2.39 & 16789 & 1 & 20 & 0 & 0 & 0 & 31 & 2482 \\
\hline & 24 & Comerces & 1920 & 18360 & 1245 & 226 & 1616 & $0 ?$ & 245 & 61 & 1944 & 16625 \\
\hline & 25 & Transopottes & 406 & 5474 & 188 & 209 & 4433 & $\theta$ & 102 & 2 & 1563 & 11333 \\
\hline & 26 & Servigos & 27831 & 3.4022 & 1580 & 124 & 1247 & 240 & 163 & 51 & 23 & 14255 \\
\hline
\end{tabular}




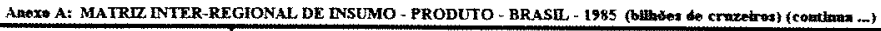

\begin{tabular}{|c|c|c|c|c|c|c|c|c|c|}
\hline & & & & emanda Fin & & & & TOTAR. & \\
\hline & SETORES & Norte & Viardeste & Coreste & Sudeste & Sul & Demlntern & Dem Final. & Geral \\
\hline & 1 Agropecuária & 5554 & 16 & 99 & 1921 & 547 & 11396 & $\$ 137$ & 19533 \\
\hline & 2 Miseraçāa & 2413 & 0 & 2 & 41 & 12 & 3781 & 2468 & 6249 \\
\hline & 3 Menerris nào Metáticos & 200 & 0 & 0 & 6 & 2 & 866 & 208 & 1074 \\
\hline & 4 Metahurgia & 224 & 0 & 0 & 5 & 2 & 673 & 231 & 904 \\
\hline & 5 Mecanica & 173 & 102 & 0 & 2 & 1 & 804 & 277 & 881 \\
\hline & 5 Material Ejétrico & 970 & 84 & 222 & 4320 & 1231 & 3026 & 6827 & 9853 \\
\hline & 7 Material de Transporte & 180 & 7 & 5 & 107 & 30 & 934 & 330 & 1264 \\
\hline & 8 Aadhira e Mlobilírio & 826 & 119 & 30 & 588 & 168 & 1357 & 1731 & 3088 \\
\hline & 9 Celutone Paptl $\&$ Graf & $\$ 46$ & 4 & 1 & 24 & 7 & 314 & 481 & 795 \\
\hline & 10 Ind da Borrecha & 26 & 1 & 0 & 4 & 1 & 527 & 31 & 938 \\
\hline & 11 Refino do Petroltor & 156 & 0 & 0 & 0 & 0 & 472 & 156 & 628 \\
\hline & 12 Quimicos Diversos & 141 & 0 & 0 & 1 & 0 & 207 & 142 & 349 \\
\hline $\mathrm{N}$ & 13 Framacèutica & 128 & 0 & a & 0 & 0 & 11 & 129 & 140 \\
\hline o) & 14 Plásticos & 64 & 0 & 0 & I & 0 & 279 & 66 & 345 \\
\hline $\mathrm{R}$ & 15 fond Textil & 592 & 5 & 0 & 0 & 0 & 302 & 398 & 1100 \\
\hline$T$ & 16 Vestuario a Cal fados & 188 & 0 & 0 & 0 & 0 & 16 & 188 & 204 \\
\hline E) & 17 findistria da Cafte & 396 & 0 & 3 & 53 & 15 & 216 & 467 & 683 \\
\hline & 18 Abate de Aaimais & 909 & a & 0 & 3 & I & 194 & 923 & 1117 \\
\hline & 19 Fabricacto de Acucar & 61 & 0 & $\theta$ & a & 0 & 10 & 61 & $\pi$ \\
\hline & 20 Outros Prod Aliment & 1477 & 7 & 17 & 336 & 96 & 686 & 1934 & 2620 \\
\hline & 21 Gudistriass Diversas & 218 & 8 & 5 & 104 & 30 & 423 & 365 & 788 \\
\hline & $22 \mid$ Energ, Agan, San., $\in$ Com & $70 z$ & 0 & 0 & 0 & 0 & 1300 & 702 & 2003 \\
\hline & 23 Construcao Civil & 18940 & 0 & 0 & 0. & 0 & $\Sigma 179$ & 18940 & 21169 \\
\hline & $24 \mid$ Comercio & 2637 & is & 43 & 374 & 249 & 3563 & 3825 & 750 \\
\hline & 25 Tramsportes & 1800 & 6 & 16 & 311 & 89 & 2765 & 2223 & 3012 \\
\hline & 26 Serviças. & 17082 & $\mathfrak{1}$ & \pm & 21 & 6 & 4150 & i71!1 & 24203 \\
\hline & 1 Agropecoaria & 53 & 20223 & 31 & 593 & 169 & 20279 & 21068 & +1367 \\
\hline & 2 Mimertéắa & 13 & 972 & -11 & -306 & -59 & 12340 & 710 & 13050 \\
\hline & 3 Minerais nào Meálicos & 0 & 185 & a & 1 & 0 & 2760 & 185 & 2945 \\
\hline & 4) Netalurgia & $\$ 2$ & 2009 & 2 & 46 & 13 & 7104 & 2118 & 9222 \\
\hline & S|Mecânica & 238 & 480 & 0 & 4 & I & 1894 & 723 & 2617 \\
\hline & 6) Material Elétrico & 84 & 953 & + & 74 & 21 & 914 & 1136 & 2050 \\
\hline & 7 Material de Transporte & 59 & 84 & I. & 25 & 7 & 977 & 177 & 754 \\
\hline & a Madteira e Mobiliário & 93 & 842 & 0 & 0 & 0 & 745 & $\$ 95$ & 1640 \\
\hline & 9 Celulose. Papel t Graf & 2 & 405 & 0 & 1 & 0 & 2344 & 408 & 2752 \\
\hline $\mathrm{N}$ & 10 hid da Borractio & o & 70 & 0 & 1 & 0 & 310 & 71 & 381 \\
\hline o & 11) Refino do Petrólea & 32 & 2372 & 4 & $\eta$ & 22 & 19213 & 5906 & 24719 \\
\hline $\mathrm{R}$ & 12 Quimicos Diversos & 12 & 2135 & 0 & 5 & 1 & 5948 & 2153 & 8101 \\
\hline$D$ & 13 Fomactulati. & 95 & 869 & 3 & 47 & 13 & 231 & 1027 & 1258 \\
\hline $\mathrm{E}$ & 14 plásticos & 10 & 323 & $\mathfrak{I}$ & 27 & 8 & 1358 & 369 & 1727 \\
\hline $\mathbf{s}$ & 15 Ind Textit & 42 & 2306 & L & 221 & 63 & 6723 & 2644 & 9367 \\
\hline$T$ & 16 Vestuario e Calçadoy & 294 & 3733 & 3 & 52 & 15 & 494 & 4096 & 4590 \\
\hline E) & 17 fradustia do Cas & I & 1384 & 0 & 1 & 0 & 468 & 1386 & 1854 \\
\hline & 18 About de Animais & 0 & 3621 & 2 & 34 & 10 & 277 & 3656 & 3943 \\
\hline & 19 Fabricąąo de Açucar & 34 & 3604 & 0 & I & 0 & 950 & 3639 & 4589 \\
\hline & 20 Outros Prod Aliment. & 282 & 12647 & 39 & 767 & 218 & 4396 & 13953 & 183.49 \\
\hline & 21 Thchistrias Diversass & 29 & 122 & i & 28 & 8 & 1499 & 188 & 1687 \\
\hline & 22 Energ. Agua San., e Com. & 0 & 15.53 & a & 0 & 0 & 3937 & 1653 & 7591 \\
\hline & 23 Construça Civil & 0 & 34193 & i) & $\hat{v}$ & 0 & 3202 & 3.4193 & 37395 \\
\hline & 24 Comencio & 26 & 7331 & 164 & 3179 & 906 & 13418 & 11696 & 28074 \\
\hline & 25|Ttansportes & 0 & $\$ 579$ & 10 & 204 & 58 & 3625 & $\$ 851$ & 9476 \\
\hline & 26) Serviças & 117 & 58623 & $1+6$ & 2439 & 693 & 16559 & 52002 & 96609 \\
\hline & 1 Apropecuatio & 13 & 39 & 1776 & 2146 & 1 & 11040 & 4025 & 15065 \\
\hline & 2 Mmeracián & 0 & 0 & 139 & 8 & 6 & 1094 & 152 & 1246 \\
\hline & 3 Miserais nảo Metálicas & 1 & $\mathrm{H}$ & 218 & 21 & 12 & 1635 & 264 & 1899 \\
\hline & $4 \mid$ Metalurgia & 2 & o & 135 & 8 & 14 & s91 & 159 & 750 \\
\hline & S| Mecañica & 5 & $\geq$ & 97 & 1 & $s$ & 55 & 109 & 168 \\
\hline & 6 Maerial Eletrico & 3 & 12 & 180 & 2 & 26 & 101 & 223 & 324 \\
\hline$c$ & 7 Moterial de Trmoporte & 1 & 3 & 49 & 0 & $\mathfrak{t}$ & 26 & 55 & 80 \\
\hline E. & 8 Madeira e Mobiliario & $?$ & 32 & $192:$ & 113 & 0 & 244 & 345 & 589 \\
\hline N & 9 Celislose, Papel e Gráf & 3 & 3 & 85 & 1 & 3 & 302 & 95 & 397 \\
\hline $\mathrm{T}$ & 10 lond da Borracha & 0 & 0 & + & o & 0 & 31 & 4 & 55 \\
\hline $\mathrm{R}$ & 11 Refano do Petróleo & 2 & 14 & 190 & $\mathrm{I}$ & 9 & 532 & 235 & 74 \\
\hline 0 & 12 Qúmicos Diversos & 3 & 2 & $12 x$ & 2 & 13 & 302 & 145 & 146 \\
\hline & 13 Farmacética & 2 & 8 & 62 & $=$ & 18 & 27 & 91 & 118 \\
\hline 0 & 14 Plásticos & 0 & 1 & iz & 0 & 1 & 56 & 14 & 0 \\
\hline E) & 15 Fad Têxtil & 2 & 17 & 190 & 0 & 6 & 335 & 215 & $\$ 0$ \\
\hline s) & 16 Vestuário Calçados & 14 & $2 x$ & 246 & 98 & 0 & 35 & 380 & 415 \\
\hline $\mathrm{T}$ & 17 tidascria do Caffe & I & 3 & 397 & 12 & 0 & 88 & 413 & 501 \\
\hline$E$ & 18 Abate de animais. & 1 & 38 & 392 & $35 \mathrm{I}$ & 0 & 230 & 683 & 213 \\
\hline & 19 Fabricaçăo de Afucar & 4 & 0 & 41 & 0 & $\mathrm{I}^{2}$ & 7 & 57 & 128 \\
\hline & 20 Outros Prod Aliment & 38 & 218 & 1214 & 830 & 0 & 1164 & $\geq: 99$ & 3464 \\
\hline & 21 Thdistrias Diversas & 0 & ? & 9 & a & 1 & 10 & 10 & $2 !$ \\
\hline & 22 Energ. Agua San. e Con & 15 & g & 533 & 255 & 15 & 2498 & 968 & 3494 \\
\hline & 23 Construf ao Civil & 0 & 0 & 1078 & $\dot{0}$ & 343 & 679 & $\$ 42 \mathrm{I}$ & $\times 100$ \\
\hline & 24 Comercio & 9 & 10 & 4557 & 1610 & 127 & $\$ 153$ & 6313 & 10701 \\
\hline & 25) Trangportes & $\mathfrak{1}$ & 17 & $12: 3$ & 256 & 28 & 2217 & soss & $\$ 326$ \\
\hline & 26] Serviços & -5 & 21 & 13.75 & 505 & 2663 & 9965 & 16740 & 31881 \\
\hline
\end{tabular}


Anexo A: MATRI2 NTER-REGIONAL DE NNUMO - PRODUTO - BRASIL, 1985 (bilhöes de cruzciros) (continua..)

\begin{tabular}{|c|c|c|c|c|c|c|c|c|c|c|}
\hline & & REGIOES & & Demanda Fi & Potal (exch & Jummy Fis & & Total & Total & Total \\
\hline & & SETORES & Norte & Nordeste & C-Oeste & Sudeste & Sul & Demintex m, & Dem.Final. & Getal \\
\hline & 1 & Agropecuaria & 122 & 839 & 46 & 25732 & 54 & 48217 & 26594 & 74810 \\
\hline & 2 & Minecasäo & 9 & 6 & .37 & 5716 & -186 & 22854 & 5509 & 28371 \\
\hline & 3 & Mirser ais ntos Metalicos: & 16 & 184 & 1 & 2082 & 77 & 23707 & 2360 & 26074 \\
\hline & 4 & Metahurgia & 249 & 111 & 128 & 20624 & 839 & 116844 & 21950 & 138819 \\
\hline & 5 & Mecinica. & 1591 & 610 & $\$ 31$ & 20483 & 897 & 29455 & 24113 & $\$ 3654$ \\
\hline & 16 & Matatial Eletrico & 408 & 1704 & 496 & 22103 & 2642 & 18439 & 27353 & 45815 \\
\hline s) & 7 & Material de Transporte & 923 & 2650 & 843 & 33609 & 847 & 39442 & 38672 & 78248 \\
\hline u & 8 & Madeiza e Mobiliario & 172 & 766 & 75 & 7040 & 9 & 6171 & 8063 & 14237 \\
\hline D) & 9 & Celubse, Papel e Grál. & 244 & 286 & 108 & 7160 & 195 & 29494 & 7994 & 37491 \\
\hline B & 10 & Ind da Boracha & 3 & 69 & 5 & 1150 & 22 & 14055 & 1248 & 15305 \\
\hline s & $\mid 11$ & Refino do Petroleo & 268 & 1676 & 254 & 24793 & 845 & 68967 & 27837 & 96815 \\
\hline $\mathrm{T}]$ & 12 & Qufimicos Diver oos & 210 & 134 & 155 & 10736 & 716 & 45871 & 11950 & 57827 \\
\hline E & $\mid 13$ & Farmacututic & 303 & 1541 & 289 & 11556 & 2713 & 4967 & 16402 & 21378 \\
\hline & 14 & Platicor & 35 & 111 & 36 & 1993 & 80 & 13173 & 2256 & 15431 \\
\hline & $\mid 15$ & Ind. Textil & 130 & 1348 & 136 & 9585 & 199 & 33014 & 11398 & 44422 \\
\hline & 16 & Vestuktio Calq̨ados & 1170 & 1820 & 460 & 27112 & 12 & 3491 & $30 S 74$ & 34068 \\
\hline & 17 & Industia do Cafte & 3 & 12 & 99 & 13982 & 5 & 4121 & 14100 & 18237 \\
\hline & 18 & Abate de Anirais & 40 & 604 & 41 & 9133 & 7 & 2723 & 9825 & 12566 \\
\hline & $\mid 19$ & Fabricaşán de Açucar & 278 & 10 & 63 & 3140 & 665 & 6494 & 4155 & 10659 \\
\hline & 20 & Outros Frod Aliment. & 480 & 2385 & 75 & 31277 & 47 & 13367 & 34263 & $\$ 7663$ \\
\hline & 21 & Inthistrias Diversas & 88 & 275 & 94 & 4054 & 349 & 9176 & 4860 & 14042 \\
\hline & 22 & 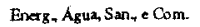 & 177 & $\$$ & 2 & 11711 & 12 & 28115 & 11908 & 40054 \\
\hline & 23 & Construçóno Civil & 0 & 0 & 0 & 80100 & 5602 & 13665 & 85702 & 99366 \\
\hline & $24 \mid$ & Comtrio & 115 & 334 & 50 & 69355 & $\$ 20$ & 50099 & 70373 & 122663 \\
\hline & 25 & Tr ansportes & 3 & 271 & 0 & $3122 \mathrm{~L}$ & 54 & 32636 & 31549 & 64515 \\
\hline & 26 & Setvicos & 1004 & 75 & 17 & 195966 & 16864 & 90075 & 213925 & 407683 \\
\hline & II & Agropectúácia & 62 & $\$ 34$ & 82 & 5702 & 8873 & 43196 & 15204 & 58400 \\
\hline & 2 & Miner açä̀ & I. & 1 & .5 & I & 504 & 2457 & 503 & 2963 \\
\hline & 3 & Monet aianão Metalicos: & 7 & 47 & 2 & 3 & 727 & 5260 & 786 & 6049 \\
\hline & 4 & Metalurgia & 27 & 26 & 22 & 1 & 2250 & 8633 & 2326 & 10959 \\
\hline & 5 & Mecinica & 350 & 170 & 149 & 1 & $\$ 794$ & 5502 & 6464 & 11969 \\
\hline & 61 & Material Elétrico & 53 & 212 & 69 & 1 & 3559 & 17.53 & 3894 & 5647 \\
\hline & 7 & Material de Transpocte & 61 & 187 & 58 & 0 & 3052 & 1574 & 3359 & 4933 \\
\hline & 8 & Madeira e Mobiliáaio & 156 & 677 & 67 & 2298 & 3582 & 5821 & 6779 & 12602 \\
\hline & 9 & Celubse, Papel e Graf. & 60 & 72 & 24 & 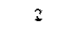 & 1878 & 7232 & 2036 & 9270 \\
\hline & 10 & Ind da Borr acha & 2 & 12 & 2 & I & 214 & 1622 & 231 & 1853 \\
\hline & 11) & ReFino do Petróleo & 92 & 318 & 43 & 3 & 4872 & 12923 & 5287 & 18215 \\
\hline & 12 & Quimicos Divergos & 41 & 29 & 25 & 14 & 2087 & $868 \mathrm{~L}$ & 2196 & 10880 \\
\hline$s$ & 13] & Parmaceutica & 14 & 70 & 12 & 1 & 690 & 204 & 788 & 993 \\
\hline 0 & 14 & Piasticos & 10 & 29 & 8 & 8 & 493 & 2877 & 548 & 3425 \\
\hline $\mathrm{L}$ & 15 & Ind Textis & 36 & 345 & 26 & 14 & 2214 & 8677 & 2635 & 11317 \\
\hline & 16 & Vestudicio Calfados & 677 & 1063 & 254 & 3945 & 11101 & 3206 & 17040 & 20251 \\
\hline & 17] & Indastria do Cale & 0 & I & 20 & 4 & 3217 & 335 & 3242 & 4079 \\
\hline & 18 & Abate de Animais & 53 & 832 & 54 & 4520 & $\$ 973$ & 5317 & 11432 & 16767 \\
\hline & 19 & Fabricaşāo de Açucar & 15 & 0 & 3 & 0 & 197 & 358 & 216 & 575 \\
\hline & 20 & Outros Prod Aliment & 638 & 3133 & 76 & 14086 & 20753 & 24819 & 38686 & 63599 \\
\hline & 21 & Indenstrias Diversas & 13 & 36 & 14 & 2 & $7 \mathfrak{H}$ & $\cos 2$ & 775 & 1828 \\
\hline & 22 & Energ, Agua, San, e Com. & 66 & 9 & 3 & 620 & 3793 & 10315 & 4492. & 14882 \\
\hline & 23 & Construçào Civil & 0 & 0 & 0 & 48 & 17052 & 2513 & 17100 & 19613 \\
\hline & 24 & Comercio & 46 & 118 & 16 & 3050 & 21447 & $\{89\} 9$ & 24678 & 45576 \\
\hline & 25 & Tr ansportes & 7 & 112 & 4 & 913 & 10304 & 13006 & 11340 & 24753 \\
\hline & 26 & Serviços & 261 & $25_{2}$ & 78 & 23 & 36973 & 14732 & 37587 & 80150 \\
\hline
\end{tabular}




\begin{tabular}{|c|c|c|c|c|c|c|c|c|c|c|c|c|c|c|c|c|c|c|c|c|c|c|c|c|c|c|}
\hline REGIAO & \multicolumn{26}{|c|}{ NORTE-DEMANDA INTERMEDIARIA } \\
\hline SETORES & $i$ & 2 & 3 & 4 & 5 & 8 & 7 & 8 & 9 & 10 & 11 & 12 & 13 & 14 & 15 & 16 & 17 & 18 & 19 & 20 & 21 & 22 & 23 & 24 & 25 & 26 \\
\hline portaçés Exterior & 20 & 0 & 8 & 83 & 34 & 1283 & 50 & 4 & 8 & 16 & 166 & 3 & 6 & 9 & 12 & 2 & 0 & & 0 & 71 & 32 & 5 & 132 & 18 & 69 & 109 \\
\hline oostos & 101 & 18 & 17 & 17 & 25 & 390 & 1 & 8 & 6 & 0 & 2 & 0 & 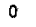 & 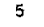 & 1 & 0 & -35 & 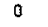 & 0 & 2 & 5 & 37 & 872 & 242 & 307 & 503 \\
\hline Tuneraçdes & 1413 & 297 & 2,33 & 116 & 126 & 884 & 138 & 892 & 191 & 38 & 35 & 51 & 18 & 65 & 143 & 34 & 25 & 89 & 7 & 414 & 68 & 516 & 1862 & 2038 & 1234 & 8940 \\
\hline tano Total & 1405 & 224 & 194 & 95 & 101 & 712 & 109 & 725 & 152 & 30 & 27 & 42 & 15 & 50 & 109 & 26 & 20 & 70 & 6 & 333 & 55 & 403 & 1544 & 1713 & 995 & 7868 \\
\hline rtribuiçoes Sociais Efetivas & 8 & 73 & 39 & 2 & 25 & 172 & 29 & 167 & 39 & 8 & & & 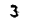 & 15 & 34 & & 5 & 19 & 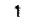 & 81 & 13 & 113 & 318 & 325 & 239 & 1072 \\
\hline tiçסes Sociais $F$ & 0 & 0 & 0 & 0 & 0 & 0 & 0 & 0 & 0 & 0 & & & $u$ & 0 & & 8 & 0 & 0 & 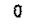 & 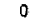 & 0 & 0 & 0 & $\alpha$ & 0 & 0 \\
\hline Ceedente Bruto & 12315 & 5426 & 403 & 298 & 164 & 3834 & 238 & 743 & 95 & 213 & 240 & 94 & 53 & 108 & 429 & 47 & 113 & 170 & 14 & 633 & 387 & 467 & $692 t$ & 2878 & 838 & 9702 \\
\hline alor Acicionado Custo & 13728 & 5723 & 636 & 412 & 290 & 4718 & 376 & 1635 & 286 & $25 t$ & 275 & 145 & 71 & 173 & 572 & 81 & 138 & 259 & 21 & 1047 & 455 & 983 & 8783 & 4916 & 2072 & 18642 \\
\hline sobre ativitade & 0 & 53 & 5 & 3 & 3 & 40 & 19 & 19 & 3 & 2 & 1 & 0 & 0 & 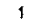 & 4 & $\dagger$ & 2 & 4 & 0 & 12 & 2 & 15 & 30 & 50 & 72 & 80 \\
\hline bre atividade & -182 & -46 & -1 & -3 & -1 & -14 & -13 & -6 & -7 & -3 & -1 & 0 & 8 & 0 & -2 & -1 & -5 & -1 & 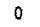 & -3 & -10 & -11 & 0 & -407 & -157 & -12 \\
\hline dionado Preço & 13546 & 5730 & 640 & 412 & 292 & 4744 & 382 & 1648 & 282 & 250 & 275 & 145 & 71 & 174 & 574 & 81 & 135 & 262 & 21 & 1056 & 447 & 987 & 8813 & 4558 & 1807 & 18710 \\
\hline Total - Norte & 4034 & 378 & 335 & 232 & 301 & 1859 & 429 & $\$ 329$ & 393 & $2 \pi$ & 34 & 147 & 36 & 48 & 411 & 94 & 574 & 846 & 38 & 1227 & 211 & 585 & 4518 & 1946 & 925 & 3550 \\
\hline Total - Nordes & 93 & 25 & 8 & 51 & 34 & 101 & 59 & 22 & 0 & 3 & 0 & 6 & & 3 & 16 & 9 & 0 & 0 & $\theta$ & 12 & 2 & 28 & 493 & 15 & 114 & 94 \\
\hline Protuchato Total - Centro & 29 & 2 & 3 & 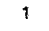 & 1 & 11 & $\mathfrak{1}$ & 1 & 1 & 0 & 4 & 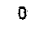 & - & 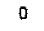 & 1 & 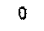 & 0 & 0 & 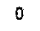 & 6 & 2 & 15 & 167 & 29 & 22 & 42 \\
\hline lo Total - Sudeste & 1438 & 81 & 52 & 97 & 188 & 1270 & 281 & 62 & 87 & 10 & 435 & 40 & 19 & 89 & 69 & 21 & 7 & $\theta$ & 11 & 155 & 77 & 290 & 5440 & 524 & 1313 & 835 \\
\hline lo Total - Sul & 272 & 15 & 11 & 11 & 28 & 194 & 81 & 14 & 18 & 2 & 16 & 7 & . & 17 & 16 & 5 & 2 & 3 & 1 & 9t & 13 & 76 & 933 & 117 & 274 & 254 \\
\hline snsumo Total & 5987 & 519 & 434 & 492 & 589 & 5109 & 882 & 1440 & 513 & 308 & 353 & 204 & 69 & 171 & 526 & 123 & 548 & 855 & so & 1584 & 349 & 1016 & 12356 & 2891 & 3025 & 5493 \\
\hline oduçãa Total G & 4142 & 1034 & 223 & 210 & 241 & 2160 & 371 & 655 & 206 & 141 & 135 & 92 & 34 & 84 & 262 & 54 & 223 & 337 & 21 & 672 & 180 & 466 & $5840^{\circ}$ & 1445 & 1256 & 3594 \\
\hline
\end{tabular}

\begin{tabular}{|c|c|c|c|c|c|c|c|c|c|c|c|c|c|c|c|c|c|c|c|c|c|c|c|c|c|c|}
\hline & & & & & & & & & & & & & & & & Af & 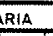 & & & & & & & & & \\
\hline SEI & 1 & 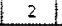 & 3 & & 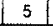 & $0^{\circ}$ & $r$ & 0 & 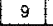 & 10 & 11 & 12 & 13 & 14 & 15 & 18 & 17 & 18 & 9 & 20 & 21 & 22 & 3 & 24 & 25 & 26 \\
\hline portações & 68 & 217 & 5 & 231 & 367 & 53 & 9 & 0 & 2 & 18 & 447 & 212 & 25 & 0 & & & & & & 096 & & $\overline{12}$ & & & 9 & 33 \\
\hline postos & . & 22 & 89 & 7 & 55 & 35 & 7 & 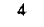 & $n$ & 20 & 275 & 78 & 8 & 1 & 18 & 9 & -18 & 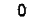 & 17 & -855 & & 182 & 1085 & 695 & 329 & 986 \\
\hline emunerạ̧б & 62 & $\$ 343$ & 442 & 504 & 465 & 189 & 183 & 265 & 243 & 27 & 922 & 433 & 93 & 15 & 687 & 578 & 64 & 73 & 590 & 1457 & 52 & 1624 & 10528 & 7777 & 2514 & 34597 \\
\hline rotal & 81 & 995 & 360 & 379 & 384 & 151 & $15 \mathfrak{1}$ & 218 & 202 & 21 & 698 & $34 t$ & 73 & 90 & 550 & 470 & 48 & 57 & 450 & 1126 & 43 & 1245 & $938 \%$ & 5565 & 2006 & 27341 \\
\hline Mknituliç̧es Sociais & 76 & 274 & 69 & 109 & 65 & 36 & 28 & 41 & 32 & 8 & 170 & 77 & 18 & 24 & 115 & 90 & 14 & 14 & 112 & 263 & 7 & 335 & 859 & 1004 & 449 & 3918 \\
\hline ס̃es S & 5 & 74 & 13 & 16 & 16 & 2 & 4 & 0 & 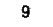 & 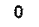 & 54 & 15 & 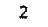 & & 22 & 18 & 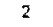 & the & 28 & 68 & 2 & 44 & 286 & 208 & 59 & 3338 \\
\hline Bnito & 25131 & 10044 & 871 & 1843 & -139 & 948 & 142 & 642 & 914 & 54 & 3838 & 2515 & 256 & 703 & 2056 & 1668 & 150 & 481 & 922 & 4003 & 1434 & 2530 & 12106 & 11629 & 3121 & 35505 \\
\hline cionado & 30393 & 11387 & 1313 & 2347 & 326 & 1135 & 325 & 907 & 1157 & 81 & 4760 & 2948 & 349 & 818 & 2743 & 2248 & 214 & 554 & 1512 & 5460 & 1486 & 4154 & 22832 & 19406 & 35635 & 70102 \\
\hline obre & 0 & 65 & 23 & & B & 7 & 3 & 4 & 7 & $n$ & 28 & $\pi$ & $\pi$ & 1 & 15 & 7 & 3 & 3 & 16 & 42 & 1 & 0 & 287 & 341 & 161 & 174 \\
\hline ofore & -5 & -86 & -1 & & -3 & 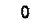 & -4 & 0 & 0 & 0 & 0 & 0 & 0 & 0 & -11 & -3 & -11 & -7 & -15 & -3 & 4 & 0 & 0 & -264 & -335 & 0 \\
\hline 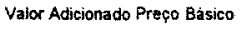 & 30388 & 11360 & 1335 & 2346 & 331 & 1137 & 324 & 911 & 1164 & 81 & 4788 & 2855 & 351 & 819 & 2747 & 2250 & 206 & 556 & 1513 & 5499 & 1487 & 4154 & 22919 & 19483 & 5461 & 70276 \\
\hline Total - & 6 & 0 & 2 & & 48 & 17 & 4 & 21 & 1 & 12 & 0 & , & 0 & 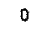 & 1 & 6 & 0 & 92 & 1 & 54 & 0 & 0 & 3 & 0 & 5 & 10 \\
\hline Total - & 8589 & 1328 & 1398 & 5110 & 1068 & 638 & 198 & 554 & 1218 & 185 & 17174 & 3692 & 470 & 779 & 5655 & 1479 & 1308 & 3051 & 2974 & 10593 & 183 & 2988 & 39948 & 3403 & 2503 & 20837 \\
\hline Proc & 40 & 5 & 1 & & 4 & 1 & 1 & 3 & 4 & 0 & 21 & 15 & d & 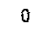 & B & 14 & 31 & 69 & 1 & 101 & 1 & 4 & 78 & 16 & 8 & 83 \\
\hline & 30 & 95 & 112 & & 809 & 150 & 183 & 9 & 268 & 46 & 1674 & 954 & 349 & 91 & 759 & 579 & 190 & 100 & 69 & 1001 & 9 & 22 & 2837 & 1218 & 965 & 3458 \\
\hline & & 17 & 2 & & 13 & 19 & 28 & 45 & 62. & 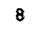 & 340 & 193 & 51 & 71 & 76 & 248 & 136 & 74 & 16 & 860 & 3 & 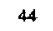 & 469 & 257 & 196 & 1127 \\
\hline & & 1684 & 1610 & 6 & 86 & 913 & 430 & 729 & 1588 & 300 & 19931 & 5148 & 907 & 908 & 20 & 340 & +1 & 330 & 076 & 2850 & 200 & 3437 & 4478 & 591 & 4015 & . \\
\hline 100 & & 13050 & 2945 & 1222 & 317 & 2050 & 754 & 1640 & 57 & 384 & 10 & & & & & & & & & & & & 77785 & & & 3608 \\
\hline
\end{tabular}

\begin{tabular}{|c|c|c|c|c|c|c|c|c|c|c|c|c|c|c|c|c|c|c|c|c|c|c|c|c|c|c|}
\hline REGIÄO & & & & & & & & & & & & & & & & cL & DIA & & & & & & & & & \\
\hline SETORES & 1 & 2 & 3 & 4 & 5 & 6 & 7 & 8 & 9 & 101 & 11 & 12 & 13 & 14 & 15 & 16 & 17 & 18 & 19 & 20 & 21 & 22 & 23 & 24 & 25 & 26 \\
\hline portaçōes Extefior & 48 & 39 & 22 & 39 & 3 & 17 & 3 & 8 & 6 & T. & 248 & 38 & 7 & $t$ & & 4 & 8 & 10 & 4 & 72 & 1 & 31 & 49 & 47 & 329 & 200 \\
\hline postos & 69 & 23 & 41 & 10 & 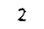 & 8 & 1 & , & s & 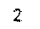 & 11 & 13 & 4 & $f$ & 7 & 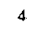 & 3 & 6 & -1 & 18 & $t$ & 83. & 551 & 364 & 191 & 847 \\
\hline muneraços & 1963 & 160 & 243 & 89 & 40 & 50 & 12 & 81 & $5 !$ & 7 & 37 & 51 & 15 & 9 & 56 & 58 & 16 & 55 & 7 & 290 & 4 & 798 & 540 & 2384 & 780 & 11389 \\
\hline alario Total & 1952 & 141 & 198 & 71 & 32 & 39 & 9 & 72 & 42 & 5 & 25 & 39 & 12 & 8 & 46 & 50 & 14 & 44 & 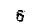 & 239 & 3 & 678 & 464 & 1997 & 626 & 9802 \\
\hline ontribuiçdes Sociais Efativas & 9 & 15 & 38 & 13 & 6 & 8 & 2 & 8 & $\mathrm{~g}$ & 1 & 10 & 7 & 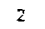 & $\mathfrak{t}$ & 8 & 8 & 2 & 10 & 1 & 42 & $*$ & 95 & 67 & 316 & 138 & 1396 \\
\hline ontribruiçöes Socizis Ficticias & $z$ & 4 & 8 & 5 & 2 & 3 & 1 & 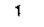 & 2 & 0 & 3 & 5 & 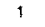 & 0 & 1 & 3 & 0 & 2 & $r$ & 9 & 0 & 25 & 9 & 71 & 16 & 1191 \\
\hline xcedente Bruto & 6780 & 485 & $\$ 49$ & 124 & 39 & 74 & 13 & 152 & 109 & 11 & 97 & 103 & 34 & 17 & 133 & 111 & 71 & 79 & 13 & 485 & 5 & 1117 & 1168 & 4920 & 1205 & 10992 \\
\hline Ior Adicionado Custo Fatores & 8744 & 645 & 685 & 213 & 79 & 124 & 25 & 233 & 160 & 18 & 134 & 153 & 49 & 27 & 189 & 170 & 87 & 134 & $2 \xi$ & 775 & 9 & $19 \neq 5$ & 1708 & 7304 & 1985 & 522390 \\
\hline mpostos sobre atividade & 0 & $t$ & 7 & 2 & 1 & 2 & 0 & 2 & 2 & 0 & 1 & 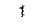 & 0 & 0 & 2 & 2 & 1 & 3 & . & $i t$ & 0 & 25 & 18 & 67 & 56 & 137 \\
\hline Subsidio sobre atvidade & .149 & .7 & -1 & .9 & 0 & 0 & -1 & $-i$ & -1 & 0 & $-i$ & 0 & 0 & 0 & -2 & -2 & -2 & -1 & 0 & -5 & 0 & .17 & 0 & .443 & -140 & 40 \\
\hline Vator Adicionado Preço B & 8594 & 638 & 691 & 207 & 80 & 125 & 25 & 235 & 161 & 18 & 135 & 154 & 49 & 27 & 189 & 170 & 86 & 136 & 21 & 782 & 9 & 1924 & 1726 & 6928 & 1902 & 22477 \\
\hline Produça Total - Norte & 120 & 6 & 49 & 6 & $\mathfrak{t}$ & 7 & 1 & 10 & 2 & 0 & $t$ & 3 & 0 & 0 & 1 & $\mathrm{t}$ & 1 & 72 & 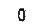 & 94 & 0 & 6 & 34 & 9 & 13 & 62 \\
\hline Produç̧áo Total - Nordes & 117 & 6 & $2 \mathfrak{1}$ & 9 & 1 & 3 & 1 & 5 & 3 & 1 & 40 & 11 & $x^{2}$ & 4 & 28 & 5 & 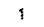 & 3 & 1 & 67 & 0 & 6 & 30 & 34 & 42 & 99 \\
\hline Produçato Total - Centro-Oeste & 4256 & 345 & 857 & 177 & 33 & 84 & 18 & 212 & 114 & 10 & 100 & 106 & 35 & 12 & 177 & 120 & 357 & 666 & 48 & 2076 & 7 & 1290 & 1909 & 2609 & 1150 & 6841 \\
\hline Prodtuçăa Total - Sudeste & 1450 & 158 & 184 & 252 & 38 & 69 & 27 & 85 & 88 & 17 & 184 & 108 & 18 & $2 t$ & 122 & 90 & 42 & 15 & 53 & 242 & 2 & 147 & 684 & 603 & 580 & $11+13$ \\
\hline$f-5 \pm 4$ & 410 & 33 & 34 & 59 & 7 & 12 & 7 & 26 & 17 & 3 & 30 & 13 & 3 & 4 & 20 & 19 & 11 & 4 & 4 & 113 & 0 & 26 & 121 & 108 & 119 & 242 \\
\hline onst & $647 t$ & 608 & 1208 & 543 & 85 & 199 & 56 & 354 & 236 & st & 61 & 292 & 69 & 43 & 361 & 245 & 415 & 777 & 107 & 2681 & 12 & 1570 & 3374 & 3773 & 2424 & 49404 \\
\hline Produçăło Total Geral & 15065 & 1246 & 1899 & 750 & 185 & 324 & BO & 589 & 397 & 55 & 747 & 446 & 118 & 70 & 550 & 415 & 501 & 913 & 128 & 3464 & 21 & 3494 & 5100 & 10701 & 4325 & 534891 \\
\hline
\end{tabular}




\begin{tabular}{|c|c|c|c|c|c|c|c|c|c|c|c|c|c|c|c|c|c|c|c|c|c|c|c|c|c|c|}
\hline GIAO & & & & & & & & & & & & 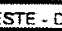 & & & 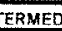 & ar & & & & & & & & & & \\
\hline SETORES & $t$ & 2 & 3 & 4 & 5 & 6 & 7 & 8 & 9 & 10 & 11 & 12 & 13 & 14 & 15 & 16 & 17 & 18 & 19 & 20 & 21 & 22 & 23 & 24 & 25 & 26 \\
\hline Importaçbes Exterior & 239 & 898 & 298 & 5755 & 989 & 2337 & 2867 & 184 & 600 & 605 & 32085 & 4868 & 1206 & 207 & 579 & 478 & 14 & 133 & 121 & 989 & 649 & 361 & 846 & 544 & 913 & 2581 \\
\hline postos & 341 & 524 & 587 & 1903 & 559 & 1137 & 989 & 179 & 554 & 572 & 424 & 1717 & 638 & 193 & 541 & 334 & 116 & 87 & -61 & 246 & 419 & 728 & 10749 & 4167 & $285 \%$ & 10834 \\
\hline emuneraçde & 9750 & 3641 & 3342 & 16481 & 13122 & 7039 & 11408 & 3983 & 4849 & 1945 & 4780 & 6587 & 2675 & 2086 & 4495 & $478 t$ & 585 & 760 & 612 & 3995 & 2515 & 9153 & 10527 & 27330 & 11629 & 145634 \\
\hline alario Total. & 9695 & 3199 & 2715 & 13174 & 10485 & 5527 & 8796 & 1730 & 3926 & +516 & 3196 & 5036 & 2164 & 1698 & 3719 & 4070 & 507 & 599 & 473 & 3296 & 2061 & 7776 & 9047 & 22892 & 9338 & 112581 \\
\hline ontribuiçdes Sociais & 44 & 342 & 519 & 2337 & 2024 & 1097 & 1809 & 202 & 726 & 302 & 1242 & 860 & 407 & 397 & 675 & 633 & 66 & 138 & 83 & 578 & 388 & 1088 & 1302 & 3625 & 2053 & 17849 \\
\hline Contriondiç口es Soctais Ficticias & 10 & 100 & 108 & 973 & 613 & 415 & 804 & 30 & 197 & 126 & 342 & 691 & 105 & 73 & 102 & 77 & 12 & 24 & 56 & 122 & 66 & 288 & 172 & a+3 & 237 & 15224 \\
\hline Excedente Bruto & 33671 & 11038 & 6062 & 22976 & 12592 & 10475 & 12951 & 3868 & 10288 & 3134 & 12558 & 13300 & 6137 & 3793 & 10779 & 9157 & 2595 & 1083 & 1110 & 6674 & 3632 & 12803 & 22753 & 56396 & 17981 & 140561 \\
\hline Valor Adticionado Custo $\mathrm{F}$ & 43420 & 14680 & 9403 & 39457 & 25714 & 17515 & 24359 & 5631 & 15137 & 5079 & 17338 & 19888 & 8812 & 5879 & 15275 & 13938 & 3179 & 1843 & 1722 & 10669 & 6147 & 21958 & 33274 & 83728 & 29609 & 286194 \\
\hline Impostos so & 0 & 14 & 102 & 427 & 329 & 216 & 326 & 56 & 152 & 62 & 185 & 166 & 76 & 59 & 146 & 146 & 24 & 44 & 22 & 150 & 70 & 286 & 358 & 768 & 840 & 1749 \\
\hline Subsidio so & .742 & -160 & -18 & -1592 & -104 & -58 & -695 & $-\$ 2$ & -108 & -85 & -94 & -44 & -37 & .17 & -133 & -131 & -78 & -13 & -7 & -64 & -218 & -189 & .6 & -5080 & -2087 & -514 \\
\hline io Preço Básico & 42678 & 14533 & 9487 & 38292 & 25939 & 17672 & 23991 & 5675 & 15181 & 5056 & 17429 & 20010 & 8851 & 5921 & $\$ 5288$ & 13952 & 3125 & 1874 & 1737 & 10763 & 5899 & 22053 & 33625 & 79414 & 28362 & 287430 \\
\hline Produçato To & 598 & 134 & 675 & 1105 & 194 & 1040 & 599 & 230 & 171 & 109 & 95 & 404 & 84 & 17 & 78 & 55 & 40 & 983 & 18 & 1296 & 301 & 67 & 654 & 104 & 189 & 794 \\
\hline Produçáco Total - Nordeste & 580 & 128 & 283 & 1603 & 292 & 357 & 506 & 151 & 309 & 395 & 5183 & 1373 & 437 & 817 & 2223 & 389 & 21 & 47 & 48 & 925 & 199 & 74 & 592 & 393 & 624 & 1268 \\
\hline Produçalo Total - Centro-Oeste & $\$ 439$ & 66 & 216 & 516 & 76 & 84 & 85 & 131 & 111 & 22 & 72 & 172 & 74 & 17 & 149 & 69 & 702 & 2083 & 14 & 3436 & 96 & 205 & 287 & 129 & 118 & 770 \\
\hline Produçăo Total - Sudeste & 24443 & $\$ 1953$ & $\{4380$ & 88783 & 25377 & 22941 & 48836 & 6848 & 20242 & 8297 & 40205 & 28815 & 9028 & 8113 & 25207 & 18058 & 12607 & 6528 & $874 t$ & 24080 & 6257 & 18062 & 51145 & 37519 & 27044 & 99918 \\
\hline Producto Total - Su & 4482 & 137 & 191 & 883 & 228 & 247 & 364 & 30 & 324 & 50 & 263 & 471 & 478 & 47 & 357 & 734 & 1611 & 822 & 41 & 5948 & 123 & 505 & 1378 & 392 & 414 & 4108 \\
\hline Consumo Total & 32132 & 13838 & 16587 & 100526 & 27716 & 28143 & 54257 & 8563 & 22311 & 10249 & 79388 & 37817 & 12527 & 9510 & 29134 & 20116 & 15112 & 10692 & 8922 & 36900 & 8043 & 18002 & 65741 & 43249 & 36153 & $\$ 20253$ \\
\hline Produça Total Gera & 74810 & 28371 & 26074 & 138819 & 53654 & 45815 & 78248 & 14237 & 37491 & 15305 & 98815 & 57827 & 21378 & 15431 & 44422 & 34088 & 18237 & 12566 & $\$ 0659$ & 47863 & 14042 & 2 & 99368 & 60.3 & 364515 & 107683 \\
\hline
\end{tabular}

\begin{tabular}{|c|c|c|c|c|c|c|c|c|c|c|c|c|c|c|c|c|c|c|c|c|c|c|c|c|c|c|}
\hline REGIAO & & & & & & & & & & & & SUt & DEMA & WDAF F & INAL & & & & & & & & & & & \\
\hline SETORES & $i$ & 2 & 3 & 4 & 5 & 6 & 7 & 8 & 9 & 10 & 11 & 12 & 13 & 14 & 15 & 16 & 17 & 18 & 19 & 20 & 21 & 22 & 23 & 24 & 25 & 20 \\
\hline Importaçóes Exterior & 187 & 94 & 69 & 454 & $22 \uparrow$ & 289 & 181 & 163 & 148 & 97 & 6037 & 915 & 56 & 46 & 147 & 284 & 3 & 177 & 7 & 1319 & 84 & 134 & 187 & 202 & 1885 & 503 \\
\hline Impostos & 286 & 55 & 131 & 150 & 125 & 140 & 62 & 158 & 137 & 69 & 268 & 323 & 30 & 43 & 138 & 198 & 26 & 116 & -3 & 328 & 55 & 270 & 2120 & 1548 & 1094 & 2130 \\
\hline Remuneraçdes & 7611 & 380 & 775 & 1301 & 2927 & 868 & 719 & 1737 & 1199 & 235 & 899 & $\$ 239$ & 124 & 463 & 1145 & 2842 & 131 & 1014 & 33 & 5331 & 327 & 3401 & 2077 & 10155 & 4462 & 28631 \\
\hline Salärio Total & 7568 & 334 & 630 & 1040 & 2339 & $68 \dagger$ & 554 & 1532 & 971 & 184 & 601 & 948 & $10 t$ & 378 & 947 & 2420 & 113 & 799 & 25 & 4387 & 268 & 2889 & 1786 & 8508 & 3583 & 22129 \\
\hline Cortribuiçбes Sociais Efetivas & 35 & 36 & 120 & 184 & $45 t$ & 135 & 114 & 179 & 179 & 37 & 234 & 162 & 19 & 70 & 172 & 376 & 15 & $\{83$ & 4 & 771 & 50 & 404 & 257 & 1347 & 788 & 3509 \\
\hline Contribnuiçotes Sociais Ficticias & B & 10 & 25 & 77 & 137 & $5 t$ & 51 & 27 & 49 & 15 & 64 & 130 & 5 & 16 & 26 & 46 & 3 & 32 & 3 & 163 & 9 & 107 & 34 & 302 & 91 & 2993 \\
\hline Excedente Brito & 26285 & 1153 & 1406 & 1894 & 2809 & 1291 & $8+6$ & 3247 & 2544 & 380 & 2363 & 2502 & 285 & 842 & 2746 & 5443 & 580 & 1446 & 60 & 8905 & 473 & 4757 & 4491 & 20954 & 6899 & 27634 \\
\hline Valor Adiciorado Custo Fatores & 33896 & 1533 & $2+82$ & 3115 & 5736 & 2159 & 1536 & 4984 & 3743 & 615 & 3262 & 3742 & 409 & $\$ 305$ & 3991 & 8285 & 711 & 2460 & 93 & 14236 & $B 00$ & 8158 & 6568 & 31109 & 11360 & 56266 \\
\hline Impostos sobre atividade & 0 & 1 & 24 & 34 & 73 & 27 & 21 & 50 & 38 & 8 & 35 & 31 & 4 & 13 & 37 & 87 & 5 & 58 & 1 & 211 & $\mathrm{~g}$ & 106 & 71 & 286 & 322 & 344 \\
\hline Subsidio sobre atwidade & -579 & -17 & -4 & -126 & -23 & -7 & -44 & $-\$ 1$ & -27 & -10 & -18 & -8 & -2 & -4 & -34 & .78 & -18 & -17 & 0 & .85 & -28 & -70 & -1 & -1888 & -801 & $-10 t$ \\
\hline Valor Adiciona do Preço Bâsico & 33316 & 1518 & 2201 & 3023 & 5788 & 2178 & 1512 & 5023 & 3754 & 612 & 3279 & 3765 & 411 & 1314 & 3695 & 8294 & 699 & 2501 & 94 & 14362 & 781 & 8194 & 6837 & 29507 & 10882 & 56508 \\
\hline Produçăo Tofal - Norte & 487 & 14 & 157 & 87 & 43 & 128 & 38 & 204 & 42 & 13 & 18 & 76 & 3 & 4 & 20 & 33 & 9 & 1325 & 1 & 1729 & 39 & 25 & 129 & 39 & 73 & 156 \\
\hline Producão Total - Nordeste & 453 & 13 & 66 & 127 & 65 & 44 & 32 & 133 & 76 & 48 & 975 & 258 & 20 & 204 & $56 \theta$ & 231 & 5 & 63 & 3 & 1234 & 26 & 28 & 117 & 146 & 239 & 248 \\
\hline Produção Tołal - Centro-Oeste & 138 & 19 & 104 & 55 & $4 t$ & 30 & 15 & 29 & 31 & 5 & 21 & 78 & 4 & 7 & 29 & 48 & 3 & 32 & 6 & 202 & 31 & 59 & 120 & 269 & 85 & 408 \\
\hline Produçäo Total - Sudeste & 3738 & 316 & 642 & 2441 & 1878 & 984 & 715 & 903 & 842 & 346 & 2487 & 2219 & 111 & 464 & 1028 & 1503 & 39 & 477 & 281 & 4154 & 225 & 815 & 2787 & 2968 & 1834 & 4220 \\
\hline Produçäo Total - StH & 19838 & 934 & 2680 & 4622 & 3810 & 1855 & 2378 & 5990 & 4239 & 663 & 5130 & 3246 & 358 & 1344 & 5495 & 9660 & 3295 & 12078 & 187 & 40271 & 587 & 5357 & 7597 & 10898 & 8661 & 15976 \\
\hline Consumo Total & 25084 & 1445 & 3848 & 7936 & 6183 & 3469 & 3420 & 7579 & 5517 & 1241 & 14936 & $7+15$ & 582 & 2111 & 7422 & 11957 & 3380 & 14286 & 481 & 49237 & 1047 & 6689 & 12976 & 16069 & $\$ 387 \uparrow$ & 23642 \\
\hline Produçăo Total Geral & 58400 & 2963 & 6049 & 10959 & 11969 & 5647 & 4933 & 12802 & 9270 & 1853 & 18215 & 10880 & 993 & 3425 & 11317 & 20251 & 4079 & 16767 & 575 & 63599 & 1628 & 14882 & 19613 & 45576 & 24753 & 80150 \\
\hline
\end{tabular}




\begin{tabular}{|c|c|c|c|c|c|c|c|c|c|c|c|c|c|c|c|}
\hline & \multicolumn{5}{|c|}{ NORTE - DEMANDA FINAL } & \multicolumn{5}{|c|}{ NORDESTE-DEMANDA FINAL } & \multicolumn{5}{|c|}{ CENTRO-OESTE - DEMANDA FINAL } \\
\hline & Dummy Fin. & Consumpo & FBCF & Var, Estoque & Exportaçoes & Durnmy Fin. & Consumo & FBCF & Var. Estoque & Exportaçoess & Durnmy Fin. & Consurno & FBCF & Var.Estoque & Exportaçoes \\
\hline 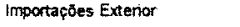 & 0 & 542 & 858 & 70 & 69 & 0 & 474 & 106 & -468 & 139 & 0 & 311 & 314 & 59 & 5 \\
\hline Impostos & 51 & 3490 & 698 & 52 & 194 & 853 & 8029 & 559 & 269 & 662 & 0 & 1825 & 438 & 62 & 244 \\
\hline Remtanteraçóes & 0 & 0 & 0 & 0 & 0 & 0 & 0 & 0 & 0 & 0 & 0 & 0 & 0 & 0 & 0 \\
\hline Satirio Total & 0 & 0 & 0 & 0 & 0 & 0 & 0 & 0 & 0 & 0 & 0 & 0 & 0 & 0 & 0 \\
\hline Contribuç̧os Sociais Efetivas & 0 & 0 & 0 & 0 & 0 & 0 & 0 & 0 & 0 & 0 & 0 & 0 & 0 & 0 & 0 \\
\hline 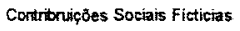 & 0 & 0 & 0 & 0 & 0 & 0 & 0 & 0 & 0 & 0 & 0 & 0 & 0 & 0 & 0 \\
\hline Excedente Bruto & .3129 & 0 & 0 & 0 & 0 & -18891 & 0 & 0 & 0 & 0 & -5462 & 0 & 0 & 0 & 0 \\
\hline Valor Adicionado Custo Fatores. & -3129 & 0 & 0 & 0 & 0 & -16991 & 0 & 0 & 0 & 0 & $-5,462$ & 0 & 0 & 0 & 0 \\
\hline impostos sobre atvidade & 0 & 0 & 0 & 0 & 0 & 0 & 0 & 0 & 0 & 0 & $a$ & 0 & 0 & 0 & 0 \\
\hline Subsidio sobre atwictade & 0 & 0 & 0 & 0 & 0 & 0 & 0 & 0 & 0 & 0 & 0 & 0 & 0 & 0 & 0 \\
\hline Vakor Adicionado Preço Básico & -3729 & 0 & 0 & 0 & 0 & -18891 & 0 & 0 & 0 & 0 & -5462 & 0 & 0 & 0 & 0 \\
\hline Produçdo Total - Norte & 3078 & 28770 & 20877 & 2016 & 4859 & 0 & 89 & 278 & 0 & 1 & 0 & 292 & 132 & 26 & 0 \\
\hline Producyato Total - Nordeste & 0 & 1105 & 421 & 0 & 0 & 18068 & 110554 & 36460 & 8918 & 13832 & 0 & 373 & 20 & -1 & 0 \\
\hline Produçăo Total - Certro-Oeste & 0 & 182 & 18 & $i$ & 1 & 0 & 477 & 16 & 31 & 0 & 5493 & 21316 & 5175 & $\$ 47$ & 3259 \\
\hline 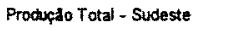 & 0 & 5155 & 2771 & 96 & 20 & 0 & $15 \$ 73$ & 1783 & 662 & 7 & 0 & 2400 & 1188 & $8:$ & 0 \\
\hline Produçáa Total - Sul & 0 & 2097 & 587 & 18 & 5 & 0 & 7470 & 522 & 244 & 3 & 0 & 692 & 295 & 119 & 0 \\
\hline Consumo Totat & 3129 & 41340 & 26030 & 2263 & 5148 & 18921 & 142266 & 39725 & 9658 & 14644 & 5493 & 27208 & 7559 & 994 & 3509 \\
\hline Produça o Total Geral & 0 & 41340 & 28030 & 2283 & 5148 & 30 & 142266 & 39725 & 9658 & 14644 & 30 & 27208 & 7559 & 994 & 3508 \\
\hline
\end{tabular}

\begin{tabular}{|c|c|c|c|c|c|c|c|c|c|c|}
\hline & \multicolumn{5}{|c|}{ SUDESTE - DEMANDA FINAL } & \multicolumn{5}{|c|}{ SUL - DEMANDA FINAL } \\
\hline & Dumntry Fin. & Consumo & FBCF & Var. Estoque & Exportaçoes & Dumny Fin. & Consumo & FBCF & Var. Estoque & Exportaçoes \\
\hline Importą̧des Exterior & 0 & 6032 & 6095 & 1146 & 174 & 0 & 1718 & 1736 & 326 & 56 \\
\hline impostos & 0 & 35428 & 8496 & 1211 & 7721 & 0 & 10092 & 2420 & 345 & 2484 \\
\hline Remumeraçdes & 0 & 0 & 0 & 0 & 0 & 0 & 0 & 0 & 0 & 0 \\
\hline Salánio Total & 0 & 0 & 0 & D & 0 & 0 & $a$ & 0 & 0 & 0 \\
\hline Condribuiqües Sociais Etetivas & 0 & 0 & 0 & 0 & 0 & 0 & 0 & 0 & 0 & 0 \\
\hline Contribnuçżes Sociais Fieticias & 0 & 0 & 0 & 0 & 0 & 0 & 0 & 0 & 0 & 0 \\
\hline Excederte Bruto & -106063 & 0 & 0 & 0 & 0 & -30214 & 0 & 0 & 0 & 0 \\
\hline Valer Adiciona do Custo Fatores & -106063 & a & 0 & 0 & a & -30214 & a & 0 & 0 & 0 \\
\hline Impostos sobre atividade & 0 & 0 & 0 & 0 & 0 & 0 & 0 & 0 & 0 & 0 \\
\hline Subsidio sobre atividade & 0 & 0 & 0 & 0 & 0 & 0 & 0 & 0 & 0 & 0 \\
\hline Valor Adiciona do Prę̧o Básico & -106063 & 0 & 0 & 0 & 0 & -30214 & 0 & 0 & 0 & 0 \\
\hline Produça Total - Norte & 0 & 5665 & 2560 & 501 & 0 & 0 & 1814 & 729 & 143 & 0 \\
\hline Prodeça Total - Nordeste & 0 & 7247 & 382 & -10 & 0 & 0 & 2064 & 109 & -3 & 0 \\
\hline Produczo Total - Centro-Oeste & 0 & 4916 & 334 & 975 & 0 & 0 & 2894 & 397 & 13 & 0 \\
\hline Produçăo Total - Sudeste & 108651 & 437904 & 127668 & 12645 & 103193 & 0 & 25673 & 8187 & 226 & 0 \\
\hline 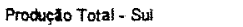 & 0 & 31195 & 1240 & 2824 & 0 & 30382 & 106437 & 28234 & 4445 & 33194 \\
\hline Consumo Total & 106651 & 528287 & 946776 & 19291 & 111088 & 30382 & 150492 & $418 \div 2$ & 5485 & 35734 \\
\hline Produçżo Total Geral & 588 & 528287 & 146776 & 19291 & 111088 & 167 & $\{50492$ & 41812 & 5495 & 35734 \\
\hline
\end{tabular}

\begin{tabular}{|c|c|c|c|c|c|c|c|c|c|c|c|c|c|}
\hline & \multicolumn{5}{|c|}{ Demanda intemedianiz } & \multicolumn{5}{|c|}{ Demanda Final } & \multicolumn{3}{|c|}{ Total } \\
\hline & Nonte & Nordeste & C-Oeste & Sudeste & Sul & Norte & Nordeste & EDest: & Sudeste & Sut & Dem Interm. & Dem. Final. & Gerat \\
\hline Importaçós Extenor & 2140 & 2701 & 1227 & 65620 & 13889 & 1339 & 253 & 689 & 13446 & 3837 & 85576 & 19564 & 105140 \\
\hline impostos & 2324 & 3329 & 2253 & 42290 & 9977 & 4444 & 9519 & 2568 & 52856 & 15341 & 60181 & 84729 & 145814 \\
\hline Remuneraçঠes & 19807 & 71025 & 19186 & 319678 & 80028 & 0 & 0 & 2 & 0 & 0 & 501785 & 0 & 501785 \\
\hline Salário Total & 17023 & 57526 & 15613 & 249192 & 65722 & 0 & 0 & 0 & 0 & 0 & 405076 & 0 & 405076 \\
\hline Contributhęos Sociais Efetivas & 2844 & 3202 & 2210 & 40706 & 9833 & 0 & 0 & 0 & 0 & 0 & 84796 & 0 & 64796 \\
\hline Comtribniçđes Sociais Fieticias & 0 & 4297 & 1363 & 21780 & $\$ 473$ & 0 & o & 0 & 0 & 0 & 31913 & 0 & 31913 \\
\hline Excedente Bruto & 46821 & 123365 & 28780 & 448168 & 132124 & 0 & 0 & 0 & 0 & 0 & 779259 & 0 & 615499 \\
\hline Valor Adicionado Custo Fatores & 66688 & 194350 & 47967 & 759846 & 212152 & 0 & 0 & 0 & 0 & 0 & 1281043 & 0 & 1117283 \\
\hline Inpostos sobre atividade & 423 & 1217 & 343 & 6780 & 1894 & 0 & 0 & 0 & 0 & 0 & 10655 & 0 & 10655 \\
\hline Subsidio sobre atridade & -886 & -760 & -823 & -12289 & -4001 & 0 & 0 & 0 & 0 & o & -18758 & 0 & -18758 \\
\hline Valor Adicionado Preço Básico & 66223 & 194847 & 47487 & 754338 & 210045 & 0 & 0 & 0 & 0 & 0 & 1272941 & 0 & 1109181 \\
\hline Produçẳo Total - Norte & 24743 & 318 & 499 & 10022 & 4870 & 56522 & 368 & 449 & 8726 & 2486 & 40452 & 68551 & 112081 \\
\hline Proctuçă Total - Nordeste & 1179 & 107111 & 540 & 19316 & 5421 & 1526 & 169704 & 392 & 7619 & 2170 & 133568 & 181471 & 333107 \\
\hline Produç̧o Total - Centro-Oeste & 337 & 541 & 23606 & 11149 & 1888 & 203 & 525 & 30297 & 6124 & 3304 & 37501 & 40450 & 83444 \\
\hline Proctuça Total - Sudest to & 12677 & 19107 & 6389 & 692045 & 38415 & 8041 & 17625 & 3767 & 681411 & 34085 & 768633 & 744930 & 1620215 \\
\hline Prochteção Total - Sul & 2457 & 5153 & 1443 & 25428 & 177063 & 2708 & 8238 & 1108 & 35260 & 172310 & 211544 & 219622 & 461540 \\
\hline Consumo Total & 45858 & 138260 & 35957 & 865877 & 251502 & 74781 & 206293 & 39269 & 805442 & 233533 & 1337454 & 1359319 & 2881349 \\
\hline Produção Total Geral & 112081 & 333107 & 83444 & 1620215 & 461548 & 74781 & 206293 & 39289 & 905442 & 233533 & 2610395 & 1359319 & 3970529 \\
\hline
\end{tabular}


ANEXO B1 - referente ao Quadro 6.3 (pag/54)

\begin{tabular}{|c|c|c|c|}
\hline \multicolumn{4}{|c|}{ SETORES BRASIL - 1985} \\
\hline \multicolumn{2}{|r|}{ IBGE } & \multicolumn{2}{|r|}{ AGREGADO } \\
\hline ORDEM & DESCRIÇÁO & ORDEM & DESCRIÇÁO \\
\hline 1 & AGROPECUARIA & 1 & AGROPECUÁRIA \\
\hline 2 & EXTRAT. MINERAL & \multirow[t]{2}{*}{2} & \multirow[t]{2}{*}{ MINERAÇÃo } \\
\hline 3 & PETROLEO E GÁS & & \\
\hline 4 & MNERAL Ñ METALICO & 3 & MINERAL N METÁLICO \\
\hline 5 & SIDERURGIA & 4 & SIDERURGIA \\
\hline 6 & METALURG. N FERROSOS & 5 & METALURG. N FERROSOS \\
\hline 7 & OUTROS METALÚRGICOS & 6 & OUTROS METALÚRGICOS \\
\hline 8 & MAQQUINAS E EQUIP. & 7 & MAQUINAS E EQUIP. \\
\hline 9 & MATERIAL ELEETRICO & 8 & MATERIAL ELETRICO \\
\hline 10 & EQUIP. ELETRONICOS & 9 & EQUIP. ELETRONNICOS \\
\hline 11 & AUTOM.JCAM/ONIBUS & \multirow[t]{2}{*}{10} & \multirow[t]{2}{*}{ MATERIAL DE TRANSPORTE } \\
\hline 12 & PEÇAS E OUT. VEICULOS & & \\
\hline 13 & MADEIRA E MOBILIÁRIO & 11 & MADEIRA E MOBILIÁRIO \\
\hline 14 & CELULOSE, PAPEL E GRÁ. & 12 & CELULOSE, PAPEL E GRÁF. \\
\hline 15 & IND. DA BORRACHA & 13 & IND. DA BORRACHA \\
\hline 16 & ELEMENTOS QUIMICOS & 14 & ELEMENTOS QUIMICOS \\
\hline 17 & REFINO DO PETRÓLEO & 15 & REFINO DO PETRÓLEO \\
\hline 18 & QUIMICOS DIVERSOS & 16 & QUIMICOS DIVERSOS \\
\hline 19 & FARMAC. E VETERINÁRIA & 17 & FARMAC. E VETERINÁRIA \\
\hline 20 & ARTIGOS PLÁSTICOS & 18 & ARTIGOS PLASTICOS \\
\hline 21 & IND. TEXTIL & 19 & IND. TEXTIL \\
\hline 22 & ARTIGOS DO VESTUARIO & 20 & ARTIGOS DO VESTUÁRIO \\
\hline 23 & FABRICAÇĀO CALÇADOS & 21 & FABRICACAO CALCADOS \\
\hline 24 & INDÚSTRIA DO CAFE & 22 & INDÚSTRIA DO CAFE \\
\hline 25 & BENEF. PROD. VEGETAIS & 23 & BENEF. PROD. VEGETAIS \\
\hline 26 & ABATE DE ANIMAIS & 24 & ABATE DE ANIMAIS \\
\hline 27 & INDÚSTRIA DE LATICINIOS & 25 & INDÚSTRIA DE LATICINIOS \\
\hline 28 & FABRICAÇĀO DE ACÚCAR & 26 & FABRICAÇAO DE ACUUCAR \\
\hline 29 & FAB. OLEOS VEGETAIS & 27 & FAB. OLEOS VEGETAIS \\
\hline 30 & OUTROS PROD. ALIMENT. & 28 & OUTROS PROD. ALIMENT. \\
\hline 31 & INDÚSTRIAS DIVERSAS & 29 & INDÚSTRIAS DIVERSAS \\
\hline 32 & S.I.U.P. & 30 & S.I.U.P. \\
\hline 33 & CONSTRUÇĀO CIVIL & 31 & CONSTRUÇAOO CIVL \\
\hline 34 & COMERCIO & 32 & COMÉRCIO \\
\hline 35 & TRANSPORTES & 33 & TRANSPORTES \\
\hline 36 & COMUNICAÇOESS & 34 & COMUNICACOOES \\
\hline 37 & INSTITUIÇÖES FINANCEIRAS & 35 & INSTITUICOES FINANCEIRAS \\
\hline 38 & SERV. PREST. A FAMILIA & 36 & SERV. PREST. À FAMILIA \\
\hline 39 & SERV. PREST. A EMPRESA & 37 & SERV. PREST. A EMPRESA \\
\hline 40 & ALUGUEL DEIMOVEEIS & 38 & ALUGUEL DE IMÓVEIS \\
\hline 41 & ADMINISTRAÇÃO PÚBLICA & 39 & ADMINISTRAÇĀO PÚBLICA \\
\hline 42 & SERV. PRIV. N MERCANTIS & 40 & SERV. PRIV. N MERCANTIS \\
\hline 43 & DUMMY FINANCEIRO & & \\
\hline 44 & PRODUÇÃO POR PRODUTO & 41 & PRODUÇĀO POR PRODUTO \\
\hline
\end{tabular}




\begin{tabular}{|c|c|c|c|}
\hline \multicolumn{2}{|r|}{$\frac{\text { PRODUTOS - BRASIL 1985-AN }}{\text { MCE }}$} & \multicolumn{2}{|r|}{ AGREGADO } \\
\hline ORDEM & DESCRICAO & ORDEM & DESCRIÇĀO \\
\hline 1 & CArE EM coco & 1 & CAFE EM COCO \\
\hline 2 & CANADE-ACOCAR & 2 & CANA-DEACCUCAR \\
\hline 3 & ARROZ EA CASCA & 3 & ARROZ EM CASCA \\
\hline 4 & TRIGO EM GRAO & 4 & TRIGO EM GEÃO \\
\hline 5 & SOIAEM GRAO & 5 & SOIA EM GRAO \\
\hline 6 & ALCODAO EM CAROCO & 6 & ALCODAO EM CAROCO \\
\hline 7 & MBHO EM GRÁO & 7 & WHHO EM GRAO \\
\hline 8 & GOVNOS E SUINOS & 8 & BOVINOS E SUANOS \\
\hline 9 & LTTE NATURAL & 9 & LuETE NATURAL \\
\hline 10 & AVES VTVAS & 10 & AVES VIVAS \\
\hline 11 & OUT. PROD. AGROFECUARIOS & 11 & OUT. PROD. AGROFECUARIOS \\
\hline 12 & MINGRIO DE FERRO & 12 & MINGERPO DE FERRO \\
\hline 13 & OUIROS MUNERAIS & 13 & Outros MnNERnts \\
\hline 14 & PETROLLOE GAS & 14 & PETROLLEOE GAS \\
\hline 15 & CARVAOE OUTROS & 15 & CARYAOE OUTROS \\
\hline 16 & PROD. MINTRAIS A METÁLICOS & 16 & PROD. MONERAAS N METALICOS \\
\hline 17 & FROD. SIDERÚRGGCOS BASICOS & 17 & PROD, STDERÚRGCOS BASICOS \\
\hline 18 & LAMPNADOS DE ACO & 18 & LAMARANOS DE ACOO \\
\hline 19 & FROD METALUEG A FERROSOS & 19 & PROD.METAL.tRGG. F FERR OSOS \\
\hline 20 & OUL. PROD. METALURGCOS & 20 & OUT. PROD. METALURGTCOS \\
\hline 21 & FABRIC, E MANOT. MAO E EOURP. & 21 & FABRIC, E MANOT. MAQ E EQUUP. \\
\hline 22 & TRATORES E MMQ, TrRRAFLAN & 22 & TRATORES E MAO TERRAPLAN. \\
\hline 23 & MUTERTAL EAETRYCO & 23 & MATERUA ELETRCO \\
\hline 24 & EQUTPAMANTOS ECETRÓNTCOS & 24 & EOURAMENTOS ELETRÓNLCOS \\
\hline 25 & AUTOM_CANINHOES $\mathrm{z}$ ONEOS & 25 & AUTOM_CAMONHOES E ONIBBOS \\
\hline 26 & JOUTROS VEICULOS E PECAS & 26 & JOUTROS VEICULOS E PECAS \\
\hline 27 & MUDERRA E MOBRENARIO & 27 & MADERRA E MOBILIARIO \\
\hline 28 & PAPELCEEIULPAPELAOO E ARTEY. & 28 & PAPEILCEIULPAPEILOOE ARTEF. \\
\hline 29 & PRODUTOS DA BORRACHA & 29 & FRODUTOS DA BORRACHA \\
\hline 30 & DLFM QULA N PETROQUIAMCOS & 30 & 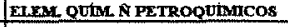 \\
\hline 31 & ALCOOL DE CANA E CEREAIS & 31 & ALCOOL DE CANA E CEREAUS \\
\hline 32 & GASOLINA PURA & 32 & GASOLINA FURA \\
\hline 33 & OLBOB COMAOSTIVETS & 33 & OLLOSOS COMBUStivers \\
\hline 34 & OUTROS PROD. DO REPTNO & 34 & TOUTROS PROD. DO REPNO \\
\hline 35 & PROD. RETROQUAMCOS BÁBICOS & 35 & FROD. PETROQUIMACOS BÁsICOS \\
\hline 36 & PESANAS & 36 & RESINAS \\
\hline 37 & GASOALCOOL & 37 & GASOALCOOL \\
\hline 38 & ADUBOS & 38 & ADUBOS \\
\hline 39 & TENTAS & 39 & TINTAS \\
\hline 40 & OUTROS PROD. QUUMACOS & 40 & lotreOs PROD. QUTMECOS \\
\hline 41 & PROD. FARM E DE FERTUMARIA & 41 & EROD. FARM E DE PERPUMARIA \\
\hline 42 & ARTIGOS DE PLÁSTICO & 42 & ARTIGOS DE PLASTICO \\
\hline 43 & ROS TEXTEIS NATURAS & 43 & FIOS TRXTEIS NATURAIS \\
\hline 44 & TECEDOS NATURAIS & $\neq 4$ & IECTDOS NATURAIS \\
\hline 45 & Fos TEXTEIS ARTHICLAS & 45 & FIOS TEXTEIS ARTHFICUAS \\
\hline 46 & TECBDOS ARTITICLNS & 46 & TXCDOOS ARTIFICLAS \\
\hline 47. & OUTROS PROD. TEXTRUS & 47 & loURROS PROD. TEXTETS \\
\hline 48 & ARTICOS DO VESTUARTO & 48 & ARTIGOS DO VESTUARHO \\
\hline 49 & PROD. COUROE CALCADOS & 49 & PROD. COURO E CALCADOS \\
\hline 50 & FRODUTOS DO CAFE & 50 & PRODUTOS DO CAYE \\
\hline 51 & ARROZ BENEFTCLADO & 51 & ARROZ BENEYICLADO \\
\hline 52 & FARINKA DE TRIGO & 52 & FARINHA DE IRIGO \\
\hline $\mathbf{5 3}$ & OUT, PROD. ALIMENT, BENEFIC, & 53 & OUT. PROD, AKINAENT. BENEFTC. \\
\hline 54 & CaRNE BOVINA & 54 & CARNE BOVINA \\
\hline 55 & CARNE DE AVES ABATDAS & 55 & CARNE DE AYES ABATDAS \\
\hline 56 & LERTE BENEFTCUADO & 56 & LSTRE BENEFTCLADO \\
\hline 57 & OUTROS LATICINIOS & 57 & GOVTROS LATICINTOS \\
\hline 58 & ACCUCAR & 58 & ACÉCAR \\
\hline 59 & OLEO VEGETAL EM BQUTO & 59 & TOLEO VEGETAI, EM BRUTO \\
\hline 60 & OLEO VEGETAL RETINADO & 60 & fol.zo VEcE TAL REFNADO \\
\hline 61 & RACOES E OUT. ALRARNTARES & 61 & RACOOES E OUT. ALMENTARES \\
\hline 62 & BEBIDAS & 62 & BEBDDAS \\
\hline 63 & PRODUTOS DrvEResos & 63 & PRODUTOS DIVERSOS \\
\hline 64 & SERV. INDUST. DE TRR PUBLCA & 64 & 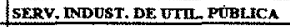 \\
\hline 65 & PROD. DA CONSTRECAOAO CTVR. & 65 & PROD. DA CONSTRECAO CIVIR \\
\hline 66 & MUROEM DE COMERCTO & 66 & MARGEM DE COMERCIO \\
\hline 67 & MARGEM DE TRANSPORTK. & 67 & MARCEM DE TRANSPORTE \\
\hline 68 & COMONCACOES & 68 & COMUNACACOES \\
\hline 69 & SECUROS & 69 & SECUROS E SERV, YINANCEIROS \\
\hline 70 & SERVICOOS FENANCEIROS & & \\
\hline 71 & ALOAAMENTO E ALEMENTACAO & 70 & ALOUAMENTO E ALMEENTACẢO \\
\hline 72 & OUTROS SRRVICOS & 71 & OUTROS SERVicos \\
\hline 73 & SATDE E EDUCMMERCANTIS & $n$ & SAÜDE E EDUC.MERCANTIS \\
\hline 74 & SERY. PREST, A RMPPESA & 73 & SERV, PREST, A EMPPRESA \\
\hline 75 & ALUGUEL DE MAOVEXS & 74 & ALUGUEX DE MMOVEUS \\
\hline 76 & ALUCUEL IMPUTADO & 75 & ALUGUEL MMPUTADO \\
\hline 77 & ADMDNISTRACÁO POBBLCA & 76 & ADM. SAÚDE, E ED. FUGBLICAS \\
\hline 78 & SAÜDE PÚBLICA & & \\
\hline 79 & EDUCACAO PÜBLICA & & \\
\hline 80 & SERV. A MERCANTIL PRIYADO & 77 & SERV. A MERCANTR, PRYVADO \\
\hline 81 & AJ, EXTRATERRRTORLAL & 78 & AL. EXTRATERRTTORLAL \\
\hline 82 & TOTAL & 79 & Irotal \\
\hline
\end{tabular}




\begin{tabular}{|c|c|c|c|}
\hline \multicolumn{4}{|c|}{ SETORES - NORTE 1985 - ANEXO B3 - ref. Quadro 6.3 toan 541} \\
\hline \multicolumn{2}{|r|}{ HBOE } & \multicolumn{2}{|c|}{ AGREGADO } \\
\hline ORD & DESCRICAO & ORD & DESCRYCAO \\
\hline 1 & AGROPECUARLA & 1 & AGROPECUARIA \\
\hline 2 & EXTR DE BNMET & \multirow[t]{2}{*}{2} & \multirow[t]{2}{*}{ EXTR DE MAN MET } \\
\hline 3 & EXTR DE AHN NAO MET & & \\
\hline 4 & FABR CMMENTO E CLNA & \multirow[t]{4}{*}{3} & \multirow[t]{4}{*}{ FABR CWENTO E CLINO } \\
\hline 5 & FABR ESTRUT CAMENTO & & \\
\hline 6 & FABR DE VDRO & & \\
\hline 7 & OUTR PROD EMN NAO MET & & \\
\hline 8 & SIDERUREIA & 4 & STDERURGA \\
\hline 9 & METALURO NAO FERROSOS & 5 & METALURG NAO FERROSOS \\
\hline 10 & FABR FUND E FORJ ACO & \multirow[t]{2}{*}{6} & \multirow[t]{2}{*}{ FABR FUND E FORJ ACO } \\
\hline 11 & FABR OUT PROD METALUR & & \\
\hline 12 & FABR MAQ EQUIP INSTAL & 7 & FABR MAQ EQUIP INSTAL \\
\hline 13 & FABR EQUIP ENERG ELETR & 8 & FABR EQUIP ENERG ELETR \\
\hline 14 & FABR CONDUTORES & & \\
\hline 15 & FABR APAR EQUIP ELETR & & \\
\hline 16 & FABR EQUIP ELETRONICO & 9 & FABR EQUIP ELETRONKO \\
\hline 17 & FABR TV RADIO & & \\
\hline 18 & FABR AUTOPECAS & 10 & FABR AUTOPECAS \\
\hline 19 & INDUSTRLA NAVAL & & \\
\hline 20 & FABR OUTROS VECULOS & & \\
\hline 21 & IMDUSTRIA DA MADERA & 11 & INOUSTRIA DA MADERA \\
\hline 22 & IND DO MOBLLARIO & & \\
\hline 23 & FABR CELULOSE & 12 & FABR CELULOSE \\
\hline 24 & FABR PAPEL PAPELAO & & \\
\hline 25 & IND EDTORIAL GRAFICA & & \\
\hline 26 & INDUSTRIA DA BORRACHA & 13 & INDUSTRIA DA BORRACHA \\
\hline 27 & PROD ELEMENTOS QUIMICOS & 14 & PROO ELEMENTOS QUMAICOS \\
\hline 28 & REFNO PETROLEO & 15 & REFMO PETROLEO \\
\hline 29 & IND PETROQ BAS INTERMED & & \\
\hline 30 & FABR RESIM FIBRAS ARTIF & & \\
\hline 31 & FABR ADUBOS FERTILIR & 16 & FABR ADUBOS FERTILIZ \\
\hline 32 & FABR PROD QUA DVERSOS & & \\
\hline 33 & WND FARMACEUTICA & 17 & IND FARMACEUTICA \\
\hline 34 & IMD PERFUMARU & & \\
\hline 35 & FABR LAMNA PLASTKCOS & 18 & FABR LAMHN PLASTICOS \\
\hline 36 & FABR ART MAT PLASTICO & & \\
\hline 37 & BENEF FIBR TEXT NAT & 19 & BENEF FIER TEXT NAT \\
\hline 38 & BENEF FIBR TEXT ARTIF & & \\
\hline 39 & OUTRAS WD TEXTES & & \\
\hline 40 & FABR ART VESTUARIO & 20 & FAER ART VESTUARIO \\
\hline 41 & IND COUROSE PELES & 21 & IND COUROS E PELES \\
\hline 42 & INDUSTRIA DO CAFE & 22 & INDUSTRLA DO CAFE \\
\hline 43 & BENEFC ARROZ & 23 & BENEFC ARROZ \\
\hline 44 & FABR CONSERVAS SUCOS & & \\
\hline 45 & BEMEF OUT PROD VEGETAIS & & \\
\hline 46 & INDUSTRIA DO FUMO & & \\
\hline 47 & ABATE ANMAIS, EXC AVES & 24 & ABATE ANMAS, EXC AVES \\
\hline 48 & ABATE E PREPAR DE AVES & & \\
\hline 49 & RESF DE LETTE,PROD LATIC & 25 & RESF DE LETTE,PROD LATIC \\
\hline 50 & INDUSTRIA DO ACUCAR & 26 & INOUSTRIA DO ACUCAR \\
\hline 51 & FABR OLEOS VEG EM BRUTO & 27 & FABR OLEOS VEO EM BRUTO \\
\hline 52 & PREPAR ALIM PARA ANIMALS & 28 & PREPAR ALLM PARA ANEMAS \\
\hline 53 & OUTRAS IND ALEAENTARES & & \\
\hline 54 & INDUSTRLA DE BEBIDAS & & \\
\hline 55 & FABR DE PROD DIVERSOS & 29 & FABR DE PROD DNERSOS \\
\hline 56 & PROD,DISTR DEENER ELET & 30 & PROO,DISTR DE ENER ELET \\
\hline 57 & SAMEAM E ABASTEC D'AGUA & & \\
\hline 58 & CONSTRUCAO CML & 31 & CONSTRUCAO CML \\
\hline 59 & COMERCIO & 32 & COHERCIO \\
\hline 60 & TRANSPORTE & 33 & TRANSPORTE \\
\hline 61 & COAUNICACOES & 34 & COMUNICACOES \\
\hline 62 & IIMST FINAN EDE SEGUROS & 35 & INST FINAN E DE SEGUROS \\
\hline 63 & SERV ALOJAM E ALHAENT & 36 & SERV ALOUAM E ALMENT \\
\hline 64 & SERV REPAR,EXC INDUSTR & & \\
\hline 65 & SERV PREST AS FAMLLAS & & \\
\hline 66 & SAUDE MERCANTIL & & \\
\hline 67 & EDUCACAO MERCANTIL & & \\
\hline 68 & SERV PREST AS EMPRESAS & 37 & SERV PREST AS EMPRESAS \\
\hline 69 & ALUGUEL & 38 & ALUGUEL \\
\hline 70 & ADAANISTRACAO PUBLICA & 39 & ADIHINISTRACAO PUBLICA \\
\hline 71 & SERY PRN NAO MERCANTIS & 40 & SERV PRN NAO MERCANTIS \\
\hline 72 & DURAMY REPARACAO & 7 & FABR MAQ EQUIP INSTAL \\
\hline 73 & DUMAY EMPRESAS & 37 & SERV PREST AS EMAPRESAS \\
\hline 74 & PRODUCAO & & PRODUCAO \\
\hline
\end{tabular}




\begin{tabular}{|c|c|c|c|}
\hline \multicolumn{4}{|c|}{ 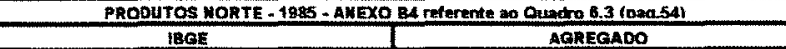 } \\
\hline OnDan & DESCRICAO & ORDEM & DESCRKCAO \\
\hline 1 & MADEIRA EM TORA & \multirow[t]{3}{*}{11} & \multirow[t]{3}{*}{ OUTROS PROD. AGROPECUARIOS } \\
\hline 2 & LEMMA E CARVAO VEGETAL & & \\
\hline 3 & OUT PROD EXT.CACAAPESCA & & \\
\hline 4 & CAFE EM COCO & 1 & CAFE EM COCO \\
\hline 5 & CAYA-DE-ACÚCAR & 2 & CANA- DE-ACUUCAR \\
\hline 5 & ARRO2 EM CASCA & 3 & ARROZ EM CASCA \\
\hline 7 & TRKCO EM GRAO & 4 & TRKCO EM ORAO \\
\hline 8 & SOSA EM GRAO & 5 & SOSA BM CRAO \\
\hline 3 & ALCODÄO EA CAROCCO & 8 & ALCODAO EM CAROCCO \\
\hline 10 & FULO EM FOLHA & 11 & LOUTROS PROD. AGROPECUARIOS \\
\hline 11 & MLLHO EM GRAO & 7 & MULHO EM GRAO \\
\hline 12 & OUT PROD AGRICOLAS & \multirow[t]{2}{*}{11} & \multirow[t]{2}{*}{ OUTROS PROD. AGROPECUARLOS } \\
\hline 13 & FLOREST, FORM CULTURAS & & \\
\hline 14 & AVES VNAS E OVOS & 10 & AVES VINAS E OVOS \\
\hline 16 & BoMmos E suinos vios & 8 & BOMnOS E SUINOS \\
\hline 16 & LETE MATURAL & 9 & LETE MATURAL \\
\hline 17 & OUT PROD OE OREEEM AMM & 11 & OUT PROO. ACROPECUARIOS \\
\hline 18 & NAMERTO DE FERRO & 12 & MAMERTO DE FERRO \\
\hline 19 & OUTROS MANER METALKCOS & \multirow[t]{2}{*}{13} & \multirow[t]{2}{*}{ OUTROS MUERANS } \\
\hline 20 & MHUER WAO MET, EXC ENERO & & \\
\hline 21 & PETMOLLEO E CAS MATURAL & 14 & PETROLEO E GAS \\
\hline 22 & CARVAO E OUT COMB MMNER & 16 & CARVAO E OUT COMB MBNEA \\
\hline 23 & CAMEMTO E CLMQUER & \multirow[t]{5}{*}{16} & \multirow[t]{5}{*}{ PROD.MMNERAS MAO METALLOS } \\
\hline 24 & ARTEF DE CONCRET E CMMEN & & \\
\hline 25 & YMDRO PLALO E DE SEGUR & & \\
\hline 26 & ARTICOS DE VDRO & & \\
\hline 27 & JOUT PROD MUN MAO METAL & & \\
\hline 28 & PROD SIOERUR BASICOS & \multirow[t]{2}{*}{17} & \multirow[t]{2}{*}{ PROD SIDERUR BASACOS } \\
\hline 29 & COQUE E DERN DO CARYAO & & \\
\hline 30 & LAMALADOS OE ACO & 18 & LAMMADOS DE ACO \\
\hline 31 & PROD METAL MAO FERROSOS & 19 & PROD METAL NAO FERROSOS \\
\hline 32 & FUMDTOOS E FORJ DE ACO & \multirow[t]{3}{*}{20} & \multirow[t]{3}{*}{ FUMDIDOS E FORJ DE ACO } \\
\hline 33 & OUT PRODUT METALURGICOS & & \\
\hline 34 & SERVXOS METALURGICOS & & \\
\hline 36 & MAQ, EQUIP E IMST INDUST & 21 & MAQ, EQUIP E IMST IKDUST \\
\hline 36 & MMQ EQUIP E IMST GERASS & & \\
\hline 37 & PECAS E ACESS PARA MAQ & & \\
\hline 38 & TRATORES E MAO RODOV & 22 & TRATORES E MAQ RODOV \\
\hline 39 & SERV MANUT E IMSTAL MAQ & 21 & MAQ EQUIP E IHST IHDUST \\
\hline 40 & EOUPP PROD E DISTRE.E. & 23 & EQUPP PROD E DISTR E.E. \\
\hline 41 & CONDUTORES ELETRICOS & & \\
\hline 42 & MATER ELET, EXC VEIC & & \\
\hline 43 & APAREL ELETRODOMESTHCOS & & \\
\hline 44 & APAREL ELETRIC PARA ESCR & & \\
\hline 45 & MATERALL ELETROHLO & 24 & MATERLAL ELETRONICO \\
\hline 46 & MAO ELETRONKC, TELECAUFO & & \\
\hline 47 & TV, RAD1O E EQUIP SOM & & \\
\hline 48 & AUTOM, CAMMH E OMIBUS & 26 & AUTOM, CAMANH E ONIBUS \\
\hline 49 & IPECAS PARA VEICULOS & 26 & PECAS PARA VEICULOS \\
\hline 60 & EMBARC, PECAS E ACESSOR & & \\
\hline 51 & SERYICOS DE REPAR MAVAL & & \\
\hline 52 & LOCOMOT E VAGOES FERROV & & \\
\hline 53 & SERYICOS DE REPAR FERROV & & \\
\hline 54 & OUT VELC, PECAS E ACESS & & \\
\hline 66 & MADER SERR, ART MADEIR & 27 & MADGR SERR, ART MADEER \\
\hline 66 & MOVES E ART DE COLCHAR & & \\
\hline 57 & CELULOSE E PASTA MECAN & 28 & CELULOSE E PASTA MECAY \\
\hline 58 & PAPEL, PAPELAO E ARTEF & & \\
\hline 69 & JORMAS, LNROS E REVST & & \\
\hline 60 & SERY GRAF,ANUXC MPREY & & \\
\hline 51 & PMEUS E CAMARAS & 29 & PNEUS E CAMARAS \\
\hline 62 & BORRACH BEMEF, ART BORR & & \\
\hline 93 & ELEM QUAH MAO PETROO & 30 & ELEM QUMM MAO PETROQ \\
\hline 64 & ALCOOL DE CANA E CEREAS & 31 & ALCOOL DE CAMA E CEREALS \\
\hline 65 & GASOLIMA PURA & 32 & GASOLMA PURA \\
\hline 66 & LOLEOS COMB, ENCL DIESEL & 33 & OLEOS COMB, ENCL DAESEL \\
\hline
\end{tabular}


PRODUTOS YOATE - 1925 (continuacjol-AMEXO BA referente ao Cuadro 0.3 loga.54)

\begin{tabular}{|c|c|c|c|}
\hline \multicolumn{2}{|r|}{ IBOE } & \multicolumn{2}{|r|}{ AGREGADO } \\
\hline ORD & DESCRICAO & ORD & DESCRACAO \\
\hline 67 & OUT PROD DO REF PETROL & 34 & OUT PROD DO REF PETROL \\
\hline 68 & GASOLUMA AUTOMOTNA & 37 & GASOLLMA AUTONOTNA \\
\hline 69 & PROD PETROOUM BASKCOS & \multirow[t]{2}{*}{35} & \multirow[t]{2}{*}{ PROD PETROOUM EASFCOS } \\
\hline 70 & PROD PETROQUIM IWTERM & & \\
\hline 71 & RESHAAS E ELASTOMEROS & 36 & RESHYAS E ELASTOMEROS \\
\hline 72 & ADUBOS E FERTILZAMTES & 38 & ADUBOS E FEATILZANTES \\
\hline 73 & TIMTAS, PICMENTOS & 39. & THTAS, PICMENTOS \\
\hline 74 & LOUTR PROD QUAmicos & 40 & LOUTR PROD QURMCOS \\
\hline 76 & PROO FARMAC MAO DOSADOS & \multirow[t]{3}{*}{41} & \multirow[t]{3}{*}{ PROD FARMAC KAO DOSADOS } \\
\hline 76 & PROD FARMAC DOSADOS & & \\
\hline 77 & PROD PERFUM, SABOES & & \\
\hline 78 & LAMHAD, FILMES DE PLAST & \multirow[t]{2}{*}{42} & \multirow[t]{2}{*}{ LAMMAD, FILMES DE PLAST } \\
\hline 79 & ART DE MATERAL PLAST & & \\
\hline 80 & FBBA BEAEF,FOS TEXT MAT & 43 & FBRA BENEF,FYOS TEXT MAT \\
\hline 81 & TECIDOS DE FIOS MATURANS & 44 & TECIDOS DE FIOS MATURAAS \\
\hline 82 & FOS DE FIBR ART E SIHT & 46 & FlOS DE FBR ART E SINT \\
\hline 83 & TECDOOS DE nOS SETET & 46 & TECIDOS DE FIOS SIUTET \\
\hline 84 & ARTIO DO VEST DE MALHA & 47 & ARTMG DO VEST DE MALHA \\
\hline 86 & ARTTE VEST, EXC MALHA & 48 & ARTTG VEST, EXC MALHA \\
\hline 88 & COUROS, PELES EAAT VAG & \multirow[t]{2}{*}{49} & \multirow[t]{2}{*}{ COUROS, PELLES E ART MAO } \\
\hline 87 & CALCADOS & & \\
\hline 88 & CAFE EM GRAO TORR, MOAD & 50 & CAFE EM GRAO TORR, MOIO \\
\hline 89 & ARROZ BENEFKCLADO & 81 & ARROZ BENEFICLADO \\
\hline 90 & FARIMHA, AMMOO DE TRISOO & 52 & FARIUHA AYMDO DE TRIGO \\
\hline 91 & SUCOS E CONSERVAS & \multirow[t]{3}{*}{83} & \multirow[t]{3}{*}{ SUCOS E CONSERYAS } \\
\hline 92 & DOUT PROD VEGETAS BEMEF & & \\
\hline 93 & FUMO BENEF, CIGARROS & & \\
\hline 34 & CARME VERDE E PREPARADA & \multirow[t]{2}{*}{64} & CARNE VERDE E PREPARADA \\
\hline 96 & COURO VERDE E SALGADO & & \\
\hline 96 & AVES ABATIDAS & 86 & AVES ABATIDAS \\
\hline 97 & LETE RESF, PAST E EM PO & 66 & LETE RESF, PAST E EM PO \\
\hline 98 & LATICHAOS & 67 & LATKCIMOS \\
\hline 99 & ACUCAR CRISTAL E REFIM & 68 & ACUCAR CRISTAL E REFIM \\
\hline 100 & OLEOS VEGETAS EM BRUTO & 69 & DLEOS VECETASS EM BRUTO \\
\hline 101 & TORTAS, FAREL SEMEN OLEAG & & \\
\hline 102 & OLEOS VEGETASS REFINADOS & 60 & OLEOS VEGETAS REFIMADOS \\
\hline 103 & RACOES, FORRAO PARA ANM & 61 & RACOES, FORRAG PARA AMIM \\
\hline 104 & OUT PROD IMD ALGMENTAR & & \\
\hline 105 & BEgaDAs & 52 & BEERDAS \\
\hline 100 & PRODUTOS MDUST DNERSOS & 63 & PRODUTOS IMDUST DIVERSOS \\
\hline 107 & SUCATA DE METAL & & \\
\hline 108 & UTISDADES, SERV MOD DN & & \\
\hline 109 & RESHDUOS RECTCLLAVES & & \\
\hline 110 & EXERGA ELETRICA & 64 & ENERCAA ELETRICA \\
\hline 111 & ACUA E ESCOTO & & \\
\hline 112 & CONSTRUCAO CML & 65 & CONSTRUCAO CML \\
\hline 113 & MARGEM DE COMERCIO & 60 & MARGEM OE COMERCIO \\
\hline 114 & TRAMSPORTE & 67 & TRANSPORTE \\
\hline 116 & COMUNICACOES & 68 & COMUNKCACOES \\
\hline 116 & SERV FINAKC E SEGUROS & 69 & SERV FIMAMC E SEGUROS \\
\hline 117 & SERY DE ALOLAM E ALMAENT & 70 & SERV DE ALOSAMA E ALIAEEYT \\
\hline 118 & SERV REPAR, EXC MDUSTR & 71 & SERV REPAR, EXC INDUSTR \\
\hline 119 & SERY PREST AS FAMALAS & & \\
\hline 120 & SERUCOS DE SAUDE MERC & 72 & SERVCOS OE SAUDE MERC \\
\hline 121 & SERYCOS DE EDUC MERC & & \\
\hline 122 & SERY PUBLIC E PROPAGANDA & 73 & SERV PUBLKC E PROPAGANDA \\
\hline 123 & OUUT SERY PREST AS EMPR & & \\
\hline 124 & ALUOUEL & 74 & ALUOUEL \\
\hline 126 & ALUEUEL BPUTADO & 76 & ALUCUEL MMPUTADO \\
\hline 128 & SERV MAO MERC PUBLCOS & 76 & SERV KAO MERC PUBLICOS \\
\hline 127 & SERV NAO MERC PRNADOS & 77 & SERV MAO MERC PRIVADOS \\
\hline 128 & SERVKOOS DOMESTRCOS & & \\
\hline 129 & SERY ADWMUIST OAS EMPR & 73 & SERV AOANIMIST DAS EMPR \\
\hline 130 & PROD MMPORT DO BRASIL & & PROD MMPOAT DO BRASIL \\
\hline 131 & PROD MAP DO RESTO MUMDO & & PROD MAP DO RESTO MUMDO \\
\hline 132 & mapostos & & MPOSTOS \\
\hline
\end{tabular}




\begin{tabular}{|c|c|c|c|}
\hline \multicolumn{2}{|r|}{ BSGE } & \multicolumn{2}{|r|}{ AGREGADO } \\
\hline ORDEM & DESCRICAOO & ORDEM & DESCRIÇAAO \\
\hline 1 & AGROPECUARIA & 1 & AGROPECUARIA \\
\hline 2 & EXTR OE MAN MET & \multirow[t]{4}{*}{2} & \multirow[t]{4}{*}{ EXTR DE MIY MET } \\
\hline 3 & EXTR OE MUM HAO MET & & \\
\hline 4 & EXTR DE PETROLEO & & \\
\hline 6 & EXTR DE CARVÃO & & \\
\hline 6 & FABR CMAEMTO E CLIMO & 3 & FABR CAMEMTO E CLIMO \\
\hline 7 & FABR ESTRUT CMENTO & & \\
\hline 8 & FABR DE VDRO & & \\
\hline 9 & OUTR PROD MH MAO MET & & \\
\hline 10 & SIDERURGIA & 4 & SIDERURGIA \\
\hline 11 & METALURG NAO FERROSOS & 5 & METALURG MAO FERROSOS \\
\hline 12 & FABR FUHD E FORJ ACO & 6 & FABR FUND E FORJ ACO \\
\hline 13 & FABA OUT PROO METALUR & & \\
\hline 14 & FABR MAQ EQUIP INSTAL & 7 & FABR MAQ EQUIP IWSTAL \\
\hline 16 & FABR DE TRATORES & & \\
\hline 16 & FABR EQUIP EXERG ELETR & 8 & FABR EQUIP ENERG ELETR \\
\hline 17 & FABR CONDUTORES & & \\
\hline 18 & FABR APAR EQUIP ELETR & & \\
\hline 19 & FABR EQUIP ELETROMICO & 9 & FABR EQUIP ELETROMICO \\
\hline 20 & FABR TV RADIO & & \\
\hline 21 & MOÚSTRL AUTOMOBLISTICA & 10 & IKDUSTRLA AUTOMOBLLSTICA \\
\hline 22 & FABR AUTOPECAS & & \\
\hline 23 & IMDUSTRIA MAVAL & & \\
\hline 24 & FAB.VEICULOS FERROVAARIOS & & \\
\hline 25 & FABR OUTROS VEICULOS & & \\
\hline 26 & INDUSTRIA DA MADEIRA & 11 & INDUSTRLA DA MADEIRA \\
\hline 27 & IMO DO MOBLLARIO & & \\
\hline 28 & FABR CELULOSE & 12 & FABR CELULOSE \\
\hline 29 & FABR PAPEL PAPELLO & & \\
\hline 30 & IND EDITORLAL GRAFICA & & \\
\hline 31 & INDUSTRA DA BORRACHA & 13 & IMDUSTRLA DA BORRACHA \\
\hline 32 & PROO ELEMENTOS QUHACOS & 14 & PROD ELEMENTOS QUMMCOS \\
\hline 33 & DESTILACAAO OE ALCOOL & & \\
\hline 34 & REFIMO PETROLEO & 16 & REFAMO PETROLEO \\
\hline 36 & IMD PETROA BAS INTERMED & & \\
\hline 36 & FABR RESII FIBRAS ARTIF & & \\
\hline 37 & FABR ADUBOS FERTILL & 16 & FABR ADUBOS FERTILD \\
\hline 38 & FABR PROO QUMM DIVERSOS & & \\
\hline 39 & INO FARMACEUTICA & 17 & IND FARMACEUTICA \\
\hline 40 & IMD PERFUMARLA & & \\
\hline 41 & FABR LAMAN PLASTICOS & 18 & FABR LAMH PLASTICOS \\
\hline 42 & FABR ART MAT PLASTICO & & \\
\hline 43 & BEMEF FIBR TEXT MAT & 19 & BEMEF FIBR TEXT NAT \\
\hline 44 & BEMEF FIBR TEXT ARTIF & & \\
\hline 48 & OUTRAS IND TEXTEIS & & \\
\hline 46 & FABR ART VESTUARIO & 20 & FABR ART VESTUARIO \\
\hline 47 & IMD COUROS E PELES & 21 & IMD COUROS E PELES \\
\hline 48 & FAB, DE CALCADOS & & \\
\hline 49 & IMOUSTRLA DO CAFE & 22 & INDUSTRIA DO CAFE \\
\hline 60 & BENEFIC ARROZ & 23 & BENEFIC ARROZ \\
\hline 61 & MOAGEM DE TRIGO & & \\
\hline 62 & FABR COHSERVAS SUCOS & & \\
\hline 53 & BENEF OUT PROD VEGETAIS & & \\
\hline 64 & IMDUSTRLA DO FUMO & & \\
\hline 58 & ABATE ANMMAIS, EXC AVES : & 24 & ABATE ANMAAS, EXC AVES \\
\hline 66 & ABATE E PREPAR DE AVES & & \\
\hline 57 & RESF DE LETTE.PROD LATIC & 26 & RESF DE LEITE,PROD LATIC \\
\hline 88 & IMDUSTRLA DO ACUCAR & 26 & LHDUSTRLA DO ACUCAR \\
\hline 59 & FABR OLEOS VEG EMA BRUTO & 27 & FABR OLEOS VEG EM BRUTO \\
\hline 60 & REFINO DE OLEOS VEGETAIS & & \\
\hline 51 & PREPAR ALMM PARA ANHMASS & 28 & PREPAR ALMM PARA ANMMAIS \\
\hline 52 & OUTRAS IWD ALIMENTARES & & \\
\hline 63 & IMDUSTRIA DE BEBIBAS & & \\
\hline 64 & FABR OE PROO ONYESSOS & 29 & FABR OE PROO ONERSOS \\
\hline 65 & PROD.DISTR DE EMER ELET & 30 & PROD,DASTR DE ENER ELET \\
\hline 66 & SANEAM E ABASTEC D'AGUA & & \\
\hline 67 & CONSTRUCAO CML & 34 & COMSTRUCAO CML \\
\hline 68 & COMERCIO & 32 & COMERCIO \\
\hline 69 & TRANSPORTE & 33 & TRANSPORTE \\
\hline 70 & COMUNICACOES & 34 & COMUMICACOES \\
\hline 71 & IMST FIMAN E DE SEGUROS & 36 & INST FIMAN E DE SEGUROS \\
\hline 72 & SERV ALOUAM E ALMMENT & 36 & SERV ALOJAM E ALIMENT \\
\hline 73 & SERY REPAR, EXC IMOUSTR & & \\
\hline 74 & SERV PREST AS FAMILLAS & & \\
\hline 76 & SAUDE MERCANTIL & & \\
\hline 76 & EDUCACAO MERCANTIL & & \\
\hline 77 & SERV PREST AS EMPRESAS & 37 & SERV PREST AS EMPRESAS \\
\hline 78 & ALUGUEL & 38 & ALUGUEL \\
\hline 79 & ADMANISTRACAO PUBLICA & 39 & ADMMISTRACAO PUBLICA \\
\hline 80 & SERY PRN MAO MERCAMTIS & 40 & SERV PRN NAO MERCARTIS \\
\hline 81 & DUMAMY REPARACAO & 7 & FABR MAO EQUIP INSTAL \\
\hline 82 & DUUMMY EMPAESAS & 37 & SERV PREST AS EMPRESAS \\
\hline
\end{tabular}


PROOUTOS - MORDESTE 1985 - AMEXO B8 ref. OUARro 6.3 (DO. 541

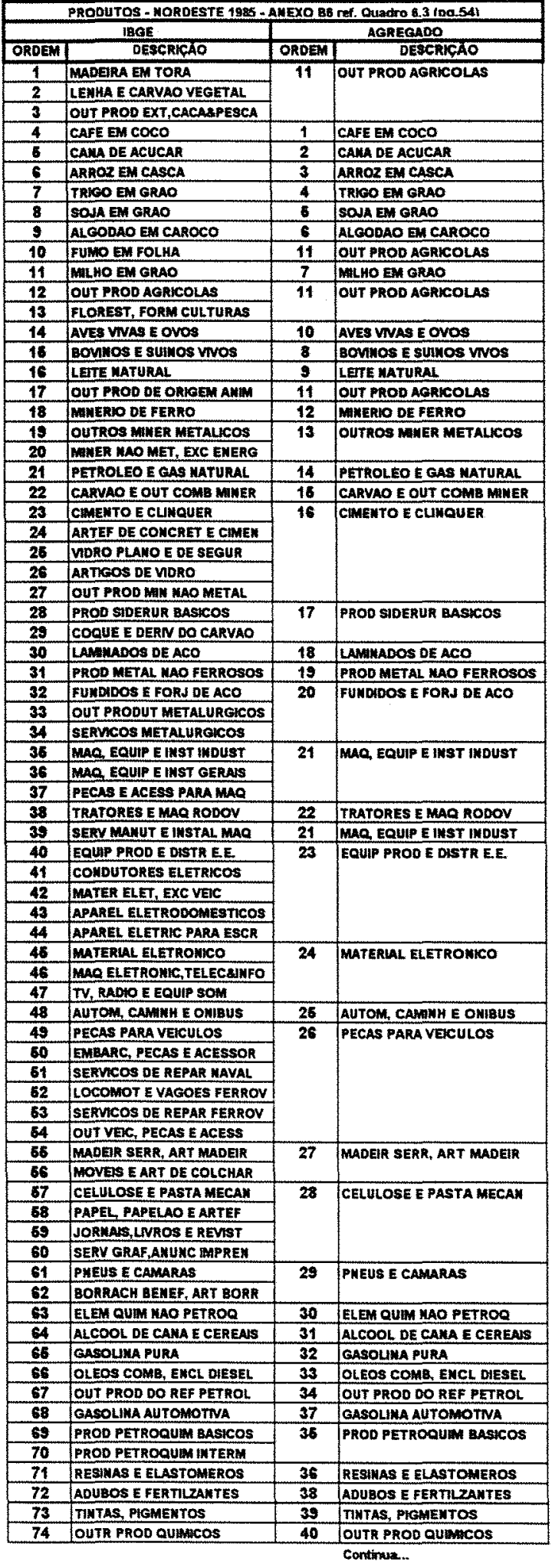




\begin{tabular}{|c|c|c|c|}
\hline 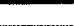 & IBCE & \multicolumn{2}{|r|}{ ACRECADO } \\
\hline ORDEM & DESCRKCAO & ORDEA & DESCRKÇAO \\
\hline 76 & PROO FARMAC MAO DOSADOS & \multirow[t]{3}{*}{41} & \multirow[t]{3}{*}{ PROD FARMAC MAO DOSADOS } \\
\hline 76 & PROD FAR:MAC DOSADOS & & \\
\hline 77 & PROD PERFUM, SABOES & & \\
\hline 78 & LAMARAD, FLMES OE PLAST & \multirow[t]{2}{*}{42} & \multirow[t]{2}{*}{ LAMMMAD, FLLMES DE PLAST } \\
\hline 79 & ART DE MATERUL PLAST & & \\
\hline 80 & FIBR BENEF, FIOS TEXT NAT & 43 & FIBR BENEF, FLOS TEXT MAT \\
\hline 81 & TECIOOS DE FOS WATURAUS & 44 & TECIDOS DE FIOS MATURAS \\
\hline 82 & FOSS DE FIBR ART E SINT & 46 & FFOS DE FIBR ART E SIMT \\
\hline 83 & TECIDOS DE FOS SATTET & 46 & TECIDOS DE FOS SAKTET \\
\hline 84 & ARTIO DO VEST DE MALHA & 47 & ARTIE DO VEST DE MALHA \\
\hline 85 & ARTTO VEST, EXC MAL HA & 48 & ARTIS VEST, EXC MALHA \\
\hline 86 & COUROS, PELES E ART VAG & \multirow[t]{2}{*}{49} & \multirow[t]{2}{*}{ COUROS, PELES E ART VAC } \\
\hline 87 & CALCADOS & & \\
\hline 88 & CAFE EM CRAO TORR, MOID & 60 & LCAFE EM ORAO TORR, MOHO \\
\hline 89 & ARROZ BEMEFTCLAOO & 61 & ARROZ BEMEFCLAOO \\
\hline 30 & FARIMHA, AMDO DE TRIGO & 52 & FARIMHA AMMDO DE TRKOO \\
\hline 91 & SUCOS E COUSERVAS & \multirow[t]{3}{*}{63} & \multirow[t]{3}{*}{ SUCOS E CONSERVAS } \\
\hline 92 & OUT PROD VEGETASS BEMEF & & \\
\hline 9 & FUMO BEMEF, CIGARROS & & \\
\hline 3 & CARNE VEADE E PREPARADA & \multirow[t]{2}{*}{54} & CARME VERDE E PAEPARADA \\
\hline 36 & COURO VEROE E SALQADO & & \\
\hline 96 & AVES ABATIDAS & $\sigma 5$ & AVES ABATIDAS \\
\hline 97 & LETE RESF, PAST E EM PO & 66 & LETE RESF, PASTE EM PO \\
\hline 98 & LATKCHOS & 67 & LATICimos \\
\hline 99 & ACUCAR CRISTAL E REFIN & 68 & ACUCAR CRISTAL E REFIM \\
\hline 100 & OLEOS VEGETAS EM BRUTO & 69 & OLEOS VEGETALS EM BRUTO \\
\hline 101 & TORTAS,FAREL SEMEY OLEAG & & \\
\hline 102 & JOLEOS VEGETAS REFILADOS & 60 & OLEOS VEGETAS REFIMADOS \\
\hline 103 & RACOES, FORRAO PARA AHM & 61 & RACOES, FORRAG PARA AKAM \\
\hline 104 & OUT PAOD IND ALMENTAR & & \\
\hline 108 & BEAIDAS & 62 & DEBDAS \\
\hline 106 & PRODUTOS IMDUST DNERSOS & 63 & PRODUTOS IXDUST DNERSOS \\
\hline 107 & SUCATA DE METAL & & \\
\hline 108 & UTUUDADES, SERV MO ON & & \\
\hline 109 & RESADUOS RECICLAVES & & \\
\hline 110 & ERERGA ELLTRICA & 64 & EMERCAA ELETRICA \\
\hline 111 & ACUA E ESCOTO & & \\
\hline 112 & CONSTRUCAO CML & 66 & CONBTRUCAO CML \\
\hline 113 & MARGEM DE COMERCIO & 66 & MARGEM DE COMERCIO \\
\hline 114 & TRAMSPORTE & 67 & TRANSPOATE \\
\hline 116 & COMUUICACOES & 68 & COMUNICACOES \\
\hline 116 & SERV FIMAYC E SECUROS & 69 & SERV FUAMC E SECUROS \\
\hline 117 & SERV DE ALONAM E ALMENT & 70 & SERV DE ALOLAM E ALMEUT \\
\hline $1+8$ & SERV REPAR, EXC IMDUSTR & 71 & SERV REPAR, EXC IMDUSTR \\
\hline 119 & SERV PREST AS FANILAS & & \\
\hline 120 & SERVCOS DE SAUDE MERC & 72 & SERVCOS DE SAUDE MERC \\
\hline 121 & SERMCOS DE EDUC MERC & & \\
\hline 122 & SERV PUBLC E PROPAGAMDA & 73 & SERY PUBLC E PROPAGAMDA \\
\hline 123 & OUT SERY PREST AS EMPR & & \\
\hline 124 & ALUCUEL & 74 & ALUGUEL \\
\hline 125 & ALUGUEL MPUTADO & 76 & ALUGUEL BAPUTADO \\
\hline 126 & SERV MAO MERC PUBLCOS & 75 & SERV MAO MERC PUBLICOS \\
\hline 127 & SERV YAO MERC PRNADOS & 77 & SERY MAO MERC PRIVADOS \\
\hline 128 & SERYVCOS DOMESTICOS & & \\
\hline 129 & SERV ADAHMIST OAS EMPR & 73 & SERV PUBLKC E PROPAGAMDA \\
\hline 130 & PROD MAPORT DO BRASIL & & PROD BMPORT DO BRASH \\
\hline 131 & PROD MP DO RESTO MUNDO & & PROD RMP DO RESTO MUNDO \\
\hline 132 & IaApostos & & MPOSTOS \\
\hline 133 & Total Cl & & Total CI \\
\hline 134 & Remuneracao & & Remuneracas \\
\hline 136 & Salario Total & & Salario Total \\
\hline 136 & Sal ol vine. & & Sat o vine. \\
\hline 137 & Sal $\mathbf{s}$ vinc. & & Sat si vinc. \\
\hline 138 & Cont Efet & & Cont Eret \\
\hline 139 & Cont Fic & & Cont Fic \\
\hline 140 & Exe Bruto & & Exc Brito \\
\hline 141 & Valor Adic. CF & & Vator Adlic. CF \\
\hline 142 & $\operatorname{Imp}$ s/ ativy & & inp s/ativ \\
\hline 143 & Sub a ativ & & Sub a ativ \\
\hline 144 & VA PB & & VA PB \\
\hline 146 & Protucas & & Protucar \\
\hline
\end{tabular}


ANEXO B8 - referente aos Ouadros 6.4 (pg.57 e 6.5 (Dg.60)

\begin{tabular}{|c|c|c|c|}
\hline \multicolumn{4}{|c|}{ 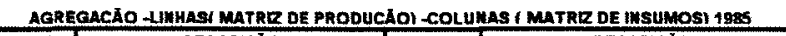 } \\
\hline ORDEA & DEsCRICÁO & ORDEM & DESCRICAO \\
\hline 1 & AGROPECUARR & 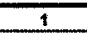 & AGROPECUARIA \\
\hline$\frac{1}{2}$ & MAMERACAO & 2 & MUERRACAO \\
\hline 3 & MAMERAL A METALLCO & 3 & MMERAL M̈ METALLCO \\
\hline 4 & SIDERURGA & 4 & METALURGM \\
\hline 5 & METALURG. A FERROSOS & & \\
\hline 8 & OUTROS METALURGICOS & & \\
\hline 7 & MQOUMMAS E EQUHP. & 5 & MECANICA \\
\hline 8 & MATERLAL ELÉETRKCO & 8 & MATERRLL ELETRICO \\
\hline$\div$ & EQUIP. ELETROMICOS & & \\
\hline 10 & MATERLAL DE TRAMSPORTE & 7 & MATERLL DE TRAMSPORTE \\
\hline 11 & MADERA EMOBALAARO & 8 & MMDERA E MOBLLARTO \\
\hline 12 & CELLLOOSE, PAPEL E GRÁF. & 9 & CELLULOSE, PAPEL E GRAF. \\
\hline 13 & MOD. DA BORRACHA & 10 & MMD. DA BORRACHA \\
\hline 14 & ELEMENTOS QUARCOS & 12 & QUUMMCOS DMERSOS \\
\hline 15 & REFIMO DO PETROLLEO & 11 & REFINO DO PETROLLEO \\
\hline 18 & QuimeOS ONERSOS & 12 & QUIIMCOS DNERSOS \\
\hline 17 & FARMAC. E VETERIMARLA & 13 & FARMACEUTICA \\
\hline 18 & ARTICOS PLASTICOS & 14 & PLAsTicos \\
\hline 19 & IIID. TEXTI & 15 & IMDÜSTRAA TEXTIL \\
\hline 20 & ARTIGOS DOO VESTUARIO & 18 & VESTUARRO E CALCAADOS \\
\hline 24 & FABRACACAO CALCADOS & & \\
\hline 22 & IIMDÚSTRLA DO CAFE & 17 & WMOÚSTRIA DO CAFE \\
\hline 23 & BEMEF. PROD. VECETALS & 20 & OUTROS PRODUTOS ALUMENTARES \\
\hline 24 & ARATE DE AMMMAIS & 18 & ABATE DE AMMMAS \\
\hline 25 & MOULSTRLA DE LATICIMOS & 20 & OUTROS PRODUTOS ALMMEMTARES \\
\hline 28 & FABRICACAO DE ACÚCAR & 18 & FABRKCACİO DE ACÚCAR \\
\hline 27 & FAB OLEOS VEGETANS & 20 & OUTROS PRODUTOS AL MEWTARES \\
\hline 28 & OUTROS PROD. ALMMENT. & & \\
\hline 28 & TMOÚSTRLAS DNVERSAS & 27 & MOUISTRUAS DNERSAS \\
\hline 30 & S.LU.P. & 22 & EMEREA, AGUA, SAK., E COMUUMUC. \\
\hline 34 & COMSTRUCAO CML & 23 & COMSTRUCAO CML \\
\hline 32 & COMÉRCIO & 24 & Conténc10 \\
\hline 33 & TRAMSPORTES & 25 & TRAKSPORTES \\
\hline 34 & COMUUMCACDOES & 22 & EMERGQU AGUA, SAM, E COMUMIC. \\
\hline 35 & IMSTTUKCOOSS FMMAMCEERAS & 28 & SERMCOOS \\
\hline 36 & SERV. PREST. A FAMHLLA & & \\
\hline 37 & SERY. PREST. A EMMPRESA & & \\
\hline 38 & ALU UUEL DE MMOVESS & & \\
\hline 39 & ADHAIISTRACAOO PÚBLKCA & & \\
\hline 40 & ISERV. PRN. II MERCAYTIS & & \\
\hline
\end{tabular}


ANEXO B7 - feferente aos Ouactos 6.4 (pg- 57) 6.5 (pg. 6D)

COLLNAS MMATRIZ OE PRODUCAOI LINHAS MMATRIZ DE INSUMOS

\begin{tabular}{|c|c|c|c|}
\hline \multirow{2}{*}{\multicolumn{4}{|c|}{$\begin{array}{l}\text { COLUMAS AGREGADAS - MATRR OE PRODUCĀO - } 1985 \\
\text { DESCFHCKU }\end{array}$}} \\
\hline & & & \\
\hline$T$ & CAAFEATCOCO & 7 & OUTROSPRODUTOS DA AGKROF \\
\hline 2 & CAYA-DE-ACUCAR & 1 & CANA-DEACUCAR \\
\hline 3 & ARROZ EM CASCA & 2 & ARROZ EM CASCA \\
\hline$\frac{\pi}{4}$ & TRIGO EM GRAO & 3 & TRIGO GM GRAO \\
\hline 5 & SOJA EM GRAO & 4 & SONA EM GRAO \\
\hline$\frac{6}{6}$ & ALGODAO EM CAROCO & 7 & OUTROS PRODUTOS DA AGROP \\
\hline 7 & MHLO EM GRAO & 5 & MLLHO GM GRAO \\
\hline 8 & BOVIMOS E SUMOS & 8 & BOVMOS E SUINOS \\
\hline g & LEITE NATURAL & 7 & OUTROS PRODUITOS DA AGROF \\
\hline 10 & AVES VIVAS & & \\
\hline 71 & OUT. PROD AGROPECUARIOS & & \\
\hline$\sqrt{2}$ & MINERHO DE FERRO & 8 & ATNERTO OE FERRO \\
\hline 73 & OUTROS MITERAS & 9 & OUTROS MINERASS \\
\hline 14 & PETROLEOE GAS & 10 & PETROLEOE GAS \\
\hline 75 & CARVAO E OUTROS & $\frac{11}{11}$ & CARVAO E OUTROS \\
\hline 38 & PROD. WUIEERNS W METALICOS & 12 & PROO. WINERALS N METALICOS \\
\hline$\pi$ & PROD. SIDERUREGCOS BASICOS & 13 & PROD SILERURGICOS BASICOS \\
\hline 78 & LAMAIADOOS DE ACO & 14 & UAMIXADOS DE ACO \\
\hline 79 & PROO. METALURG YFERROSO & 15 & PROD. MET ALURG W FERKOSO \\
\hline 20 & OUT. PROD METALURGICOS & 16 & OUT, BROD METALURGLOS \\
\hline 21 & FABRIC. EMAMUT. MAO EEQU & 17 & MECANICA \\
\hline 22 & TRATOKES E MAO TCRRAPLAI. & & \\
\hline 23 & MATERLLL ELETRICO & 18 & MATERAL ELETKICO \\
\hline 24 & EOUPAMENTOS ELETRONICOS & & \\
\hline$\frac{25}{25}$ & AUTOM,CAMINHOES E ONIBUS & 19 & MATERLAL DE TRANSPORTE \\
\hline 27 & MADROS VEICOLOS E PECAS & 20 & MADEIRA E MOBILIARIO \\
\hline 28 & PAPEL,CELUL PAPELAO E ARTE & 21 & PAPEL CELUL PAPELAO E ARTE \\
\hline 29 & PRODUTOS DA BORRACHA & 22 & PRODUTOS DA BORRACHA \\
\hline 30 & ELEM QUMM N PETROQUMICO & 26 & PRODUTOS OUMAICOS DIVERSO \\
\hline 31 & ALCOOL DE CAMA E CEREASS & 25 & ALCOOL DE CAMA E CEREEAS \\
\hline 32 & GASOLIIA PURA & 23 & PROD. REFIMADOS OE PETROLE \\
\hline 33 & OLEOS COMBUSTIVES & & \\
\hline 3 & TOUTROS PROD. DO REFINO & & \\
\hline 35. & PROO. PETROOUMMICOS BASTCO & & \\
\hline 36 & RESIIAS & 26 & PRODUTOS GUMACOS DINERSO \\
\hline 37 & GASOALCOL & 23 & PROD REFIXADOS OE PETROLE \\
\hline 38 & ADUBOSOS & 24 & ADUBOS \\
\hline 39 & TINTAS & 26 & PROOUTTOS QULTICOS DIVEKSO \\
\hline 30 & OUTROS PROD QUMMICOS & & \\
\hline 41 & PROD. FARM E DE PERFUMARLI & 27 & FARMACEUTICA \\
\hline 42 & ARTIGOS DE PLASTICO & 28 & PLASTICOS \\
\hline 43 & FIOS TEXTESTLATURAS & 29 & PRODUTOS TEXTETS \\
\hline 74 & TECIDOS MATURAS & & \\
\hline$\$ 5$ & FIOS TEXTESS AR TIFICLAIS & & \\
\hline 46 & TECDOOS ARTIFICLAS & & \\
\hline 47 & OUTROS PROO TEXTES & & \\
\hline 48 & ARTIGOS DO VESTUARIO & 30 & VESTTUARLO E CALCADOS \\
\hline 49 & PROD. COUROE CALCAOOS & & \\
\hline 50 & PRODUTOS DO CAFE & 31 & PROOUTOS DO CAEE \\
\hline 51 & ARROZ BEREFICLAOO & 3 & ARROZ BEMEFICUDO \\
\hline 52 & FARIMAA OE TRRGO & 37 & OUTROS PROD. ALLMENTARES \\
\hline 53 & OUT, PROO ALLENT BEMEFL. & & \\
\hline 54 & CARME BOVIM & 32 & CARME BOVMA \\
\hline 55 & CARME DE AVES ABATIDAS & 33 & CARNE DE AVES ABATIDAS \\
\hline 56 & LEITE BEMEFICAADO & 37 & OUTROS PROO. ALLMENTARES \\
\hline 57 & OUTROS LATICIRIOS & & \\
\hline 58 & ACUCAR & 34 & ACCUCAR \\
\hline 59 & OLEO VEGETAL EM BRUTO & 37 & OUTROS PROO. ALIMESTARES \\
\hline 60 & OLEO VEGETAL REFIKADO & & \\
\hline 61 & RACOES E OUT. ALBMENTARES & 36 & RACOES E OUT. ALIMENTARES \\
\hline 82 & BEBLOS & 37 & OUTROS PROD. ALINIESTARES \\
\hline 63 & PRODUTOS DNERSOS & 38 & PRODUTOS DIVERSOS \\
\hline 64 & SEERV. INOUST. DE UTIL PUBLC & 33 & ENERGIA AGUA SAH., E COMU \\
\hline 55 & PROO. DA CONSTRUGAO CML & 40 & COMSTHUCAO CIML \\
\hline 68 & MARGEM DE COHERCIO & 41 & COMERCIO \\
\hline 67 & MARGEM DE TRAYSPORTE & 42 & TRANSPORTES \\
\hline 68 & COMUMICACOES & 39 & ENERGLA AGUA SAM E COMU \\
\hline 69 & SEGUROS E SERV. FINANCEIRO & 43 & SERVIÇOS \\
\hline 70 & ALOAAMEMTO E ALMMEMACAO & & \\
\hline 74 & OUTROS SERVCOS & & \\
\hline 72 & SAUDE E EDUC.MERCAMTIS & & \\
\hline 73 & SERV. PREST. A EHPRESA & & \\
\hline 74 & ALUGUEL DE WOVESS & & \\
\hline 75 & ALUGUEL WMPUTADO & & \\
\hline 76 & ADO SAUDE E ED PUBLICAS & & \\
\hline 77 & SER NMERCANTI PRVADO & & \\
\hline
\end{tabular}




\section{REFERÊNCIAS BIBLIOGRÁFICAS}

ABLAS, L.A. Q. Intercâmbio desigual e subdesenvolvimento regional no Brasil. São Paulo: FIPE, Pioneira 1985. 97p.

BACHARACH. M. Biproporcional matrices \& input-output change. Cambridge: Cambridge Univertisty Press, 1970.170 p.

BAER. W. A economia brasileira. São Paulo: Forense Universitária, 1996. 416p.

BRASIL. Congresso Nacional. Comissão Especial Mista. Desenvolvimento econômico inter-regional brasileiro. Uma política espacial para o desenvolvimento nacional equilibrado. Brasilia, 1993.v.3, 87p.

CARLEIAL, M.F. A questão regional no Brasil contemporâneo. Curitiba: UFPR, Departamento de Economia, 1992. 21p. (Texto Para Discussão, 03).

CAVALCANTI, J.E.A. Avaliação do padrão de desenvolvimento da economia do Nordeste - 1975-80. Revista Brasileira de Economia, v.48, n.1, p.107-124, jan./mar. 1994.

CELLA, C. The input-output measurement of interindustry linkages. Oxford Bulletin of Economics and Statistics, v.46, p.73-84, 1984.

CHENERY, H. Regional analysis. In: CHENERY, H.; CAO-PINA, The struture and growth of Italian economy. Rome: U.S. Mutual Security Agency, 1953.

CLEMENTS, B. On the decomposition and normalization of interindustry linkages. Economics Letters, v.33, p. 337-340, 1990.

CONFEDERAÇÃO NACIONAL DA INDÚSTRIA. Economia brasileira: comparações regionais. Rio de Janeiro, 1996. 78p. 
DERVIS, K. J. M.; ROBINSON, S. General equilibrium models for development policy. Cambridge: Cambridge University Press, 1984. 526p.

ELLIS, H.S. The economy of Brasil. Berkeley: University of California Press, 1969. $408 \mathrm{p}$.

FIGUEIREDO, F.O. Introdução à contabilidade nacional. 4ed. Rio de Janeiro: Forense Universitária, 1975. 212p

FUNDAÇÃO INSTITUTO BRASILEIRO DE GEOGRAFIA E ESTATISTICA. Matriz de relações intersetoriais, Brasil 1970. Rio de Janeiro. 1979.266p.

FUNDAÇÃO INSTITUTO BRASILEIRO DE GEOGRAFIA E ESTATÍSTICA. Censo Demográfico 1980. Rio de Janeiro, 1983.

FUNDAÇÃO INSTITUTO BRASILEIRO DE GEOGRAFIA E ESTATISTICA. Matriz de relações intersetoriais Brasil 1975. Rio de Janeiro. 1987.565p.

FUNDAÇÃO INSTITUTO BRASILEIRO DE GEOGRAFIA E ESTATÍSTICA. Novo sistema de contas nacionais: (metodologia e resultados provisórios ano base 1980). Rio de Janeiro, 1988 (Textos para Discussão, 10).

FUNDAÇÃO INSTITUTO BRASILEIRO DE GEOGRAFIA E ESTATÍSTICA. Matriz de insumo-produto Brasil 1980. Rio de Janeiro. 1989. (Série Relatórios Metodológicos, 7) 203p.

FUNDAÇÃO INSTITUTO BRASILEIRO DE GEOGRAFIA E ESTATÍSTICA. Censos econômicos-1985. Rio de Janeiro, 1991.

FUNDAÇÃO INSTITUTO BRASILEIRO DE GEOGRAFIA E ESTATÍSTICA. Censo demográfico 1991. Rio de Janeiro, 1994.

FUNDAÇÃO INSTITUTO BRASILEIRO DE GEOGRAFIA E ESTATÍSTICA. Matriz de relações intersetoriais Brasil 1985. Rio de Janeiro,1995.

FUNDAÇÃO INSTITUTO BRASILEIRO DE GEOGRAFIA E ESTATÍSTICA. Contagem da população 1996. Rio de Janeiro, 1997. 2.v.

INSTITUTO DE PESQUISA ECONÔMICA APLICADA. Pesquisa das desigualdades regionais: indicadores sociais nos anos 90 . Rio de Janeiro, 1997.

GUILHOTO, J.J.M. A model for economic planning and analysis for the brazilian economy. Urbana, 1986. 267p. Thesis (Ph.D.). University of Illinois. 
GUILHOTO, J. Um modelo compútavel de equilíbrio geral para planejamento e análise de políticas agrícolas (PAPA) na economia brasileira. Piracicaba, 1995. $258 \mathrm{p}$. Tese (Livre-Docência) - Escola Superior de Agricultura Luiz de Queiroz, Universidade de São Paulo.

GUILHOTO, J.J.M.; HEWINGS, G.J.D.; SONIS, M. Interdependence, linkages and multipliers in Asia: an international input-otput analysis multiregional framework: integrations of alternative approaches: Urbana: University of Illinois, Regional Economics Applications Laboratory. 1997.33p. (Discussion Paper, 97-T-2).

GUILHOTO, J.J.M.; SONIS, M.; HEWINGS, G.J.D. Linkages and multipliers in a multiregional framework: integracions of alternative approaches. Urbana: University of Illinois, Regional Economics Applications Laboratory, 1996 20p.(Discussion Paper, 96-T-8).

GUILHOTO, J.J.M.; SONIS, M..; HEWINGS, G.J.D.; MARTINS, E.B. Índices de ligações e setores-chave na economia brasileira: 1959/80. Pesquisa e Planejamento Econômico, v.24, n.2, p.287-314, 1994.

HADDAD, P.R. Contabilidade social e economia regional: análise de insumo-produto. Rio de Janeiro: Zahar Ed., 1976. 242p.

HADDAD, P.R. O que fazer com o planejamento regional no Brasil na próxima decada. Planejamento e Políticas Públicas, v.1, n.1, p.67-92, ago. 1989.

HEWINGS, G.J.D.; HULU, E. The development and use of interregional input-output models for Indonesia, 1980 e 1991, under conditions of limited Information. Review of Urban and Regional Development Studies, v.5, p.133-153, 1993.

HIRSCHMAN, A.O. The strategy of economic development. New Havery: Yale University Press, 1958.217p.

ISARD, W. Interregional and regional input-output analysis: a model of a spaceeconomy. Review of Economics and Statistics, n.33, p.319-328, 1951.

LAVINAS, L.; GARCIA, E. H.; AMARAL, R.A. Desigualdades regionais: indicadores socieoeconômicos nos anos 90. Rio de Janeiro: IPEA/DIPES, 1997. 48p (Texto para Discussão, 460).

LEÃO, A.S.C.; SILVA. C.R.; GIESTAS, E.; NÓBREGA, J. matriz de insumo-produto do Brasil. Revista Brasileira de Economia, v.27, n.3, p.3-10, julho/set. 1973. 
LEONTIEF, W. The structure of the americam economy. 2.ed. New York: Oxford University Press, 1951. 264p.

LEONTIEF, W. A economia de insumo-produto. 2.ed. São Paulo: Nova Cultural, 1986.

McGILVRAY, J. Linkages, key sectors and develolpment strategy. In: LEONTIEF, W. Structure, system and economic policy. Cambridge: Cambridge University Press, 1977. cap.4, p.49-56.

MILLER, R.E.; BLAIR, P.D. Input-output analysis: foundations and extensions. Englewood Cliffs: Prentice-Hall, 1985. 464p.

MIYAZAWA, K. Input-output analysis and the structure of income distribuiton. Berlin: Springer-Verlag, 1976. 135p.

MOSES, $\mathrm{L}$. The stability of interregional trading patterns and input-output analysis. The American Economic Review, n.45, p.803-832, 1955.

NEGRI, B. Concentração e desconcentração industrial em São Paulo (1880-1990). Campinas: UNICAMP, 1996. 242p.

RASMUSSEN, P. Studies in intersectoral relations. Amsterdam: North Holland. 1956. $210 p$.

RIJCKEGHEM, W. van. A intersectoral consistency model formm economic planning in Brazil. In: ELLIS, H.S. The Economy of Brazil. Berkeley:. University of California Press,1969. cap.13, p.376-402.

ROUND, J.I. An interregional input-output approuch to the evaluation of nonsurvey methods. Journal of Regional Science, v. 18, p.179-194, 1978.

ROUND, J.I. Compensating feedback effects in interregional input-outuput models. Journal of Regional Science, v.19, n.2, p.145-155, 1979.

ROUND, J.I. Nonsurvey Techniques: A Critical Review of the Theory and the Evidence. International Regional Science Review, v 8, n.3, p. 189-212, 1983.

SILVA, A.B.; CONSIDERA, B.O.S.;VALADÃO, H.M. Produto interno bruto por unidade de federação. Rio de Janeiro: IPEA/DIPES, 1996. 105p., (Texto para Discussão, 424). 
SILVA, A.B.O.; CONSIDERA, C.M.; MAGALHÃES, K.M.M.; RAMOS, O.R.L. Matriz de insumo-produto do Nordeste - 1980 e 1985. Fortaleza: BNB, 1992

SILVA, A.B.O.; CONSIDERA, C.M.; MAGALHÃES, K.M.M.; BITTENCOURT, S.M. Matriz de insumo-produto do Norte - 1980 e 1985. Belém: SUDAM, 1994. 384p.

SONIS, M., HEWINGS, G.J.D. Fields of influence in input-output systems. Urbana: Universty of Illinois, Regional Economics Applications Laboratory, 1995. 